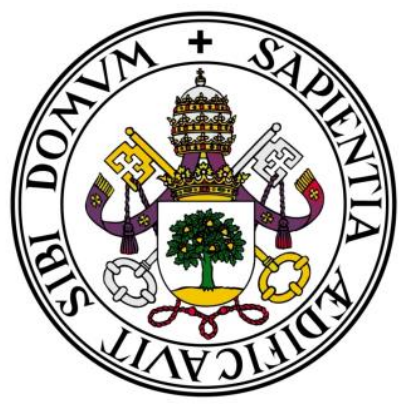

Universidad de Valladolid

FACULTAD DE MEDICINA

DEPARTAMENTO DE BIOQUÍMICA Y BIOLOGÍA MOLECULAR Y FISIOLOGÍA.

TESIS DOCTORAL:

\title{
LA TÉCNICA DE PINZA RODADA EN EL TRATAMIENTO FISIOTERÁPICO DE LA LUMBALGIA INESPECÍFICA CRÓNICA
}

Presentada por D. a Susana Domingo Esteban para optar al grado de doctor por la Universidad de Valladolid.

Dirigida por:

Dr. Francisco José Navas Cámara. 


\section{AGRADECIMIENTOS}

Una vez llegados a la meta, me gustaría dar las gracias a todos aquellos que han hecho posible el final de esta maratón.

A los amigos que han ido alentando en cada kilómetro recorrido y no han dejado que me rindiera.

A Héctor Hernández Lázaro por su ayuda y buena disposición en esta época en la que cada uno mira para sí mismo. A Chus y María por sus ánimos y sus aplausos.

A los pacientes que aceptaron participar en este proyecto y sin cuya ayuda no se hubiera llevado a cabo.

Y, especialmente, al Dr. Francisco José Navas Cámara por creer en mí y en mi proyecto, por darme ánimos cuando todo estaba en color gris oscuro, por enseñarme los entresijos de la investigación, por mantener los pies en la tierra y no en un pedestal donde otros se encuentran y no te ayudan a calentar ni a estirar en esta "carrera" y al lado del cual pude darme cuenta de la pequeña hormiguita que soy en este vasto mundo investigador que ahora empiezo a conocer un poco mejor. Gracias.

Y por supuesto, a mi marido y a mis hijos, por todo SIEMPRE.

A todos vosotros, mi más sincero agradecimiento. 


\section{ABREVIATURAS}

AP: Atención Primaria

BA: Balance Articular

CE: Capa Externa

CI: Capa Interna

CL: Músculo Cuadrado Lumbar

CM: Capa Media

DA: Músculo Dorsal Ancho

EIPS: Espina lliaca Postero Superior

EVA: Escala Visual Analógica

F0: Fase 0

F1: Fase 1

F2: Fase 2

F3: Fase 3

FP: Fascia Profunda

FS: Fascia Superficial

FTL: Fascia Toracolumbar

GC: Grupo Control

GMI: Imaginería motora graduada (del inglés Graded Motor Imagery)

GP: Grupo Pinza

ILD: Inclinación Lateral Derecha

ILI: Inclinación Lateral Izquierda

IMC: Índice de Masa Corporal

IT: Incapacidad Temporal

LIC: Lumbalgia Inespecífica Crónica

LRP: Lámina Reticular Paraespinal

MFL: Capa media de la FTL

MVF: Retroalimentación visual en espejo (del inglés Mirror Visual Feedback)

NRT: Terapia Neuro-Refleja (del inglés Neuro Reflex Therapy)

OE: Músculo Oblicuo Externo

OI: Músculo Oblicuo Interno

PENS: Neuroestimulación Eléctrica Percutánea (del inglés Percutaneous Electrical Nerve Stimulation) 
PFL: Capa posterior de la FTL

PR: Pinza Rodada

PSN: Perfil de Salud de Nottingham

RMN: Resonancia Magnética Nuclear

ROT: Reflejo Osteo-Tendinoso

Rx: Radiografia

SPI: Músculo Serrato Postero Inferior

SACYL: Sanidad Castilla y León

TAC: Tomografía Axial Computarizada

TrA: Músculo Transverso del Abdomen

TC: Tejido Conjuntivo

TENS: Estimulación Eléctrica Transcutánea (del inglés Transcutaneous

Electrical Neuro Stimulation)

TNF: Factor de Necrosis Tumoral (del inglés Tumor Necrosis Factor)

TSC: Tejido Subcutáneo

TSLM: Test de Schober Lumbar Modificado 
ÍNDICE 


\section{ÍNDICE}

\section{INTRODUCCIÓN}

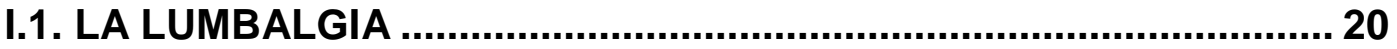

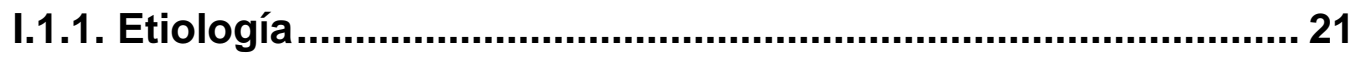

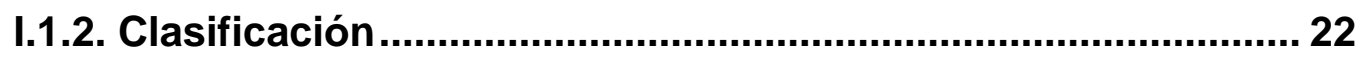

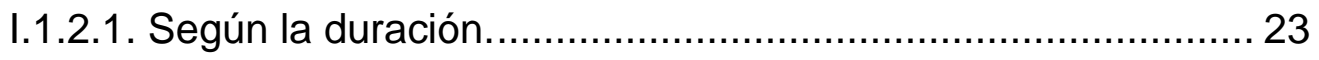

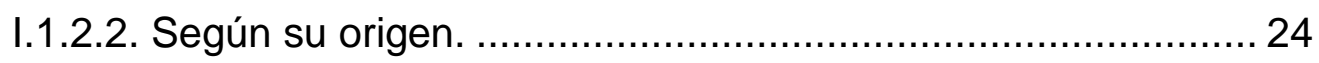

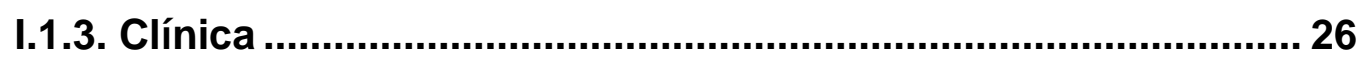

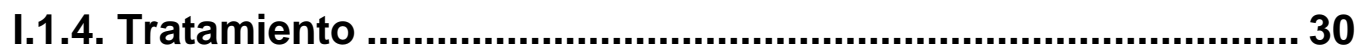

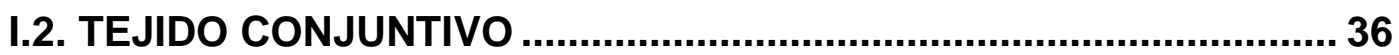

I.2.1. Fundamentos básicos del tejido conjuntivo .......................... 36

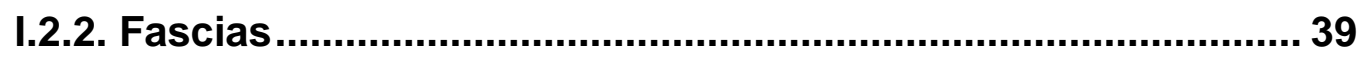

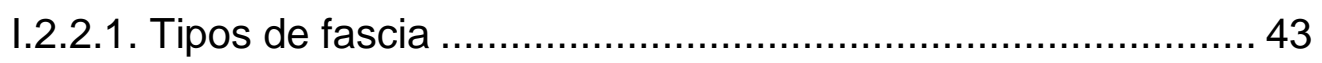

1.2.2.1.1. La fascia superficial ................................................... 44

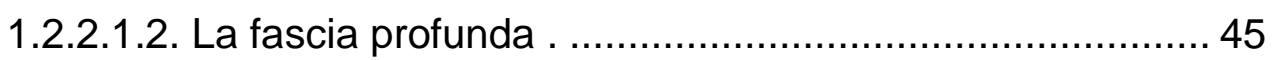

I.2.2.2. Funciones de la fascia..................................................... 47

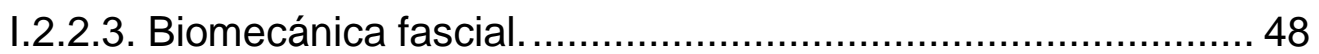

I.2.2.4. Inervación de las fascias ................................................... 51

I.3. DISTRIBUCIÓN METAMÉRICA Y TÉCNICAS FISIOTERÁPICAS

DE TEJIDO CONJUNTIVO ..................................................................54

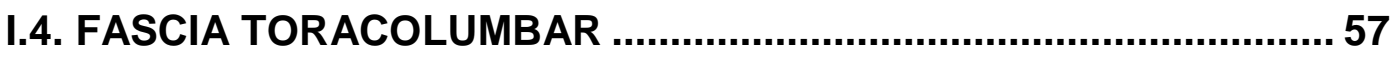

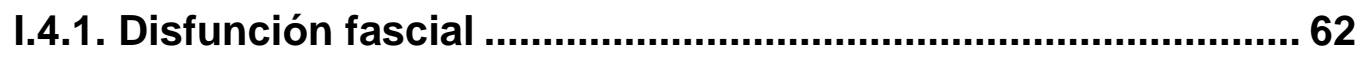

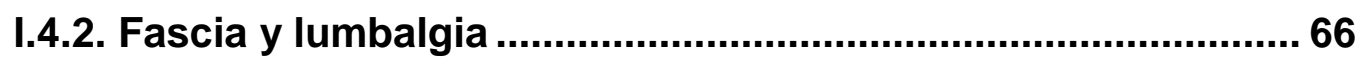

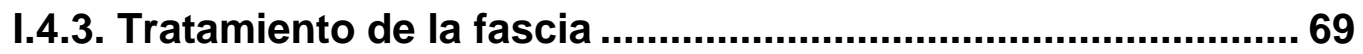

I.5. LA TÉCNICA DE LA PINZA RODADA............................................ 71

II. JUSTIFICACIÓN DEL TRABAJO ........................................76

III. HIPÓTESIS Y OBJETIVOS ..................................................79

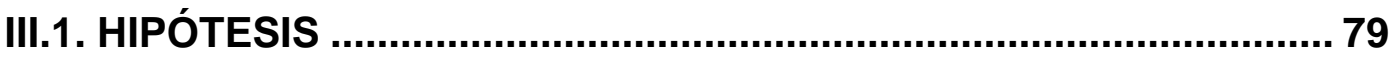

III.2. OBJETIVOS

3.2.1. Objetivo primario o principal ................................................ 79 


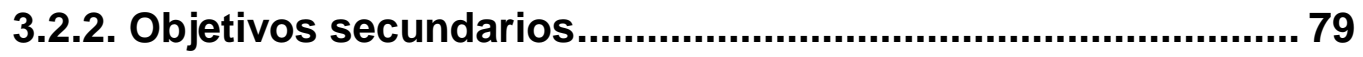

IV. MATERIAL Y MÉTODOS................................................... 81

IV.1. ÁMBITO

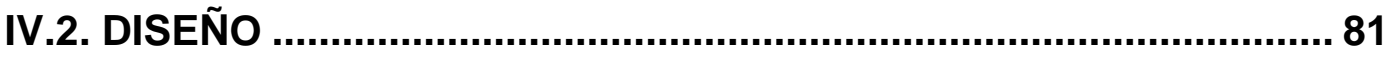

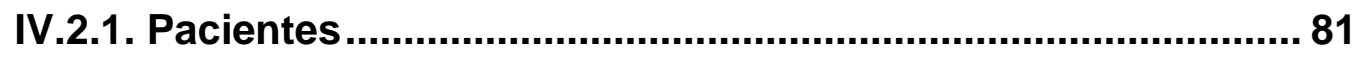

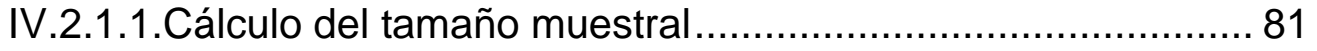

IV.2.1.2. Criterios de Inclusión y Exclusión....................................... 82

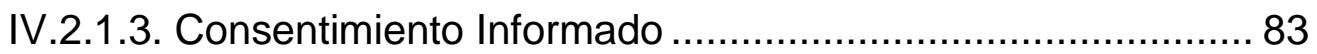

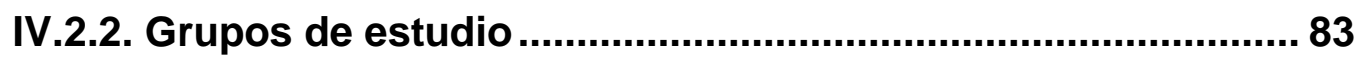

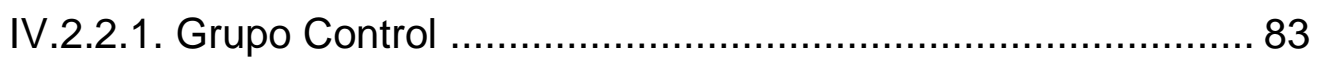

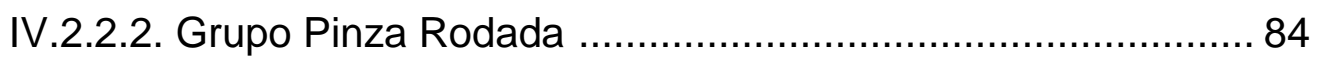

IV.2.3. Valoración del paciente. Variables de estudio....................... 85

IV.2.3.1. Cuestionario Sociodemográfico ....................................... 86

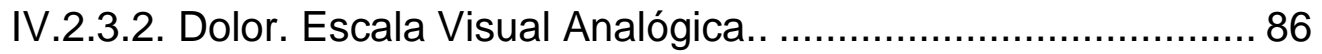

IV.2.3.3. Balance Articular de la Columna Lumbar ........................... 87

IV.2.3.3.1. Flexión Lumbar. Test de Schober................................ 87

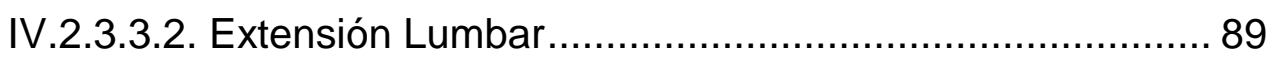

IV.2.3.3.3. Inclinaciones Laterales del tronco ............................... 89

IV.2.3.4. Incapacidad funcional. Cuestionario de Roland-Morris....... 91

IV.2.3.5. Escala de Depresión de Zung.......................................... 92

IV.2.3.6. Calidad de vida. Perfil de Salud de Nottingham ................. 93

IV.3. RECOGIDA DE DATOS Y ANÁLISIS ESTADÍSTICO .................... 95

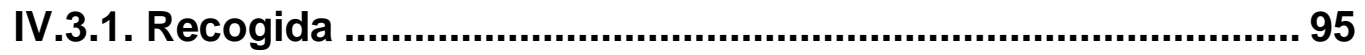

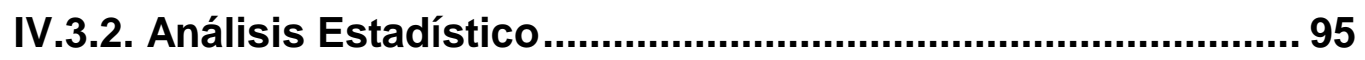

IV.4. REVISIÓN BIBLIOGRÁFICA.........................................................98

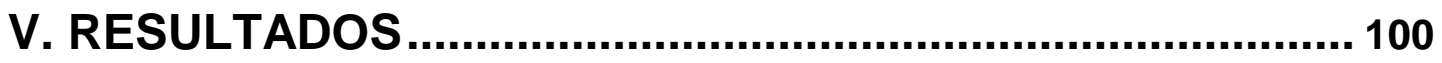

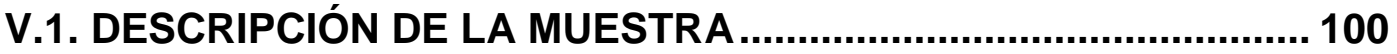

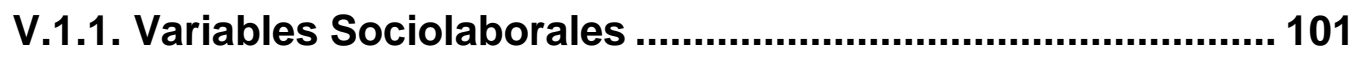

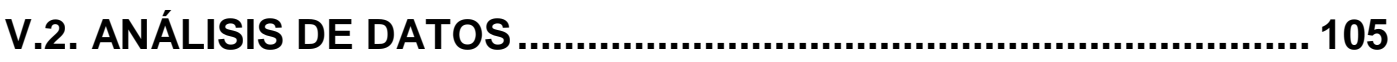




\section{V.2.1. Comparación de variables antropométricas entre el} Grupo Control y el Grupo Pinza en la Fase 0, previa al tratamiento. 105

V.2.2. Análisis de las diferentes variables del estudio

V.2.2.1. Análisis del dolor mediante la EVA. ................................ 108

V.2.2.2. Análisis de las variables de Balance Articular ................... 110

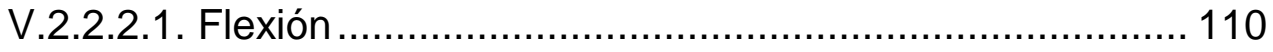

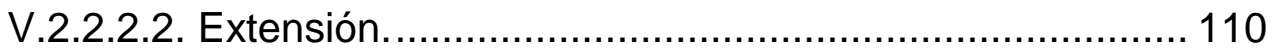

V.2.2.2.3. Inclinación lateral derecha ......................................... 113

V.2.2.2.4. Inclinación lateral izquierda ..................................... 113

V.2.2.3. Análisis de las variables medidas mediante

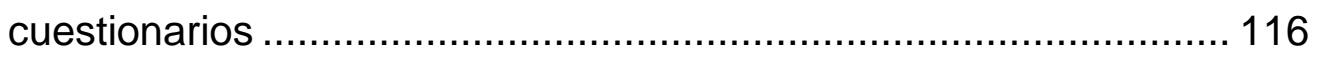

V.2.2.3.1. Cuestionario de Roland Morris ................................... 116

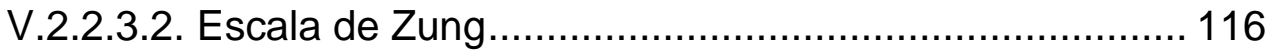

V.2.2.3.3. Perfil de Salud de Nottingham .................................. 119

V.2.3. Análisis de las variables en los diferentes grupos

Grupo Control y Grupo Pinza y en cada una de las fases, en función del sexo............................................................................. 130

V.2.3.1. Variables antropométricas. ............................................. 130

V.2.3.2. Análisis del dolor mediante la EVA. ................................ 131

V.2.3.3. Análisis de las variables de Balance Articular................... 133

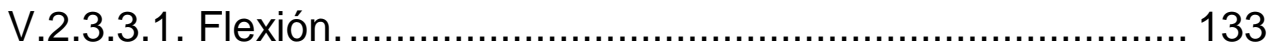

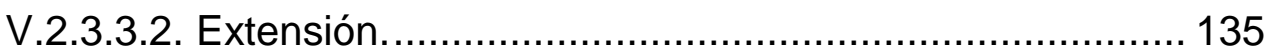

V.2.3.3.3. Inclinación lateral derecha......................................... 137

V.2.3.3.4. Inclinación lateral izquierda ....................................... 139

V.2.3.4. Análisis de las variables medidas mediante

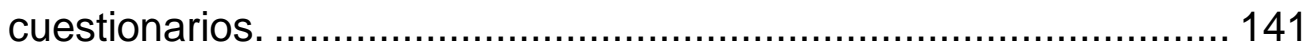

V.2.3.4.1. Escala de Roland Morris............................................... 141

V.2.3.4.2. Cuestionario de Zung ............................................... 143

V.2.3.4.3. Perfil de Salud de Nottingham .................................. 145

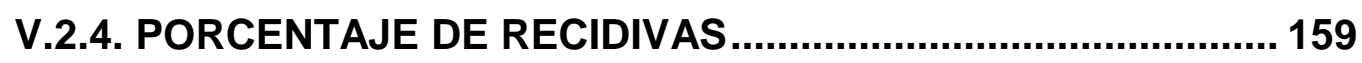

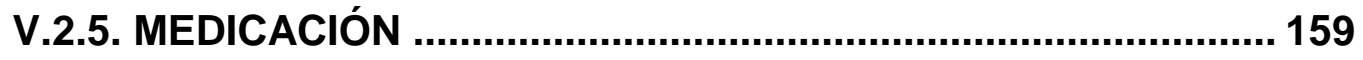




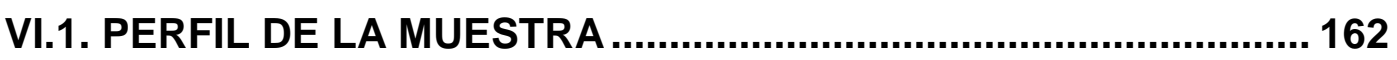

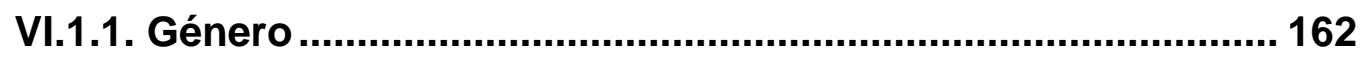

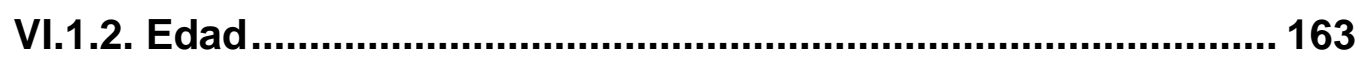

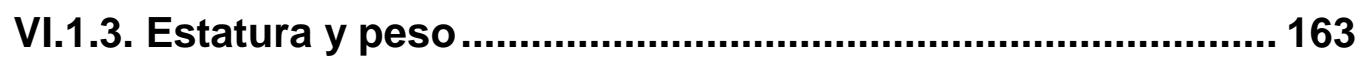

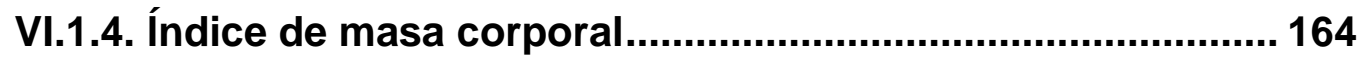

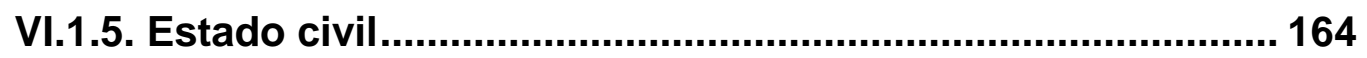

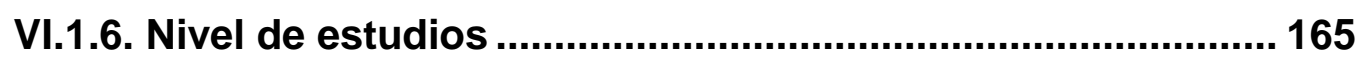

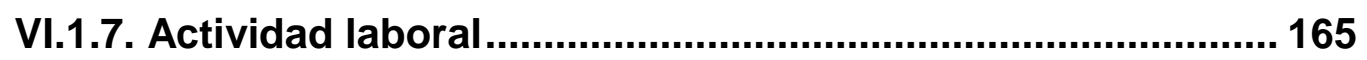

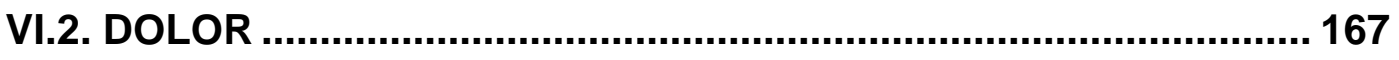

VI.2.1. Análisis del dolor del Grupo Pinza frente al Grupo

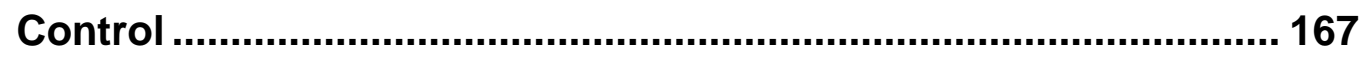

VI.2.2. Análisis del dolor por sexos ................................................ 169

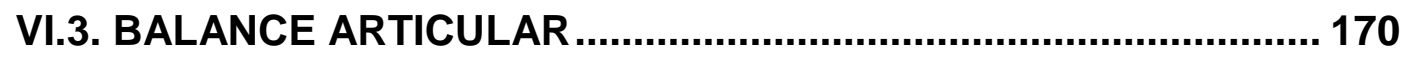

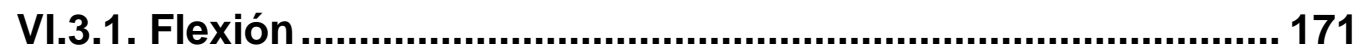

VI.3.1.1. Análisis de la Flexión del Grupo Pinza frente al

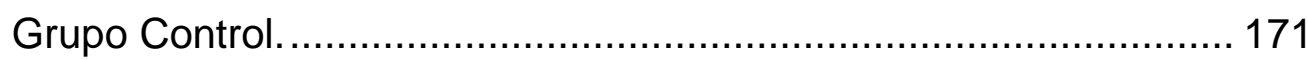

VI.3.1.2. Análisis de la Flexión por sexos ...................................... 172

VI.3.2. Extensión ....................................................................... 174

VI.3.2.1 Análisis de la Extensión del Grupo Pinza frente al

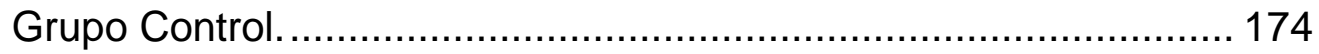

VI.3.2.2. Análisis de la Extensión por sexos.................................. 174

VI.3.3. Inclinación lateral derecha e izquierda ................................ 175

VI.3.3.1. Análisis de la Inclinación lateral derecha e izquierda del Grupo Pinza frente al Grupo Control. ..................................... 175

VI.3.3.2. Análisis de la Inclinación lateral derecha e izquierda

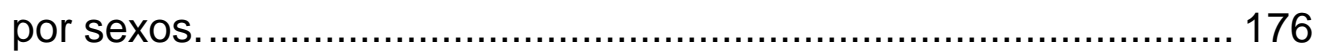

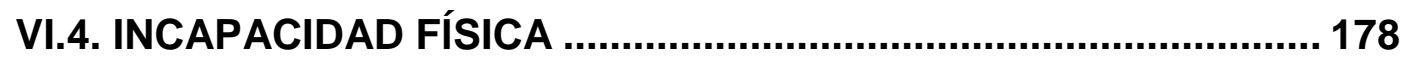

VI.4.1. Análisis de la Escala de Roland Morris en el Grupo

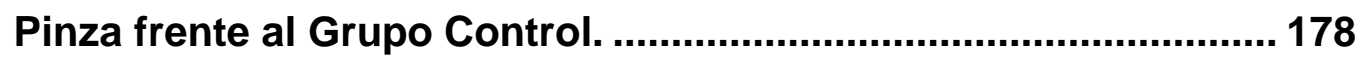

VI.4.2. Análisis de la Escala de Roland Morris por sexos. ............ 179

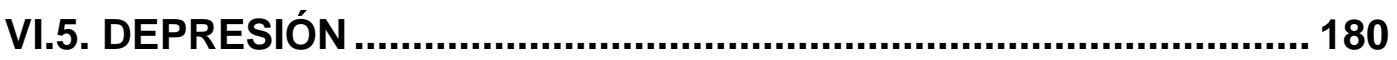


VI.5.1. Análisis de la Escala de Zung en el Grupo Pinza

frente al Grupo Control.................................................................... 180

VI.5.2. Análisis de la Escala de Zung por sexos............................ 182

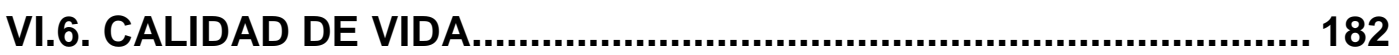

VI.6.1. Análisis de la dimensión Energía del Perfil de salud de Nottingham en el Grupo Pinza frente al Grupo Control y por sexos. 184

VI.6.2. Análisis de la dimensión Dolor del Perfil de salud de Nottingham en el Grupo Pinza frente al Grupo Control y por sexos. 185

VI.6.3. Análisis de la dimensión Reacciones Emocionales del Perfil de salud de Nottingham en el Grupo Pinza frente al Grupo Control y por sexos. 186

VI.6.4. Análisis de la dimensión Sueño del Perfil de salud de Nottingham en el Grupo Pinza frente al Grupo Control y por sexos.

VI.6.5. Análisis de la dimensión Aislamiento social del Perfil de salud de Nottingham en el Grupo Pinza frente al Grupo Control y por sexos. 186

VI.6.6. Análisis de la dimensión Movilidad Física del Perfil de salud de Nottingham en el Grupo Pinza frente al Grupo Control y por sexos. 187

VI.6.7. Análisis de del Perfil de salud de Nottingham Total en el Grupo Pinza frente al Grupo Control y por sexos. 187

VI.7. RECIDIVAS 188

VI.8. MEDICACIÓN .......................................................................... 188

VI.9. LIMITACIONES DEL ESTUDIO ............................................ 189

VII. CONCLUSIONES....................................................... 191

VIII. BIBLIOGRAFIA........................................................... 194

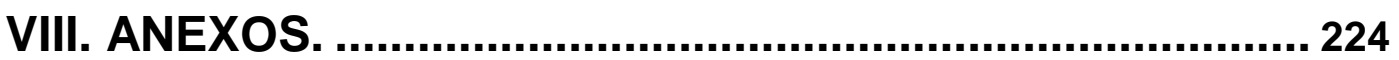


Anexo I. Flujograma de derivación de la lumbalgia en la Gerencia de Atención Primaria de Soria........................................ 224

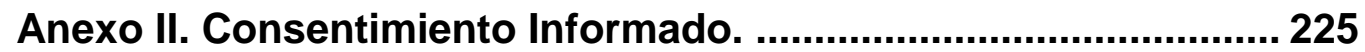

Anexo III. Permiso de la Gerencia de Salud de Soria.......................226

Anexo IV. Cuestionario Sociodemográfico..................................... 227

Anexo V. Escala Visual Analógica. EVA. ........................................ 228

Anexo VI. Cuestionario de Roland Morris...................................... 229

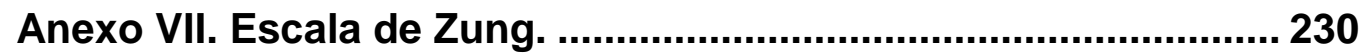

Anexo VIII. Perfil de Salud de Nottingham.................................. 231 


\section{ÍNDICE DE TABLAS}

Tabla 1. Clasificación de la lumbalgia en función del tiempo de evolución

Tabla 2. Carga laboral según la actividad. 29

Tabla 3. Variables por sexo y grupo que no siguen una distribución normal.

Tabla 4. Comparación de valores medios antropométricos entre

Grupo Control y Grupo Pinza........................................................ 105

Tabla 5. Grado de dolor (EVA) en los Grupos Control y Pinza................. 109

Tabla 6. Balance articular de la Flexión en los Grupos Control y Pinza... .. 111

Tabla 7. Balance articular de la Extensión en los Grupos Control y Pinza.

Tabla 8. Balance articular de Inclinación lateral derecha en los Grupos Control y Pinza

Tabla 9. Balance articular de ILI en los Grupos Control y Pinza. 115

Tabla 10. Valores del cuestionario de Roland-Morris en los Grupos

Control y Pinza

Tabla 11. Valores del cuestionario de de ZUNG en los Grupos Control y Pinza.

Tabla 12. Valores medios de PSN ENERGíA en los Grupos Control .y Pinza.

Tabla 13. Valores medios de PSN DOLOR en los Grupos Control

y Pinza

Tabla 14. Valores medios de PSN REACCIONES EMOCIONALES en.los Grupos Control y Pinza..

Tabla 15. Valores medios de PSN SUEÑO en los Grupos Control y Pinza. 124 
Tabla 16. Valores medios de PSN AISLAMIENTO SOCIAL en los Grupos Control y Pinza...

Tabla 17. Valores medios de PSN MOVILIDAD FÍSICA en los Grupos Control y Pinza

Tabla 18. Valores medios de PSN TOTAL en los Grupos

Control y Pinza.

Tabla 19. Comparación de las variables de edad y antropométricas por grupos y por sexos antes del tratamiento (Fase 0) 130

Tabla 20. Grado de dolor (EVA) en los grupos por sexos. 132

Tabla 21. Balance articular de la Flexión en los grupos por sexos. 134

Tabla 22. Balance articular de la Extensión en los grupos por sexos. 136

Tabla 23. Balance articular de Inclinación Lateral Derecha en grupos por sexos.

Tabla 24. Balance articular de Inclinación Lateral Izquierda en grupos por sexos.

Tabla 25. Valores del cuestionario de Roland-Morris en los grupos por sexos. 142

Tabla 26. Valores del cuestionario de ZUNG en los grupos por sexos...... 144

Tabla 27. Valores medios de PSN ENERGíA en los grupos por sexos.... 146

Tabla 28. Valores medios de PSN DOLOR en los grupos por sexos. 148

Tabla 29. Valores medios de PSN REACCIONES EMOCIONALES en los grupos por sexos. 150

Tabla 30. Valores medios de PSN SUEÑO en los grupos por sexos. 152

Tabla 31. Valores medios de PSN AISLAMIENTO SOCIAL en los grupos por sexos.

Tabla 32. Valores medios de PSN MOVILIDAD FÍSICA en los grupos por sexos. 156

Tabla 33. Valores medios de PSN TOTAL en los grupos por sexos. 158 
Tabla 34. Distribución de las puntuaciones para cada dimensión de la versión española del NHP en la Población General de 41 años o más de Barcelona

Tabla 35. Puntuaciones medias y desviaciones estándar para cada dimensión de la versión española del NHP por sexo en la población general de 41 años o más de Barcelona .... 184 


\section{ÍNDICE DE FIGURAS}

Figura 1. Clasificación del tejido conjuntivo o conectivo............................. 37

Figura 2. Matriz extracelular del tejido conectivo fascial. ............................ 39

Figura 3. Vista macroscópica de la fascia en antebrazo. ............................ 40

Figura 4. Vista macroscópica de la fascia en brazo .................................. 40

Figura 5. Vistas histológicas de la fascia................................................. 40

Figura 6. Diferentes tejidos conectivos considerados como tejidos

fasciales según la terminología del International Fascia Research Congress.

Figura 7. Diagrama mostrando la organización del tejido subcutáneo y de las fascias superficial y profunda 44

Figura 8. Vista macroscópica de la fascia profunda de la región

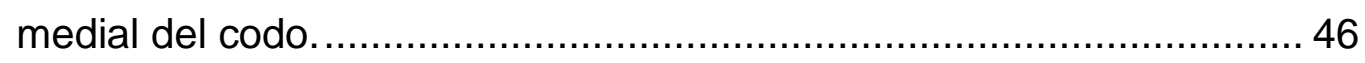

Figura 9. Ejemplos de estructuras tensegríticas. A: Icosaedro ................... 49

Figura 10. Ejemplos de estructuras tensegríticas. B: Con membranas elásticas en vez de bandas elásticas.

Figura 11. Representación tridimensional de la fascia y representación fascial como sistema de integración (tensegridad) ............................... 49

Figura 12. Distribución en dermatomas de los nervios espinales................ 54

Figura 13. Reflejo víscero-músculo cutáneo ………………………........ 55

Figura 14. Vista dorsal de la Fascia Toraco-Lumbar................................. 58

Figura 15. La Fascia Toraco Lumbar. ................................................... 60

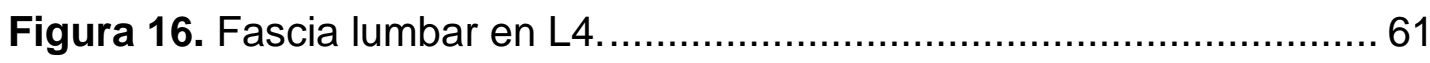

Figura 17. Publicaciones indexadas sobre fascia...................................... 66

Figura 18. Pliegue de la Pinza Rodada.................................................. 72

Figura 19. Hiperemia reactiva a la realización de la Pinza Rodada. ........... 73

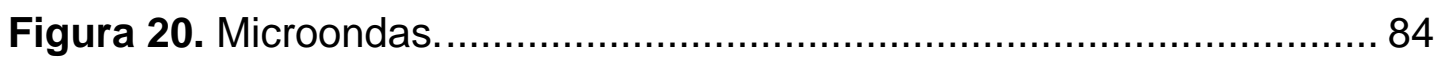




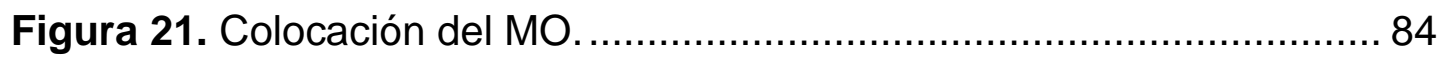

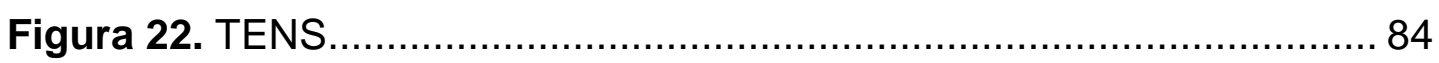

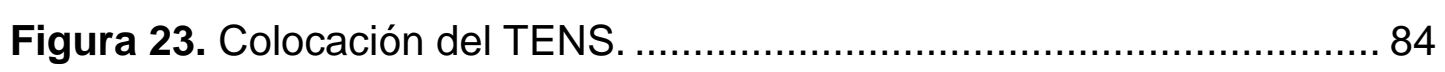

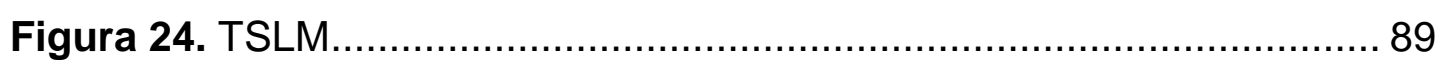

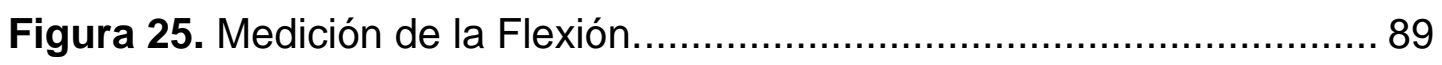

Figura 26. Medición de la Extensión. ………………...............................90

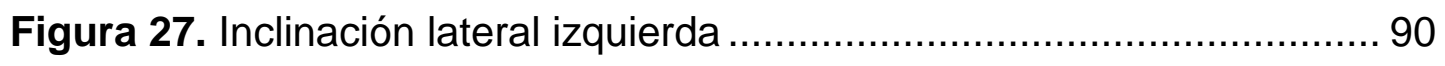

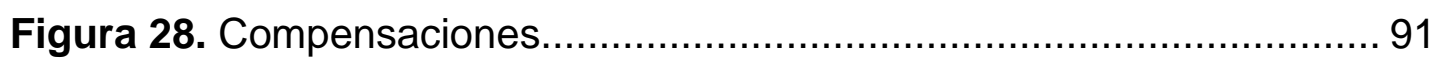

Figura 29. Esquema de la participación de la población objeto de

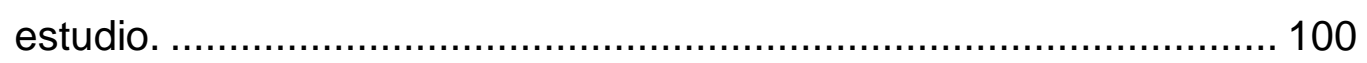

Figura 30. Porcentaje de pacientes en cada grupo............................... 101

Figura 31. Distribución de la población por sexo...................................... 101

Figura 32. Distribución de la población por grupos de edad ..................... 102

Figura 33. Distribución de la población según el estado civil ..................... 102

Figura 34. Distribución de la población según el nivel de estudios ........... 103

Figura 35. Distribución de la población según la exigencia física

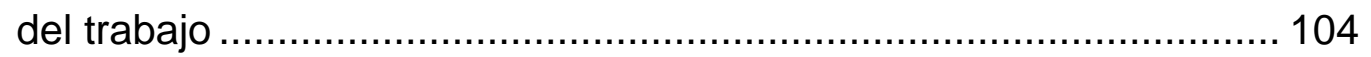

Figura 36. Distribución de la población según la situación laboral ............ 104

Figura 37. Comparación de los valores medios de edad entre el Grupo

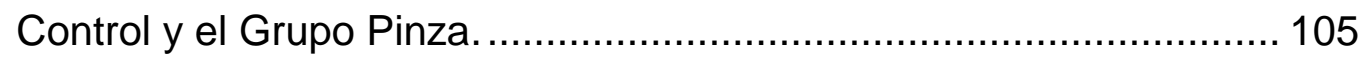

Figura 38. Comparación de los valores medios de peso entre el Grupo Control y el Grupo Pinza............................................................. 106

Figura 39. Comparación de los valores medios de talla entre el Grupo Control y el Grupo Pinza.................................................................. 106

Figura 40. Distribución porcentual de los rangos de IMC por grupos........ 107

Figura 41. Evolución del grado de dolor en los Grupos Control y Pinza. 
Figura 42. Evolución del balance articular en Flexión en los Grupos Control y Pinza.

Figura 43. Evolución del balance articular de Extensión en los Grupos Control y Pinza

Figura 44. Evolución del balance articular de ILD en los Grupos Control y Pinza

Figura 45. Evolución del balance articular de ILI en los Grupos Control y Pinza

Figura 46. Evolución de los valores obtenidos en el cuestionario de

Roland- Morris en los Grupos Control y Pinza

Figura 47. Evolución de los valores obtenidos en la Escala de Zung en los Grupos Control y Pinza

Figura 48. Evolución del PSN ENERGíA en los Grupos Control y Pinza

Figura 49. Evolución del PSN Dolor en los Grupos Control y Pinza. 121

Figura 50. Evolución del PSN REACCIONES EMOCIONALES en los Grupos Control y Pinza

Figura 51. Evolución del PSN SUEÑO en los Grupos Control y Pinza. .... 124

Figura 52. Evolución del PSN AISLAMIENTO SOCIAL en los Grupos

Control y Pinza. 126

Figura 53. Evolución del PSN MOVILIDAD FÍSICA en los Grupos Control y Pinza

Figura 54. Evolución del PSN TOTAL en los Grupos Control y Pinza....... 129

Figura 55. Evolución del grado de dolor en los grupos por sexos. 132

Figura 56. Evolución del balance articular en Flexión en los grupos por sexos.

Figura 57. Evolución del balance articular de Extensión en los grupos por sexos. 
Figura 58. Evolución del balance articular de Inclinación lateral derecha en los grupos por sexos.

Figura 59. Evolución del balance articular de inclinación lateral izquierda en los grupos por sexos.

Figura 60. Evolución de los valores obtenidos en el cuestionario de Roland- Morris en los grupos por sexos.

Figura 61. Evolución de los valores obtenidos en la Escala de Zung en los grupos por sexos.

Figura 62. Evolución del PSN ENERGÍA en los grupos por sexos. 146

Figura 63. Evolución del PSN Dolor en los grupos Control y Pinza en los grupos por sexos.

Figura 64. Evolución del PSN REACCIONES EMOCIONALES en los grupos por sexos. 150

Figura 65. Evolución del PSN SUEÑO en los grupos por sexos. 152

Figura 66. Evolución del PSN AISLAMIENTO SOCIAL en los grupos por sexos.

Figura 67. Evolución del PSN MOVILIDAD FíSICA en los grupos por sexos. 156

Figura 68. Evolución del PSN TOTAL en los grupos por sexos. 158

Figura 69. La calidad de vida es el resultado de la diferencia entre las expectativas y la realidad de la experiencia. 


\section{INTRODUCCIÓN}

\section{I.1. LA LUMBALGIA}

La lumbalgia es un dolor localizado y generado en la región lumbar (por debajo del reborde costal y por encima del pliegue glúteo), con o sin irradiación, que tiene como efecto final una repercusión en la movilidad normal de la zona debida a la sensación dolorosa ${ }^{1-4}$.

Desde la II Guerra Mundial se ha considerado el dolor lumbar en los países industrializados como un fenómeno sanitario de primer orden, con un aumento importante y desproporcionado en la población ${ }^{5}$. Así, la lumbalgia representa un importante problema de salud pública en las sociedades occidentales por su alta prevalencia y repercusión socioeconómica, generando un alto número de consultas y una elevada utilización de los servicios sanitarios con considerable pérdida de días laborales ${ }^{6,7}$.

Más del $70 \%$ de las personas de los países desarrollados experimentan dolor lumbar en algún momento de su vida ${ }^{8-10}$, siendo la prevalencia anual en la población general de entre el $22 \%$ y el $65 \%$, al margen del nivel socioeconómico ${ }^{6,11,12}$.

Koes et al. ${ }^{13}$, afirman que cada año entre el $15 \%$ y el $45 \%$ de los adultos lo padece, siendo más frecuente en la franja de los 35-55 años. Así, del $70 \%$ al $80 \%$ de las lumbalgias se inician entre los 25 y los 64 años $^{10,14}$ y aproximadamente el $30 \%$ de los trabajadores europeos la asocian al trabajo. El $90 \%$ de los pacientes se recupera en 6 semanas, aunque en un $2 \%-7 \%$ se convierte en crónica y más del 20\% de las mismas recurren en 6 meses, afectando sobre todo a las personas de más edad. En numerosas ocasiones la lumbalgia se convierte en una enfermedad crónica intermitente ${ }^{15}$.

Es la segunda causa de consultas médicas, la quinta de hospitalización y la tercera que implica intervención quirúrgica. Además, es la tercera causa de incapacidad funcional crónica después de las afecciones respiratorias y de los traumatismos ${ }^{11,12}$. Pocos pacientes vuelven al trabajo después de una baja superior a 6 meses y ninguno después de dos años ${ }^{10}$. 
Las políticas sanitarias en la lumbalgia se ejecutan con un coste muy alto y sus resultados cualitativos son inadecuados ${ }^{5}$.

Como se desprende de los párrafos anteriores, llama la atención que tratándose de una patología muy prevalente y a pesar de haberse diseñado y propuesto guías de práctica clínica, no se haya observado una reducción tangible en su incidencia o en sus repercusiones a largo plazo ${ }^{16}$.

\section{I.1.1. Etiología}

Hay que tener en cuenta que la lumbalgia no es un diagnóstico ni una enfermedad, sino un síntoma y que, por lo tanto, puede ser debido a múltiples enfermedades de diferente gravedad y repercusión.

La comprensión de la fisiopatología del dolor lumbar requiere un enfoque holístico y su abordaje terapéutico debe ser multidisciplinar. Muchas son las variables que pueden afectar a la presentación o progresión del dolor lumbar crónico. Cassidy et al. ${ }^{14}$ encontraron como una de estas principales variables, la centrada en los aspectos mecánicos del sistema de compresión, tensión, cizallamiento, torsión y niveles de carga, pero también influyen factores fisiológicos, psicológicos, socioeconómicos y psicosociales ${ }^{17}$.

La resolución del dolor lumbar no ha mejorado estadísticamente en los últimos años, viéndose incluso incrementado. Se han identificado dos mecanismos primarios en su presentación: la fatiga muscular y el estiramiento del músculo, del tendón o del tejido conectivo ${ }^{18}$. Esto unido al miedo a la recurrencia del dolor de espalda indica que el modelo general conduce a una causa multifactorial, por tanto, el tratamiento podría serlo también: una combinación de terapia física y psicológica con atención a los mecanismos de trabajo o las actividades de la vida diaria que incrementarían el daño y retardarían la recuperación ${ }^{18}$.

La postura de bipedestación, sobre todo estática, y el movimiento de paso de sedestación a bipedestación son mecanismos de exacerbación regular $\mathrm{y}$ frecuente del dolor de espalda ${ }^{19}$ debido a esta fatiga $\mathrm{y}$, posiblemente, las continuas exigencias del tejido conectivo durante estos 
movimientos prolongan el círculo de dolor ${ }^{18}$. El ejercicio puede reducir el desequilibrio muscular que podría causar la lumbalgia, y mejorar la resistencia a la fatiga de la musculatura implicada.

Los músculos de la pared abdominal ayudan en el control motor de la columna vertebral, habiéndose detectado déficits funcionales de estos en poblaciones con dolor lumbar. Las investigaciones de la pared abdominal en los pacientes con lumbalgia se basan principalmente en los músculos, por lo general en el transverso del abdomen ( $\operatorname{TrA})$ y en el oblicuo interno (OI). Debido a las funciones de la pared abdominal, los músculos abdominales y sus tejidos conectivos asociados deben ser considerados como una unidad. Sin embargo, en personas con lumbalgia, los cambios en la morfología del tejido conectivo pueden ser más evidentes que los observados en los músculos Oblicuo Externo (OE), OI, y $\operatorname{TrA}^{19}$.

El dolor discogénico es considerado como la causa más frecuente de lumbagia crónica ${ }^{20}$. Las últimas investigaciones sobre la patogénesis del dolor lumbar proponen la hipótesis de que un $\mathrm{pH}$ bajo puede ser la causa del desarrollo y progresión de la lumbalgia. Este bajo $\mathrm{pH}$ promueve la producción de mediadores inflamatorios y el agotamiento de proteoglicanos en el daño del disco intervertebral. La respuesta inflamatoria cambia el equilibrio de nutrientes en el núcleo, dando lugar a un círculo vicioso y favoreciendo el dolor lumbar crónico ${ }^{18,21}$. El daño en el tejido conectivo juega una papel importante en el mantenimiento del círculo vicioso del dolor lumbar ${ }^{18}$.

Aún así, no existe una relación directa de la lumbalgia mecánica o inespecífica con su causa. La genética del individuo es determinante para establecer diferencias entre sujetos, de manera que, ante las mismas condiciones laborales, sociales y psicológicas la lumbalgia puede hacerse patente o no existir ${ }^{21}$.

\section{I.1.2. Clasificación}

La lumbalgia se puede clasificar en función de su duración y en función de su origen. 


\section{I.1.2.1. Según la duración.}

Atendiendo a su duración, la clasificación de la lumbalgia es muy discutida. En general, la mayoría de autores coinciden en hacer tres grupos para clasificar su evolución en lumbalgia aguda, lumbalgia subaguda y lumbalgia crónica ${ }^{22}$. La falta de consenso se pone de manifiesto a la hora de intentar delimitar el periodo correspondiente a cada estadio (Tabla 1).

Tabla 1. Clasificación de la lumbalgia en función del tiempo de evolución

\begin{tabular}{|l|c|c|c|}
\hline & AGUDA & SUBAGUDA & CRÓNICA \\
\hline Sanz et al. $^{23}$ & $<1$ semana & $1-7$ semanas & $>7$ semanas \\
\hline Kovacs $^{3}$ & $<2$ semanas & $2-12$ semanas & $>12$ semanas \\
\hline Abenhaim et al. $^{24}$ & $<4$ semanas & $4-12$ semanas & $>12$ semanas \\
\hline Van Tulder et al. $^{25}$ & $<6$ semanas & $6-12$ semanas & $>12$ semanas \\
\hline
\end{tabular}

Por lo general, existe acuerdo y se considera lumbalgia crónica cuando la sintomatología se prolonga más allá de 12 semanas. Pero, desde que muchos pacientes con lumbalgia se han dado cuenta de que sus síntomas se estancan, disminuyen o presentan episodios recurrentes de dolor, puede no ser siempre apropiado utilizar un sistema de clasificación tan rígido $^{26,27}$. En cualquier caso, el período comprendido entre las 8 y las 12 semanas se considera de alto riesgo para el desarrollo de cronicidad e incapacidad ${ }^{28}$. Así, la clasificación de aguda o crónica no es tanto un tema de cronología, sino de variación entre individuos y sus percepciones ${ }^{29}$. De ahí, la dificultad de encuadrar un paciente como agudo o crónico, pues no existe un consenso generalizado para ello.

La lumbalgia aguda tiende a la resolución espontánea, y desaparece por sí misma antes de 1 mes en más del $70 \%$ de los casos. Los estudios de Hestbaek et al. ${ }^{30}$, que hacen referencia a la duración de la lumbalgia, establecen que al cabo de un año casi el $62 \%$ de los pacientes sigue padeciendo dolor. Los costes que genera el $70 \%$ de pacientes con lumbalgia aguda representan menos del $25 \%$ del total de los costes que se derivan de la afección. Por otra parte, el Grupo Español de Trabajo del Programa Europeo COST B13 ${ }^{4}$ afirma que el impacto de la lumbalgia sobre la incapacidad y la merma de la calidad de vida depende más de su duración 
que de su intensidad, por lo que los casos crónicos son los que generan mayor sufrimiento a los pacientes. Por todos esos motivos, el verdadero problema médico, social y económico es la lumbalgia crónica ${ }^{31}$.

El flujograma de procesos de la Gerencia de Atención Primaria de Soria establece como dolor lumbar crónico aquel de duración mayor de 7 semanas. (Anexo I). Además, la lumbalgia que se prolonga más de 6 semanas tiene tendencia a cronificarse, por lo que, en nuestro estudio vamos a considerar y trabajar con la lumbalgia crónica, entendiendo ésta como aquella cuyos síntomas van más allá de 6 semanas.

\section{I.1.2.2. Según su origen.}

Desde el punto de vista de su origen, encontramos tres tipos de lumbalgia ${ }^{6,15,27,32-34}$.

a) Lumbalgia inespecífica. Cuando no se puede determinar la causa que produce el dolor lumbar.

b) Lumbalgia asociada a radiculopatía o estenosis espinal.

c) Lumbalgia asociada a otras causas espinales específicas, como infecciones, neoplasias, osteoporosis, artritis, etc.

El paciente es clasificado en una de las anteriores categorías en función de la existencia o no de "señales de alerta" (Red Flags), que según la Guía de Práctica Clínica para la Lumbalgia Inespecífica son ${ }^{4}$ :

- Para enfermedad sistémica:

Dolor que aparece por primera vez antes de los 20 años ó después de los 55 años; dolor no influido por posturas, movimientos y esfuerzos; dolor exclusivamente dorsal; déficit neurológico difuso; imposibilidad persistente de flexionar 5o la columna vertebral; deformación estructural (de aparición reciente); mal estado general; pérdida de peso; fiebre; antecedentes de traumatismo reciente; cáncer o uso de corticoides (osteoporosis) o drogas por vía parenteral; inmunodepresión o SIDA.

- Para derivación a cirugía: 
- Para derivación inmediata y urgente: Paresia relevante, progresiva o bilateral; pérdida de control de esfínteres de origen neurológico; anestesia en silla de montar (posible síndrome de la cola de caballo).

- Para derivación para valoración quirúrgica: Dolor radicular (no lumbar), cuya intensidad sigue siendo intolerable pese a la aplicación durante 6 o más semanas de todos los tratamientos no quirúrgicos recomendados (posible hernia discal con criterios quirúrgicos); dolor que aparece sólo durante la deambulación y la limita, requiere flexión o sedestación para desaparecer, persiste pese a 6 meses de tratamiento conservador y se acompaña de imágenes de estenosis espinal (posible estenosis espinal sintomática).

Si existe alguna señal de alerta, se valora prescribir las pruebas complementarias oportunas. Si no hay ninguna señal de alerta, se puede asumir que el paciente tiene una lumbalgia inespecífica, en cuyo caso no es necesario solicitar pruebas complementarias. El 90\% de los casos de lumbalgia se atribuyen a alteraciones mecánicas de estructuras vertebrales, en la mayoría de carácter inespecífico (Lumbalgia Mecánica o Inespecífica) ${ }^{35}$.

Conviene prestar atención a posibles factores psico-socioeconómicos que podrían complicar la valoración y el tratamiento. Se conocen como "Yellow Flags", y representan factores de riesgo de evolución a lumbalgia crónica:

- Episodios previos de dolor lumbar

- Pérdida del puesto de trabajo por lumbalgia en el último año

- Presencia de dolor lumbar irradiado (ciatalgia) con signo de Lasegue positivo, afectación de ROT

- Atrofia y debilidad muscular

- Sensación subjetiva de enfermedad

- Gran fumador

- Presencia de síntomas depresivos acompañantes o de problemas personales (sociales, familiares, económicos), alcoholismo, etc.

- Falta de satisfacción laboral

- Implicación de problemas médico-legales 
- Autopercepción de mala salud

- Creencia de que el dolor debe ser eliminado ("curado") antes de volver al trabajo o a la actividad normal

Por tanto, en la lumbalgia inespecífica no puede establecerse un diagnóstico causal concreto, debido a la ausencia de correlación entre los síntomas y las pruebas diagnósticas por imagen y laboratorio ${ }^{5}$, aunque sí se puede decir que se trata de un dolor de tipo mecánico. De ahí que, una vez valoradas las Red Flags, no se estime oportuno solicitar dichas pruebas ${ }^{36}$. Aunque, para estar seguros de que no existen las señales de alerta ya se han tenido que realizar algunas de ellas.

\section{I.1.3. Clínica}

Como ya se ha comentando anteriormente, existen diferentes criterios en cuanto a la terminología y a la clínica que se aplican a la lumbalgia, dificultando la comparación de datos epidemiológicos y resultados terapéuticos. También se dificulta la labor de intercambio entre diferentes áreas de conocimiento ${ }^{32}$. Todo ello hace que la comparación de los distintos estudios sea muy compleja.

Clínicamente, la lumbalgia mecánica se caracteriza por dolor que aumenta con el movimiento, puede incrementarse si la actividad física se hace reiterada y persistente, y se alivia o desaparece con el reposo ${ }^{4,7}$. El paciente presenta dificultades para realizar las actividades de la vida diaria. La compresión o irritación de raíces nerviosas determina la presencia de síndromes radiculares o plexuales $^{6}$. Su evolución, aunque variable, es lentamente progresiva, cursando con fases asintomáticas 0 poco sintomáticas de duración desigual ${ }^{36}$.

Actualmente se define la lumbalgia inespecífica como todo aquel dolor localizado en la zona de referencia y no causado por fracturas, traumatismos directos o enfermedades sistémicas, en el que no existe una compresión radicular demostrada y subsidiaria de tratamiento quirúrgico (como ocurre en 
una minoría de casos de hernia discal sintomática o estenosis espinal sintomática) $)^{4,15}$.

Habitualmente, no existe en la lumbalgia una correlación lineal entre la clínica referida por el paciente y la alteración anatómica hallada por técnicas de imagen, por lo que llegar a un diagnóstico etiológico o causal de certeza sólo es posible entre el $10 \%$ y el $20 \%$ de los casos, que responden a un origen inflamatorio, infeccioso, neoplásico o mixto. Es decir, que entre el $80 \%$ y el $90 \%$ de los pacientes presentan una lumbalgia que podemos encuadrar dentro del grupo de las llamadas inespecíficas ${ }^{4,7,37}$, ya que, el origen del dolor no puede ser identificado. La proporción de pacientes con lumbalgia inespecífica es mayor en aquellos con dolor lumbar de menos de un mes de evolución ${ }^{27-28}$.

Las pruebas diagnósticas planteadas a la hora de determinar la existencia de una lumbalgia, no son claras. La presencia o no de hallazgos en la RX simple de columna lumbar, y los resultados en TAC y RMN no aportan ninguna ventaja en el manejo terapéutico de los pacientes ${ }^{38}$. Sin embargo, la RMN puede ser un elemento básico para diagnosticar y facilitar las decisiones de tratamiento en casos donde no puede ser identificada causa estructural con otras pruebas ${ }^{39}$. Por ello, cuando nos encontramos ante un paciente con lumbalgia, uno de los objetivos es identificar el tejido o estructura espinal responsable del dolor ${ }^{27}$. Se han observado elementos que intervienen en un proceso lumbálgico y predisponen su aparición ${ }^{40}$.

Estos Factores de Facilitación son:

- Sexo y edad.

La edad avanzada y el género femenino incrementan el riesgo de dolor crónico, aunque en general, durante los años de trabajo, hombres y mujeres tienen dolor lumbar con la misma frecuencia ${ }^{41}$.

En cuanto a la edad, del $70 \%$ al $80 \%$ de las lumbalgias se inician entre los 25 y los 64 años $^{10,14}$.

- Fortaleza y flexibilidad de la musculatura de la espalda. 
Una columna vertebral con una resistencia muscular pobre incrementa el riesgo de lesiones ocupacionales, mientras que, por el contrario, una buena forma física es una importante defensa para la lumbalgia ${ }^{42}$.

- Factores relacionados con el trabajo

Los factores ocupacionales tienen un importante impacto. En la Tabla 2 se muestra una clasificación que distingue los trabajos en función de su carga física. Así, los trabajadores que realizan tareas pesadas o requieren esfuerzos físicos, aquellos con poca satisfacción laboral, con condiciones pobres de trabajo, los que son nuevos en el puesto o no son lo suficientemente valorados por sus superiores son más propensos a padecer dolor lumbar crónico ${ }^{43}$.

Cuando la vibración que resulta de la conducción prolongada se combina con el levantamiento y transporte de cargas, el riesgo de lumbalgia aumenta considerablemente. La lesión de la espalda suele ser causada por un sobre esfuerzo y no por un traumatismo directo. Así mismo, los movimientos complejos del tronco a altas velocidades, principalmente con inclinación y torsión, aumentan el riesgo relacionado con los trastornos de lumbalgias ocupacionales ${ }^{42}$. $Y$ no sólo eso, sino que las posiciones mantenidas con inclinación del tronco hacia delante también suponen riesgo de lumbalgia, que se incrementa hasta seis veces cuando la flexión anterior se acompaña de torsión del tronco ${ }^{45}$.

En general, el retorno al trabajo, si es posible, es beneficioso para la recuperación ${ }^{46}$. Aunque según la versión de Haldorsen et al. ${ }^{47}$ el trabajo también puede ser causa de presentación de un cuadro de lumbalgia, existiendo una relación entre la incapacidad laboral por lumbalgia y la insatisfacción laboral, el bajo compañerismo, la monotonía en el trabajo, el tipo de trabajo, los bajos salarios, la inestabilidad laboral y la inseguridad económica .

La patología lumbar tiene una influencia considerable en la salud pública, pues se ha convertido en una de las primeras causas de absentismo laboral $^{48}$ y constituye un importante problema socio-económico a nivel 
mundial. Se debe intentar atenuar estas serias consecuencias a largo plazo, comenzando por la asistencia desde Atención Primaria que constituye el primer nivel de acercamiento sanitario al paciente.

Tabla 2. Carga laboral según la actividad

\begin{tabular}{|c|c|c|}
\hline Carga Laboral & Actividad & Ejemplos \\
\hline Liviana & $\begin{array}{l}\text { Estar sentado moviendo las } \\
\text { manos y piernas con } \\
\text { moderación }\end{array}$ & $\begin{array}{l}\text { Trabajo de escritorio, escribir } \\
\text { en teclado, conducir en } \\
\text { tráfico lento } \\
\text { Trabajo en línea de montaje } \\
\text { Supervisión de un sitio de } \\
\text { trabajo }\end{array}$ \\
\hline Moderada & $\begin{array}{l}\text { Caminar rápido } \\
\text { Sentarse moviendo brazos y } \\
\text { piernas con vigor } \\
\text { Estar de pie, haciendo trabajo } \\
\text { liviano o moderado que incluye } \\
\text { caminar un poco } \\
\text { Levantar o empujar con } \\
\text { moderación }\end{array}$ & $\begin{array}{l}\text { Entregar el correo } \\
\text { Conducir maquinarias } \\
\text { pesadas; limpieza industrial } \\
\text { Recoger frutas y vegetales }\end{array}$ \\
\hline Pesada & $\begin{array}{l}\text { Levantar objetos pesados, } \\
\text { empujar o tirar } \\
\text { intermitentemente } \\
\text { Subir escaleras con equipo } \\
\text { pesado }\end{array}$ & $\begin{array}{l}\text { Aserruchar, cepillar, excavar, } \\
\text { apalear, trabajar con mazo, } \\
\text { instalar techos } \\
\text { Reabastecer estanterías, } \\
\text { remover asbesto } \\
\text { Combatir incendios }\end{array}$ \\
\hline
\end{tabular}

Fuente: Work Safe $\mathrm{BC}^{43}$

- Factores psicosociales

El impacto de los factores psicológicos es controvertido. La lumbalgia es un factor estresante en sí mismo, que asociado a depresión, constituyen dos síntomas complejos que se afectan mutuamente en sentido negativo ${ }^{40,49}$. La depresión o la sensación de estar enfermo podrían asociarse a un aumento 
del riesgo de cronicidad ${ }^{43}$. Dentro de este apartado, se pueden incluir como factores predisponentes las recurrencias y las estancias hospitalarias ${ }^{43}$.

Hay que tener en cuenta que el dolor de espalda se ve influenciado por elementos como la cultura, la educación, el lugar de trabajo, la experiencia personal de lumbalgia y las secuelas como la incapacidad ${ }^{50}$, por lo que el componente subjetivo es muy complejo.

Según las características ya reseñadas, el presente trabajo de tesis doctoral se va a centrar en la lumbalgia inespecífica crónica (LIC).

\section{I.1.4. Tratamiento}

A pesar de que el dolor de espalda en general, y el lumbar en particular, siguen siendo objeto de controversias en la literatura científica, actualmente se dispone de varias guías y revisiones sobre la gestión del dolor lumbar agudo y crónico en la práctica clínica, y dentro de ella, en Atención Primaria ${ }^{23-24,51-52}$.

En el tratamiento de la lumbalgia, independientemente de su etiología, dos son los objetivos prioritarios: el alivio del dolor y la recuperación y mantenimiento de la función. Aunque el término recuperación se utiliza con mucha frecuencia, su definición no está clara, ni existe un acuerdo sobre las mediciones que han de realizarse para comprobar la evolución de la lumbalgia inespecífica ${ }^{3}$.

Pocos tratamientos de los empleados han demostrado su eficacia de acuerdo con unos estándares científicos adecuados ${ }^{3}$. Por ello, encontrar tratamientos óptimos para una patología tan frecuente representa un reto para clínicos e investigadores ${ }^{53}$. La práctica clínica habitual en el tratamiento de la lumbalgia inespecífica ha carecido tradicionalmente de base científica, por ello, muy pocos de los tratamientos utilizados se han evaluado rigurosamente a pesar de su cotidiana aplicación ${ }^{3}$.

La American Task Force, teniendo en cuenta criterios como el impacto de la enfermedad en la población, las características de la intervención y el 
tipo de diseño, distingue cinco niveles de calidad de la evidencia científica a la hora de considerar una técnica terapéutica ${ }^{54}$.
A.- Existe adecuada evidencia científica para recomendar la adopción de la técnica.
B.- Existe cierta evidencia científica para recomendar la adopción de la técnica.
C.- Existe una insuficiente evidencia científica, por lo que la decisión de adoptar la técnica debe basarse en otros criterios.
D.- Existe una cierta evidencia científica para recomendar la no adopción de la técnica.
E.- Existe una adecuada evidencia científica para recomendar la no adopción de la técnica.

Atendiendo a estos criterios, la "Guía de Práctica Clínica del Programa

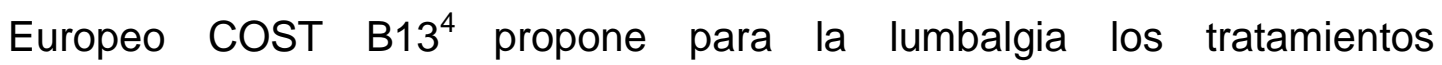
recomendados con niveles A y B de evidencia científica. Son los siguientes:

- Información al paciente y programas educativos breves.

En los pacientes crónicos los programas educativos centrados en el manejo activo (evitación del reposo, mantenimiento de la actividad, regreso temprano a las actividades normales, etc.) son efectivos para mejorar el grado de incapacidad funcional (nivel A) y mejorar el retorno al trabajo (nivel B), aunque no el dolor.

- Evitar el reposo en cama.

Si en algún momento el dolor impide al paciente adoptar otra postura, se puede tolerar durante un máximo de 48 horas, ya que se estima que cada día de reposo en cama conlleva una pérdida del $2 \%$ de la potencia muscular ${ }^{3}$. El reposo en cama aumenta la intensidad y la duración del dolor, el grado de incapacidad funcional, la duración de la baja laboral, y el riesgo de cronificación del episodio. Además, es similar o peor que no aplicar ningún tratamiento o aplicar un placebo (nivel A).

- Mantener el mayor grado posible de actividad física. 
Aconsejar mantener el mayor grado de actividad posible, mejora el dolor y el grado de incapacidad, y acorta el período de baja laboral (nivel A).

- Fármacos de primera línea.

Analgésicos, opiáceos menores, AINE y miorrelajantes. El tratamiento farmacológico es la primera línea terapeútica elegida para la LIC, sin embargo, suele ser ineficaz a largo plazo ${ }^{55}$. En los pacientes con lumbalgia crónica, estos fármacos están indicados exclusivamente para el tratamiento sintomático y transitorio de las exacerbaciones (durante un máximo de 3 meses) y no como tratamiento habitual o de fondo ${ }^{56}$.

Los más utilizados son:

1. Los antiinflamatorios por vía sistémica: eficaces (hasta 3 meses) para disminuir la intensidad del dolor.

2. Las benzodiacepinas: eficaces para reducir la intensidad del dolor (nivel A), pero no para mejorar la contractura muscular (nivel C).

3. Los miorrelajantes no benzodioacepínicos: efectivos para mejorar el dolor, pero no para mejorar la contractura muscular (nivel C).

- Intervención neurorreflejoterápica (NRT).

Es la implantación muy superficial de material quirúrgico sobre terminaciones nerviosas de la piel para desencadenar efectos que mejoren su dolencia (Kovacs) $^{57}$. No es necesario abrir la piel ni anestesiar al paciente. La intervención NRT es eficaz y segura para el tratamiento de la lumbalgia (nivel A).

- Ejercicio.

A partir de las 2-6 semanas con lumbalgia, el ejercicio es efectivo a medio plazo para mejorar el dolor, el grado de actividad y el retorno al trabajo (nivel A). El ejercicio es más efectivo a corto plazo que los tratamientos pasivos considerados como controles (nivel B).

- Escuelas de Espalda.

Las Escuelas de la Espalda (centradas en el manejo activo de la lumbalgia por parte del paciente) son efectivas para mejorar a corto plazo el dolor y el estado funcional en las lumbalgias subaguda y crónica (nivel B). 
- Fármacos de segunda línea. Antidepresivos.

Los antidepresivos tricíclicos o tetracíclicos tienen un efecto analgésico que disminuye la intensidad del dolor lumbar (nivel A), pero no mejoran el grado de incapacidad (actividad diaria) (nivel B).

El tratamiento farmacológico no siempre es efectivo, mientras que las terapias manuales (manipulaciones, masaje, ejercicios...) resultan eficaces en gran parte de las lumbalgias crónicas ${ }^{57,58}$.

- Tratamiento psicológico (cognitivo-conductual).

El tratamiento cognitivo-conductual es efectivo para mejorar el dolor, el estado funcional y el retorno al trabajo (nivel A). Por ello, hablar con el paciente y aconsejarle en la correcta realización de gestos es importante a la hora de prevenir o mejorar la lumbalgia.

- Parches de capsaicina.

La aplicación de parches de capsaicina es más eficaz que el placebo para el alivio del dolor a corto plazo (hasta tres semanas) (nivel A).

- Fármacos de tercera línea. Opiáceos.

El tramadol, sólo o asociado con paracetamol, es más eficaz que el placebo para mejorar el dolor y el grado de incapacidad (nivel A).

- Programas multidisciplinarios de rehabilitación.

Los programas multidisciplinarios de rehabilitación mejoran el dolor, el grado de incapacidad y el retorno al trabajo en los pacientes crónicos en los que han fracasado los tratamientos monodisciplinarios previos (nivel A). Son más efectivos que la rehabilitación ambulatoria tradicional (nivel B) y aportan ventajas con respecto a otros tratamientos más sencillos en los pacientes con mal pronóstico laboral (es decir, pocas probabilidades de regresar al trabajo) (nivel C).

- Neuroestimulación eléctrica percutánea (PENS)

La estimulación eléctrica percutánea consiste en la administración de una corriente eléctrica directamente en los tejidos profundos, con la finalidad de estimular a las fibras aferentes gruesas (fibras sensitivas) en las localizaciones próximas a la patología origen del dolor con el fin de aliviarlo. 
Esta técnica muestra una eficacia del nivel B para mejorar el dolor en la LIC.

- Cirugía.

En los pacientes que manifiestan los criterios de indicación, la cirugía obtiene resultados similares a un programa de tratamiento cognitivoconductual con ejercicio (nivel B).

Por otra parte, hay tratamientos que no han sido adecuadamente evaluados aunque tienen sus defensores como las corrientes interferenciales, la onda corta, la termoterapia, las fajas y los corsés lumbares, la electroestimulación medular, la ozonoterapia o los fármacos anti-TNF (factor de necrosis tumoral) ${ }^{4,58-60}$. Así mismo, según la "Guía de Práctica Clínica del Programa Europeo COST B13"4, existen tratamientos que han sido evaluados pero no pueden ser recomendados por falta de evidencia científica sobre su efectividad (acupuntura, manipulación vertebral, infiltraciones en punto gatillo...). De entre ellos, merecen una mención especial el masaje y la estimulación eléctrica transcutánea (TENS), por ser frecuentes en los protocolos de tratamiento de la lumbalgia en Atención Primaria.

- Masaje.

Comparado con otras intervenciones, el masaje puede ser más efectivo que la manipulación y la acupuntura, sin embargo, es más efectivo que los ejercicios en la lumbalgia crónica sólo a corto plazo (nivel A $)^{61,62}$.

\section{- TENS}

EI TENS es una modalidad terapéutica no invasiva de aplicación analgésica. Esta técnica consiste en el estímulo eléctrico de nervios periféricos a través de los electrodos en la superficie de la piel. El desarrollo y el uso del TENS para el dolor se fundamentaron en la teoría del Control de la Puerta (Gate Control), ya en la segunda mitad del siglo $X^{63-65}$. El dolor es vehiculizado por fibras "C" amielínicas y "A" mielínicas. Las fibras propioceptivas "B" de gran diámetro, mielínicas, son estimuladas e inhiben el influjo nociceptivo a nivel segmentario de la médula, provocando a nivel suprasegmentario la producción de endorfinas ${ }^{66,67}$. 
La revisión sistemática de Khadilkar et al. ${ }^{68}$ informa de una tendencia hacia la mayor reducción del dolor en el grupo de pacientes tratados con TENS comparado con el tratamiento placebo. Las características de los parámetros del dispositivo del TENS eran heterogéneos: frecuenciaintensidad óptima, duración del tratamiento y localización de los electrodos, por lo que, es necesaria la realización de estudios más específicos y bien diseñados para determinar el uso del TENS y sus parámetros ${ }^{69,70}$.

En los últimos años están apareciendo nuevas intervenciones para la lumbalgia como el GMI (Graded Motor Imagery), una técnica de tratamiento designada para tratar el dolor crónico y que intenta normalizar los procesos centrales del dolor, y el MVF (Mirror Visual Feedback), que han mostrado facilidad para corregir los cambios corticales y mejorar los síntomas en dolor crónico. La reorganización cortical es un rasgo común para dirigir la LIC ${ }^{71}$.

Hay una tendencia actual hacia el fortalecimiento de los músculos del Core en el plan de tratamiento de la lumbalgia ${ }^{72}$. El concepto de Core se empezó a desarrollar en los años noventa bajo el nombre de "Core Stability". Recoge una serie de tratamientos basados en el refuerzo de la estabilidad de unos determinados músculos considerados Core $^{73}$. Entre los músculos que lo forman encontramos: los erectores espinales (longuísimo e iliocostal), el cuadrado lumbar (CL), los multífidos, los abdominales (TrA, OI, OE, recto mayor del abdomen), psoas (PS), diafragma y musculatura del suelo pélvico, formando una caja muscular con 29 pares de músculos. Dentro de estos, los más importantes son el transverso del abdomen y los multífidos, que forman parte de la musculatura profunda ${ }^{74}$.

El transverso del abdomen es un músculo implicado en la estabilidad de la columna lumbar. Su activación es anterior a la musculatura agonista del movimiento que se va a realizar ${ }^{75}$, es decir, es activado por el SNC previamente, de forma que se reduzcan los desplazamientos y los movimientos dentro del rango de movimiento fisiológico en la columna lumbar $^{76}$. Estos ajustes anticipatorios forman parte del patrón motor del movimiento. En la lumbalgia existe un retardo en la activación del transverso del abdomen, lo que hace que no exista un buen control motor y que las 
estructuras pasivas se vayan dañando en gestos cotidianos. Este dolor retroalimenta las posiciones antiálgicas, modificando la correcta alineación, lo que perpetúa el mal gesto y el dolor en el tiempo ${ }^{77}$. Así pues, el $\operatorname{Tr}$ A se presenta como un músculo importante en la LIC.

Como ya se ha comentado con anterioridad, el dolor de espalda es multifactorial. Por lo tanto, el tratamiento también debe ser multifactorial: una combinación de terapia física y psicológica con atención a los mecanismos en el trabajo o en las actividades de la vida diaria que exacerban la lesión y retrasan su recuperación ${ }^{78}$. Una de las explicaciones ofrecidas para interpretar la ineficacia de los tratamientos en la LIC es la falta de éxito en la definición de los subgrupos de pacientes que tienen más probabilidades de responder a un enfoque de tratamiento específico ${ }^{79}$. Govenden ${ }^{80}$ apoya la teoría de que los pacientes deben ser tratados desde una perspectiva biopsicosocial, por ello, el acercamiento terapéutico desarrollado debe ser multidisciplinar e individualizado. Este acercamiento multidisciplinar es la llave del éxito de programas para reducir el deterioro social y ocupacional en la LIC. Es posible conseguir los mismos resultados con estrategias menos intensivas si se mantiene dicho acercamiento. Además, las expectativas de los pacientes hacia el tratamiento prescrito deben ser tenidas en cuenta a la hora de valorar los resultados. Está ampliamente reconocido que la perspectiva del paciente es esencial en la toma de decisiones médicas y en el juicio sobre los resultados de tratamiento. La opinión del paciente sobre su dolor lumbar determina no sólo la expresión subjetiva de su dolencia, sino también su opinión sobre la utilización de los cuidados en salud y su vuelta al trabajo ${ }^{8}$.

\section{I.2. TEJIDO CONJUNTIVO}

\section{I.2.1. Fundamentos básicos del tejido conjuntivo}

La denominación de tejido conectivo o conjuntivo (TC) fue utilizada por primera vez por Johan Muller (citado en Goats y Keir ${ }^{81}$. Es uno de los cuatro tejidos que componen el cuerpo humano, constituye el $16 \%$ del peso corporal y contiene el $23 \%$ del agua del organismo ${ }^{82,83}$. 
EI TC deriva del mesénquima, tejido embrionario del que también provienen el tejido muscular, los vasos sanguíneos y el tejido linfático. Bajo este nombre se incluyen una gran variedad de tejidos que proporcionan al organismo, entre otras propiedades, fuerza, elasticidad y densidad, interviniendo además en la nutrición y la defensa ${ }^{82}$. El TC experimenta un reemplazo de forma periódica del $30 \%$ en 6 meses o del $75 \%$ en 2 años ${ }^{84}$.

Existen numerosas clasificaciones del TC. Según Gartner y Hiatt (85) se pueden distinguir: el TC embrionario, el TC propiamente dicho, y el TC especializado, que incluye cartílago, hueso y sangre (Figura 1).

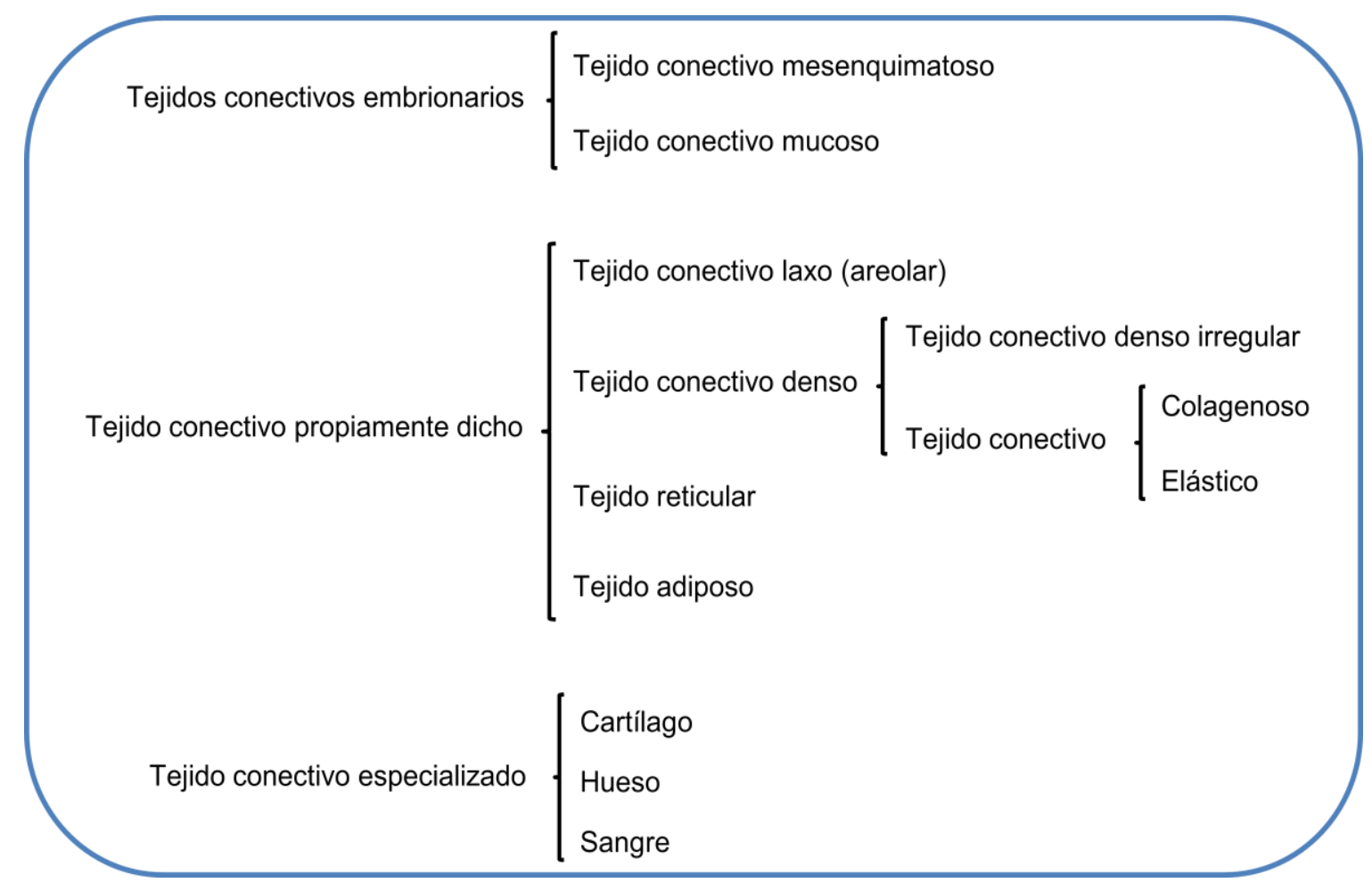

Figura 1. Clasificación del tejido conjuntivo o conectivo ${ }^{86}$.

Desde otro punto de vista, el TC se clasifica en tres grupos según la densidad, la proporción y la orientación de sus fibras y el tipo de células presentes $^{87}$ :

- TC denso regular: presente en los ligamentos y tendones.

- TC denso irregular: presente en las cápsulas articulares, el periostio y las aponeurosis. Es multidireccional.

- TC laxo: presente en las envolturas viscerales, neurológicas y musculares, y en la fascia subcutánea. 
Básicamente, puede decirse que el TC está formado por elementos celulares y extracelulares. Los elementos celulares pueden, a su vez, dividirse en células propias: fibroblastos, condroblastos, osteoblastos; y células conjuntivas libres: mastocitos, macrófagos, etc. Estos fibroblastos dotan de plasticidad al $\mathrm{TC}^{88}$. Los elementos extracelulares conforman la "matriz extracelular" que representa el espacio entre las células, relleno por diferentes tipos de fibras, principalmente colágeno, aunque existen otros tipos de fibras reticulares y elásticas (elastina). Estas fibras se encuentran inmersas en una sustancia sin color, transparente y homogénea denominada "sustancia amorfa o fundamental" que tiene consistencia de gel hidratado y está compuesta por proteoglicanos, glucosaminoglicanos y glucoproteínas estructurales o de adhesión ${ }^{83}$ (Figura 2). Sostiene las células, las mantiene unidas y proporciona el medio en el que se establece el intercambio de sustancias entre la sangre y las células. Además, interviene en la actividad metabólica ${ }^{85}$.

Tanto el colágeno como la elastina dotan al TC de sus propiedades. El colágeno es una proteína encargada de proporcionar a los tejidos de los que forma parte la fuerza y protección necesaria frente a los estiramientos excesivos. Esta propiedad protectora del colágeno, procede de su estructura helicoidal, que aporta una gran resistencia mecánica al estiramiento axial ${ }^{90}$, pero una escasa capacidad de defensa frente a fuerzas de compresión. La síntesis del colágeno depende de las tensiones mecánicas, y de la cantidad, la calidad y la dirección del movimiento. Ante una tensión continua y prolongada en el tiempo, las moléculas se orientan en serie, y ante tensiones repetitivas de corta duración, las moléculas de colágeno se orientan de forma paralela ${ }^{82,90,91}$. Esta orientación paralela condicionada por microtraumatismos repetitivos da lugar al entrecruzamiento anómalo de sus fibras, volviéndose el tejido más compacto y perdiendo progresivamente su elasticidad y sus propiedades mecánicas. De esta manera, el colágeno provee a los tejidos como los ligamentos, los tendones y las fascias de resistencia a la tensión y al estiramiento ${ }^{87}$. 


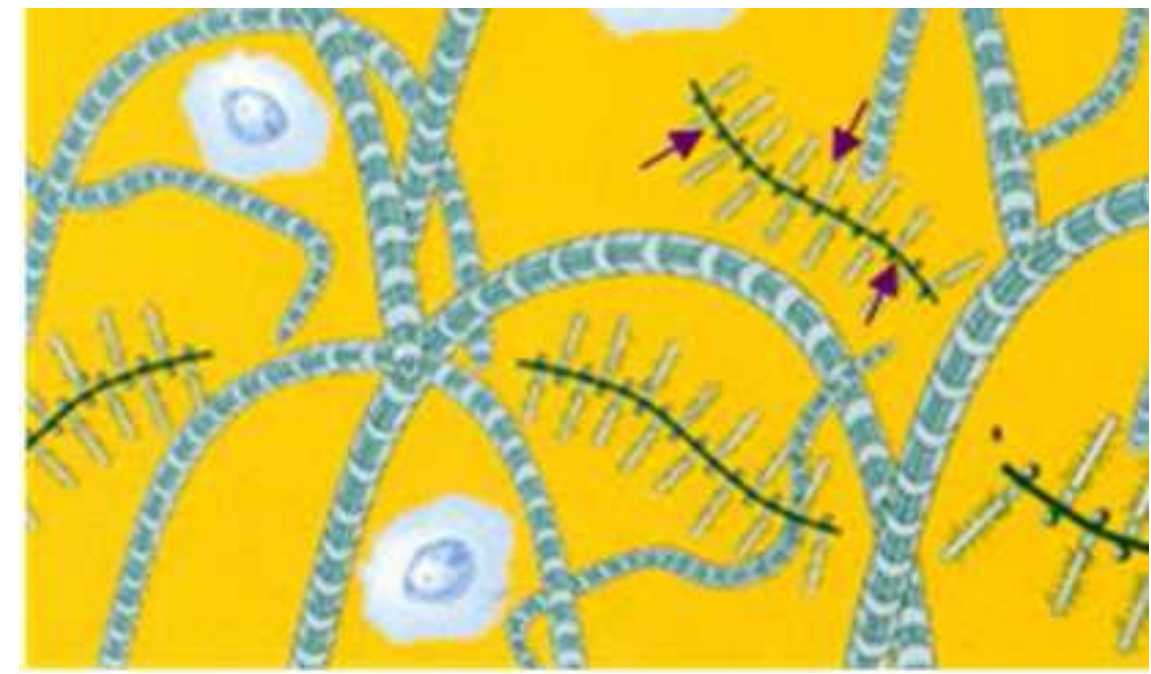

Figura 2. Matriz extracelular del tejido conectivo fascial. Matriz extracelular del tejido conectivo fascial. Debido a su enorme apetencia hídrica, los proteoglicanos (flechas) atraen moléculas de agua continuamente, en tanto que la red de fibras de colágeno se opone al aumento de volumen. El resultado es una estructura hidratada que ofrece permanentemente resistencia a la compresión (adaptado de Ross et al. en Rodríguez $I^{89}$ ).

Las fibras de colágeno tienen una estructura más ondulada en personas jóvenes que en adultos, dotándoles de mayor plasticidad y por tanto, de mayor resistencia. El ejercicio regular favorece esta arquitectura más joven del colágeno, lo que lleva a una mayor capacidad elástica.

Por otro lado, la elastina es la proteína encargada de proporcionar a estructuras como la fascia, la piel, los tendones y los vasos la suficiente elasticidad para que, después de estirarse, las fibras elásticas regresen a su posición de reposo ${ }^{85}$.

\section{I.2.2. Fascias}

Aunque el concepto de fascia no está claro, ya que puede variar de un texto a otro y de un país a otro ${ }^{92}$, se puede definir como una banda o capa de TC fibroso, principalmente laxo y dispuesto en capas que envuelve, separa o vincula juntos músculos, órganos y otras estructuras del cuerpo ${ }^{93}$. Por eso, sólo las capas bien definidas de TC fibroso pueden ser llamadas propiamente fascia, siendo incorrecto el uso de este término para denominar todos los TC del cuerpo. Es una membrana fibrosa, blanquecina, flexible y resistente (Figuras 3 y 4 ). 

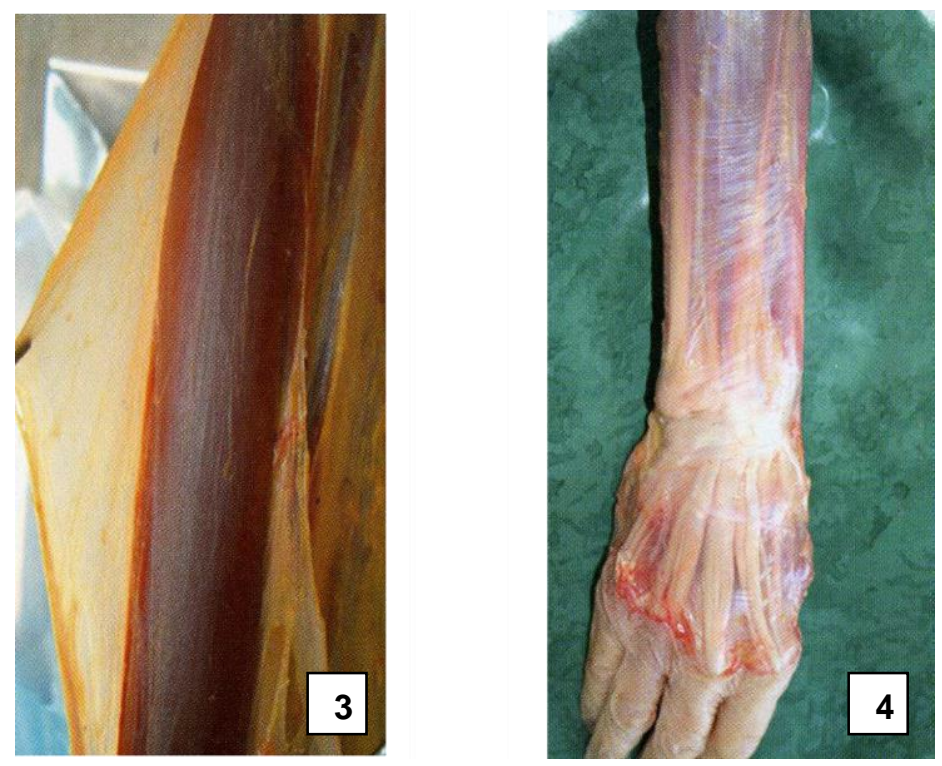

Figura 3. Vista macroscópica de la fascia en antebrazo ${ }^{95}$. Figura 4. Vista macroscópica de la fascia en brazo ${ }^{95}$.

Esta definición de fascia se extiende a los TC que incluyen aponeurosis, ligamentos, tendones, retináculos, cápsulas articulares, epimisio, meninges, periostio, y todas las fibras del endomisio e intermusculares. Los tejidos fasciales son vistos como una red tensional interconectora que adapta la densidad y la longitud de sus fibras en función de las demandas tensionales locales ${ }^{94}$.

El colágeno es el componente más importante del sistema fascial, formado principalmente por colágeno de tipo I, el más resistente a las tensiones, protegiendo a la fascia de elongaciones excesivas ${ }^{90}$ (Figura 5).
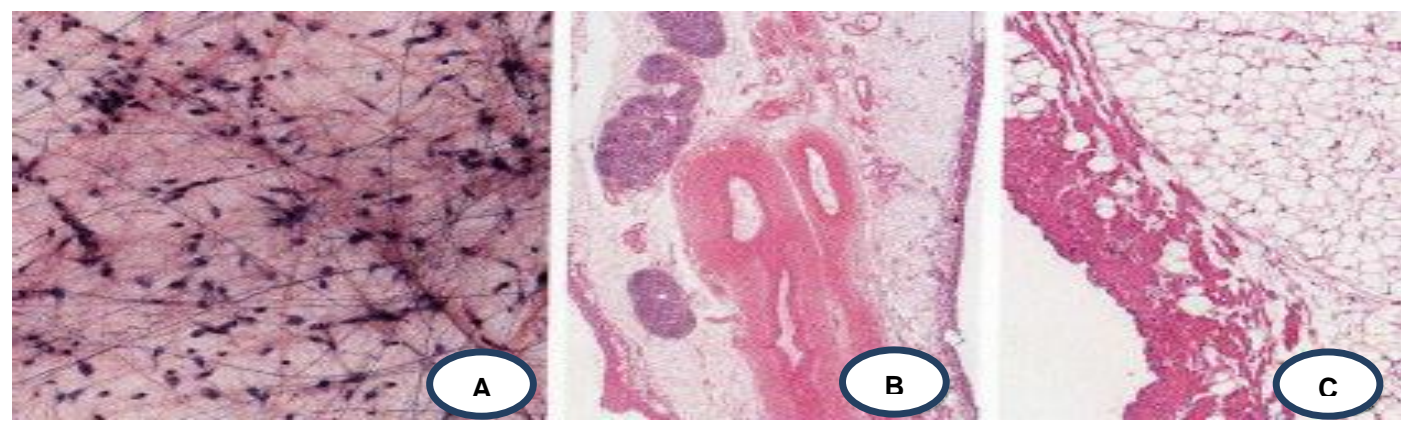

Figura 5. Vistas histológicas de la fascia ${ }^{95}$. A: tejido conectivo laxo con fibras de colágeno y elastina. B: sección transversal de tejido con fibras de colágeno y una parte central de tejido adiposo rodeando vasos y nódulos linfáticos. C: fina capa de fibras colágeno densa e irregular. 
Los TC difieren en función de su densidad y del alineamiento direccional de las fibras de colágeno (Figura 6). Por ejemplo, la fascia superficial se caracteriza por tener menor densidad y mayor multidireccionalidad de sus fibras, mientras que los tendones son más densos y en los ligamentos las fibras son más unidireccionales. La fascia intramuscular (epimisio, perimisio y endomisio) puede presentar variación en los grados de densidad y direccionalidad ${ }^{94,96}$. Todas ellas contienen una cantidad variable de fibroblastos con capacidad de contracción, denominados miofibroblastos ${ }^{97}$.

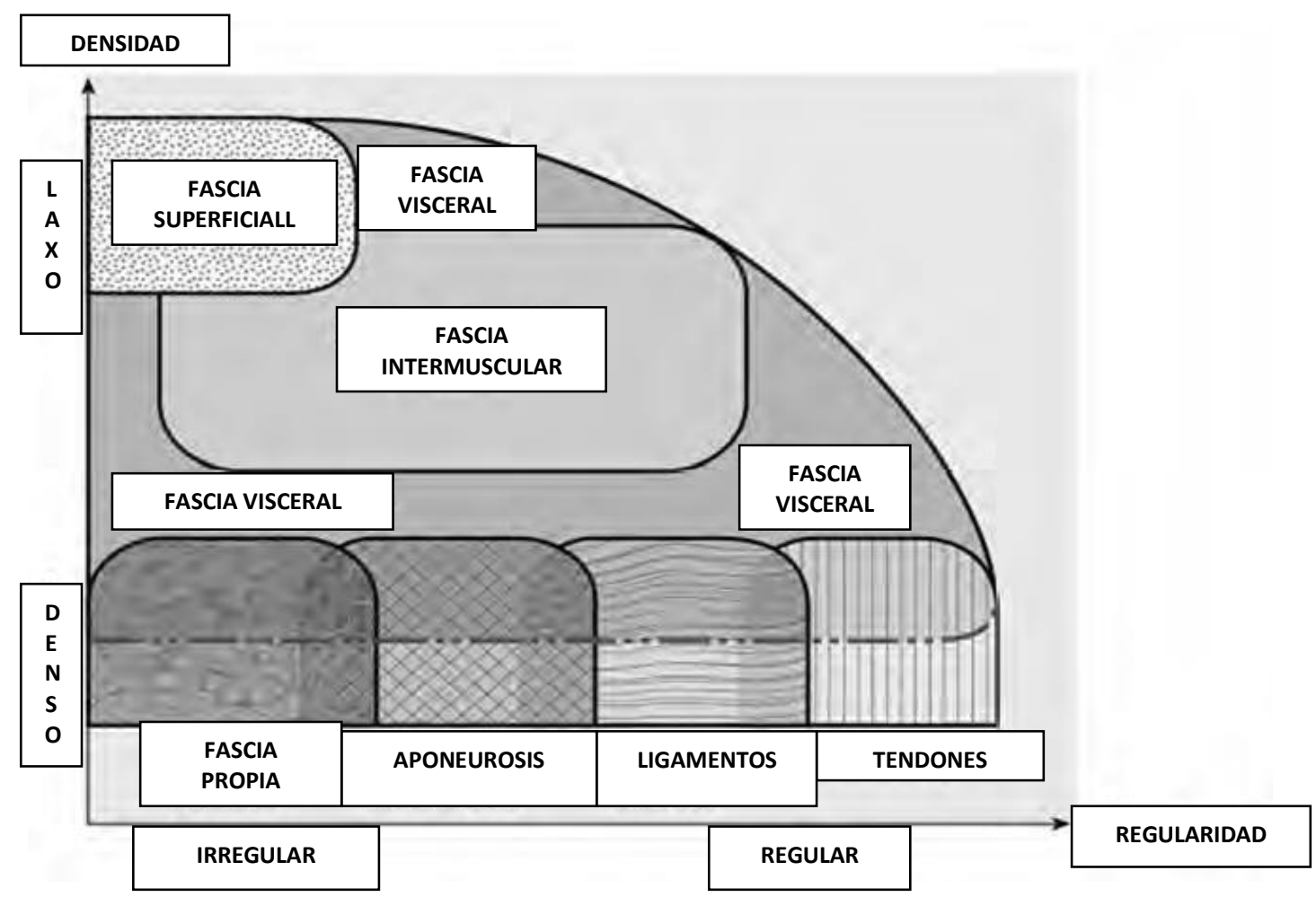

Figura 6. Diferentes tejidos conectivos considerados como tejidos fasciales según la terminología del International Fascia Research Congress ${ }^{98}$.

La fascia es prácticamente inseparable de todas las estructuras corporales, y crea una continuidad entre los tejidos a fin de mejorar la función y el soporte ${ }^{99}$. Ha sido muy difícil de estudiar, lo que ha dado lugar a ambigüedades en la nomenclatura ${ }^{99}$. Ya se ha comentado que todavía no se ha aceptado y establecido formalmente una terminología consistente para clasificar y categorizar la fascia, por lo que existen discrepancias en lo que concierne a la definición oficial, la terminología, la clasificación y la clínica de esta estructura ${ }^{100,101}$. Todo ello conlleva un efecto negativo en la 
comunicación entre profesionales sanitarios, impidiendo así su colaboración en investigación ${ }^{102}$. La fascia representa un tópico creciente de interés en todo el mundo, por lo que es prioritario reducir la ambigüedad de términos fundamentales, para que la investigación sobre ella pueda avanzar adecuadamente $e^{100,101,103}$.

EI TC muscular (la fascia profunda en el raquis y el epimisio en los miembros) es una estructura sin solución de continuidad que reviste el músculo y se extiende por su interior, vía perimisio y endomisio. Esta continuidad significa que la contracción de cada fibra muscular se propaga por todo el TC denso, existiendo una vía miofascial de transmisión de estas fuerzas. Por tanto, cuando el músculo se contrae, parte de la fuerza que genera se transmite vía miotendinosa para controlar el aparato locomotor, pero otra parte se transmite (vía miofascial) entre las fibras del mismo músculo y hacia músculos adyacentes ${ }^{93,104}$.

La fascia se mantiene en un estado de tensión basal gracias a las fibras musculares que se insertan en ella. Los receptores y las terminaciones nerviosas libres presentes en este tejido están preparados para percibir cualquier variación de tensión, y por tanto, todo movimiento corporal. Cuando una parte del cuerpo realiza un gesto, los receptores son estimulados, aportando información precisa sobre ese movimiento, su dirección, velocidad, amplitud, etc. Cualquier alteración fisiológica de la fascia profunda puede modificar la arquitectura muscular y cambiar sus propiedades mecánicas, provocando la activación incorrecta de los receptores nerviosos y alterando estas señales o inputs. Pueden aparecer entonces gestos incoordinados y aferencias nociceptivas ${ }^{93}$.

La fascia está implicada en el control motor periférico y en la propiocepción, siempre en estrecha colaboración con el Sistema Nervioso Central. Factores externos o internos (irritaciones mecánicas y químicas) pueden incidir en la normal homeostasis de la fascia, estimulando al propio TC a fabricar un exceso de nuevas fibras de colágeno o cambiar la concentración de las macromoléculas en la matriz extracelular. Es una reacción protectora que intenta reparar la lesión o adaptarse a los estímulos 
recibidos. Se forma así un espesamiento, densificación o superposición de colágeno que provoca que esta membrana, en condiciones normales muy deslizante, se vuelva rígida y adherida, con la inevitable pérdida o déficit de su función como elemento coordinador ${ }^{93}$.

\section{I.2.2.1. Tipos de fascia}

Como ya se ha dicho al comienzo de este apartado, la definición de fascia es más bien ambigua ya que su grosor, función, composición y dirección dependen de su localización. Se crean de esta manera, varias capas a diferentes profundidades que forman una red tridimensional metabólica y mecánica ${ }^{97}$. Así, de la piel hacia los planos musculares, se encuentran normalmente tres capas de TC fibroso: la fascia superficial (FS), la fascia profunda (FP), y el epimisio, aparte de todas las fascias viscerales. Esta distinción de capas fasciales no es siempre tan clara, ya que, en ocasiones, una o varias desaparecen o están fuertemente unidas entre $\mathrm{si}^{93}$. Se pueden incluir, aunque no son objeto de estudio en este trabajo, la fascia meníngea que cubre el sistema nervioso central, y la fascia visceral o esplácnica, que recubre las cavidades corporales y los órganos.

Según Marquart y Varnaiso ${ }^{105}$ los aspectos histológicos de la parte profunda de la piel dependen principalmente de su localización anatómica. Muchas veces los términos hipodermis y tejido celular subcutáneo (TCS) se emplean de forma simultánea e inadecuada, ya que la hipodermis no puede ser considerada como TCS, sino como parte de la piel. Otras veces se sitúa la fascia superficial dividiendo el TCS en dos capas fibroadiposas, superficial y profunda, y la fascia profunda, que envuelve todos los músculos del cuerpo, mostrando diferentes características en función de la región. Debajo de la fascia profunda está el epimisio, tanto en las extremidades como en algunas regiones del tronco. Los ligamentos de la piel conectan la fascia superficial a la piel y a la fascia profunda, formando una red tridimensional entre los lóbulos adiposos ${ }^{93}$. 
En la región del tronco, desde la superficie corporal hacia la profundidad la disposición de los tejidos se sucede en el siguiente orden ${ }^{106}$ (Figura 7):

- La piel, formada por la epidermis y la dermis.

- La capa superficial de la hipodermis.

- La fascia superficial, formada por fibras de colágeno y elastina.

- La capa profunda de la hipodermis.

- La fascia profunda, que envuelve los grandes músculos del tronco.

- La fascia epimisial, que está debajo de la fascia profunda en las extremidades.

- Las fascias viscerales.

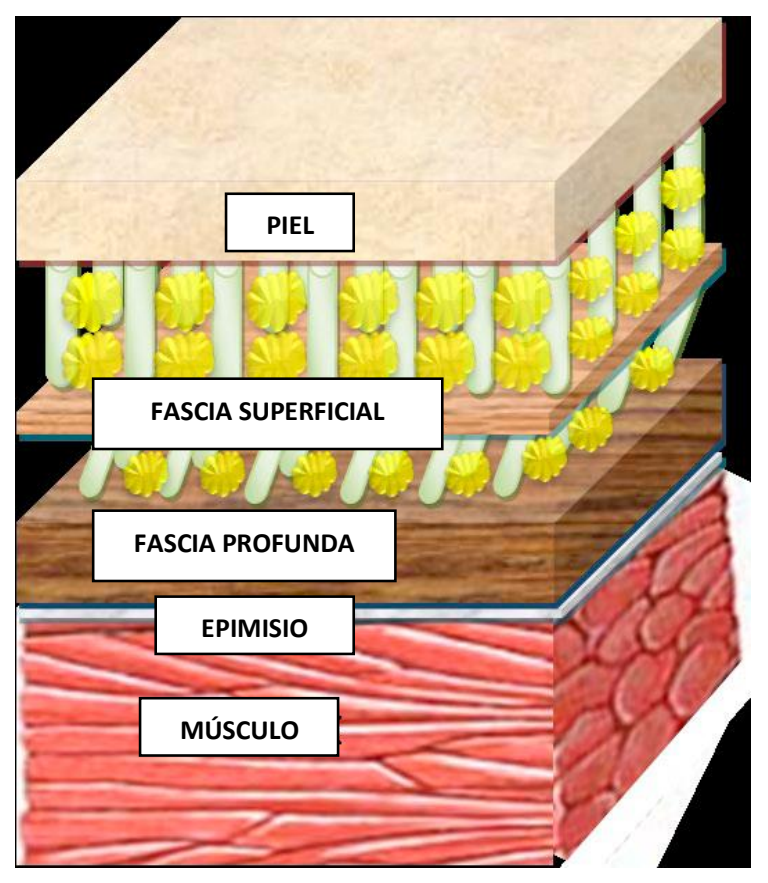

Figura 7 Diagrama mostrando la organización del tejido subcutáneo y de las fascias superficial y profunda ${ }^{93}$

\subsection{La fascia superficial (FS).}

La piel está formada por tres capas: epidermis, dermis e hipodermis. La capa subcutánea o hipodermis, se puede dividir a su vez en tres capas: la superficial, la intermedia o FS y la profunda. La FS es una capa de TC laxo areolar localizado directamente bajo la piel ${ }^{107}$. Está formada por fibras de colágeno interconectadas, poco densas y mezcladas con abundantes fibras elásticas ${ }^{93}$. Además, es una estructura rica en agua ${ }^{97}$. 
La FS forma una membrana muy elástica y deslizante, esencial para la regulación térmica, los cambios metabólicos y la protección de los vasos y los nervios ${ }^{106}$. Juega un papel importante en la integridad de la piel y sirve de soporte a estructuras subcutáneas como las venas. En ella se pueden encontrar fibras musculares (platisma en cuello, esfínter anal externo...) y nerviosas. Algunos autores sugieren su participación en el sistema exteroceptivo ${ }^{93,108}$.

Su disposición y espesor puede variar a lo largo del cuerpo, siendo más gruesa en los miembros inferiores que en los superiores, en la parte posterior que en la anterior del tronco, y en mujeres que en hombres. En las prominencias óseas se adhiere a la fascia profunda ${ }^{93}$.

La FS y todos los ligamentos de la piel pueden ser observados fácilmente con tomografía axial computarizada (TAC), resonancia magnética nuclear (RMN) y ultrasonidos ${ }^{93}$.

\subsubsection{La fascia profunda (FP).}

Al pellizcar la piel, es evidente que la hipodermis se continúa con la dermis y se desliza sobre la fascia muscular gracias a una capa fina más profunda, la fascia profunda. Se trata de una membrana fibrosa, situada debajo de la hipodermis ${ }^{100}$, que forma una intrincada red que envuelve y separa los músculos, forma envolturas para los nervios y los vasos, refuerza los ligamentos, y mantiene todas las estructuras unidas ${ }^{93}$ (Figura 8). Envuelve todos los músculos del cuerpo, pero tiene diferentes características según la región. Se puede dividir en FP de las extremidades y FP del tronco $^{92}$. Debajo de la FP los músculos pueden deslizar libremente gracias al TC laxo rico en ácido hialurónico que se interpone entre el epimisio y la $\mathrm{FP}^{93}$.

La FP está formada a su vez por varias capas que pueden deslizar unas sobre otras y afectarse de manera individual, aunque adquieren gran resistencia a la tracción cuando trabajan juntas ${ }^{93}$. Modelos tridimensionales de la fascia crural y toracolumbar demostraron que la FP está formada por tres subcapas de TC con diferentes densidades y orientaciones ${ }^{107,109}$. En cada subcapa las fibras de colágeno son paralelas entre sí, pero su 
disposición cambia respecto a las adyacentes formando un ángulo de aprox. $70^{\circ}-80^{\circ}$ grados entre ellas. Cada capa está separada de la siguiente por una capa fina de TC laxo que permite el deslizamiento de una sobre otra. De esta manera, desde un punto de vista mecánico, cada capa puede considerarse independiente. La respuesta de cada capa a la tracción depende de su orientación, si sigue la dirección de las fibras de colágeno u otra dirección, pero actuando en conjunto presentan gran resistencia a la tracción ${ }^{93}$.
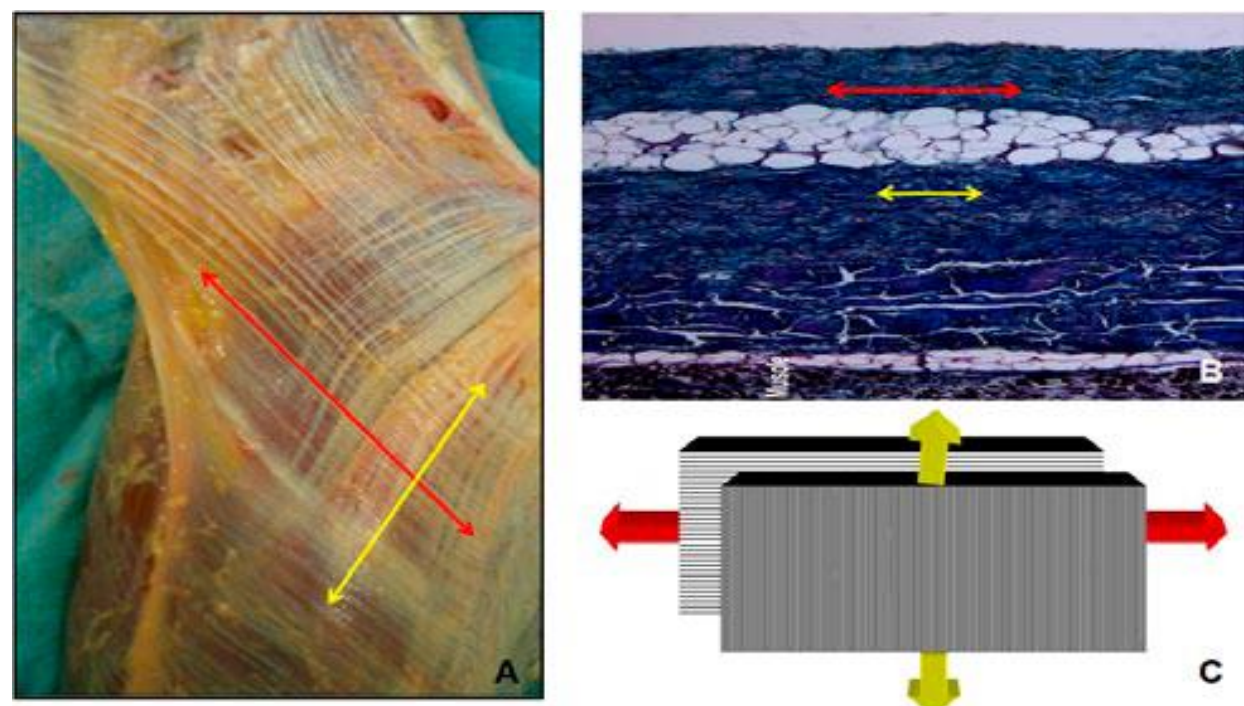

Figura 8. A: vista macroscópica de la fascia profunda de la región medial del codo $^{93}$. Nótense las bandas fibrosas en capas superpuestas. La dirección principal de las fibras de colágeno de las dos capas se resaltan con el rojo y el amarillo de las flechas. B: vista histológica de la misma fascia. La presencia de tejido conectivo laxo interpuesto entre las dos capas de colágeno permite el deslizamiento local, y así, desde un punto de vista mecánico, las capas simples pueden ser consideradas independientemente. C: esquema del comportamiento de la fascia profunda. La estructura multicapa permite a la fascia profunda resistir la tracción, incluso cuando se ejerce en diferentes direcciones.

Estas observaciones muestran que la fascia incorpora un sistema vacuolar denso de agua capaz de deslizar independiente de la contracción de los músculos subyacentes ${ }^{110,111}$.

La FP está formada a su vez por una capa interna y otra externa. La superficie externa de la FP se extiende por todo el cuerpo de manera uniforme, mientras que su superficie interna se conecta con los músculos subyacentes. Esta integración de la fascia con el músculo quedó patente en 2001 cuando Thomas Myers ${ }^{112}$, terapeuta manual de EEUU, retomó en su 
libro Anatomy Trains, el concepto de cadena muscular de Busquets, aportando la idea de la fascia como elemento integrador, es decir, con el concepto anatómico de continuidad miofascial ${ }^{93}$. El músculo estriado está rodeado por la fascia, formando una unidad inseparable conocida como miofascia. Además, el TC extramuscular tiene una conexión íntima con el TC intramuscular ${ }^{113}$. Por ello, la fisiología de las fascias debe ser estudiada junto al músculo.

Las conexiones entre el músculo y la FP son constantes. Así, en función de los movimientos, los músculos específicos son activados, estirando selectivamente porciones de la fascia profunda. La fascia puede ser la causante de las cadenas cinéticas ${ }^{93}$.

Determinados planos fibrosos autónomos dentro de la FP permiten a los músculos contraerse sin oponerse a las acciones de otros músculos que se insertan en la misma fascia. Si debido a una alteración (p.e. cirugía), este sistema de deslizamiento dentro de la fascia aponeurótica cambia, la contracción del músculo se verá alterada. La fascia no puede ser separada de la acción del músculo: cada vez que un músculo se contrae, se produce el estiramiento de la fascia ${ }^{93}$.

Por todo ello, se puede afirmar que el conocimiento de la estructura y función de la fascia puede ayudar a mejorar los resultados de todas las terapias manuales y físicas que afectan al sistema fascial ${ }^{93}$.

\section{I.2.2.2. Funciones de la fascia.}

Desde el punto de vista estructural, el TC tiene dos funciones: separar y permitir el deslizamiento, o conectar y transmitir fuerzas ${ }^{94}$. La continuidad fascial es esencial para la transmisión de la fuerza muscular, para la correcta coordinación motora y para mantener los órganos en su lugar. Es decir, las principales funciones de la fascia son ${ }^{106}$ :

- Cubrir y revestir estructuras.

- Organizar, separar y formar compartimentos corporales.

- Unificar, relacionar y conectar estructuras.

- Proteger y servir de sostén. 
De esta manera, la FS facilita ${ }^{97}$ el deslizamiento de los músculos debajo de la piel mientras se contraen. Cuando las cicatrices o las quemaduras hacen que la piel se adhiera a la fascia muscular, se compromete el movimiento. Y proporciona la separación de la exterocepción cutánea y de la propiocepción de la fascia muscular profunda.

Mientras que la FP sincroniza la actividad de las unidades motoras alineadas en paralelo que actúan con el mismo movimiento (unidad miofascial), y la actividad de varios músculos alineados en serie que actúan con el movimiento de un segmento en la misma dirección.

\section{I.2.2.3. Biomecánica fascial.}

Dentro de la biomecánica fascial conviene prestar atención a cuatro conceptos básicos para la comprensión de su comportamiento funcional: la tensegridad, la tixotropía, la mecanotransducción y el fenómeno piezoeléctrico.

- Tensegridad

Las fascias representan una estructura tisular tridimensional ininterrumpida que se extiende desde la cabeza hasta los pies y desde el exterior a la profundidad ${ }^{82,107,114}$. Las fascias rodean y penetran en todas las estructuras del cuerpo humano ${ }^{100}$ siguiendo el principio estructural de la tensegridad. Éste es un concepto arquitectónico basado en el empleo de componentes aislados comprimidos que se encuentran dentro de una red tensada continua, de tal modo que los elementos comprimidos no se tocan entre sí y están unidos únicamente por medio de componentes traccionados, que son los que delimitan espacialmente dicho sistema ${ }^{115}$ (Figuras 9 y 10).

En ningún momento encontramos interrupción de la fascia, únicamente toma relevo en las estructuras óseas, gracias a la interpenetración con las trabéculas ósea mediante las fibras de Sharpey ${ }^{116}$.

La continuación de la fascia a lo largo de todo el cuerpo puede deberse a su origen embriológico en el mesodermo ${ }^{99,117}$. Está presente en todos los segmentos del cuerpo, ya que no solo envuelve cada estructura (músculo, órgano, vaso, nervio...), sino que, se insinúa en el interior de cada 
una de ellas para formar su matriz y su sostén ${ }^{94,116}$. Considerando que el recorrido de la fascia es continuo, cualquier cambio estructural en una determinada parte del cuerpo genera restricciones en las partes distales.
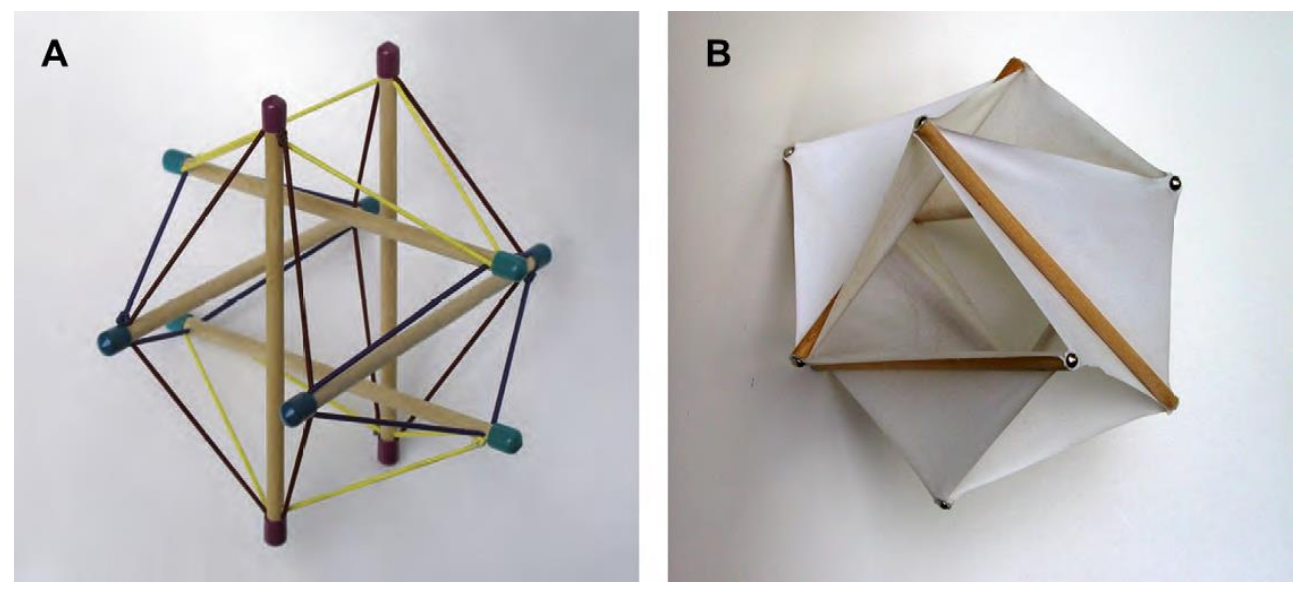

Figura 9. Ejemplos de estructuras tensegríticas. A: Icosaedro.

Figura 10. B: Con membranas elásticas en vez de bandas elásticas ${ }^{98}$.

Existe un estado de pretensión en la red estructural, compuesta por elementos de tensión y compresión opuestas, que autoestabilizan su forma. Este equilibrio de fuerzas mecánicas es lo que denominamos tensegridad (tensión-integral) $^{118}$. Dicho de otra manera, indica una estructura de elementos rígidos y elementos elásticos que confieren al conjunto rigidez y flexibilidad al mismo tiempo. Este principio de tensegridad se puede aplicar en el cuerpo desde el nivel celular hasta el nivel orgánico ${ }^{119}$ (Figura 11 ).
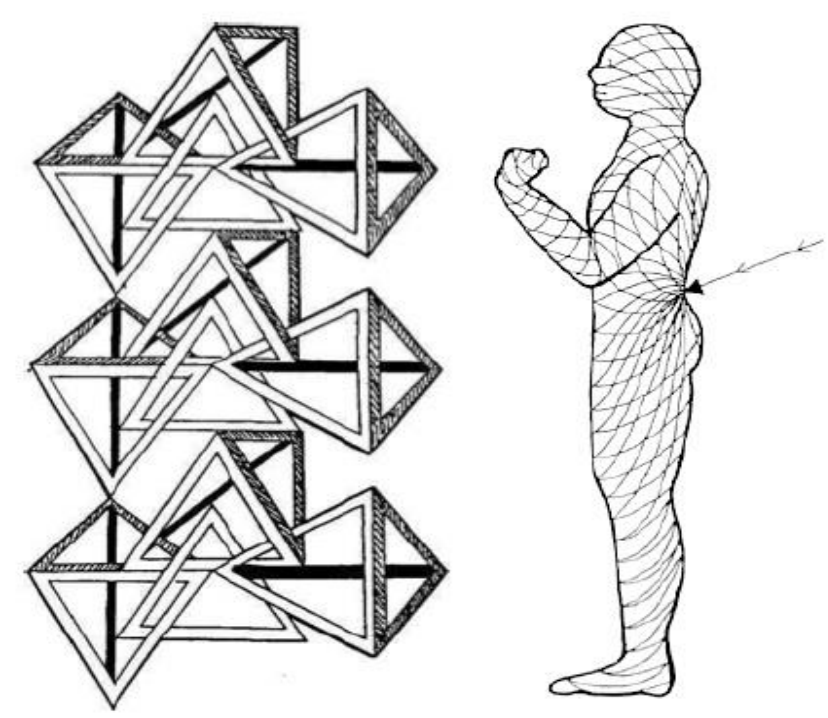

Figura 11. Representación tridimensional de la fascia y representación fascial como sistema de integración (tensegridad) ${ }^{82}$. 
Debido a esta estructural de tensegridad, las restricciones miofasciales se distribuyen y expanden desde un punto localizado, pudiendo llegar a zonas muy distales y provocando reacciones inesperadas.

- Tixotropía

Tixotropía es la capacidad de un líquido para reducir su viscosidad aparente mientras se aplica una cierta cantidad de calor o energía mecánica, como el corte o la vibración. Después de la aplicación de calor o de la fuerza mecánica, se produce una modificación de la viscosidad, seguida de una recuperación gradual cuando se retira la fuerza. El efecto está en función del tiempo $^{120}$. Esta reducción de la viscosidad es debida a una ruptura temporal de la estructura interna del sistema y a su alto contenido en agua, que permite la propagación de la energía desde una partícula a otra al aplicarle fuerzas de tensión o de compresión ${ }^{82}$.

\section{- Mecanotransducción}

Es un mecanismo molecular a través del cual el efecto de fuerzas mecánicas sobre determinadas células provocan cambios en su bioquímica intracelular y en su expresión genética. Así, las terapias físicas, la danza, el ejercicio y algunas formas de movimiento pueden influir en las actividades celulares, incluido el crecimiento celular, la diferenciación e incluso respuestas inmunes ${ }^{118}$.

- Fenómeno de piezoelectricidad

Este fenómeno, "electricidad de presión", se observa en estructuras físicas que se caracterizan por una distribución geométrica simétrica y generalizada de sus componentes, como es el caso de determinados cristales. Al aplicar una fuerza mecánica (presión) a la estructura, ésta se altera molecularmente, rompiendo su geometría y creando una diferencia de potencial eléctrico. $\mathrm{Y}$ al contrario, si aplicamos una corriente eléctrica a un cristal, se generan variaciones dimensionales de su estructura debidas a un aumento de presión. A partir de este fenómeno se puede explicar la manera que tienen de transmitirse los impulsos mecánicos a través del sistema fascial $^{82}$. 
Si llevamos este efecto al cuerpo humano, estructuras como la piel, los huesos, los vasos sanguíneos, las fascias y los músculos, se comportan como si fueran cristales líquidos, ya que al aplicar cualquier acción mecánica, el sistema fascial se comprime, generando una diferencia de potencial eléctrico. Esta diferencia de potencial se estabiliza y propaga la información eléctricamente a través del colágeno, por todo el TC, creando una red integrada. Por lo tanto, la capacidad del colágeno para transmitir y mantener de forma ininterrumpida este flujo de información, determina las propiedades básicas del sistema fascial (flexibilidad, resistencia, elasticidad y elongación $)^{82}$.

La piezoelectricidad se utiliza en fisioterapia para restablecer el comportamiento correcto de los tejidos del cuerpo humano. De esta forma se puede restaurar el equilibrio alterado por un traumatismo, coordinando la circulación de las corrientes biológicas, de tal manera, que al aplicar corrientes eléctricas en puntos neurálgicos se armoniza el sistema fascial, estimulando sus propiedades básicas. Teniendo en cuenta el recorrido ininterrumpido de la fascia y de su componente principal, el colágeno, el restablecimiento del equilibrio puede afectar a diferentes zonas del cuerpo, incluyendo las más alejadas ${ }^{121}$.

Todo ello, podría explicar cómo la aplicación de terapias físicas influye en la fisiología de la célula y los tejidos ${ }^{118}$. El masaje reflejo, por ejemplo, es una terapia que consiste en provocar reacciones reflejas locales o a distancia de la región estimulada, susceptible de ejercer una acción favorable sobre el organismo ${ }^{66}$.

\section{I.2.2.4. Inervación de las fascias}

EI TC, y por ende la fascia, proporciona señales mecánicas y químicas a diferentes tejidos ${ }^{114,122}$. Por ello puede decirse que la fascia participa en dos funciones fundamentales a través de sus receptores:

- en la percepción del movimiento durante los esquemas motores, en las tres dimensiones espaciales. 
- En la coordinación motora entre los músculos posturales estáticos y los músculos implicados en las posturas dinámicas.

Las investigaciones sobre la microestructura fascial, que revelan la presencia de receptores de Golgi, suponen una aportación especialmente significativa en la fisiología del sistema. Tradicionalmente, se había considerado la existencia de dichos receptores únicamente en los ligamentos, en las cápsulas y en las uniones miotendinosas. Sin embargo, hoy se sabe que solamente un $10 \%$ de los receptores de Golgi se encuentra en los tendones, y que el $90 \%$ restante se localiza en la porción muscular de la unión miotendinosa, en las cápsulas articulares, en los ligamentos y en la fascia $^{123}$.

Además de estos órganos tendinosos de Golgi, diversos estudios ${ }^{93,96}$ demostraron la existencia de otros receptores en la fascia, mecanorreceptores como los corpúsculos de Paccini (atribuyendo a la fascia sensibilidad a la vibración), los órganos de Ruffini (la fascia también es capaz de responder a impulsos lentos y presiones sostenidas) y un tercer grupo de receptores, las terminaciones nerviosas libres de fibras sensitivas tipo III (mielínicas) y tipo IV (no mielinizadas) ${ }^{91,123,124}$. Los corpúsculos de Paccini y los receptores de Ruffini son activados en cada estiramiento de la fascia ${ }^{93}$ y sólo pueden funcionar si están embebidos en un tejido capaz de alargarse. Sin importar en qué parte del cuerpo estén localizados, siempre transmiten el mismo tipo de impulso nervioso al cerebro. Para que la información se transmita de forma correcta estos receptores deben estar situados dentro de una estructura con una orientación topográfica en tres dimensiones espaciales. Los compartimientos fasciales y los tabiques intermusculares, forman justamente esta clase de estructura ${ }^{125}$.

El microscopio electrónico y técnicas especiales de tinción han demostrado la existencia de estas fibras neurosensitivas en la fascia, contribuyendo a la propiocepción y a la nocicepción de la misma, siendo quizás sensible a la presión manual, la temperatura y la vibración $n^{91,124,126,127}$. 
El conocimiento, por una parte, del tipo de receptores sensibles a los cambios dinámicos y de tensión o torsión y, por otra, del tipo de adaptación lenta o rápida, permite prever los efectos terapéuticos de diferentes procedimientos fisioterápicos en el sistema nervioso ${ }^{94}$. Distintas técnicas de manipulación pueden estimular estos receptores: los "thrust "de alta velocidad y las técnicas de vibración estimulan los receptores de Pacini, mientras que las técnicas lentas y profundas lo hacen sobre los de Ruffini ${ }^{123}$.

La inervación de la fascia varía según su función ${ }^{106,128,129}$ :

- En la FS se encuentran termorreceptores y receptores sensibles a la presión como los corpúsculos de Paccini.

- En la FP se observan husos musculares, órganos tendinosos de Golgi y terminales nerviosos libres. Los receptores de la FP son todos propioceptores capaces de actuar como nociceptores, siempre que se estiren más allá de su límite fisiológico normal.

Las capas superficiales de la fascia corporal tienen más terminaciones sensitivas que los TC situados más internamente. La zona de transición entre la FP y el TCS parece tener la mayor concentración de receptores sensoriales de tipo nociceptivo ${ }^{84,126}$.

Según lo analizado hasta aquí, la fascia está equipada anatómicamente para jugar un papel importante en la transmisión de tensión y propiocepción en la flexión espinal ${ }^{130}$. Solo el $70 \%$ de de la tensión muscular es dirigida a los tendones, el 30\% restante de la fuerza muscular es transmitida al TC que rodea los músculos, destacando el papel de la FP en la coordinación periférica de músculos agonistas, antagonistas y músculos sinérgicos ${ }^{93}$. Además, las microlesiones del TC lumbar pueden dar lugar a un perjuicio de la función de los mecanorreceptores, conllevando una disfunción muscular y, por tanto, alteraciones biomecánicas en dicha región ${ }^{92}$. 


\section{I.3. DISTRIBUCIÓN METAMÉRICA Y TÉCNICAS FISIOTERÁPICAS DE TEJIDO CONJUNTIVO.}

La utilización de técnicas de TC se basa en el conocimiento del proceso de desarrollo embrionario que explica las reacciones a distancia. En el estadio precoz de la formación del embrión, la correspondencia topográfica entre la víscera, el plano cutáneo y la metámera común es total. Esta disposición se ve modificada por dicho desarrollo embrionario que distancia piel, víscera y músculo, conservando la distribución nerviosa. Con esta organización se define el concepto de metámera como el segmento medular con influencia en dermatoma, miotoma, esclerotoma, angiotoma y viscerotoma ${ }^{131}$.

El patrón de distribución metamérica torácica y abdominal se dispone a modo de bandas dermatómicas desde la base del cuello hasta el pubis, y la organización refleja elemental se basa en la noción de metámera y más específicamente, en la inervación de los elementos de la misma (Figura 12).

\section{Dermatomas}
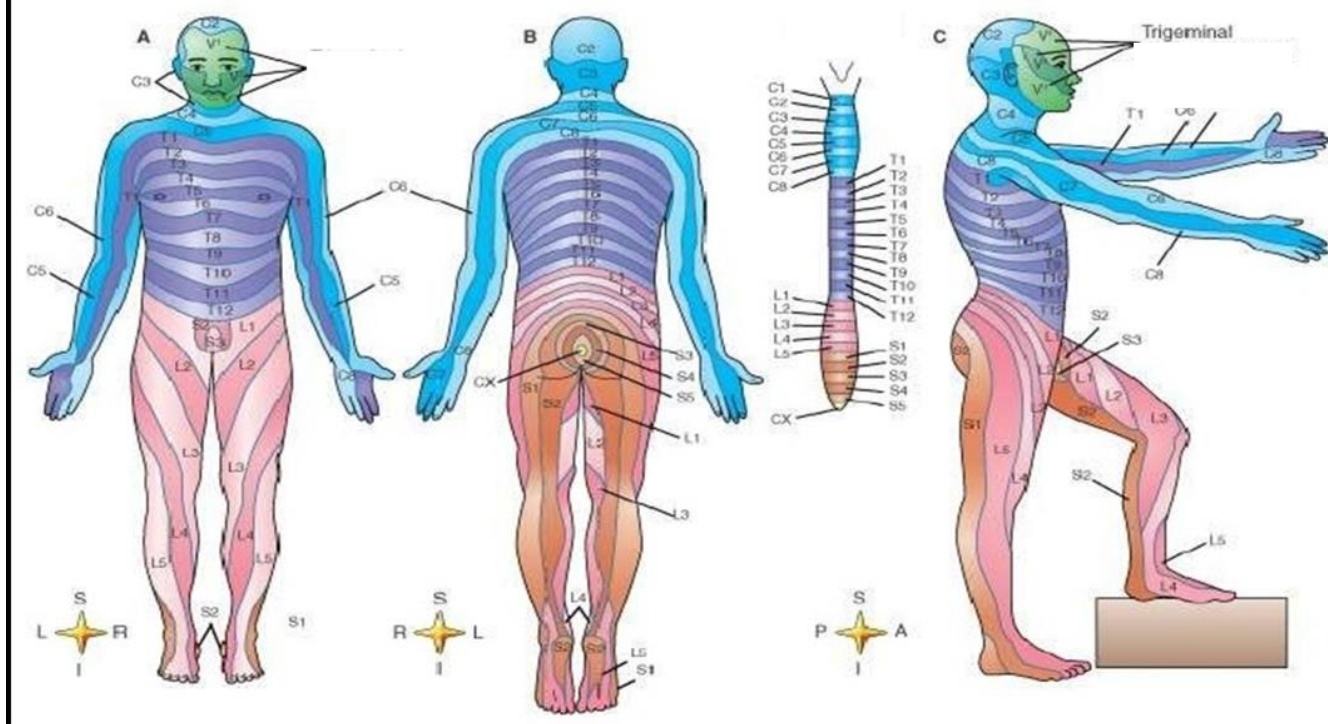

Figura 12 Distribución en dermatomas de los nervios espinales. A. Parte anterior de la superficie corporal. B. Parte posterior de la superficie corporal. C. Parte lateral de la superficie corporal. C: segmentos y nervios cervicales. T: segmentos y nervios torácicos. L: segmentos y nervios lumbares. S: segmentos y nervios sacros. Modificado de Patton y Thibodeau ${ }^{132}$. 
Teóricamente, la metámera está constituida por dos mitades medulares simétricas a derecha e izquierda con un nervio espinal que enlaza la médula espinal con las diferentes estructuras del organismo. Este nervio se divide en diferentes ramas formadas por fibras motoras, sensitivas y autónomas. El sistema nervioso autónomo simpático consta de dos componentes principales: el vascular y el visceral. El componente vascular está asociado con los nervios raquídeos e inerva las fascias, el músculo liso vascular, el de los folículos pilosos y las células secretoras de las glándulas sudoríparas de la piel. El componente visceral inerva músculo liso, cardiaco, tejido ganglionar, órganos glandulares de las vísceras torácicas, abdominales, pelvianas y perineales ${ }^{133}$.

En el marco del diagnóstico clínico, el dolor, la contractura y la modificación cutánea de la zona afectada son elementos indispensables para la puesta en marcha de un mecanismo reflejo ${ }^{134}$. Todo arco reflejo está constituido por un receptor, una neurona aferente o sensitiva, los centros nerviosos de integración, una neurona eferente o motora y un efector ${ }^{135}$. Los receptores y efectores pueden ser somáticos o viscerales formándose así los reflejos víscero-músculos cutáneos (Figura 13).

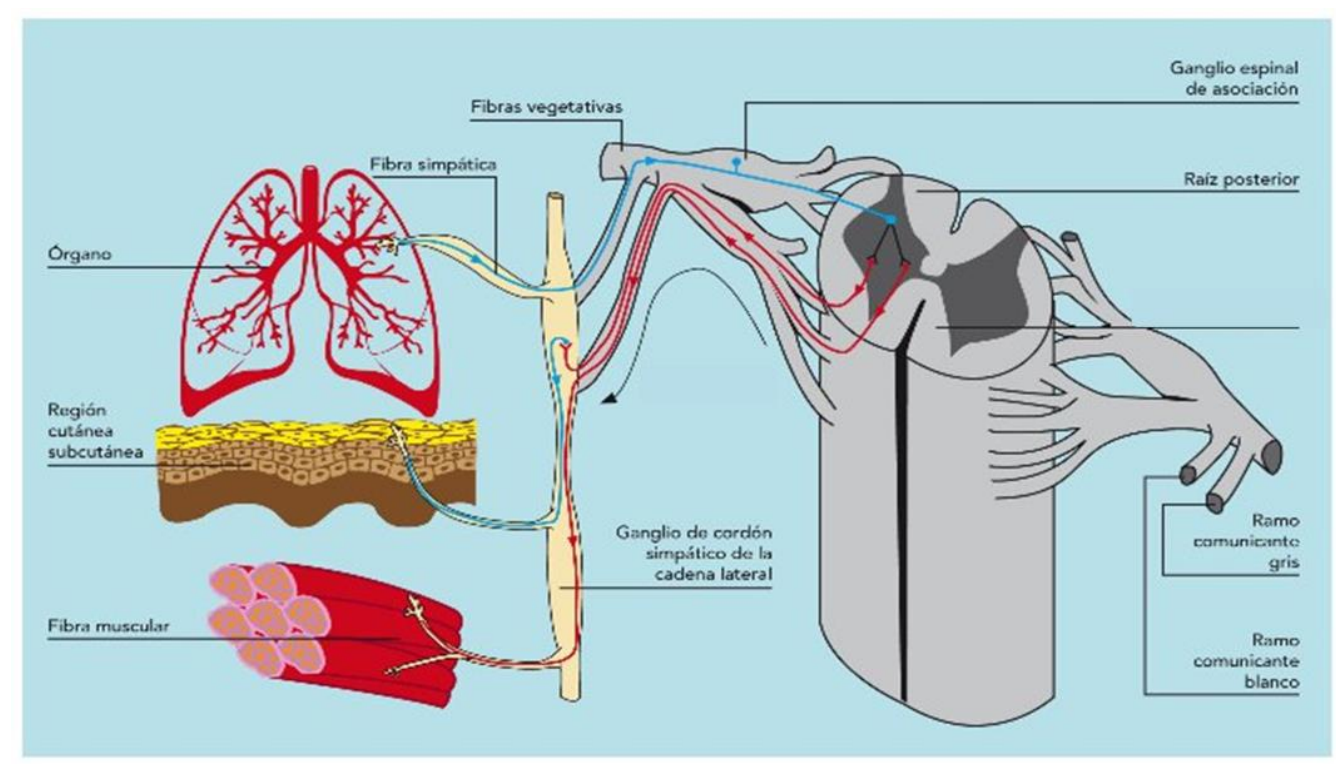

Figura 13. Reflejo víscero-músculo cutáneo ${ }^{131}$

Su comprensión exige el conocimiento de la anatomofisiología de las estructuras implicadas, de la zona periférica refleja, y de los sistemas 
nerviosos periférico y central. Para localizar estas zonas periféricas reflejas se puede realizar ${ }^{134}$ :

a) una palpación superficial en busca de sensibilidad cutánea modificada, de dolor provocado o de una infiltración de TCS (dermalgias reflejas de Jarricot y zonas de Head).

b) una palpación profunda en busca de una contractura muscular o una zona más extensa afectada en profundidad (Técnica de Dicke).

Asimismo, las perturbaciones locales de la actividad vasomotora de un tejido, de su equilibrio electrolítico, de la permeabilidad capilar, del trofismo y de otras funciones que están bajo la influencia directa o indirecta del sistema nervioso simpático pueden condicionar, de forma refleja, el cambio de la textura del tejido que lo recubre, por ejemplo la piel que recubre las apófisis espinosas, indicando una afectación de la zona ${ }^{136}$.

La irritación o la patología de un tejido o de un órgano perturban la actividad de otros tejidos que forman parte de la misma metámera. Esos tejidos irritados secundariamente, que se encuentran en la zona de proyección, pueden llegar a convertirse a la larga, en fuentes de irritación secundarias estableciendo un círculo vicioso autoalimentado. Esto tiene implicaciones terapéuticas importantes, no solamente porque el elemento somático es accesible y fácilmente localizable, sino también porque él puede ser el factor más importante en la prolongación de la patología primaria ${ }^{136}$.

Por su parte, las terapias manuales pueden tener un simple efecto local, pero lo más común es que actúen también mediante un mecanismo reflejo dependiente de la metámera. Así, el efecto inhibidor de las terapias reflejas a nivel espinal sobre el dolor es bien conocido ${ }^{135}$. El reflejo miotático, esencial en el funcionamiento muscular del individuo, es empleado en técnicas como las manipulaciones vertebrales y numerosas movilizaciones articulares; pero existen otros reflejos, como el vásculo-cutáneo, revelado muy a menudo de forma local por una zona eritematosa, que puede explicar alguna de las acciones reflejoterápicas. 
En este sentido, la manipulación de la piel y del tejido subcutáneo puede tener efectos beneficiosos sobre tejidos remotos al área de tratamiento. Estos efectos son mediados por reflejos nerviosos que involucran tanto plexos autónomos como plexos somáticos sensoriales presentes en la piel y en el tejido subcutáne ${ }^{81}$. La estimulación de los mecanorreceptores cutáneos activa el mecanismo del "Gate-Control" (Teoría de la compuerta o de la puerta de entrada) ${ }^{137,138}$, bloqueando la transmisión de información a través de las fibras de pequeño diámetro que transmiten el dolor en sentido ascendente en la médula espinal ${ }^{81}$. Esto explicaría la acción analgésica de las técnicas fisioterápicas de TC.

Por otra parte, se ha demostrado, que la intervención sobre un segmento medular puede tener repercusiones sobre los siete segmentos suprayacentes y los tres segmentos subyacentes por medio de colaterales aferentes $^{139}$, lo que explicaría un efecto terapéutico amplificado a los territorios controlados por dichas metámeras.

\section{I.4. FASCIA TORACOLUMBAR}

La FP de las extremidades se convierte, en su continuación hacia el tronco, en la Fascia Toracolumbar (FTL) ${ }^{93}$ que rodea, compartimentaliza y protege a todos los músculos y huesos de la región lumbar ${ }^{133}$. Está compuesta de capas muy finas de TC, fuertemente adheridas a los músculos que envuelve, separándolos de la pared abdominal posterior. Como se detallará posteriormente, se distinguen capas de TC denso separadas por otras de TC menos viscoso que, normalmente, permite a las densas deslizar una sobre otra durante el movimiento del tronco ${ }^{140}$ (Figuras 10 y 11). Desde un punto de vista mecánico, la cercana relación entre la fascia y los músculos del tronco implica que el papel jugado por la fascia en los movimientos no puede ser separado de la acción muscular ${ }^{93}$.

La FTL contiene terminaciones nerviosas nociceptivas cuya irritación puede provocar un dolor lumbar ${ }^{140}$. La investigación reciente indica que la fascia podría desempeñar una función importante en la coordinación y en la propiocepción y, por tanto, en el control de la postura y de los movimientos 
complejos. Aun así, el papel jugado por la FTL en la LIC es poco conocido $^{113}$. Por ello, la FTL será el objeto de nuestro estudio, pues es en esta zona donde los pacientes con lumbalgia refieren dolor (Figura 14 ).

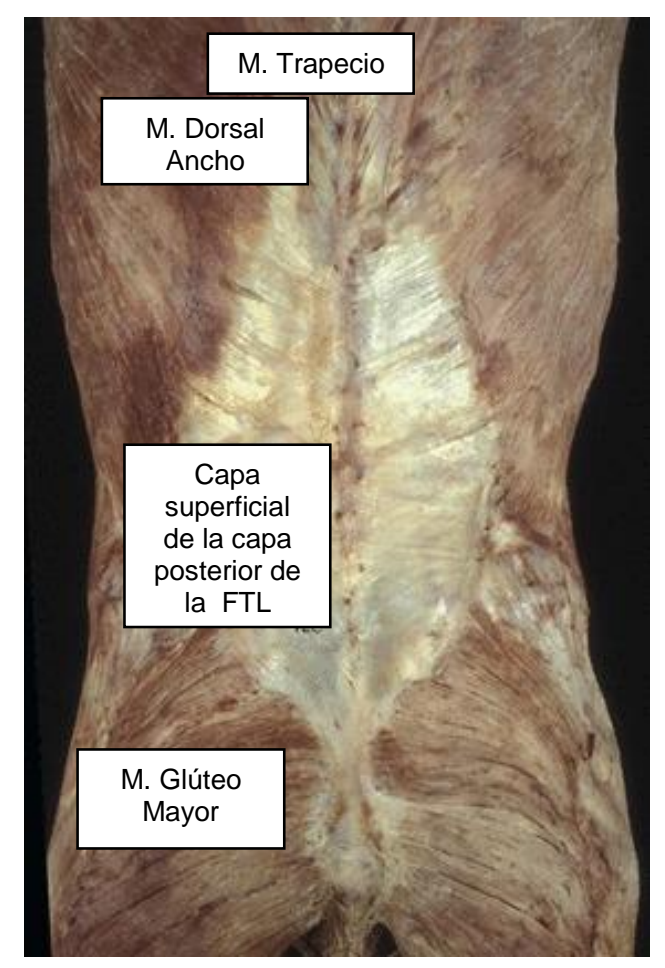

Figura 14 Vista dorsal de la Fascia Toraco-Lumbar ${ }^{92}$

Existen varias teorías sobre la estructura de la FTL, pero el modelo de tres capas es el más comúnmente contemplado en los estudios de investigación recientes ${ }^{92,141}$. Supone un plano de separación para grupos musculares y facilita su deslizamiento (Figura 15).

- La capa anterior, que cubre el músculo CL y se une a las apófisis transversas. Es muy fina y no es capaz de transmitir tensión desde los músculos abdominales a la columna toraco-lumbar.

- La capa media, por detrás del CL, se une a las apófisis transversas y a los ligamentos intertransversos. Se sitúa entre el $\mathrm{CL}$ y los músculos paraespinales. Para algunos autores es una continuación de la aponeurosis del $\operatorname{TrA}^{92}$ y del OI.

- La capa posterior de la FTL se origina en las apófisis espinosas, envuelve a los músculos erectores y se enlaza al TrA. Se continúa con la fascia del dorsal ancho (DA) y la del glúteo mayor (GM). Esta capa posterior está formada a su vez por una capa superficial 
y una profunda. La lámina superficial está dominada por la aponeurosis del DA y del serrato posterior inferior (SPI). La lámina profunda encapsula la musculatura paraespinal y actúa como un amplificador hidráulico, asistiendo a la musculatura paraespinal en el soporte de la columna vertebral. Una capa delgada de tejido adiposo-conectivo separa las diferentes láminas de la fascia profunda del tronco permitiendo el deslizamiento entre ellas ${ }^{142}$.

Estas tres capas, anterior, media y posterior, forman un triángulo interfascial situado a lo largo del borde lateral de los músculos paraespinales desde la $12^{\text {a }}$ costilla hasta la cresta iliaca, denominado LIFT ("lumbar interfascial triangle"). A lo largo del borde lateral, se forma un rafe donde la capa posterior se encuentra con la aponeurosis del TrA. Este rafe es un grueso complejo de TC denso, que distribuye la tensión entre las capas de la FTL. En la base de la columna lumbar se fusionan todas las capas de la FTL en un denso compuesto que se fija firmemente a la espina ilica posterosuperior y al ligamento sacrotuberoso ${ }^{92}$.

Se confirma de este modo, que los músculos paraespinales están envueltos por una vaina retinacular continua, formada por la lámina profunda de la capa posterior de la FP del tronco. Esta vaina se extiende desde los procesos espinosos hasta los transversos ${ }^{88}$. Así, junto a la columna vertebral, la fascia compartimentaliza a los músculos interespinales. El ángulo costal señala la extensión más externa de la masa común. Las capas más profundas de la FP forman compartimentos para los intertransversos. Por delante de las apófisis transversas, la FP rodea a los músculos PS y $\mathrm{CL}^{133}$. 


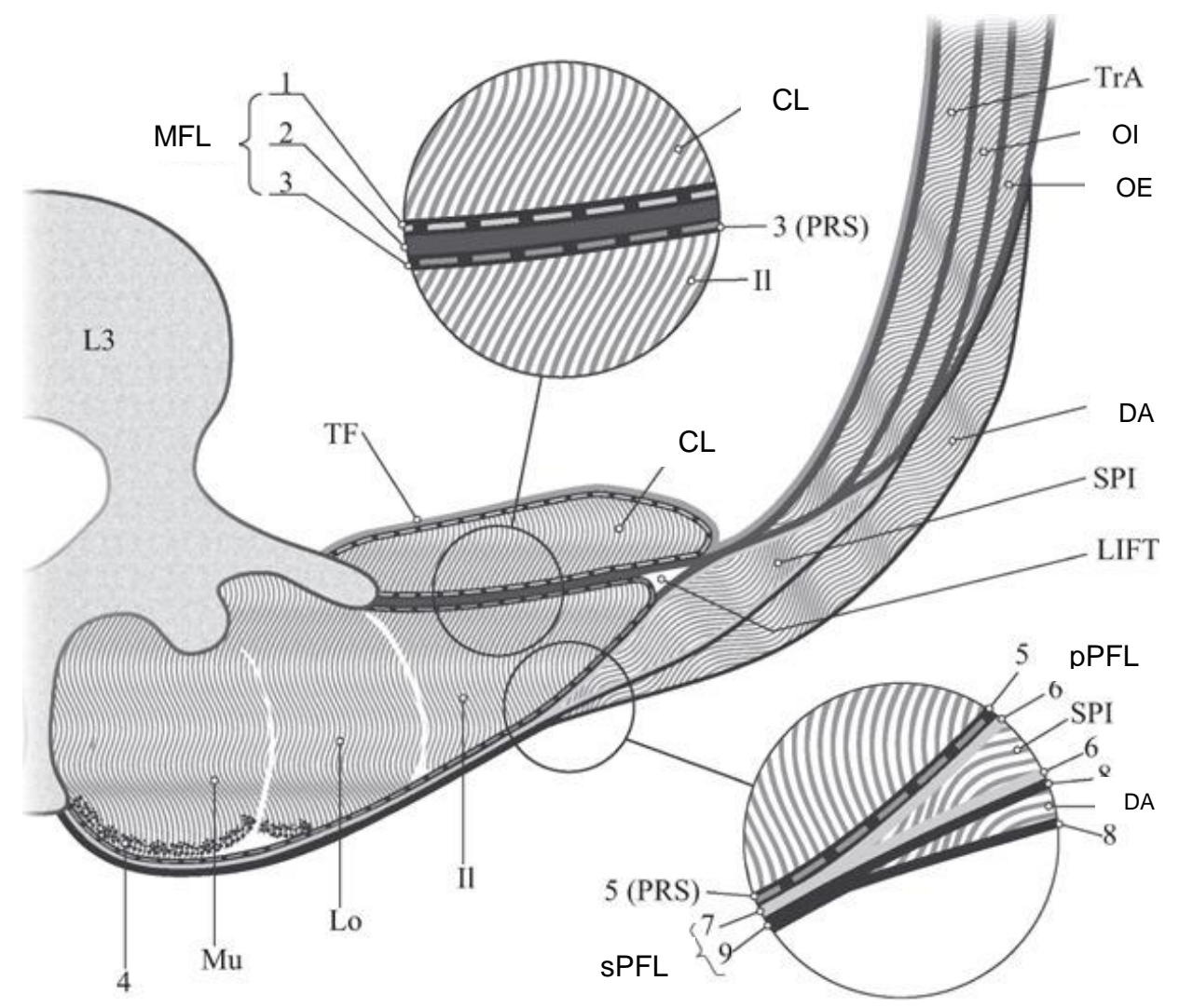

Figura 15. La Fascia Toraco Lumbar ${ }^{141}$.Sección transversal de la capa posterior (PFL) y media (MFL) de la FTL y su relación muscular a nivel L3. Hay que tener en cuenta que el SPI a menudo no está presente por debajo de L3.

Resumiendo, la fascia del músculo TrA cubre medialmente la fascia del músculo CL. Anterior y medialmente, dicha fascia se fusiona con la fascia del PS. EI DA forma la lámina superficial de la PFL junto con el SPI, cuando está presente. Los tres músculos paraespinales (multífidus $(\mathrm{Mu})$, longíssimus (Lo) e iliocostal (II) están contenidos en la lámina reticular paraespinal (LRP), o lo que es lo mismo, en la capa profunda de la pPFL. El epimisio se sitúa anteriormente a la aponeurosis.

El círculo superior muestra las diferentes capas fasciales que constituyen la MFL. Esta MFL está formada por tres estructuras: (1) la fascia del CL; (2) la aponeurosis de los músculos abdominales, 3) la LRP, lámina profunda de PFL encapsulando los músculos paraespinales.

El círculo inferior muestra las diferentes capas fasciales que constituyen la PFL. (5) LRP (6) y (7) fascia del SPI; (8) y (9) fascia del DA. Los números 5, 7 y 9 forman la PFL. Los números 7 y 9 forman la lámina superficial de la capa posterior (sPFL). La capa posterior de la FTL apoya los movimientos en 
el plano sagital y tiene una orientación longitudinal, mientras que la capa anterior contribuye a la estabilidad en los planos coronales y sagitales. La fascia que encapsula los músculos paraespinales es circular ${ }^{92}$ (Figura 16).

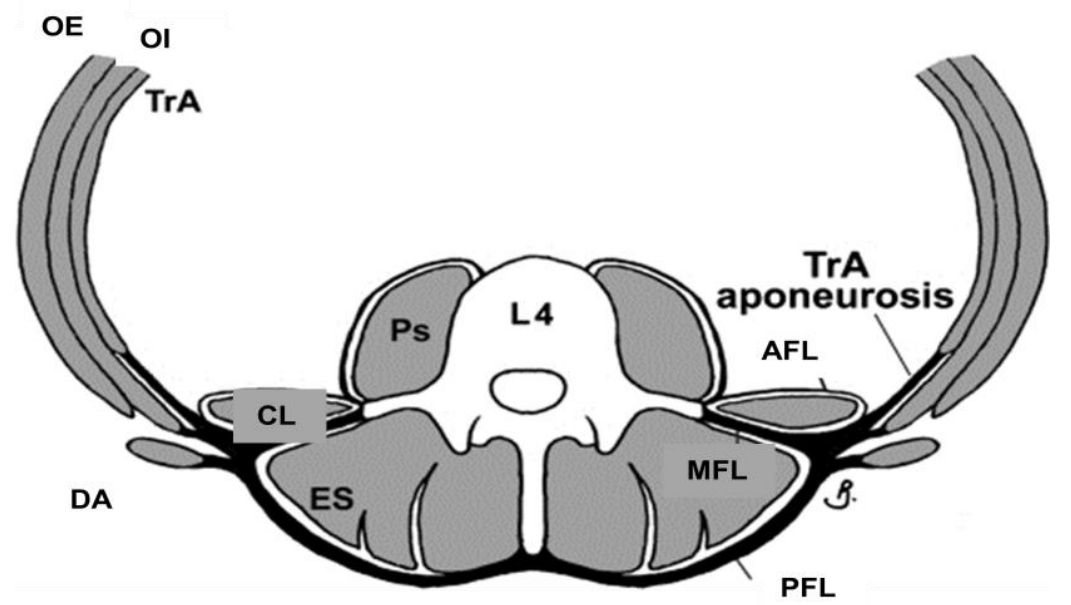

Figura 16. Fascia lumbar en $\mathrm{L} 4^{143}$.

La FTL se continúa con la fascia paraespinal en la zona torácica y cervical. Numerosos músculos del tronco y de las extremidades se insertan en los planos de TC de la FTL, pudiendo modular su tensión y su rigidez ${ }^{92}$. Todo ello integra los tejidos conectivos pasivos y las estructuras musculares activas del área lumbopélvica.

Las fascias del tronco se unen a los músculos subyacentes, de forma que, cuando éstos se contraen las tensan, activando los neurorreceptores que se encuentran en su interior. Ésta podría ser la base de la propiocepción. La FTL contribuye a la estabilidad espinal y se convierte en una firme conexión entre el tronco y los miembros inferiores (MMII) ${ }^{125}$, siendo muy importante en la postura, la transferencia de cargas y la respiración ${ }^{92}$.

EI TC laxo presente entre la fascia profunda y los músculos subyacentes permite el deslizamiento de unos músculos sobre otros ${ }^{94}$. Esto ha sido demostrado mediante imágenes dinámicas de ultrasonidos en las capas de la $\mathrm{FTL}^{144}$. Existe además, una capa de ácido hialurónico lubrificador entre la FP y el músculo ${ }^{114,141}$. 
Los estudios histológicos confirman lo explicado anteriormente, que la FTL tiene una formación estratificada ${ }^{106}$, y que la capa posterior de la FTL muestra un número de láminas variable según el nivel espinal: en L1 hay dos láminas, tres a nivel L3-5 y cinco láminas a nivel sacro ${ }^{145}$. La aponeurosis del músculo DA es el componente principal de esta capa fascial. Una parte de estas fibras de colágeno se inserta sobre los procesos espinosos de las vértebras lumbares, y, otra parte, cruza al lado opuesto del cuerpo, proporcionando inserciones para las numerosas fibras musculares del $\mathrm{GM}^{106,141}$. Los músculos DA y GM están conectados a la capa posterior de la FTL. Individualmente, cada uno de ellos es capaz de aumentar la tensión en la FTL en el mismo lado o en el lado contrario. El efecto de ceñido de las fascia mediante contracción de estos dos músculos aumenta la fortaleza del raquis a lo largo de múltiples segmentos, disminuyendo potencialmente el posible movimiento de traslación anormal de las vértebras lumbares ${ }^{125}$.

A través de su propia fascia-aponeurosis, el erector de la columna se funde con el DA y el GM solamente a nivel del sacro. La fascia-aponeurosis del músculo TrA sobre los procesos transversales forma el límite inferior del compartimento del erector de la columna ${ }^{125}$.

A nivel de L5 y sacro existe una fuerte conexión entre las láminas superficiales y profundas de la FTL. El TrA y los músculos Ol se unen indirectamente a la FTL a través del rafe formado por la fusión de la MFL a la PFL de la misma fascia ${ }^{140}$.

Estas distintas capas de la FTL son un sofisticado sistema de transmisión de tensiones de la espalda a la pelvis, las piernas y los brazos $^{130}$, por lo que la rigidez de las mismas afecta a la estabilidad espinal. La tensión de la FTL puede ser ajustada por el músculo TrA, de ahí su gran importancia en las patologías de esta zona ${ }^{130}$.

\section{I.4.1. Disfunción fascial}

La fascia es una estructura importante del cuerpo, aunque poco reconocida a nivel médico, que juega un papel clave en la respuesta del 
paciente al tratamiento. Muchos investigadores han especulado sobre las anormalidades de la fascia y su responsabilidad en alteraciones como la fibromialgia y el dolor lumbar ${ }^{146}$.

El conocimiento de la estructura y función de la fascia puede ayudar a mejorar los resultados de todas las terapias manuales y físicas que afectan al sistema fascial ${ }^{93}$. Cada región del cuerpo tiene una mezcla de diferentes tipos de fascia.. La fascia puede ser considerada a todos los efectos otro órgano del cuerpo, habiéndose localizado en las alteraciones fasciales la principal causa de disfunción en el cuerpo humano ${ }^{106}$.

Cuando se habla de restricción miofascial, se hace referencia al cambio estructural de la fascia producido por diferentes traumatismos, entendiendo este término en su significado más amplio (traumatismos directos, microtraumatismos, posturas viciosas, inmovilización...). Una tensión de corta duración, pero aplicada de modo repetitivo, facilita la densificación del tejido, que se vuelve más compacto, más resistente y, sin embargo, pierde progresivamente su elasticidad. Se ha demostrado que una simple presión manual provoca alteraciones en la viscoelasticidad del tejido ${ }^{147,148}$.

El colágeno es una estructura casi inextensible, que puede densificarse cuando es sometido a una hipomovilidad $o$ a un estrés mecánico excesivo. A medida que pierde elasticidad, pierde gradualmente sus propiedades mecánicas, como la resistencia. Así, cuanto menos movimiento haya, más duro se vuelve el colágeno; cuanto más duro, menor movilidad $^{81}$. La FTL presenta una rigidez creciente cuando es estirada consecutivamente, disminuyendo su capacidad para la deformación ${ }^{149}$.

Estas restricciones pueden manifestarse en el lugar en el que se ha producido el traumatismo o a distancia del mismo, teniendo en cuenta el recorrido ininterrumpido de la fascia. Cuando estas restricciones no se tratan, se inicia un círculo vicioso de tensión y espasmo muscular, creando así una disfunción orgánica y apareciendo dolor ${ }^{82}$. 
Los traumatismos y el aumento del estrés mecánico producido, estimula la síntesis de las fibras de colágeno en el tejido afectado, produciendo una disminución del volumen de la sustancia fundamental y dando lugar a un TC menos fluido y más denso. El endurecimiento del tejido trae consigo una disminución de la entrada de nutrientes y un atrapamiento de los desechos metabólicos, ya que la circulación de fluidos se ve bloqueada. De esta forma se puede llegar al punto crítico de provocar una isquemia relativa en la $z{ }^{9}{ }^{97}$ reduciéndose las propiedades del tejido conectivo (elasticidad, viscoelasticidad y plasticidad) debido a los entrecruzamientos patológicos de sus fibras. Este proceso, provoca una disminución o incluso un bloqueo de la capacidad de deslizamiento de las estructuras vecinas, obligando al cuerpo a crear compensaciones que suplan los movimientos bloqueados. Cuando el proceso se instaura, se altera la correcta respuesta estabilizadora del sistema miofascial, fenómeno denominado Disfunción miofascial. En dicha disfunción se produce una sobrecarga en todos los segmentos del sistema fascial, alterando todos los componentes y la función de la estructura corporal y creando a su vez una descoordinación, provisional o permanente, de los movimientos en todos los segmentos y niveles corporales ${ }^{82}$.

El cuerpo humano en numerosas ocasiones sufre microtraumatismos produciéndose un fenómeno de acumulación lenta y gradual de pequeñas lesiones $^{150}$. Las fascias, por sus propiedades elásticas, protegen al organismo de estas lesiones y acaban viéndose afectadas. Los microtraumatismos de repetición, los grandes traumatismos y cualquier mecanismo que altere el metabolismo de los proteoglicanos y del ácido hialurónico, provocan cambios en la estructura fascial, disminuyendo su elasticidad y, por tanto, modificando su comportamiento mecánico ${ }^{150}$.

Todas las capas fasciales necesitan ácido hialurónico para deslizar una sobre otra. Si la cantidad de ácido disminuye o no se distribuye regularmente, el deslizamiento del TC se ve comprometido. Cualquier cambio en la viscoelasticidad del sistema fascial activa los nociceptores. El ácido hialurónico se hace más adhesivo y menos lubricado, alterando las 
líneas de fuerza entre varias capas fasciales ${ }^{97}$. Debido al endurecimiento, las capacidades elásticas, plásticas y viscoelásticas de la fascia quedan reducidas de forma que la capacidad de deslizamiento de las estructuras adyacentes se ve también reducida o bloqueada ${ }^{83}$. Así, el endurecimiento de las estructuras de colágeno podría ser responsable, por ejemplo, de las crepitaciones que se observan tras inmovilizaciones articulares prolongadas. La hipomovilidad del tejido provoca que el entrecruzamiento de las nuevas fibras de colágeno sintetizadas pase de ser fisiológico a patológico, pudiendo formarse "enlaces" con fibras de colágeno propias de otros elementos como las que conforman la estructura ósea ${ }^{151}$.

En presencia de la disfunción, se produce una sobrecarga en todos los segmentos del sistema fascial $\mathrm{y}$, particularmente, en la columna vertebral, alterando el funcionamiento de la movilidad corporal ${ }^{93,152}$. Además, cuando existe una disfunción local, todo el sistema miofascial participa en la construcción de un nuevo nivel de equilibrio (homeostasis) para el funcionamiento óptimo del cuerpo, es decir, la fascia responde a la disfunción globalmente hasta encontrar un nuevo equilibrio ${ }^{148}$. Como respuesta a una lesión el tejido fascial tiende a deshidratarse, a perder elasticidad y a acortarse. Pero, estos efectos no se producen sólo a nivel local, sino que se pueden afectar áreas del cuerpo alejadas del lugar del trauma $^{153}$.

Es importante tener en cuenta que, la disfunción miofascial no supone estrictamente un problema muscular pero implica a los músculos, en tanto en cuanto, compromete su vascularización, su capacidad para trabajar en el seno de un grupo funcional, y su capacidad de deslizamiento en el compartimento ${ }^{116}$.

A raíz de lo dicho hasta aquí, podemos concluir que no es posible mantener un cuerpo saludable sin que exista un sistema fascial saludable. El sistema fascial puede encontrarse en una excesiva tensión o puede estar demasiado distendido. En ambas situaciones, la función corporal queda afectada $^{81}$. 


\section{I.4.2. Fascia y lumbalgia}

El movimiento y la estabilidad de la región lumbosacra dependen del equilibrio de fuerzas distribuidas entre los planos miofasciales asociados a la FTL. Como ya se ha comprobado en párrafos anteriores, las propiedades mecánicas de la fascia influyen en los grupos musculares que estabilizan esta región. Por ello, entender la construcción de este complejo miofascial es fundamental en el análisis biomecánico y la implantación de una efectiva rehabilitación en sujetos con dolor lumbar ${ }^{140}$. La investigación sobre la fascia puede ayudar a entender aspectos de problemas musculoesqueléticos como los puntos gatillo, las lumbalgias y la fibromialgia ${ }^{150}$.

Desde principios de los años noventa son numerosos los grupos de investigación que se dedican a estudiar las propiedades de las fascias. En el momento en que se ha entendido su importancia han comenzado a proponerse nuevos métodos de tratamiento de patologías en las que las fascias están involucradas. Por ello, la literatura científica en este campo ha experimentado un aumento significativo de artículos indexados en Medline o Scopus, como muestra la Figura 17.

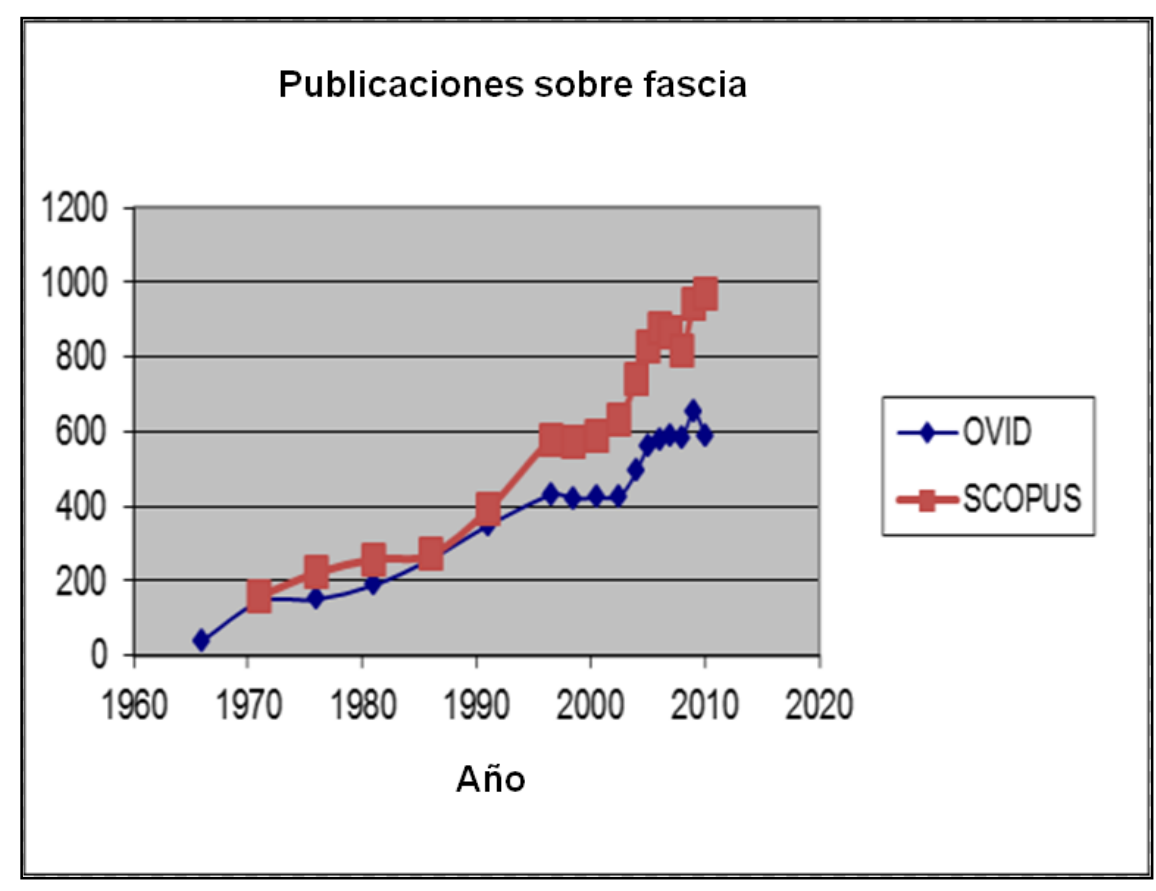

Figura 17. Publicaciones indexadas sobre fascia ${ }^{94}$. 
Todo ello, ha conducido a que en octubre de 2007 en la Universidad de Medicina en Harvard, tuviera lugar el primer Congreso Mundial sobre la Investigación Fascial, evento que se ha ido repitiéndo en 2009, 2012 y 2015, respectivamente.

Los tejidos blandos limítrofes de la movilidad articular (ligamentos, músculos, tendones, cápsula y fascias) están compuestos principalmente por TC. Ya en 1991 Goats y Keir ${ }^{81}$, afirmaban que, en los procesos lumbálgicos, recuperar la elasticidad del TC disminuida por la fibrosis, resultaba efectivo para evitar la cronicidad del dolor y mejorar la movilidad. Se basaban en que el movimiento anormal podría estar influenciado por el mal estado del TC que rodea e infiltra los músculos ${ }^{81,83}$.

Entre otras teorías, la lumbalgia puede tener su origen en un daño ligamentoso, muscular o $\operatorname{articular}^{130}$. A pesar de que la fascia ha sido olvidada en la investigación de la lumbalgia durante las últimas décadas, existen estudios recientes en modelos experimentales ${ }^{88,154}$, que muestran que los animales en los que se induce una lumbalgia crónica presentan una alteración de la estructura del TC comparados con los que no la padecen. En otros estudios ${ }^{130}$ se revela una densidad mayor de miofibroblastos, o se observa la ausencia de mecanorreceptores en la FTL. Esto sugiere la presencia de inflamación y/o fibrosis en los sujetos con lumbalgia. Así, los tejidos blandos paravertebrales lumbares, incluido el TC no especializado, emergen como potenciales componentes en la patofisiología de la lumbalgia ${ }^{127}$.

Los sujetos que sufren un dolor lumbar crónico presentan inflamación de la fascia local, degeneración de fibras de colágeno y microcalcificaciones. La falta de deslizamiento de las diferentes capas de la FTL y las alteraciones morfológicas de los tejidos genera una tensión mecánica no fisiológica que provoca dolor lumbar. Se crea una falta de coordinación en la activación de la musculatura que envuelve la FTL, resultando inestabilidad mecánica de la columna. El dolor resultante se ve intensificado por el estrés, ya que la fascia está inervada por el sistema nervioso simpático. Todo esto afecta negativamente a la postura y a la marcha ${ }^{97}$. 
Las técnicas fisioterápicas de TC no especializado para la zona lumbar representan, por tanto, una importante baza terapéutica por dos razones: 1) la inflamación de estos tejidos puede causar dolor y empeorar la función; 2) la respuesta de estos tejidos ante un estiramiento estático podría mejorar la clínica ${ }^{154}$.

Por otra parte, en estudios sobre dolores neuropáticos crónicos, se han observado zonas teno-celulo-miálgicas con un engrosamiento del tejido subcutáneo, tensiones aponeuróticas, dolores tendinosos y contracturas musculares que responden positivamente a técnicas de TC. Por regla general, son técnicas que molestan al paciente durante las dos o tres primeras sesiones, pero permiten suprimir las modificaciones tisulares y la lumbalgia que las acompaña ${ }^{155}$.

En la práctica clínica diaria, los pacientes que padecen lumbalgia inespecífica, presentan frecuentemente en la zona lumbar alteraciones del TC similares a las descritas. Es una zona dolorosa a la palpación y a la presión en la que se aplican como tratamiento, entre otras, maniobras de TC: masajes del tipo fricción, palpado-rodado, amasamiento superficial, masaje transversal profundo y método Dicke ${ }^{155}$.

Heuleu y Augé ${ }^{156}$ afirman que una perturbación mecánica del segmento lumbar conlleva, habitualmente por vía refleja, un infiltrado cutáneo y su adherencia al plano aponeurótico profundo. Este fenómeno puede ser extenso o puntual. Es un signo patognomónico de un conflicto subyacente y su constatación determina un punto de atención importante para el futuro tratamiento. Es frecuente que en el paciente con lumbalgia, los infiltrados del TCS en la región lumbar estén bien localizados, en forma de barra transversal en la región lumbo-sacra. Hay que tener en cuenta que no existen diferencias estructurales ni de composición de la FTL condicionadas por el género, por la edad, ni por la localización derecha o izquierda ${ }^{157}$.

En un sistema fascial superficial sano, la piel puede moverse fácilmente sobre la superficie de los músculos. En el dolor miofascial crónico la fascia superficial casi siempre está adherida, sin posibilidad de 
desplazamiento libre ${ }^{81}$. El entrenamiento o tratamiento de la fascia necesario para devolverle su movilidad debe ser realizado una o dos veces a la semana, hasta alcanzar un estado adecuado en 6-24 meses ${ }^{84}$.

A la luz de todo lo comentado hasta aquí, la evaluación del estado del TC puede representar una herramienta importante para valorar y realizar un seguimiento en los pacientes con lumbalgia. Aunque su manipulación facilita el diagnóstico y el tratamiento de un amplio rango de patologías, no existen hasta el momento muchos datos que relacionen el tratamiento del TC con la lumbalgia ${ }^{83,127}$, aunque para autores como Schleip ${ }^{130}$, la fascia lumbar juega un papel importante en la LIC. Así, los factores biomecánicos de estructuras pasivas han de tenerse muy en cuenta en la LIC, pues pueden ser causa de dolor lumbar o, al menos, indicativos de su existencia ${ }^{158}$.

\section{I.4.3. Tratamiento de la fascia}

Ya se ha dicho que el TC puede entenderse como un compuesto de capas de colágeno y fibras elásticas ${ }^{159}$ incluidas en la sustancia fundamental, que puede ser modificada con la aplicación de energía (calor o presión mecánica) para cambiar su forma agregada de gel más denso a un estado más fluido, propiedad que se denomina tixotropía y que señala una pérdida de la viscosidad ante la manipulación ${ }^{123}$.

Con la terapia manual se pretende restaurar su equilibrio tensional. Se procede creando calor localmente en el punto de densificación con el objetivo de modificar la estructura del TC denso, restaurando su fluidez y elasticidad, para así devolver a la fascia la movilidad normal y la capacidad de deslizamiento entre los distintos elementos miofasciales ${ }^{93}$. Un diagnóstico palpatorio permitirá averiguar las zonas del tejido alteradas, densificadas, y por tanto, susceptibles de ser tratadas.

La notable plasticidad del tejido fascial, que modifica tanto su textura como su maleabilidad al ser sobreestimulado hace que a través de la manipulación se pueda restaurar su elasticidad fisiológica. 
La manipulación fascial actúa en diferentes capas ${ }^{106}$ :

- Moviliza la hipodermis o el TC laxo subcutáneo.

- Modifica la consistencia de la matriz extracelular de la fascia profunda.

- Restaura el deslizamiento entre las fibras de colágeno endofasciales.

- Rompe las adherencias entre las capas de la fascia profunda en el tronco.

La terapia manual se define como el uso de técnicas manuales para evaluar, manipular y tratar los tejidos blandos del paciente ${ }^{153}$. El masaje es una de estas terapias manuales que actúa sobre el tejido blando en general $y$, por tanto, incide sobre la FS de forma directa mediante presiones, distorsiones, bombeos, etc.; también actúa de forma indirecta o refleja sobre la FP ${ }^{160}$.

Las técnicas de TC utilizan la palpación para remodelar el TC y darle elasticidad $^{138}$. Suelen provocar una hiperemia reactiva y un aumento de la temperatura local. La hiperemia es el resultado de la liberación de histamina por parte de los mastocitos y de los reflejos del sistema nervioso autónomo. Estos efectos pueden durar varias horas después de la manipulación.

La FTL se estira un $20 \%$ menos en sujetos con lumbalgia crónica. Esta reducción de movilidad puede ser debida al movimiento anormal de los componentes del tronco y/o a patología del TC, cuya alteración puede ser un factor predisponente de lumbalgia. La fibrosis y las adherencias son consecuencias importantes de la afectación de este tejido; causan pérdida de movilidad de las capas adyacentes, y podrían restringir los movimientos corporales. Así, la palpación de la movilidad de la FTL es esencial a la hora de investigar las alteraciones del TC ya que estas intervienen en el desarrollo de lumbalgia ${ }^{106}$.

Por otra parte, debido a su elevada inervación sensorial, que incluye fibras nociceptivas, es lógico pensar que la afectación de la FTL juegue un importante papel en el dolor, y por tanto, en la instauración de la lumbalgia $^{126,161}$. 
Las técnicas manuales de tratamiento fascial son efectivas para liberar la movilidad fascial y aliviar la percepción del dolor a corto plazo en sujetos con lumbalgia inespecífica ${ }^{162}$. Por otra parte, el masaje resulta efectivo en la disminución de la lumbalgia de tipo ocupacional ${ }^{163}$. El tratamiento siempre va dirigido a puntos exactos de la fascia. Sólo la manipulación de un área limitada transformará la fricción en calor, modificando la consistencia de la matriz extracelular de la fascia, que es sensible al calor. De hecho, cualquier presión dada tiene una acción más profunda, más intensa cuando el área de manipulación se reduce. Se requieren entre 2 y 10 minutos de manipulación para desarrollar el grado necesario de calor, siendo un poco menor para patologías agudas y un poco mayor para las crónicas ${ }^{164,165}$.Esta variabilidad en el tiempo depende de la cronicidad de la fibrosis fascial y de su consistencia ${ }^{106}$.

Aproximadamente los dos tercios del volumen de la fascia corresponden a agua. Por ello, se debe hidratar después de efectuar cualquier técnica fascial ${ }^{84}$.

\section{I.5. LA TÉCNICA DE LA PINZA RODADA}

La maniobra de Pinza Rodada o Palpado Rodado (PR) ${ }^{166}$ consiste en tomar un pliegue cutáneo entre los dedos de ambas manos (pulgares en oposición) y desplazarlo a lo largo del tronco o de las extremidades, transversalmente al recorrido del dermatoma ${ }^{167}$. En el caso de la columna lumbar el paciente se encuentra en decúbito prono, con los brazos a lo largo del tronco y la técnica se realiza de forma paralela a la línea de las apófisis espinosas de la columna vertebral, de caudal a craneal $^{168}$ (Figura 18).

En la PR el tejido superficial a la fascia profunda (TC que recubre los músculos) es pellizcado, traccionado y enrollado en un movimiento de oleaje. Esto se traduce en un mecanismo de elongación del TC, liberando adherencias que podrían restringir la movilidad.

Esta técnica moviliza la sangre en los capilares cutáneos provocando hipervascularización e híperoxigenación lo que permite la reestructuración del TC. Se trata de una técnica de masaje destinada a movilizar el TC 
rompiendo las adherencias del mismo. Se despega la piel del plano subyacente y no el músculo ${ }^{169}$.

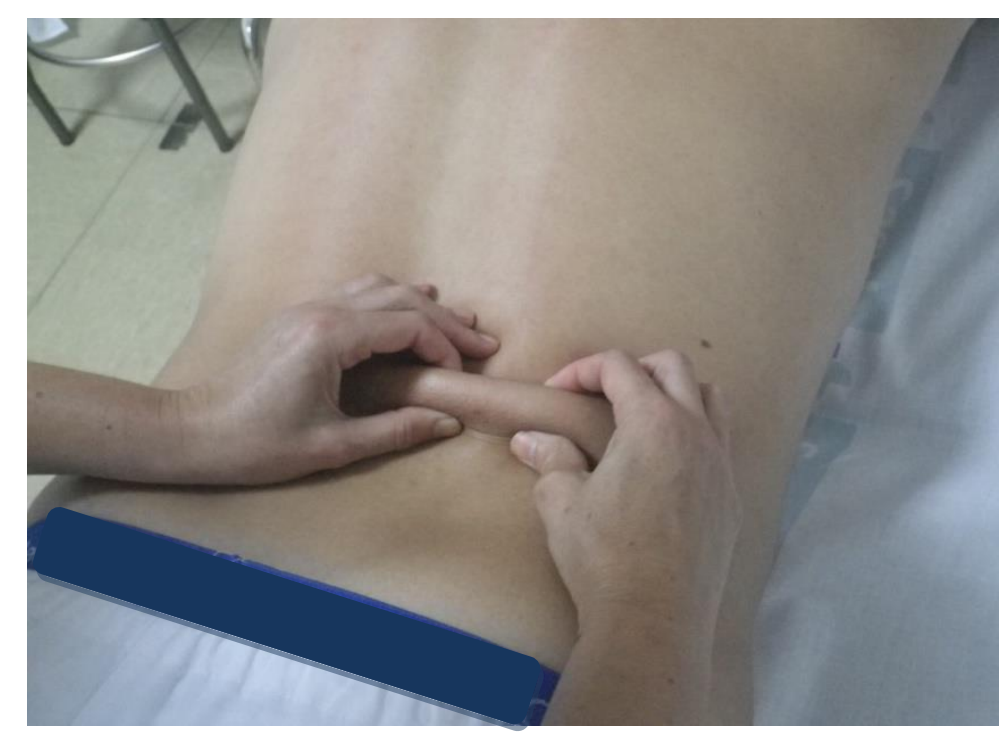

Figura 18. Pliegue de la Pinza Rodada.

Hay que añadir que todo masaje produce efectos fisiológicos, mecánicos y emocionales en el paciente: mejora el flujo sanguíneo y linfático, rompe adherencias, mejora la movilización de los tejidos blandos y reduce el dolor. Pero esta técnica, además, se emplea en el diagnóstico y el tratamiento de zonas hiperálgicas tanto en medicina, como en cirugía estética y plástica.

Una alteración del tejido blando causa acortamiento muscular para proteger el área, lo que podría explicar la contractura muscular del área lumbar en la lumbalgia ${ }^{153}$. Así, la PR actúa sobre la piel y el TCS, que se encuentra infiltrado y con adherencias. La piel es capaz de vehiculizar la acción terapéutica a través de procesos bioquímicos y neurológicos interpuestos. A través de la PR se realiza la búsqueda de la dermalgia refleja, con la que se ponen de manifiesto dos aspectos: por una parte, el terapeuta observa objetivamente el engrosamiento del tejido dérmico y el enrojecimiento de la zona (hiperemia reactiva) (Figura 19), lo que pone en evidencia el reflejo célulo-dérmico; $y$, por otra parte, el paciente experimenta de forma subjetiva un dolor de intensidad creciente hasta un punto de hiperestesia máxima ${ }^{170}$. 
La constitución del pliegue cutáneo entre el pulgar y los otros cuatro dedos puede ser imposible al comienzo de las sesiones de terapia en caso de infiltrado resistente. Además, la maniobra puede resultar dolorosa para el paciente y fatigante para el terapeuta ${ }^{166}$.

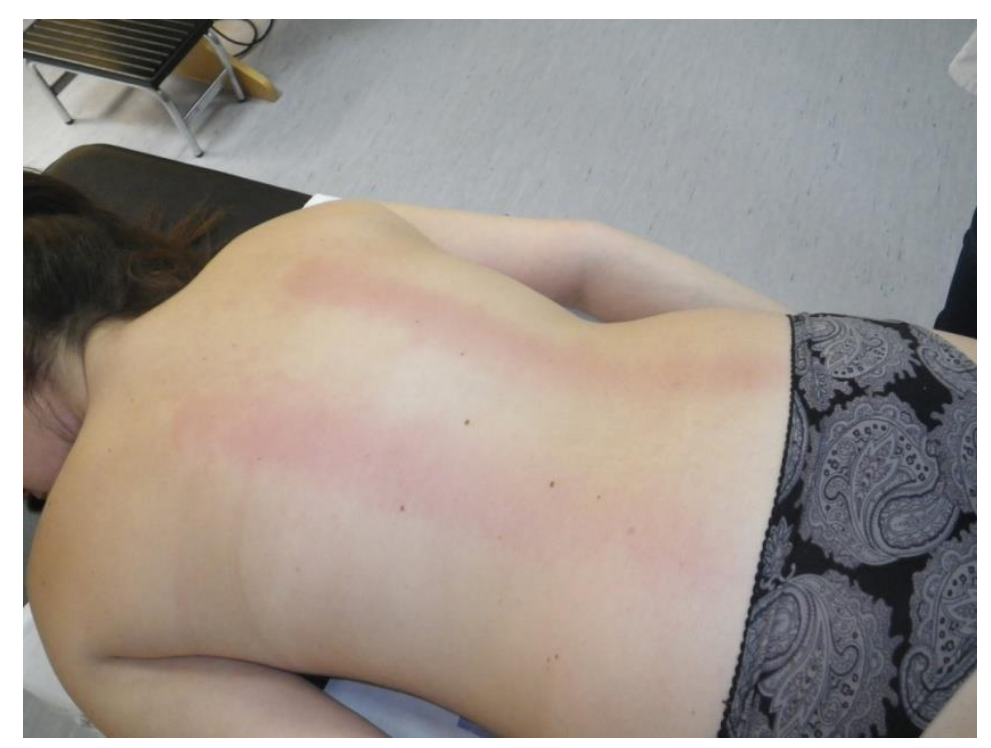

Figura 19 Hiperemia reactiva a la realización de la PR.

Al realizar la PR el fisioterapeuta debe evaluar la presencia de un estiramiento cutáneo anormal, así como la calidad de la consistencia del pliegue (pastosa o edematosa) y la intensidad del desplazamiento de la piel. Es decir, se registran la densidad y la resistencia del rodamiento del "pliegue cutáneo móvil”167,168. La presencia de dolor, sensación lacerante o alteración en la sensibilidad serán considerados como signos positivos de afectación de la zona explorada ${ }^{171}$. Las zonas de hiperalgesia, la rigidez muscular y los trastornos vegetativos sugieren también alteraciones de las articulaciones intervertebrales o intercostales ${ }^{172}$.

Si se practica sistemáticamente la maniobra de la PR en los planos cutáneos correspondientes a una raíz afectada de neuralgia (neuralgia cérvicobraquial, crural, o ciática, por ejemplo) se constata que a menudo existen zonas muy limitadas (algunos centímetros cuadrados) en los que se evidencia un espesamiento de los planos cutáneos extremadamente sensibles a la presión. Este examen es interesante en las neuralgias largas, donde puede suceder que la sensibilidad de estas zonas desaparezca inmediatamente tras la manipulación del TC de la zona lumbar. Esto 
demuestra la relación que existe entre la irritación radicular y esta alteración trófica local ${ }^{169}$.

Son necesarias de 4 a 5 sesiones para recuperar las características normales de flexibilidad tisular de esta zona y conseguir que desaparezca la sensación de dolor "insoportable", dejando lugar a una sensación gratificante ${ }^{156,167}$. 


\section{JUSTIFICACIÓN}




\section{JUSTIFICACIÓN DEL TRABAJO}

La LIC no susceptible de tratamiento específico representa un relevante problema de salud que afecta, entre otras, a personas en edad laboral. Es causa muy frecuente de incapacidad para el trabajo y se asocia a pérdida de productividad y elevados costes ${ }^{36,173,174}$.

El $85 \%$ de los afectados por lumbalgia suele carecer de un diagnóstico concreto. Incluso cuando se realiza un diagnóstico específico, su validez puede ser cuestionada ${ }^{175}$. La lumbalgia crónica suele tener causa multifactorial y las manifestaciones clínicas son variables en cada enfermo ${ }^{6}$.

Aunque el $90 \%$ de los pacientes retorna al trabajo en los tres primeros meses, son habituales las recidivas y la limitación funcional. La intervención terapéutica no farmacológica, generalmente se fundamenta en recomendaciones de salud, consejos posturales y fisioterapia ${ }^{176}$.

Dicho esto, es evidente que un abordaje multidisciplinar reduce el dolor y mejora la función en estos enfermos, teniendo en cuenta siempre el aspecto de la rehabilitación biopsicosocial ${ }^{177}$. Desde el punto de vista fisioterápico el tratamiento indicado para la LIC es muy variable ${ }^{12,178}$. Como se ha expresado en apartados anteriores, para evaluar y tratar correctamente a un paciente con LIC es necesario tener en cuenta el estado de los tejidos blandos ${ }^{179,180}$.

En Fisioterapia es acuciante la necesidad de demostrar que los resultados clínicos de la práctica diaria se fundamentan en los principios del método científico. Si se sabe que un tratamiento fisioterápico tiene efectividad clínica hay que demostrar científicamente esa realidad. Sólo de esa forma se puede argumentar la utilización de las diferentes técnicas en el tratamiento de las distintas patologías.

Desde nuestro punto de vista, es de gran interés conocer las características clínicas de los pacientes con LIC asistidos en nuestra Unidad, así como, revisar el tratamiento recibido, los resultados obtenidos y hacer un seguimiento de las posibles recidivas. Resulta de particular utilidad saber si 
existen factores asociados o relacionados con los efectos del tratamiento fisioterápico. Todo ello podría implicar una posible modificación de los protocolos fisioterapéuticos de la LIC. La posibilidad de utilizar diferentes técnicas fisioterápicas para mejorar los tratamientos abre numerosas puertas a la investigación.

En la Unidad de Fisioterapia "Soria Tarde" existe un protocolo establecido por Atención Primaria para el tratamiento de la lumbalgia crónica, que consiste en Electrotermoterapia (Infrarrojos o/y TENS o/y Microondas o/y Ultrasonidos), Cinesiterapia o Terapia Manual y Educación Sanitaria, prescribiéndose de 10 a 15 sesiones de tratamiento, bien de forma diaria o a días alternos.

En este trabajo de tesis doctoral nos preguntamos ¿Incorporar la técnica de PR al protocolo de tratamiento en la LIC podría resultar beneficioso?. 


\section{HIPÓTESIS Y OBJETIVOS}




\section{HIPÓTESIS Y OBJETIVOS}

\section{III.1. HIPÓTESIS}

La inclusión de la técnica de Pinza Rodada en el tratamiento de la LIC, mejora los resultados del protocolo fisioterápico habitual aplicado en la Unidad de Fisioterapia de Atención Primaria "Soria Tarde" en la ciudad de Soria. Esta mejoría se medirá atendiendo a las modificaciones de la valoración del dolor mediante la Escala Visual Analógica (EVA) estableciendo un poder estadístico del $80 \%$ y una precisión del 5\%. También se valorará la evolución de otros parámetros clínicos que avalen los beneficios de la técnica de Pinza Rodada.

\section{III.2. OBJETIVOS}

Para aceptar o rechazar la hipótesis se han planteado los siguientes objetivos:

\subsubsection{Objetivo primario o principal}

D Evaluar la eficacia de la técnica de PR como complemento del tratamiento fisioterápico estándar de la LIC en la modificación de:

- Dolor (EVA)

- Movilidad/Balance articular (BA)

- Incapacidad física (Escala de Roland-Morris)

- Depresión (Cuestionario de Zung)

- Calidad de vida percibida (Nottingham)

\subsubsection{Objetivos secundarios}

$>$ Establecer si existen diferencias entre grupos en función del sexo. Analizar el índice de recidivas en un periodo de 6 meses. 


\section{MATERIAL Y MÉTODOS}

\section{IV.1. ÁMBITO}

El Área de Salud de Soria, provincia esencialmente agrícola y ganadera, ocupa una superficie de $10284 \mathrm{~km}^{2}$. Su población es de 93291 habitantes (padrón municipal 2013), correspondiendo prácticamente el 50\% a cada sexo, aunque es ligeramente mayor el número de hombres. Está dividida en 15 Zonas Básicas de Salud existiendo un Complejo Hospitalario formado por el Hospital Santa Bárbara (260 camas), hospital de referencia del Área, y el Hospital Virgen del Mirón (130 camas).

El estudio ha sido realizado en la Unidad de Fisioterapia del Centro de Salud La Milagrosa, "Soria Tarde", que asiste a toda la población correspondiente a los Centros de Salud Soria Norte, Soria Sur y Soria Rural, en horario vespertino.

\section{IV.2. DISEÑO}

Se trata de un estudio observacional analítico de cohorte de incepción a realizar en población adulta y con un seguimiento que se ha prolongado durante 6 meses.

\section{IV.2.1. Pacientes}

Los pacientes se han seleccionado entre la población adulta que asiste a la Unidad de Fisioterapia del Centro de Salud La Milagrosa, "Soria Tarde", mediante muestreo no probabilístico consecutivo, según los criterios de inclusión detallados más adelante. El periodo de selección de pacientes comenzó en febrero de 2013 y finalizó en agosto de 2014, cuando se cubrió el tamaño muestral necesario.

\section{IV.2.1.1.Cálculo del tamaño muestral}

Basándonos en el estudio de Lee y $\mathrm{Ko}^{181}$, para conseguir una potencia del $80,00 \%$ y detectar diferencias en el contraste de la hipótesis 
nula $\mathrm{H}_{0}: \mu_{1}=\mu_{2}$ mediante una Prueba T-Student bilateral para dos muestras independientes, teniendo en cuenta que el nivel de significación es del $5,00 \%$, y asumiendo que la media del valor de la EVA del grupo de control es de 4,43 unidades, la media del grupo experimental es de 2,97 unidades y la desviación típica de ambos grupos es de 1,88 unidades, será necesario incluir 27 sujetos en el grupo control y 27 sujetos en el grupo experimental, completando el estudio 54 sujetos. Teniendo en cuenta que el porcentaje esperado de abandonos es del $10,00 \%$ sería necesario reclutar 30 individuos en el grupo control y 30 individuos en el grupo experimental, es decir 60 individuos para completar el estudio. Podríamos utilizar un tamaño muestral menor basándonos en otro tipo de estudios, como los que consideran el cambio mínimo clínicamente relevante de la EVA ${ }^{182}$, sin embargo, con el tamaño calculado (30 individuos en cada grupo) cubrimos las necesidades de ambos planteamientos.

\section{IV.2.1.2. Criterios de Inclusión y Exclusión}

Los criterios de inclusión de los pacientes en el estudio fueron los siguientes:

- Edad mayor de 16 años.

- Diagnóstico de dolor lumbar de más de 7 semanas de evolución (consideramos este periodo de más de 7 semanas como lumbalgia inespecífica de evolución prolongada no provocado por infecciones, neoplasias, metástasis, osteoporosis, artritis inflamatorias, fracturas, o cualquier otra patología orgánica patente.

- Paciente remitido por su médico general al Servicio de Fisioterapia por no presentar signos de alarma (Red Flags)

- El paciente debía someterse a una analítica y radiografía simple previas para descartar la presencia de un cuadro de características no mecánicas $\mathrm{y}$, especialmente, un posible trastorno grave. En los Protocolos de Atención Primaria de Soria se contempla la realización de pruebas diagnósticas a partir de las 6-7 semanas de duración de la lumbalgia.

- Ausencia de dolor radicular. 
- Ausencia de deterioro cognitivo.

- Cumplimentación de consentimiento informado (Anexo II)

Los criterios de exclusión aplicados fueron:

- Abandono del estudio en cualquiera de sus fases.

- Cambios en las características clínicas del paciente que supusieran signos de alarma.

\section{IV.2.1.3. Consentimiento Informado}

Todos los pacientes firmaron, de forma voluntaria, un Consentimiento Informado antes de la participación en el estudio. Previamente fueron informados sobre los detalles del desarrollo del estudio, sobre la cumplimentación de los formularios, y acerca de la privacidad de los datos personales que se recogen en las encuestas.

En todo el estudio se han seguido los principios éticos recogidos en la Declaración de Helsinki de la Asociación Médica Mundial sobre principios éticos para las investigaciones en seres humanos ${ }^{183}$.

Para la realización del estudio se contó con el permiso de la Gerencia de Atención Primaria del Área de Salud de Soria (Anexo III).

\section{IV.2.2. Grupos de estudio}

Los pacientes fueron distribuidos en dos grupos según el orden consecutivo de llegada: el primero al grupo control y el siguiente al grupo pinza, y así sucesivamente.

\section{IV.2.2.1. Grupo Control (GC)}

Los pacientes recibieron el protocolo de tratamiento habitual de la unidad de Fisioterapia consistente en:

- Termoterapia con microondas durante $15 \mathrm{~min}$. (Figuras 20 y 21)

- TENS aplicado a una frecuencia de $100 \mathrm{~Hz}$, con una duración del impulso de $150 \mu \mathrm{s}$, y durante un tiempo de 20 min. (Figuras 22 y 23)

- Consejos de higiene postural.

- 15 sesiones a lo largo de 21 días, descansando los fines de semana. 


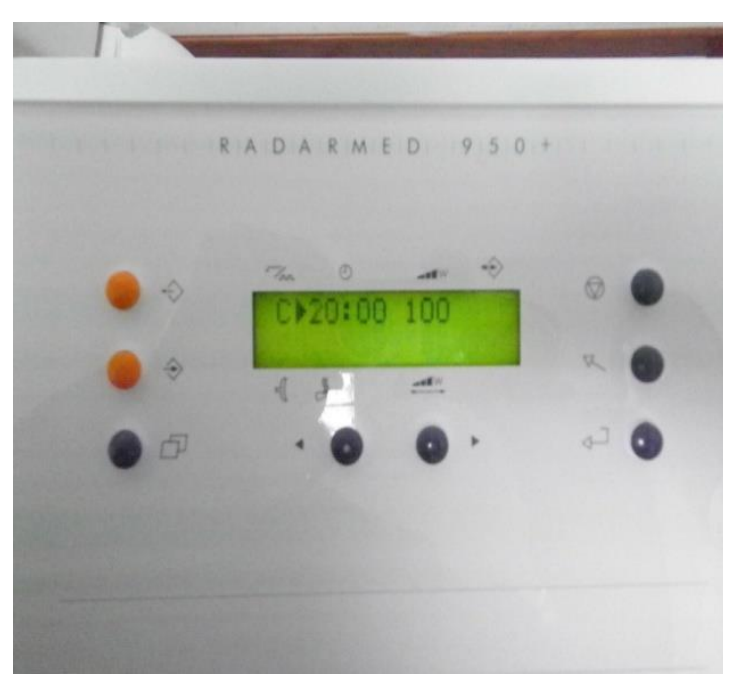

Figura 20. Microondas.

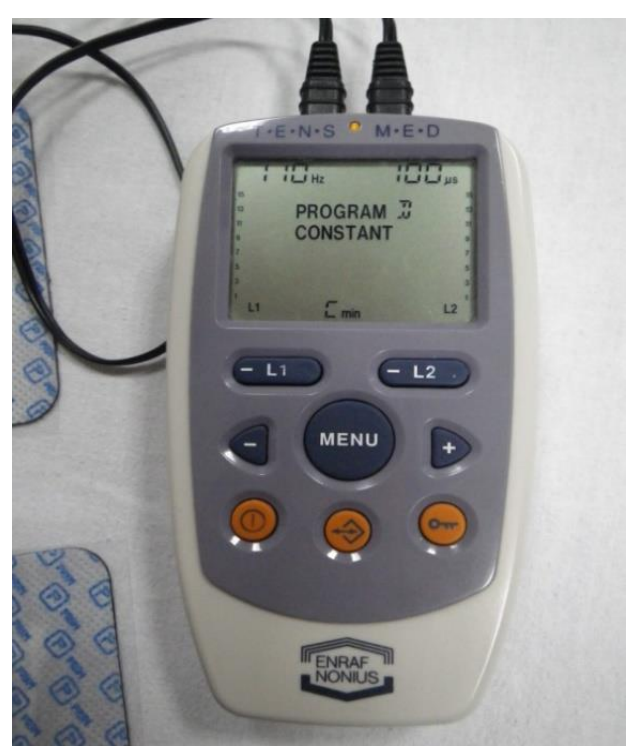

Figura 21. TENS

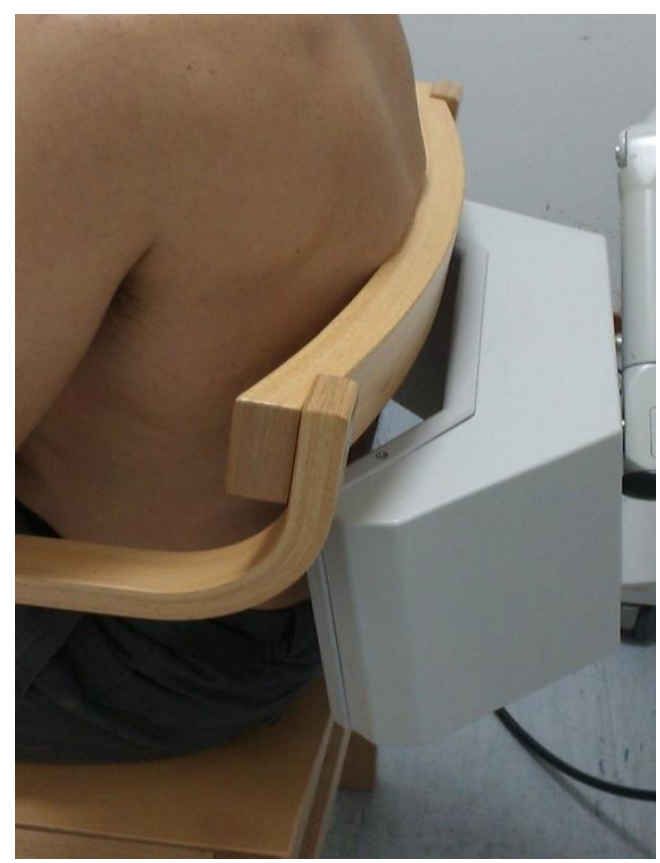

Figura 22. Colocación del MO.

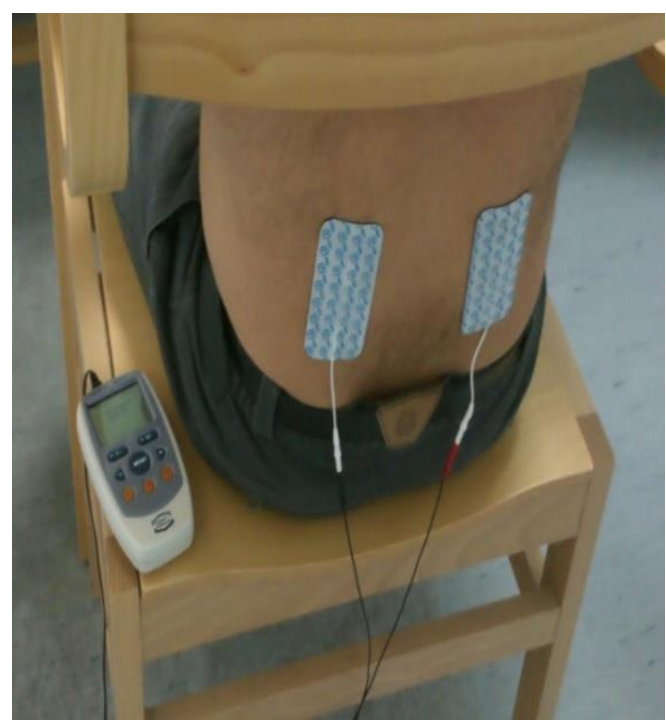

Figura 23 Colocación del TENS.

IV.2.2.2. Grupo Pinza Rodada (GP)

Los pacientes recibieron el protocolo de tratamiento habitual descrito para el GC y además la técnica de Pinza Rodada aplicada según se describe a continuación:

- 5 sesiones, distribuidas en las 3 semanas de tratamiento a razón de 2 la primera semana (lunes y jueves), 2 la segunda semana (lunes y jueves), y 1 
la tercera semana de tratamiento (lunes) (2/2/1). El resto de las sesiones eran idénticas a las del GC.

\section{IV.2.3. Valoración del paciente. Variables de estudio.}

En cada paciente se hizo una valoración clínica y psicosocial, con las pruebas y cuestionarios que se citan a continuación, en los días "0", inmediatamente antes del tratamiento (FASE 0), "21" inmediatamente después de finalizar el tratamiento (FASE 1), "90" a los 3 meses de haber iniciado el tratamiento (FASE 2) y "180" a los 6 meses de haber iniciado el tratamiento (FASE 3). Con ellas se obtuvieron los valores de las variables que nos indicaron el perfil del paciente y su evolución a lo largo de los 6 meses de seguimiento.

Además del perfil sociodemográfico, que se detallará más adelante, los aspectos valorados fueron:

- $\quad$ El dolor mediante la EVA del dolor ${ }^{184-187 .}$

- El balance articular (BA) de la columna lumbar medido con cinta métrica en flexión, en extensión y en inclinación lateral a ambos lados, derecha e izquierda.

- La incapacidad física mediante el cuestionario de Roland Morris $^{188,189}$.

- $\quad$ El grado de depresión por medio de la Escala de Zung ${ }^{190}$

- La calidad de vida a través del Perfil de Salud de Nottingham ${ }^{191}$

Para la medición de las variables cuantificables que se han valorado en el estudio, los pacientes cumplimentaron los correspondientes cuestionarios, cuya fiabilidad y validez han sido comprobadas y resultan de fácil aplicación y desarrollo por parte, tanto del entrevistador, como de la persona estudiada.

Intentando incurrir en el menor número de errores de interpretación y, en la medida de lo posible, disminuir los sesgos relativos a la cumplimentación de los cuestionarios, se garantizó la confidencialidad y el 
total anonimato de los datos obtenidos, evitando con ello una posible simulación en las respuestas.

\section{IV.2.3.1. Cuestionario Sociodemográfico}

Mediante un cuestionario diseñado al efecto, se determinaron variables de tipo sociodemográfico (Anexo IV) que recogía los datos personales, datos relativos a la edad, el sexo, el estado civil, el nivel de estudios, la situación laboral y el puesto de trabajo. Este cuestionario se rellenaba sólo al inicio del estudio, en la primera fase.

Así mismo, se anotaron la existencia de recidivas y la medicación que tomaban en cada etapa del seguimiento.

\section{IV.2.3.2. Dolor. Escala Visual Analógica. (EVA).}

Según la Asociación Internacional para el Estudio del Dolor (AIED), este se define como una experiencia sensitiva y emocional desagradable asociada a una lesión tisular real o potencial. De esta definición se desprenden varios conceptos importantes. El primero, que el dolor es una experiencia subjetiva y, por tanto, diferente para cada individuo; y segundo, que la lesión tisular puede no existir, es decir no es necesaria la presencia de una lesión morfológica que justifique el dolor de un paciente ${ }^{137}$.

La OMS recomienda usar la EVA para la valoración del dolor. Esta escala fue creada por Scott Huskinson ${ }^{186}$ en 1974 y es el método de medición empleado con más frecuencia en muchos centros de evaluación del dolor ${ }^{185}$. La EVA es un instrumento simple, sólido, sensible y reproducible, siendo útil para reevaluar el dolor en el mismo paciente en diferentes ocasiones. Tanto su validez como su fiabilidad para la medición del dolor han sido demostradas en numerosos estudios ${ }^{182-185,187}$.

Consiste en una línea de $10 \mathrm{~cm}$ que representa el espectro continuo de la experiencia dolorosa. La línea puede ser vertical u horizontal y termina en ángulo recto en sus extremos. En dichos extremos aparecen las descripciones de "no dolor" en un extremo y "el peor dolor imaginable" en el otro, sin ninguna otra descripción a lo largo de la línea (Anexo V). 
Su principal ventaja estriba en el hecho de que no contienen números o palabras descriptivas. Al paciente no se le pide que describa su dolor con palabras específicas, sino que es libre de indicarnos sobre una línea continua la intensidad de su sensación dolorosa en relación con los dos extremos de la misma.

El paciente marca en la línea el punto que mejor describe la intensidad de su dolor. La longitud en $\mathrm{cm}$ de la línea es la cuantificación del dolor que clínicamente se corresponderá con la siguiente escala:

- Ausencia de dolor: $0 \mathrm{~cm}$.

- Dolor ligero: 1 a $3 \mathrm{~cm}$.

- Dolor moderado: 4 a $7 \mathrm{~cm}$.

- Dolor severo: 8 a $10 \mathrm{~cm}$.

En cada momento de la valoración se registra la marca para comprobar la evolución del dolor a lo largo del estudio.

\section{IV.2.3.3. Balance Articular de la Columna Lumbar}

Los pacientes con lumbalgia sienten dolor al movimiento, por lo que este se reduce como consecuencia de una posición antiálgica. En el presente estudio se tomaron medidas de flexión, extensión e inclinación lateral derecha e izquierda.

La medida del rango articular usando varios movimientos no es práctica a la hora de investigar, ya que para alcanzar hallazgos estadísticamente significativos se requiere una amplia proporción de sujetos y que éstos presenten la misma alteración. Es por eso, y por la poca fiabilidad de los resultados en rotación, que se ha prescindido de esta variable en el estudio ${ }^{192,193}$ que se ha centrado en la movilidad en los planos sagital y frontal.

\section{IV.2.3.3.1. Flexión Lumbar. Test de Schober}

El test de Schober a nivel lumbar-permite distinguir la capacidad de la flexión lumbar y el grado de restricción que ésta pueda tener ${ }^{194}$. Esta prueba permite mediciones seriadas en pacientes con enfermedad progresiva. Para 
la medición de la flexión, el paciente se encuentra en bipedestación con los pies descalzos y ligeramente separados. Se efectúa una marca sobre la piel en la zona correspondiente a la apófisis espinosa de la vértebra L5 así como $10 \mathrm{~cm}$ más arriba. En flexión anterior, la distancia entre las dos marcas cutáneas se amplía hasta $15 \mathrm{~cm}$, mientras que en flexión posterior se acorta hasta $8-9 \mathrm{~cm}^{195}$. Si el aumento de la distancia entre las dos marcas provocado por la flexión anterior es menor de $5 \mathrm{~cm}$, indica una limitación de la flexión lumbar.

Tanto el test de Schober total como el lumbar se suelen criticar ya que no introducen la articulación L5-S1 que es una de las zonas que más participa en la movilidad en flexión lumbar ${ }^{196}$. El estudio radiológico de Mette y Demiautte ${ }^{197}$ demuestra que el Test de Schober Lumbar Modificado (TSLM) refleja mejor la movilidad vertebral que el test de Schober original, ya que $10 \mathrm{~cm}$ por encima solo evalúa la movilidad hasta L3. Es por eso que en este estudio se eligió el TSLM.

La colocación del paciente en el TSLM es similar al Schober lumbar: paciente en bipedestación erguido, pero relajado, descalzo, con los pies separados a la altura de los hombros y los brazos a lo largo del tronco ${ }^{195}$. Con lápiz dermográfico se realiza una marca en la unión lumbosacra, en la línea que une el centro de las dos fositas lumbares laterales (hoyuelos de Venus). Si estos no se aprecian, se localizan las dos espinas iliacas posterosuperiores (EIPS) (aproximadamente la altura de L5) mediante palpación a partir de la cresta iliaca. De esta primera marca se traza la segunda a $5 \mathrm{~cm}$. por debajo, y la tercera $10 \mathrm{~cm}$ por encima ${ }^{195}$ (Figura 24). A continuación, el sujeto se inclina hacia delante, todo lo que sea posible sin doblar las rodillas, mantenido los brazos y los dedos extendidos como si fuera a tocarse los pies. Con una cinta métrica flexible, se mide la distancia entre las marcas (Figura 25).

El grado de flexión es la distancia existente entre estas marcas en la posición de flexión máxima restando $15 \mathrm{~cm}$. 
Una vez efectuada la medición se pide al sujeto que flexione ligeramente las rodillas y se le ayuda a levantar el tronco para evitar provocar molestias innecesarias durante la prueba.

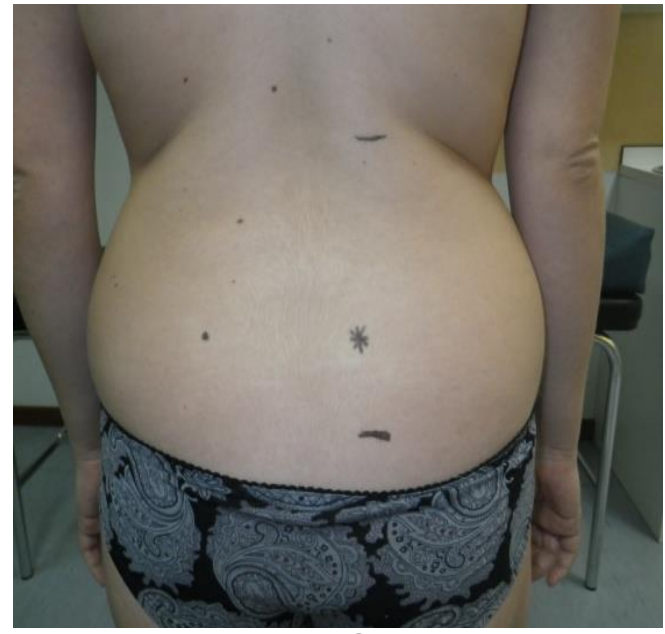

Figura 24. TSLM

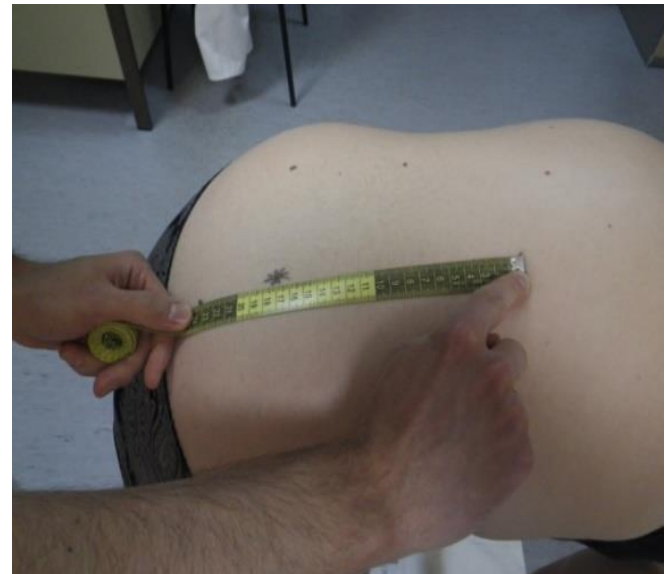

Figura 25. Medición de la Flexión.

\section{IV.2.3.3.2. Extensión Lumbar}

Se utilizan los mismos puntos de referencia establecidos para la prueba de Schober modificada ${ }^{195}$. El sujeto coloca las palmas de las manos sobre las nalgas mientras permanece de pie en la posición de partida cero. Se establece una marca en la línea media a la altura de la espina ilíaca posterosuperior (EIPS) y otra marca en la línea media $15 \mathrm{~cm}$ por encima de la EIPS. A continuación, se le indica que se incline hacia atrás lo máximo posible. La reducción de la distancia tras una extensión máxima de la columna se resta de la distancia inicial de $15 \mathrm{~cm}$. (Figura 26).

IV.2.3.3.3. Inclinaciones Laterales del tronco.

Para medir la inclinación lateral, a ambos lados, se emplea el método descrito por Mellin ${ }^{198}$. Se coloca al paciente en bipedestación erguido, pero relajado, descalzo, con los pies separados a la altura de los hombros y los brazos a lo largo del tronco. Con un lápiz dermográfico se dibuja una línea en el muslo en el lugar donde se sitúa el dedo medio de la mano homolateral $^{195}$ (Figura 27). 


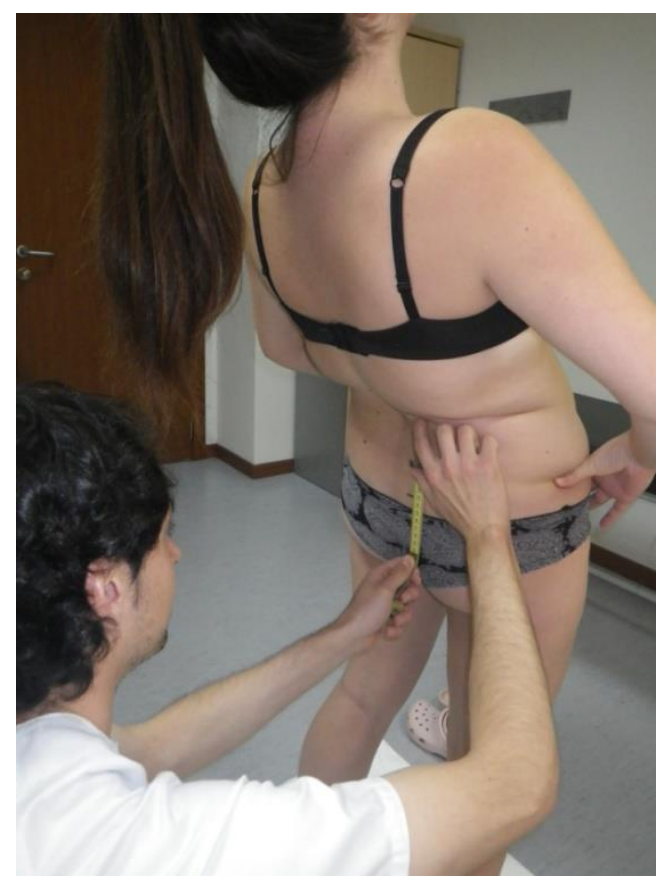

Figura 26. Medición de la Extensión.

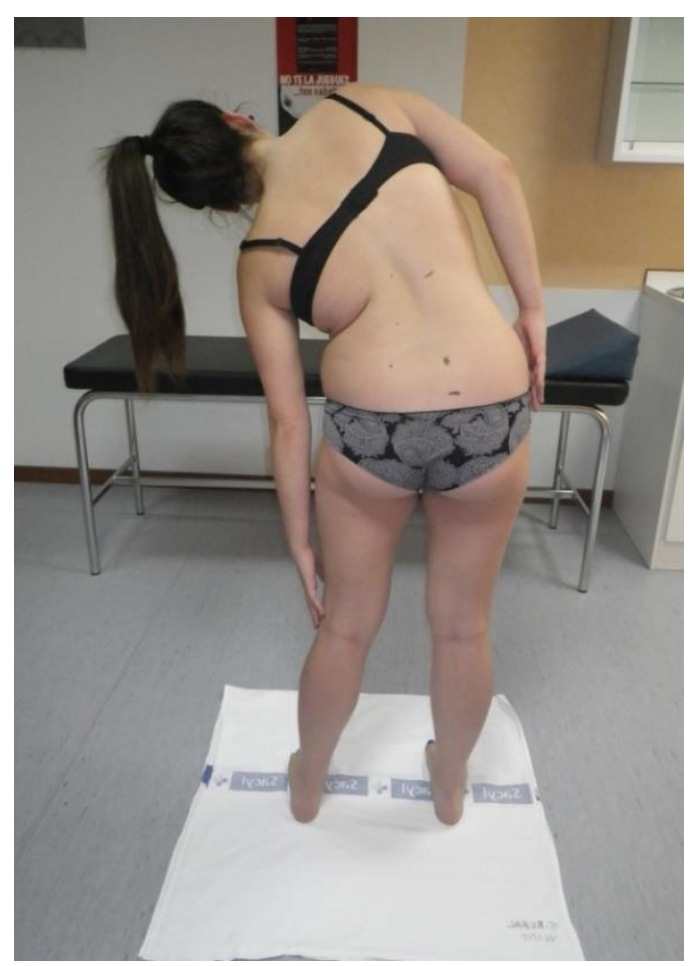

Figura 27. Inclinación lateral izquierda

Se indica al paciente que haga una inclinación lateral resbalando la mano con intención de tocar el maleolo externo de la pierna correspondiente. El movimiento tiene que ser en el plano frontal ya que es muy fácil 
compensar con una ligera flexión del tronco ${ }^{195}$. Se realiza una nueva señal en la posición que ocupa ahora el dedo medio. La medición es centimétrica.

El paciente retorna a la posición inicial y con una cinta métrica flexible se mide la distancia entre las marcas. Esa distancia es la medida de la inclinación lateral ${ }^{195}$. Se repite lo mismos en el lado contrario.

Hay que tener mucho cuidado con las compensaciones. Como se muestra en la Figura 28, una compensación en flexión de tronco provoca que la medida sea errónea, ya que la marca estará desplazada hacia atrás.

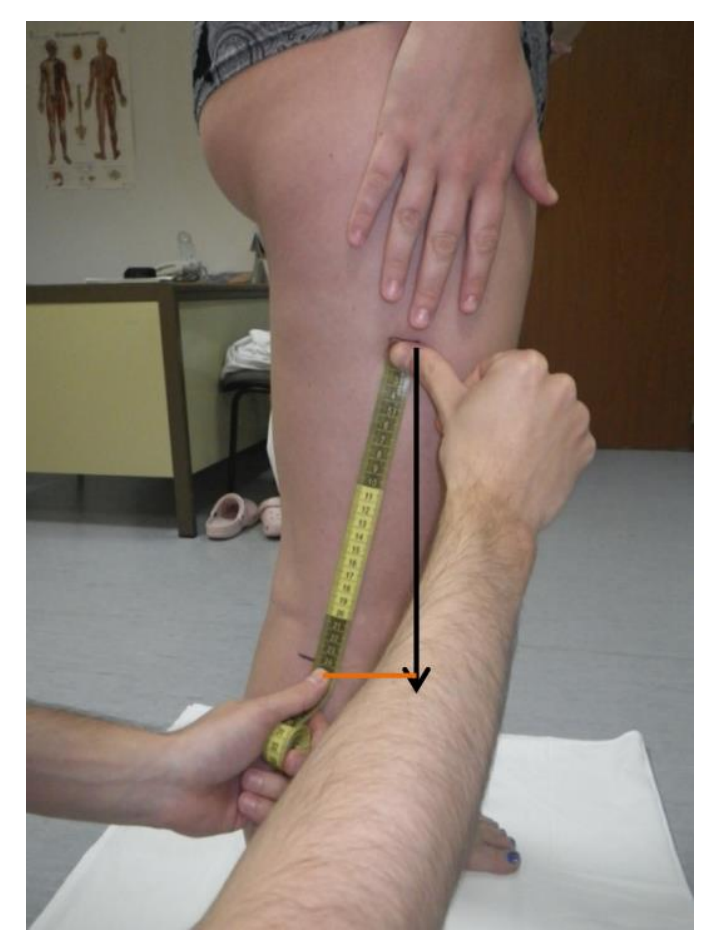

Figura 28. Compensaciones.

IV.2.3.4. Incapacidad funcional. Cuestionario de Roland-Morris.

La incapacidad física se define como la limitación en la realización de las actividades cotidianas ${ }^{188}$ y está fuertemente asociada a condiciones musculoesqueléticas como artritis, lumbalgia y otras alteraciones de tejidos blandos. La carga de estas condiciones puede crecer de forma exponencialmente alta en ausencia de rehabilitación ${ }^{199}$. El cuestionario de Roland Morris es una herramienta excelente para medir la incapacidad física (Anexo VI). Sirve para determinar de manera fiable el grado de incapacidad física derivado de la LIC. 
Es importante señalar que la escala de Roland-Morris no se utiliza para medir la intensidad del dolor, ni siquiera de manera indirecta, puesto que el dolor y la incapacidad no se correlacionan entre sí; hay pacientes con lumbalgia muy intensa y poca incapacidad, y viceversa ${ }^{40}$.

El cuestionario se debe usar en pacientes que sepan leer, aunque lo hagan con dificultad o no tengan estudios, y está diseñado para ser usado especialmente en Atención Primaria. Debe ser contestado directamente por el paciente (autoadministrado en $5 \mathrm{~min}$ ), preferiblemente solo, es decir, sin influencias de terceras personas y $\sin$ ayuda del personal sanitario $\mathrm{o}$ auxiliar.

Consiste en 24 frases que describen la capacidad funcional de la espalda del sujeto. Para establecer el grado de incapacidad, basta con contar el número de frases señaladas por el paciente y ese será el resultado. Los valores extremos oscilan entre 0 (ausencia de incapacidad por lumbalgia) y 24 (máxima incapacidad posible). Cuanto más alto sea el valor alcanzado peor es el funcionamiento de la espalda.

Una incapacidad por debajo de 4 puntos es muy leve. Además, una variación en la puntuación sólo tiene relevancia clínica si es de 2 ó más puntos aunque el dintel óptimo está entre 3 y 4.

\section{IV.2.3.5. Escala de Depresión de Zung.}

La escala de autoevaluación para la depresión de Zung fue diseñada por W.W Zung ${ }^{191}$ para evaluar el nivel de depresión. Es una encuesta corta y auto administrada (Anexo VII).

La OMS recomienda usar esta escala de Zung (Self-Rating Depresión Scale: SRDS) para valorar el estado emocional del paciente ${ }^{200}$. Su elección se debe, por una parte a su validez, y por otra a que fue una de las primeras en validarse en nuestro idioma. Está indicada para individuos que acuden a consulta médica por patología de tipo somático, pero en los que es posible encontrar un fondo depresivo-angustioso objetivable por medio de la escala. La escala de Zung informa sobre la presencia y severidad de la sintomatología depresiva y es sensible a los cambios en el estado clínico ${ }^{200,201}$. 
La prueba consta de 20 frases relacionadas con la depresión: diez preguntas elaboradas de forma positiva, y otras diez, de forma negativa. Tienen gran peso los síntomas somáticos y los cognitivos, con 8 ítems para cada grupo, más dos ítems referentes al estado de ánimo y otros dos a síntomas psicomotores.

El paciente cuantifica la frecuencia de aparición de los síntomas, no su intensidad según una escala de Likert. Cada pregunta se evalúa en una escala de 1-4 para los ítems de sentido negativo, y de 4-1 para los positivos (poco tiempo, algo de tiempo, una buena parte del tiempo, y la mayor parte del tiempo).

El resultado puede presentarse como puntuación total (suma de los valores de cada ítem, oscilando los valores entre 20 y 80 puntos) o como puntuación normalizada (suma de los valores expresada como porcentaje de la máxima puntuación posible Sx100/80) oscilando los valores entre 25 y 100.

El rango de calificación usado es el de 20-80, estableciéndose entre:

- 25-49: Rango normal

-50-59: Ligeramente deprimido

-60-69: Moderadamente deprimido

- 70 o más: Severamente deprimido

Los índices de fiabilidad son buenos, y los de validez aceptables. Ha sido validada como método de cribaje de depresión en Atención Primaria ${ }^{200}$.

V.2.3.6. Calidad de vida. Perfil de Salud de Nottingham (PSN).

El Nottingham Health Profile (NHP) fue diseñado en Gran Bretaña para medir la percepción de salud y para evaluar en qué forma se ven afectadas las actividades cotidianas por los problemas de salud. El diseño está influido por los contenidos del cuestionario Sickness Impact Profile.

Sus autores lo consideran útil para la valoración de las intervenciones médicas o sociales, como medida de resultado de comparaciones entre 
grupos, como encuesta en poblaciones seleccionadas, para el seguimiento de pacientes con enfermedades crónicas y para ensayos clínicos en grupos escogidos $^{188}$.

Ha sido adaptado en nuestro país por Alonso et al. ${ }^{190}$ como Perfil de Salud de Nottingham (PSN) donde quedan descritas con detalle las bases de la metodología seguida en este proceso de adaptación cultural.

Es un instrumento genérico para la medida del sufrimiento físico, psicológico y social, asociado a problemas médicos, sociales y emocionales, así como para determinar el grado en que dicho sufrimiento afecta a la vida de los individuos. Se trata de un cuestionario autoadministrado, que se cumplimenta en unos 10-15 minutos. Se han mostrado aceptables además, otras formas de cumplimentación como: entrevista personal, telefónica o cassette con preguntas pregrabadas.

Consta de dos partes: (Anexo VIII)

- La primera está formada por 38 ítems de respuesta SI-NO, que exploran 6 dimensiones de la salud: energía, dolor, reacciones emocionales, sueño, aislamiento social y movilidad física. Los enunciados de cada ítem hacen referencia a diferentes estados de salud con la que el encuestado deberá identificarse (SI) o no hacerlo (NO).

- La segunda parte consta de 7 preguntas sobre la existencia de limitaciones, a causa de su salud, en 7 actividades funcionales de la vida diaria: trabajo, tareas domésticas, vida social, vida familiar, vida sexual, aficiones y tiempo libre.

De la primera parte del cuestionario, se obtienen seis puntuaciones diferentes, correspondientes a cada una de las dimensiones evaluadas. Para el cálculo de cada dimensión se suman los valores de los items que la conforman y se divide por el número de items. El valor obtenido se multiplica por 100 obteniendo valores que van del 0 al 100. La valoración será 0 en el caso de que la persona interrogada conteste negativamente a todos los ítems de la dimensión y no padezca ningún problema de los que ésta refleja. 
La puntuación será 100 si el paciente contesta afirmativamente a todos los items indicando que los padece todos. Esta forma de valoración es la que se utilizó en la validación sueca, francesa y española.

Los autores desaconsejan la obtención de un valor sumatorio total del cuestionario, aunque en algunos estudios se ha utilizado y por ello se ha decidido analizarlo también en este trabajo.

Las preguntas de la segunda parte del cuestionario, sólo pueden ser analizadas como variables categóricas.

\section{IV.3. RECOGIDA DE DATOS Y ANÁLISIS ESTADÍSTICO}

\section{IV.3.1. Recogida}

Los datos se recogieron en el periodo comprendido entre febrero de 2013 y agosto de 2014, a través de las encuestas y mediciones llevadas a cabo siempre por la misma persona y siempre distinta de quien realizaba la técnica de PR.

Mediante llamada telefónica se concertaba cita previa con el paciente en las sucesivas fases. Todas los datos fueron captados entre las 15:30 y las 19:00 horas del día de visita.

\section{IV.3.2. Análisis Estadístico}

Los datos obtenidos en el estudio se han analizado con el programa estadístico SPSS.22 para Windows 7, con licencia para la Universidad de Valladolid. En todos los casos el nivel de significación estadística se expresa mediante el valor de "p" y el intervalo de confianza utilizado ha sido del $95 \%$. Se han considerado diferencias significativas cuando el valor de "p" es inferior a 0,05 .

En primer lugar, para la descripción de la población objeto de estudio se han calculado porcentajes para las variables sociodemográficas cualitativas $y$ valores medios para las variables antropométricas cuantitativas. Posteriormente, se ha procedido a la comparación de los valores medios entre los grupos objeto de análisis. Al comparar las medias 
de las variables cuantitativas entre el GC $(n=30)$ y el GP $(n=35)$, por el número de pacientes se ha asumido que los resultados siguen una distribución normal.

Al comparar la media de las mismas variables, teniendo en cuenta además el sexo, se empleó el Test de Kolmogorov Smirnov para comprobar si los valores seguían una distribución normal, ya que el número de integrantes de cada grupo se reducía y no puede asumirse que la distribución sea normal.

En la Tabla 3 se expresan todas las variables estudiadas en cada uno de los grupos y fases, teniendo en cuenta el sexo de los participantes. Las variables que aparecen marcadas con una " $\mathrm{X}$ " no siguen una distribución normal dentro del correspondiente grupo. De esta forma, cuando los valores en cada grupo siguen una distribución normal la comparación de las medias de las diferentes variables entre grupos se realiza mediante el test "t de Student" para muestras independientes. Si no siguen una distribución normal se aplica el test no paramétrico " $U$ de Mann Whitney".

Para analizar la evolución de los valores medios de cada variable a lo largo del tiempo, es decir en las cuatro fases de seguimiento, si la distribución del valor de la variable es normal en todas las fases, se utiliza el test Anova de un factor (la fase evolutiva) para muestras repetidas, y si la distribución no es normal, se aplica la prueba no paramétrica de Friedman. 


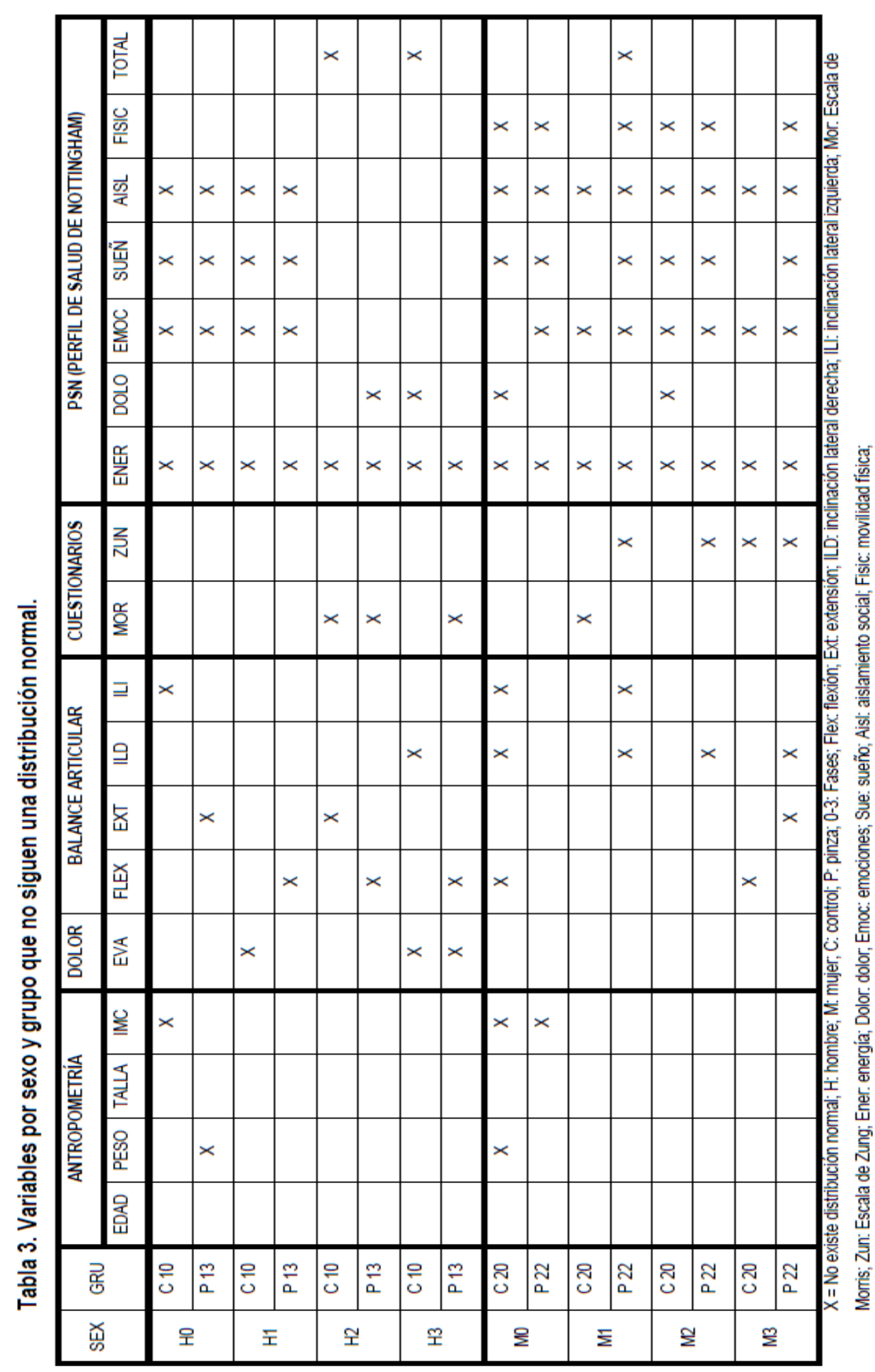




\section{IV.4. REVISIÓN BIBLIOGRÁFICA}

La revisión bibliográfica se realizó en las bases de datos Medline, biblioteca Cochrane, Physiotherapy Evidence Database (PEDro), Scielo y Uptodate. 


\section{RESULTADOS}




\section{RESULTADOS}

En primer lugar, y en relación con los resultados obtenidos, se ha realizado una descripción general de la población estudiada, donde se incluyen los datos relativos a las variables sociodemográficas. En segundo lugar, se ha desarrollado el análisis de los datos obtenidos estableciendo las comparaciones entre los diferentes grupos para las distintas variables estudiadas.

\section{1. DESCRIPCIÓN DE LA MUESTRA}

El número total de pacientes que acudió por lumbalgia a la Unidad de Fisioterapia, durante el periodo previsto para la captación de pacientes (1 año) fue de 97, aunque una vez aplicados los criterios de inclusión y exclusión el número se redujo a 83 (Fase 0). Antes de completar la primera fase lo abandonaron el estudio 13 personas; otras dos lo hicieron antes de finalizar la segunda fase y otras tres antes de finalizar el estudio. Es decir, la población total que ha completado el estudio ha sido de 65 pacientes, 30 pertenecientes al GC $(46,15 \%)$ y 35 al GP $(53,84 \%)$ (Figuras 29 y 30$)$.

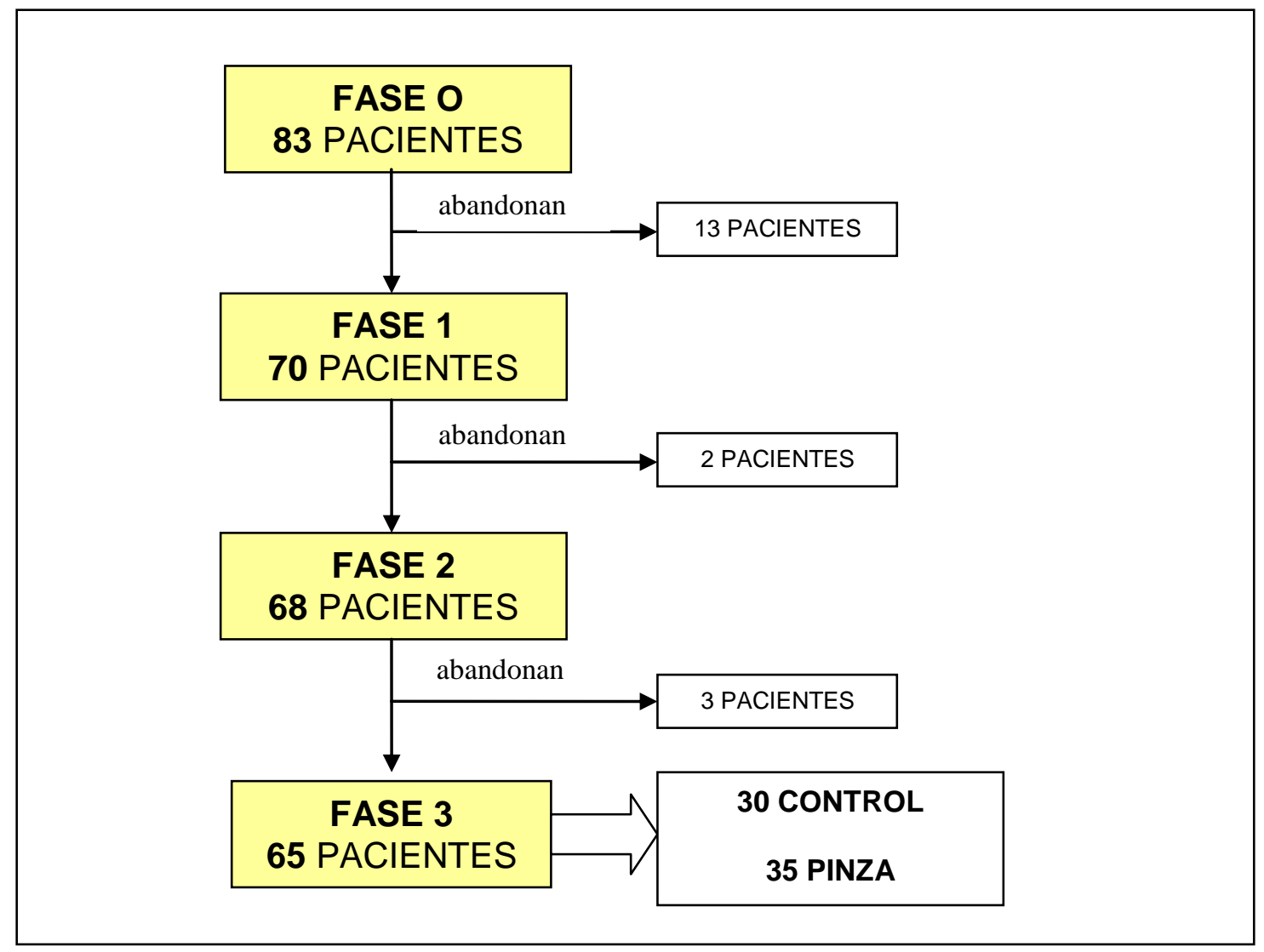

Figura 29. Esquema de la participación de la población objeto de estudio. 


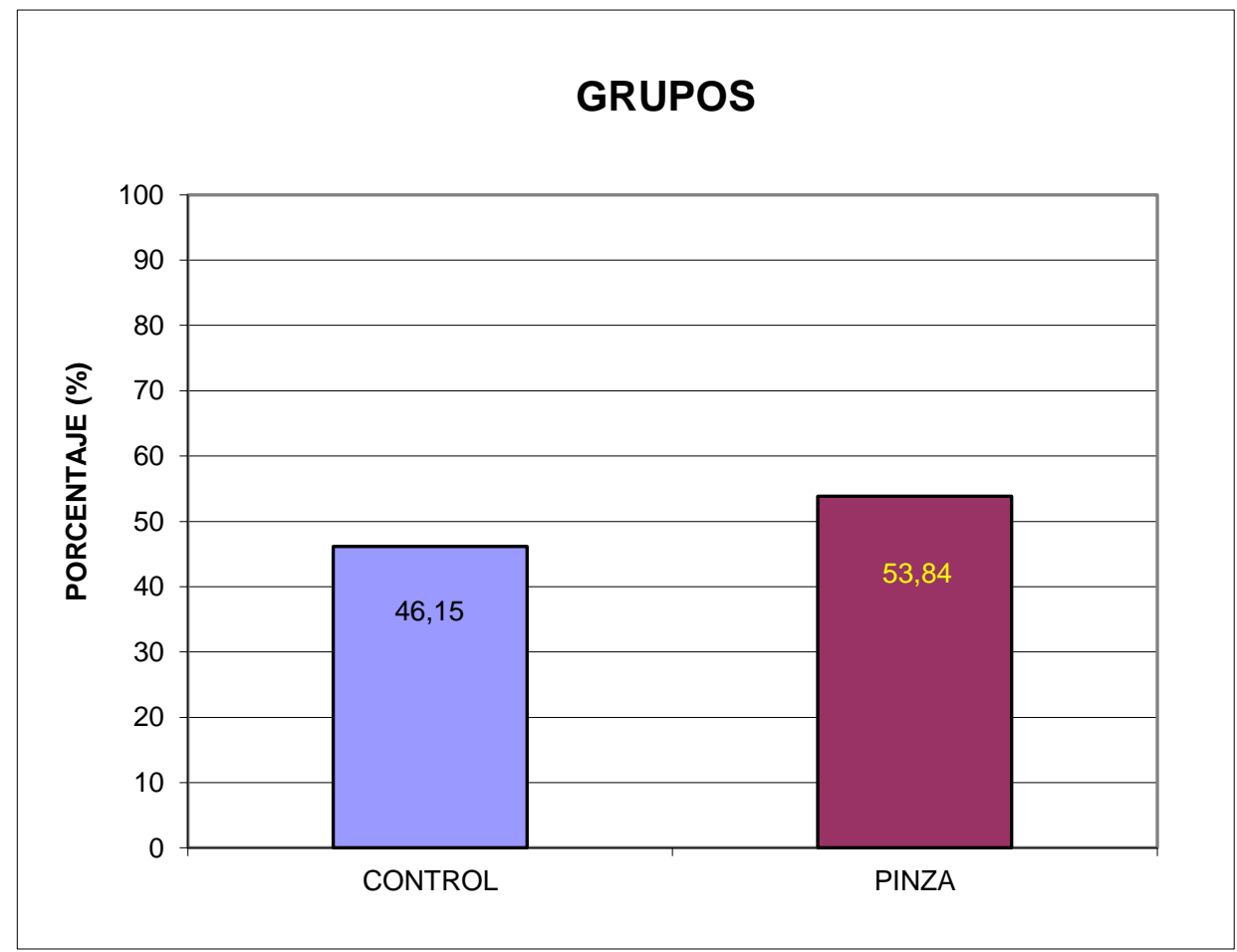

Figura 30. Porcentaje de pacientes en cada grupo.

\section{V.1.1. Variables Sociolaborales}

La distribución de la muestra en función del sexo señala que en el estudio han participado un $65 \%$ de mujeres y un $35 \%$ de hombres (Figura 31 ).

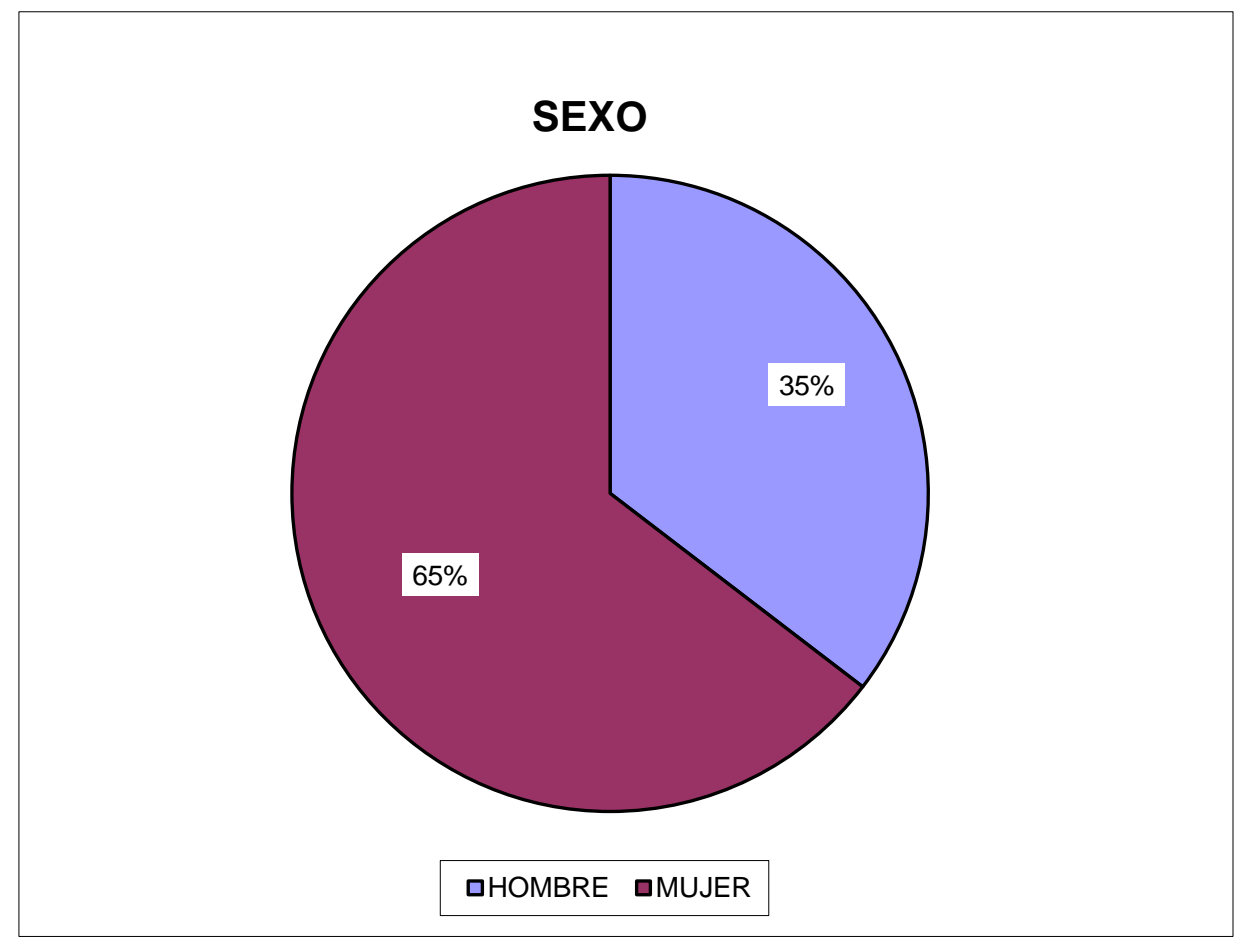

Figura 31. Distribución de la población por sexo 
Por Grupos de Edad la mayor parte de los pacientes se encuentra entre 35-45 años, con una edad media de la población de 46,60 \pm 15,16 años, siendo de $48,65 \pm 17,25$ para hombres y de $45,47 \pm 13,98$ para mujeres. Prácticamente el $50 \%$ se sitúa entre los 35-54 años (Figura 32 ).

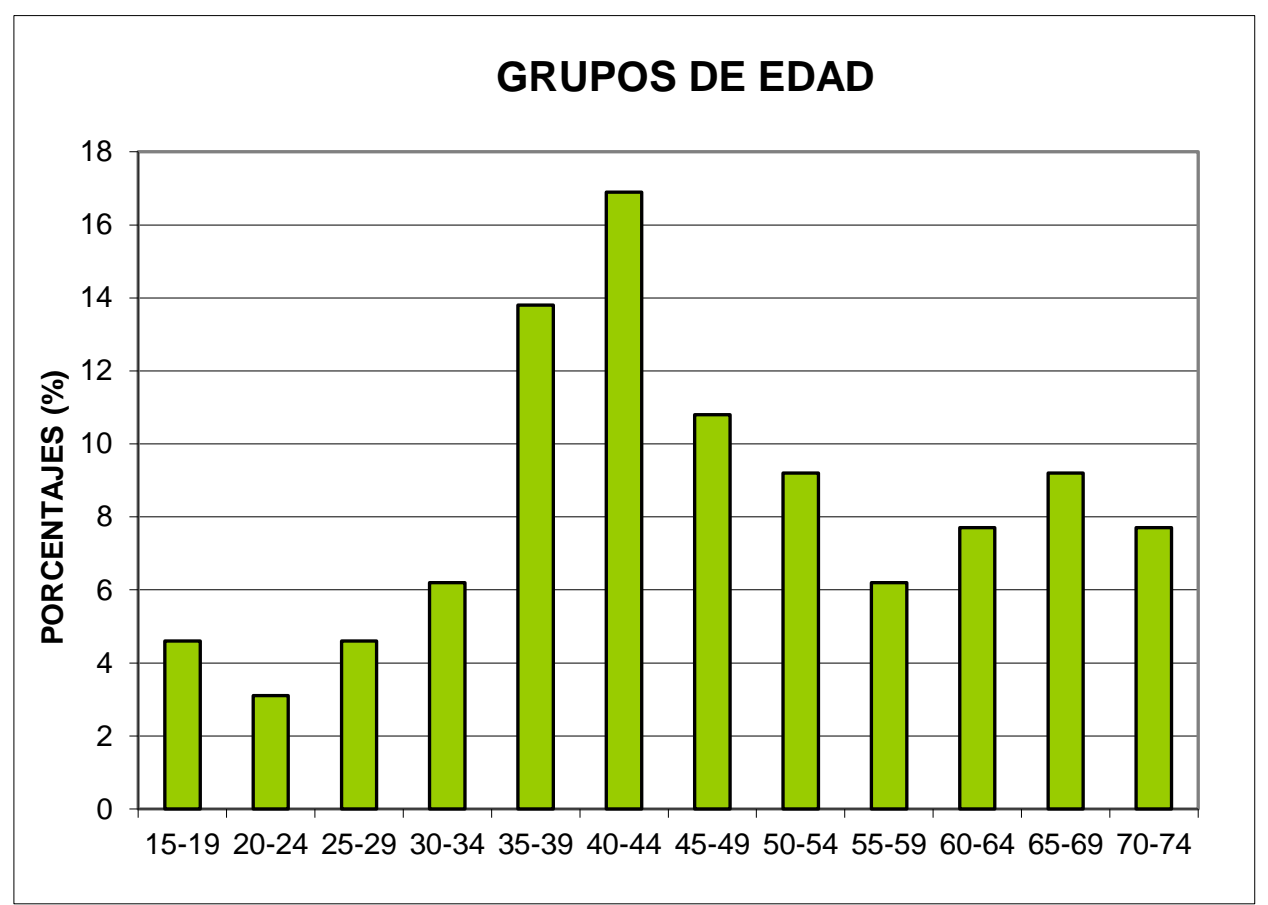

Figura 32 Distribución de la población por grupos de edad

La mayor parte de la población se reparte entre solteros y casados, representando los separados y los viudos un pequeño porcentaje (Figura 33).

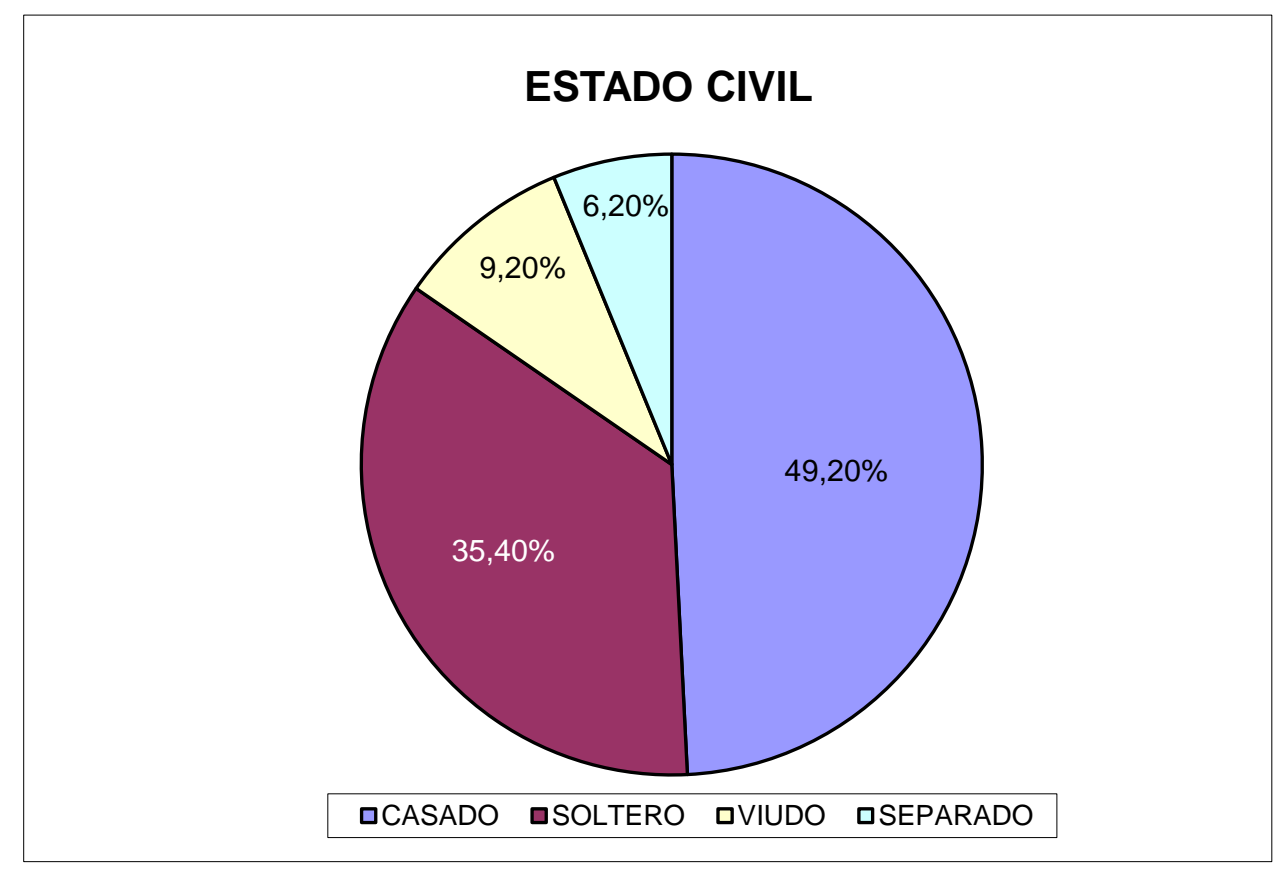

Figura 33. Distribución de la población según el estado civil 
En cuanto al nivel de estudios realizados, la mayoría de los pacientes había cursado sólo estudios de primaria, seguido de aquellos que completaron el bachillerato; un porcentaje ligeramente inferior realizó estudios universitarios y el grupo menos numeroso pertenece a los pacientes que acabaron la educación secundaria (Figura 34).

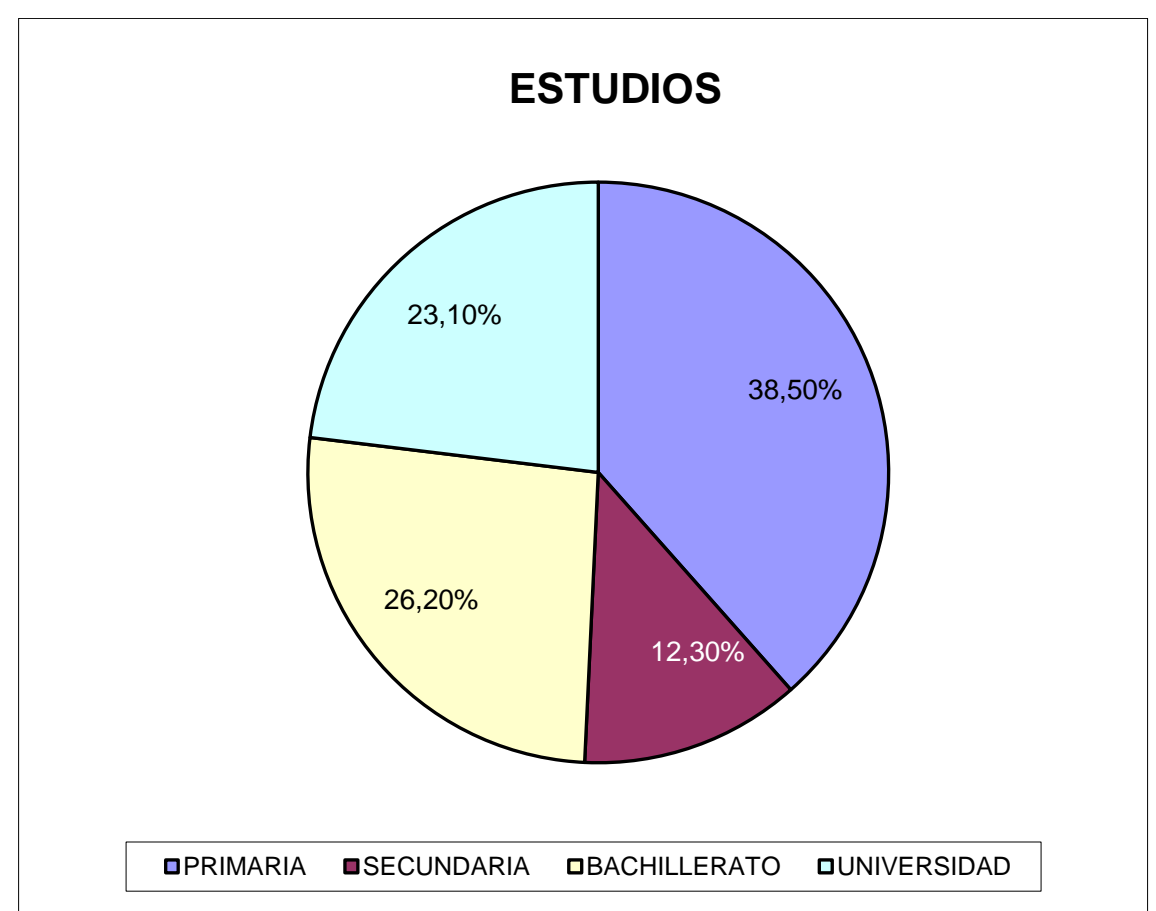

Figura 34. Distribución de la población según el nivel de estudios

En la variable de Profesión, codificada según las exigencias físicas del trabajo, sólo un $12 \%$ realizaba un trabajo físicamente duro, seguido por el grupo de pacientes considerado inactivo. El grupo más numeroso desarrollaba un trabajo medio (37\%) y el resto (31\%) trabajos suaves (Figura 35$)$. 


\section{EXIGENCIA FÍSICA DEL TRABAJO}

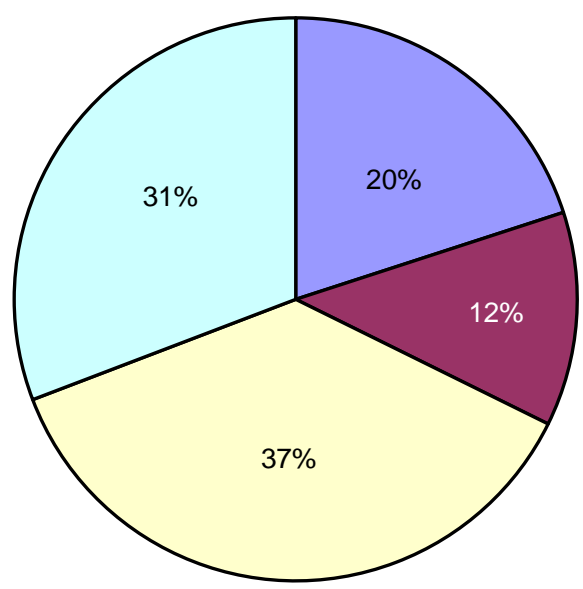

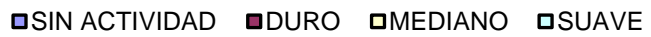

Figura 35. Distribución de la población según la exigencia física del trabajo

Teniendo en cuenta la situación laboral de los pacientes, un elevado porcentaje se encontraban en activo, mientras que sólo un 6,20 \% estaban en paro. El porcentaje intermedio corresponde a elementos pasivos laboralmente hablando (Figura 36).

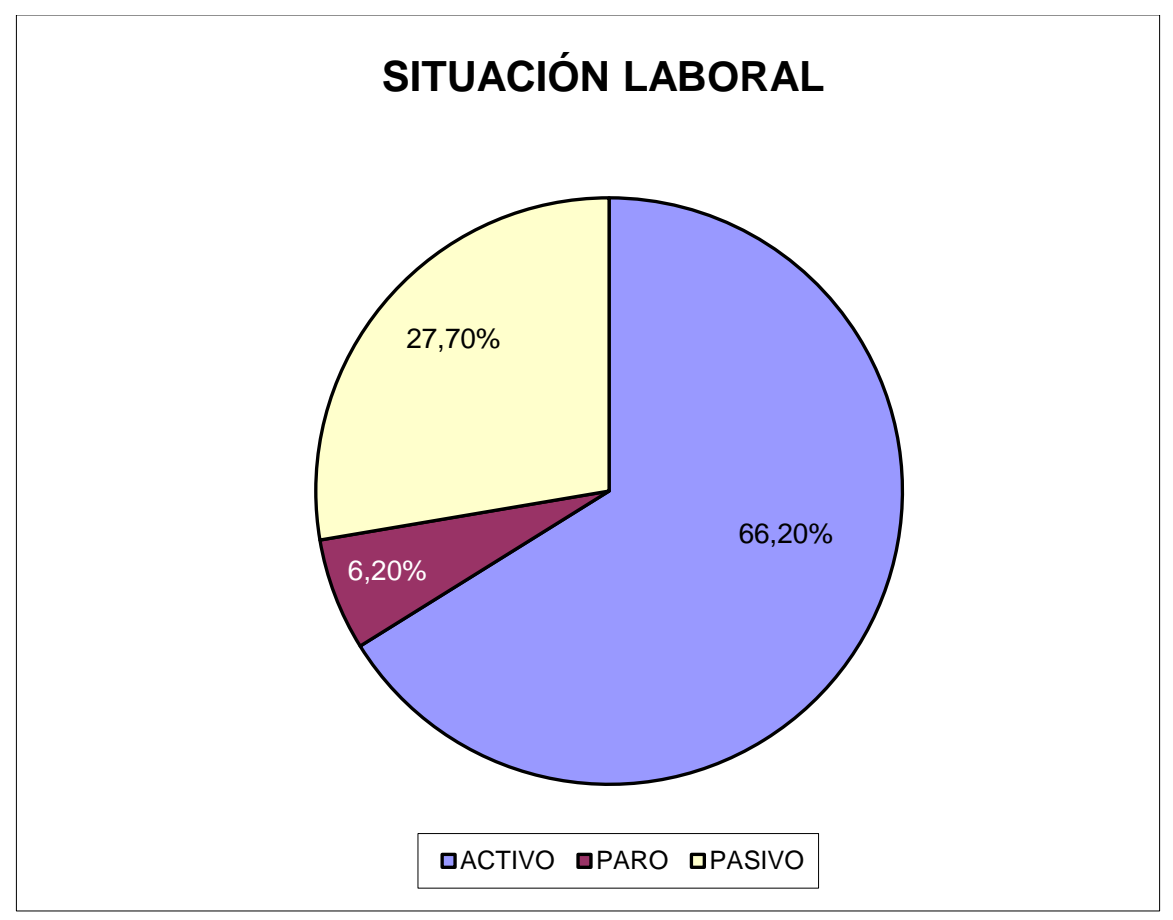

Figura 36. Distribución de la población según la situación laboral 


\section{V.2. ANÁLISIS DE DATOS}

V.2.1. Comparación de variables antropométricas entre el Grupo Control y el Grupo Pinza en la fase 0, previa al tratamiento.

En cuanto a la edad y a las medidas antropométricas (Peso, Talla e IMC), no se apreciaron diferencias significativas entre el GC y el GP, siendo la distribución de los rangos de IMC similar en ambos grupos (Tabla 4 y Figuras $37,38,39$ y 40 ).

Tabla 4. Comparación de valores medios entre grupos

\begin{tabular}{|c|c|c|c|}
\hline & $\mathrm{GC}$ & GP & $\mathrm{p}$ \\
\hline EDAD (años) & $49,0 \pm 13,3$ & $44,5 \pm 16,5$ & 0,240 \\
\hline PESO (Kg) & $69,7 \pm 14,7$ & $70,7 \pm 13,8$ & 0,778 \\
\hline TALLA (m) & $1,64 \pm 0,06$ & $1,67 \pm 0,10$ & 0,142 \\
\hline $\operatorname{IMC}\left(\mathrm{Kg} / \mathrm{m}^{2}\right)$ & $25,82 \pm 4,69$ & $25,19 \pm 3,68$ & 0,548 \\
\hline
\end{tabular}

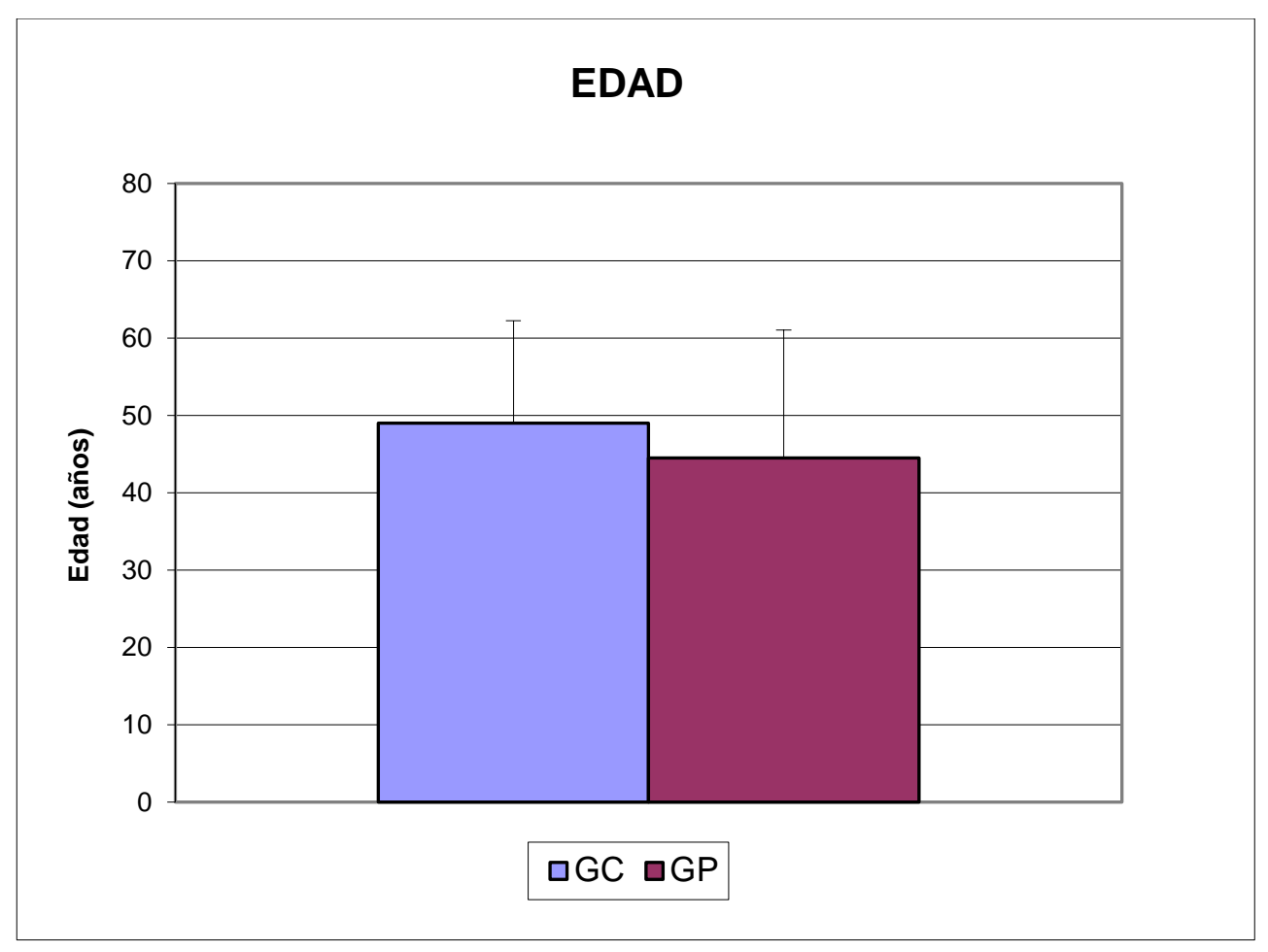

Figura 37. Comparación de los valores medios de edad entre GC y GP. 


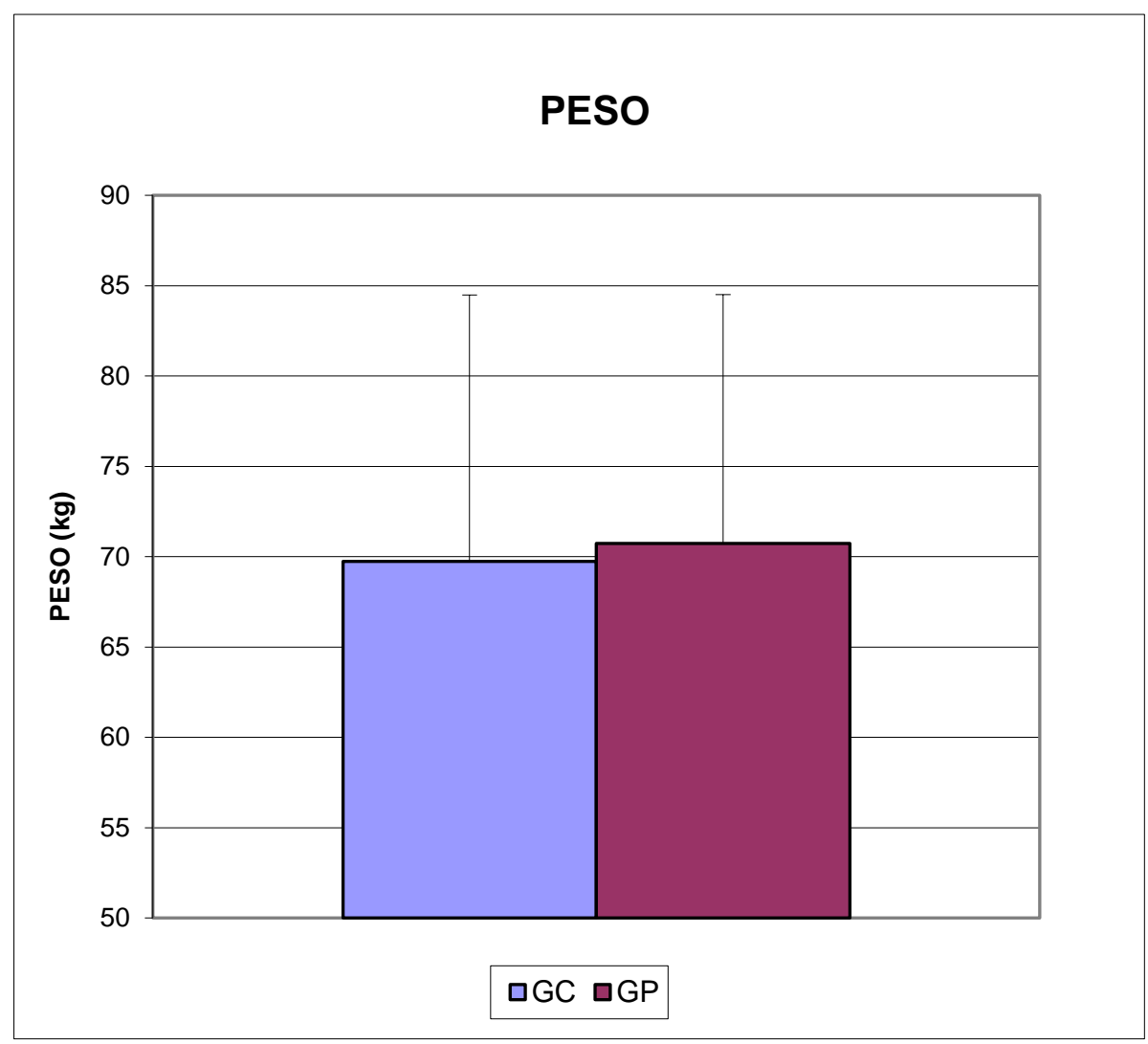

Figura 38. Comparación de los valores medios de peso entre GC y GP.

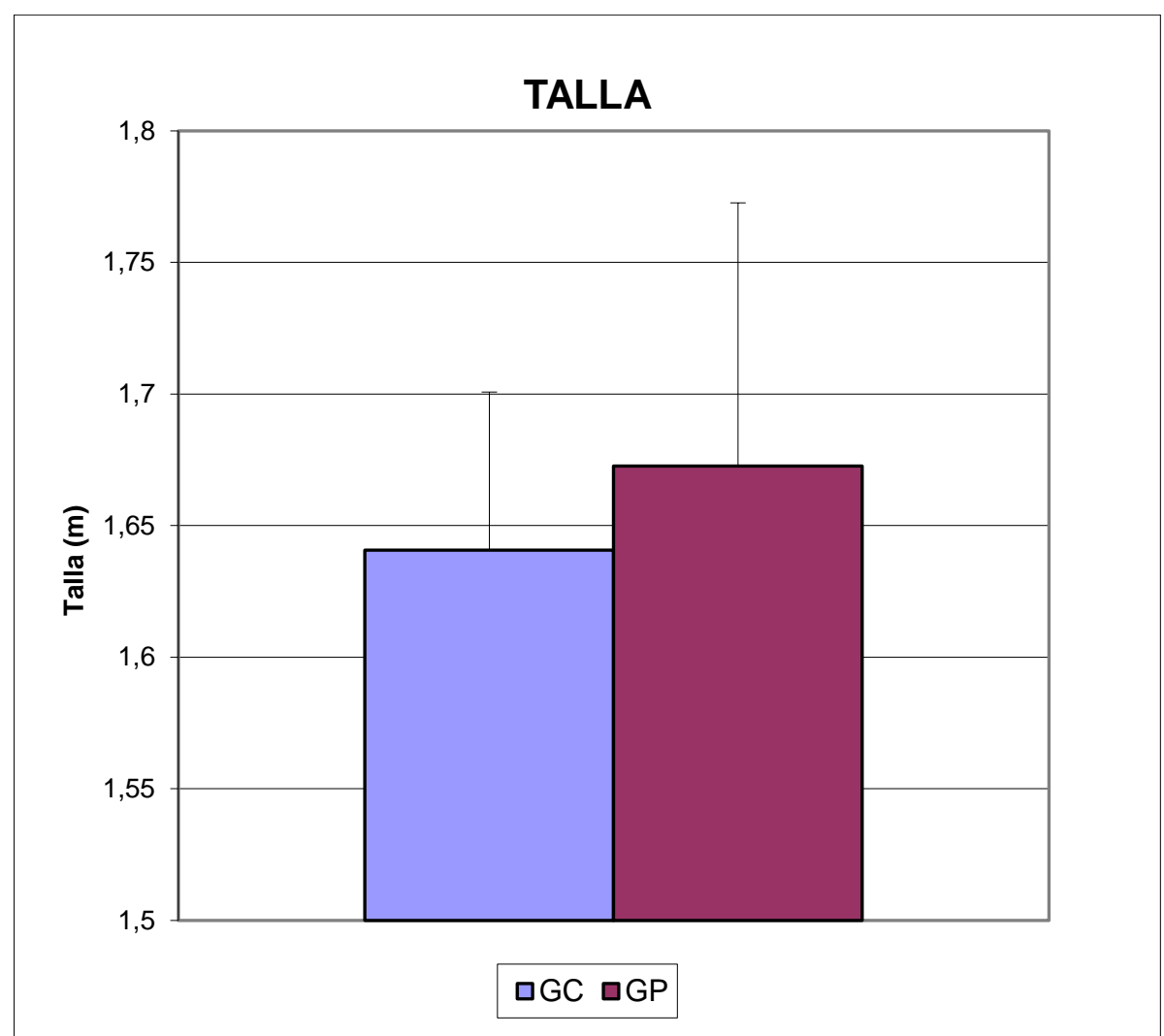

Figura 39. Comparación de los valores medios de talla entre GC y GP. 
Así mismo, el IMC indicó que un 1,5\% presentaba bajo peso, un 57\% eran normopeso, un 32,3\% mostraban sobrepeso y un 9,3\% sufrían obesidad, sin que se pudieran establecer diferencias significativas entre los porcentajes de los distintos grupos.

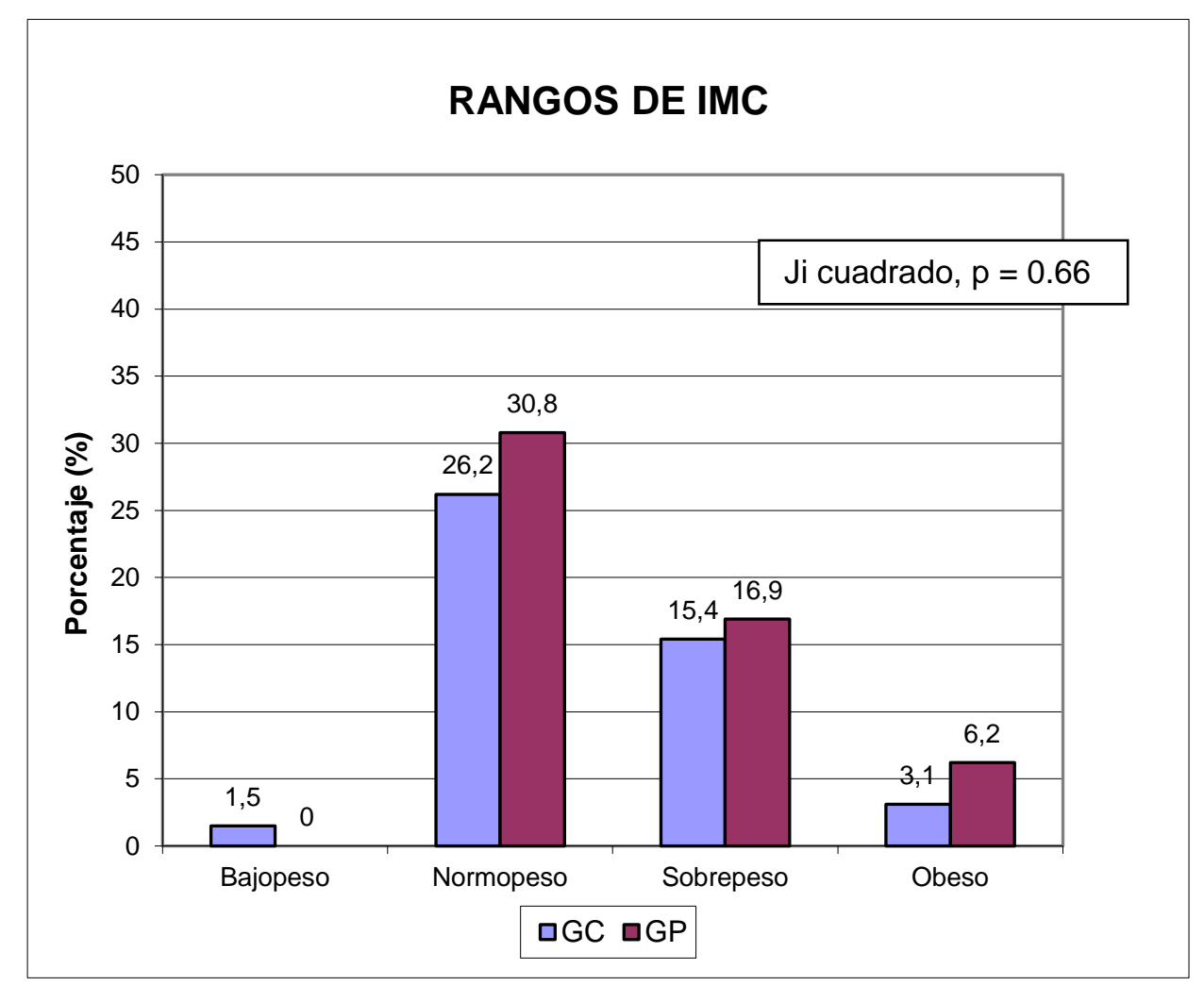

Figura 40. Distribución porcentual de los rangos de IMC por grupos. 


\section{V.2.2. Análisis de las diferentes variables del estudio GC vs GP.}

V.2.2.1. Análisis del dolor mediante la EVA.

En la Tabla 5 y en la Figura 41 se muestran los valores medios obtenidos en la Escala Visual Analógica del dolor (EVA) y su evolución durante el estudio.

- Análisis intergrupo

Antes del tratamiento, el grado de dolor era similar en ambos grupos, encontrándose dentro de un rango moderado (entre 4 y 7 puntos). Después del tratamiento, los pacientes del GP mostraban menos dolor (ligero) que los del GC (ligero-moderado). Esa diferencia se mantuvo en las fases 2 y 3.

- Análisis de la evolución intragrupo

Partiendo de valores semejantes, en la Fase 1 el dolor disminuyó en ambos grupos de forma significativa, aunque de forma más acentuada en el GP. El GC mostró un incremento del dolor en la Fase 2, para volver a descender en Fase 3. El GP, sin embargo, mantuvo los niveles de la Fase 1 en las Fases 2 y 3. 
Tabla 5. Grado de dolor (EVA) en los GC y GP.

\begin{tabular}{|c|c|c|c|c|c||}
\hline EVA & FASE 0 & FASE 1 & FASE 2 & FASE 3 & p intragrupo \\
\hline GC & $6,12 \pm 1,63$ & $4,22 \pm 2,03$ & $5,41 \pm 2,12$ & $4,66 \pm 2,50$ & $\begin{array}{c}\text { F0 vs F1 }<\mathbf{0 , 0 0 1} \\
\text { F0 vs F3 } \mathbf{0 , 0 1 9} \\
\text { F2 vs F3 }=\mathbf{0 , 0 2 0}\end{array}$ \\
\hline p intergrupos & 0,700 & $\mathbf{0 , 0 0 1}$ & $<\mathbf{0 , 0 0 1}$ & $\mathbf{0 , 0 0 2}$ & \\
\hline GP & $5,94 \pm 1,95$ & $2,70 \pm 1,62$ & $2,92 \pm 2,03$ & $2,92 \pm 1,88$ & $\begin{array}{l}\text { F0 vs F2 }<0, \mathbf{0 0 1} \\
\text { F0 vs F3 }<\mathbf{0 , 0 0 1}\end{array}$ \\
\hline \hline
\end{tabular}

p: Valor de significación estadística para la comparación intergrupos e intragrupos

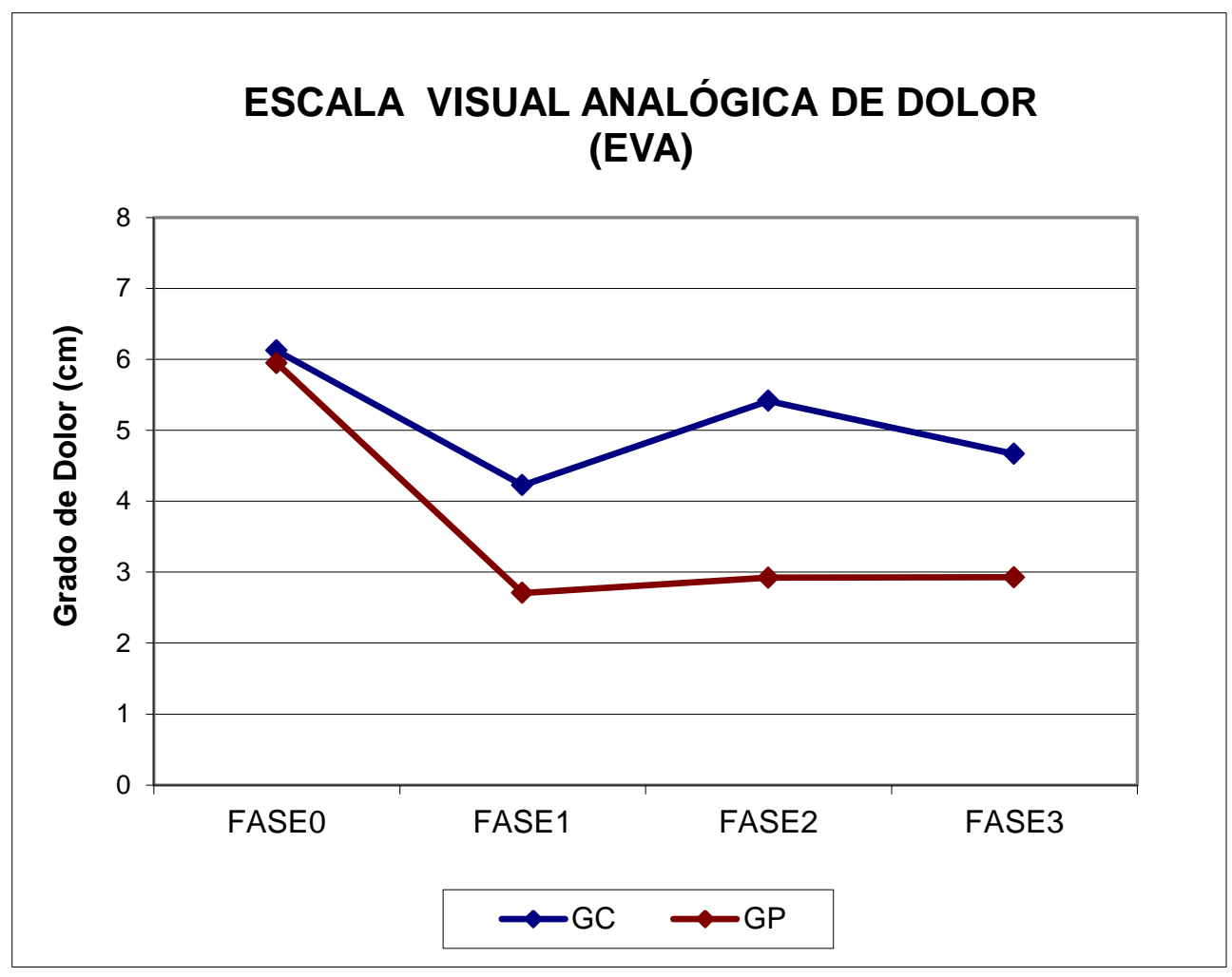

Figura 41. Evolución del grado de dolor en los GC y GP. 
V.2.2.2. Análisis de las variables de Balance Articular

\section{V.2.2.2.1. Flexión}

La Tabla 6 y la Figura 42 representan los valores obtenidos en el grado de flexión y su evolución a lo largo del estudio.

- Análisis intergrupo

Los valores de Flexión son siempre mayores en el GP que en el GC, incrementándose las diferencias en la última fase del estudio (Fase 3).

- Análisis de la evolución intragrupo

La evolución del grado de flexión es similar en ambos grupos en las fases 0,1 y 2 . Es en la Fase 3 donde los valores divergen, aumentando en el GP y descendiendo en el GC. De cualquier forma, justo después del tratamiento la ganancia de flexión es significativa solo en el GP.

\section{V.2.2.2.2. Extensión.}

La Tabla 7 y la Figura 43 informan sobre los valores obtenidos en el grado de extensión y su evolución a lo largo del estudio.

- Análisis intergrupo

Aunque los dos grupos parten de valores semejantes, en la Fase 1, al finalizar el tratamiento, el GP aumenta de forma muy significativa su grado de extensión comparado con el GC. En las fases 2 y 3 esas diferencias desaparecen.

- Análisis de la evolución intragrupo

El GC no aumenta su capacidad de extensión a lo largo de todo el estudio. Sin embargo, el GP experimenta un incremento significativo del balance articular en extensión en la Fase 1, valores que se mantienen elevados en las fases 2 y 3 comparados con la situación de partida. 
Tabla 6. Balance articular de la Flexión en los GC y GP.

\begin{tabular}{|c|c|c|c|c|c|}
\hline $\begin{array}{c}\text { FLEXIÓN } \\
\text { (cm) }\end{array}$ & FASE 0 & FASE 1 & FASE 2 & FASE 3 & p intragrupo \\
\hline GC & $4,98 \pm 1,76$ & $5,46 \pm 1,63$ & $5,31 \pm 1,37$ & $4,98 \pm 1,69$ & $p>0,050$ \\
\hline p intergrupos & $\mathbf{0 , 0 1 2}$ & $\mathbf{0 , 0 1 4}$ & $\mathbf{0 , 0 2 9}$ & $<\mathbf{0 , 0 0 1}$ & \\
\hline GP & $5,98 \pm 1,25$ & $6,40 \pm 1,34$ & $6,05 \pm 1,29$ & $6,44 \pm 1,06$ & $\begin{array}{c}\text { F0 vs } F 3=\mathbf{0 , 0 1 5} \\
\text { F2 vs F3 = } \mathbf{0 , 0 3 3}\end{array}$ \\
\hline
\end{tabular}

p: Valor de significación estadística para la comparación intergrupos e intragrupos

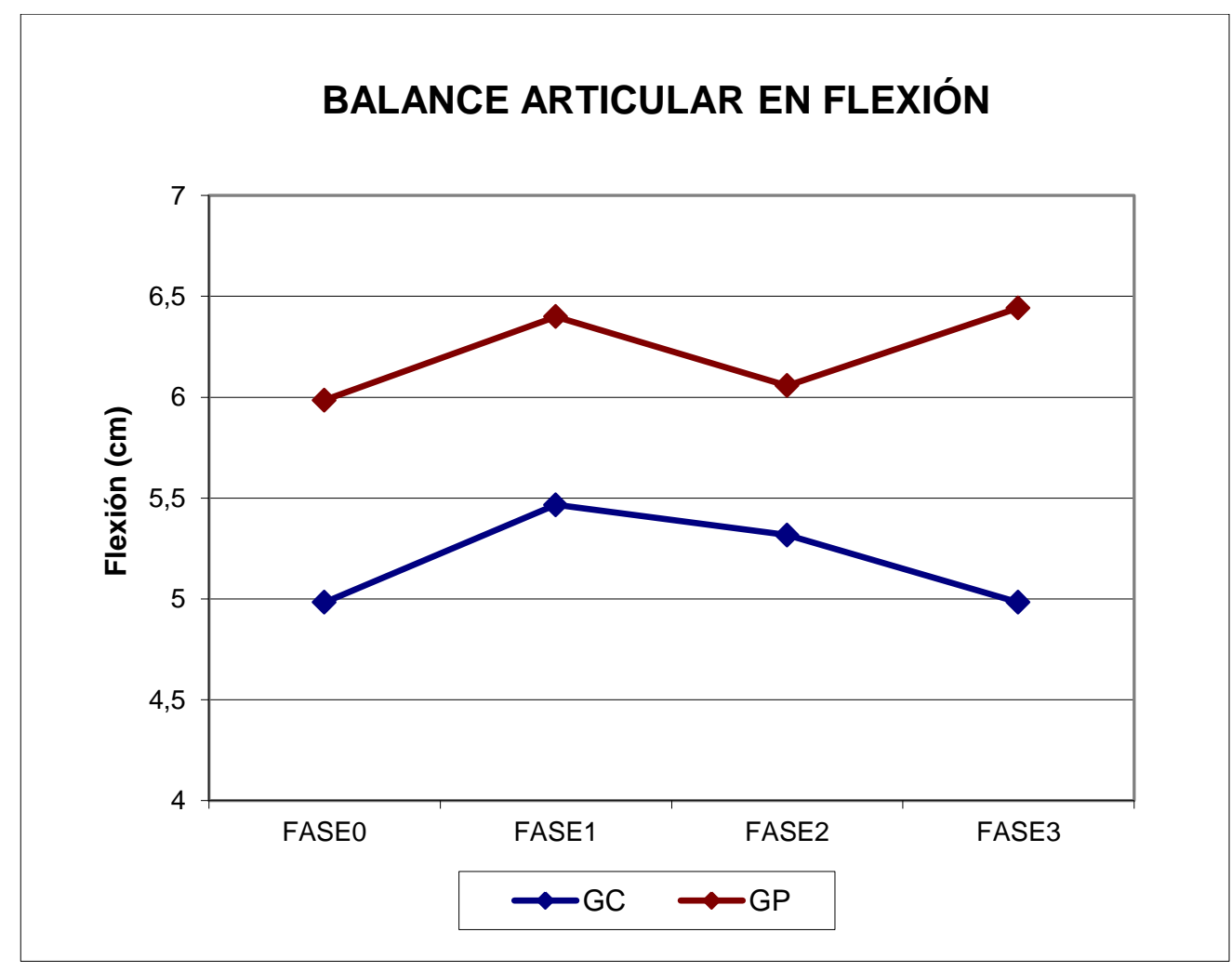

Figura 42. Evolución del balance articular en Flexión en los GC y GP. 
Tabla 7. Balance articular de la Extensión en los GC y GP.

\begin{tabular}{||c|c|c|c|c|c||}
\hline $\begin{array}{c}\text { EXTENSIÓN } \\
\text { (cm) }\end{array}$ & FASE 0 & FASE 1 & FASE 2 & FASE 3 & p intragrupo \\
\hline $\mathbf{G C}$ & $2,08 \pm 1,02$ & $2,41 \pm 1,09$ & $2,38 \pm 0,70$ & $2,50 \pm 0,90$ & $p>0,050$ \\
\hline $\mathbf{p}$ & 0,420 & $\mathbf{0 , 0 0 3}$ & 0,050 & 0,140 & \\
\hline intergrupos & $2,30 \pm 1,10$ & $3,20 \pm 0,96$ & $2,85 \pm 1,17$ & $2,84 \pm 0,92$ & $\begin{array}{c}\text { F0 vs } F 2=\mathbf{0 , 0 0 5} \\
\text { FP }\end{array}$ \\
\hline
\end{tabular}

p: Valor de significación estadística para la comparación intergrupos e intragrupos

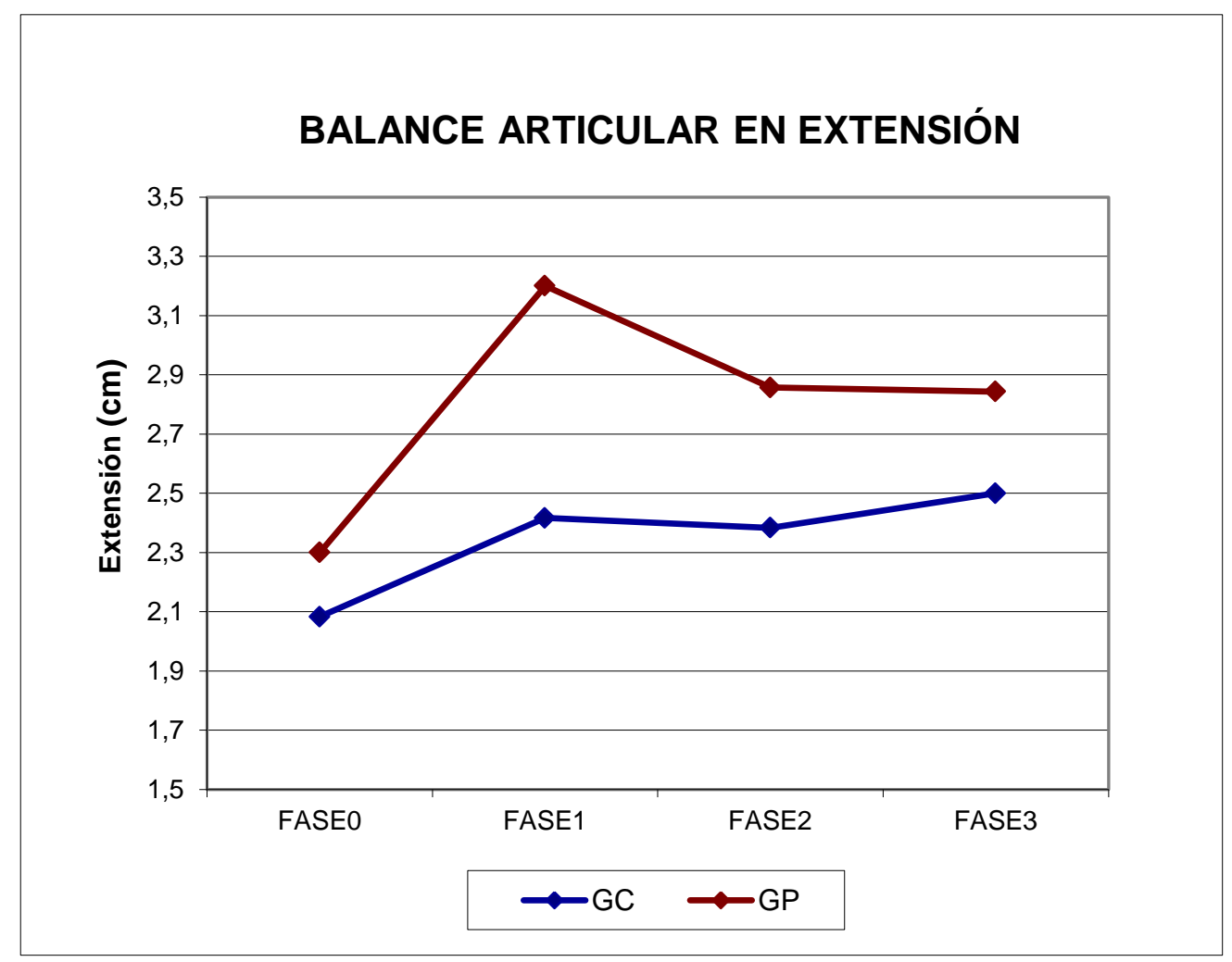

Figura 43. Evolución del balance articular de Extensión en los GC y GP. 
V.2.2.2.3. Inclinación lateral derecha (ILD).

En la Tabla 8 y en la Figura 44 se pueden analizar los valores obtenidos en el grado de ILD y su evolución durante el estudio.

- Análisis intergrupo

Ambos grupos parten de valores semejantes, pero en la Fase 1 el GP experimenta un aumento significativo comparado con el GC. Esas diferencias se mantuvieron, con distinto grado de significación en las fases 2 y 3.

- Análisis de la evolución intragrupo

Mientras que el GC mantuvo los valores de inclinación en el mismo rango a lo largo del estudio, el GP los mejoró en la Fase 1 aunque, posteriormente, volvieron a los mostrados en la Fase 0.

V.2.2.2.4. Inclinación lateral izquierda (ILI).

En la Tabla 9 y en la Figura 45 se muestran los valores obtenidos en el grado de ILI y su evolución durante el estudio.

- Análisis intergrupo

A pesar de la aleatorización de los pacientes, los grupos parten con unos valores diferentes. Tras el tratamiento, el grado de ILI sigue siendo superior en el GP. Esas diferencias se mantienen en la Fase 2 y dejan de ser significativas en la Fase 3.

- Análisis de la evolución intragrupo

La evolución de ambos grupos a lo largo del estudio es similar. Se gana inclinación lateral en la Fase 1 para luego volver a los valores basales. La ganancia que se produce justo después del tratamiento es tanto en el GP como en el GC. 
Tabla 8. Balance articular de Inclinación lateral derecha en los GC y GP.

\begin{tabular}{|c|c|c|c|c|c|}
\hline $\begin{array}{c}\text { ILD } \\
\text { (cm) }\end{array}$ & FASE 0 & FASE 1 & FASE 2 & FASE 3 & p intragrupo \\
\hline GC & $15,17 \pm 4,31$ & $16,13 \pm 4,14$ & $15,40 \pm 3,83$ & $15,03 \pm 4,41$ & $p>0,050$ \\
\hline $\mathbf{p}$ intergrupos & 0,091 & $\mathbf{0 , 0 1 2}$ & $\mathbf{0 , 0 2 2}$ & $\mathbf{0 , 0 4 5}$ & \\
\hline GP & $17,07 \pm 4,57$ & $18,71 \pm 3,86$ & $17,64 \pm 3,83$ & $17,20 \pm 4,13$ & $\begin{array}{c}\text { F1 vs } F 2=\mathbf{0 , 0 3 5} \\
F 1 \text { vs } F 3=\mathbf{0 , 0 0 8}\end{array}$ \\
\hline
\end{tabular}

p: Valor de significación estadística para la comparación intergrupos e intragrupos

INCLINACIÓN LATERAL DERECHA

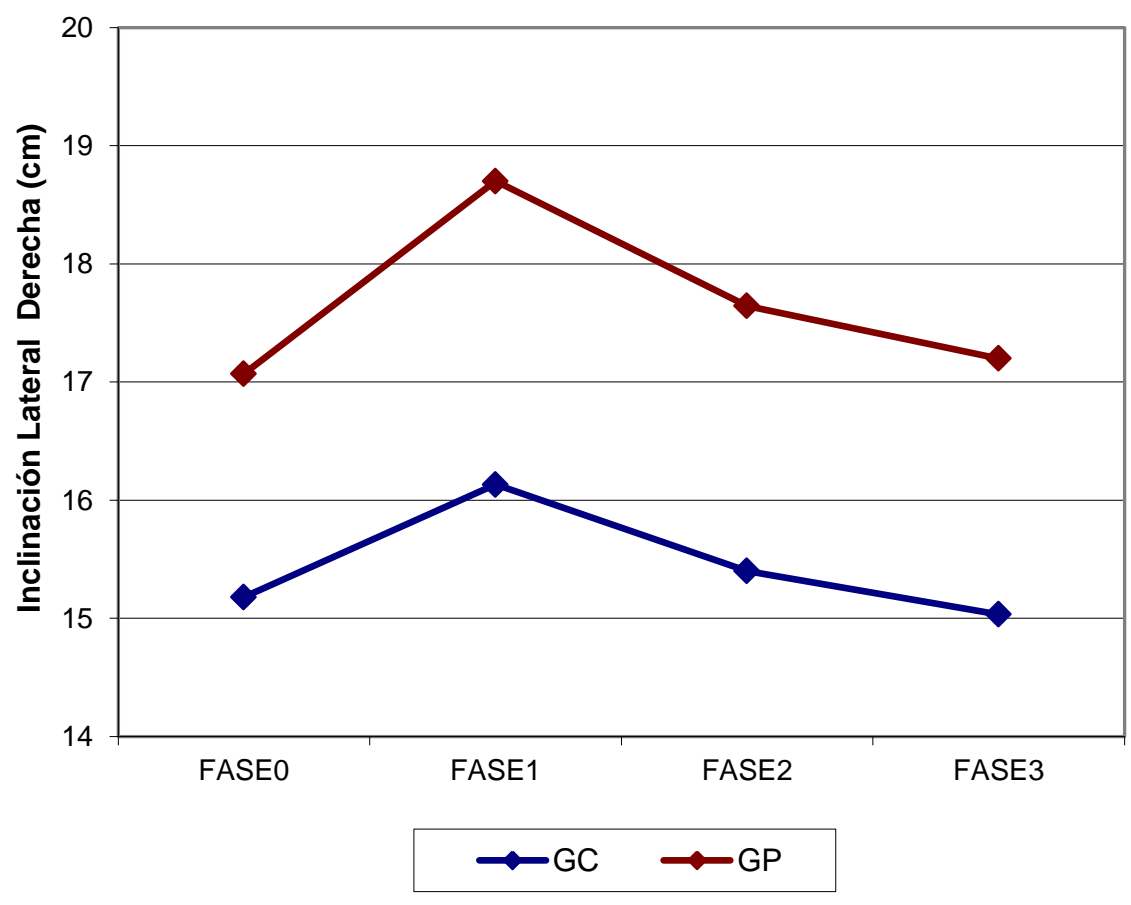

Figura 44. Evolución del balance articular de ILD en los GC y GP. 
Tabla 9. Balance articular de ILI en los GC y GP.

\begin{tabular}{|c|c|c|c|c|c||}
\hline $\begin{array}{c}\text { ILI } \\
\text { (cm) }\end{array}$ & FASE 0 & FASE 1 & FASE 2 & FASE 3 & p intragrupo \\
\hline GC & $15,15 \pm 3,79$ & $16,88 \pm 4,37$ & $15,15 \pm 4,56$ & $15,56 \pm 4,87$ & $\begin{array}{c}F 0 \text { vs F1 }=\mathbf{0 , 0 0 7} \\
F 1 \text { vs F2 }=\mathbf{0 , 0 0 2}\end{array}$ \\
\hline p intergrupos & $\mathbf{0 . 0 2 3}$ & $\mathbf{0 , 0 2 6}$ & $\mathbf{0 , 0 2 4}$ & 0,092 & \\
\hline GP & $17,59 \pm 4,49$ & $19,23 \pm 3,94$ & $17,70 \pm 4,31$ & $17,45 \pm 4,04$ & $\begin{array}{c}\text { F1 vs F2 }=\mathbf{0 , 0 1 9} \\
\text { F1 vs F3 }=\mathbf{0 , 0 0 7}\end{array}$ \\
\hline
\end{tabular}

p: Valor de significación estadística para la comparación intergrupos e intragrupos

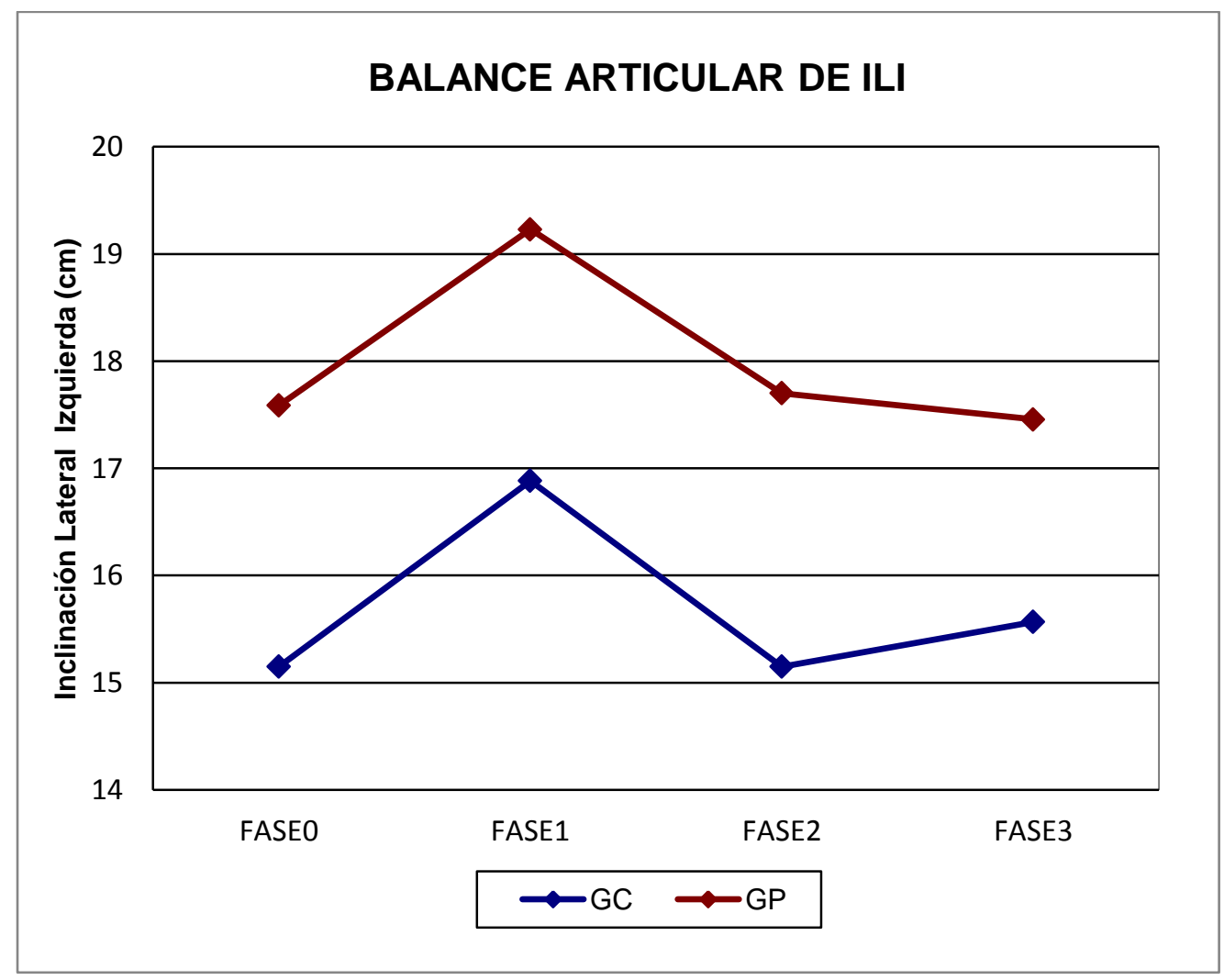

Figura 45. Evolución del balance articular de ILI en los GC y GP 
V.2.2.3. Análisis de las variables medidas mediante cuestionarios.

\section{V.2.2.3.1. Cuestionario de Roland Morris}

Ninguno de los dos grupos de estudio presentaba grandes valores de incapacidad. A pesar de ello, ambos redujeron su puntuación en el cuestionario al final del estudio.

En la Tabla 10 y en la Figura 46 se exponen los valores obtenidos en el Cuestionario de Roland Morris y los cambios observados a lo largo del estudio.

- Análisis intergrupo

De nuevo los dos grupos parten de unos valores que no difieren significativamente. Aunque la diferencia entre las medias de ambos grupos en cada fase va aumentando a lo largo de todo el estudio no llegan a ser significativas.

- Análisis de la evolución intragrupo

La evolución en ambos grupos muestra el mismo perfil, un descenso progresivo de los valores medios de la escala de Roland-Morris, mucho más significativo en el GP que muestra ya diferenicas justo después del tratamiento.

\section{V.2.2.3.2. Escala de Zung}

En todas las fases los pacientes de GC y GP se encontraron dentro del considerado rango normal de depresión.

Los valores obtenidos en la Escala de Zung y los cambios observados a lo largo del estudio se exponen en la Tabla 11 y en la Figura 47.

- Análisis intergrupo

La comparación entre las medias de ambos grupos en todas las fases no ofrece diferencias significativas.

- Análisis de la evolución intragrupo

Partiendo de valores similares la evolución final es la misma en ambos grupos, valores significativamente menores al final del estudio comparados con los de la Fase 0. Ese descenso es progresivo y más significativo en el GP que en el GC que muestra un repunte de los valores en la Fase 2. 
Tabla. 10 Valores del cuestionario de Roland-Morris en los GC y GP.

\begin{tabular}{||c|c|c|c|c|c||}
\hline $\begin{array}{c}\text { MORRIS } \\
\text { (puntuación) }\end{array}$ & FASE 0 & FASE 1 & FASE 2 & FASE 3 & p intragrupo \\
\hline GC & $9,7 \pm 4,17$ & $8,13 \pm 5,26$ & $7,56 \pm 5,19$ & $7,16 \pm 5,60$ & $\begin{array}{c}\text { F0 vs F2 }=\mathbf{0 , 0 0 9} \\
\text { F0 vs F3 } \mathbf{0 , 0 1 1}\end{array}$ \\
\hline $\begin{array}{c}\text { p } \\
\text { intergrupos }\end{array}$ & 0,400 & 0,170 & 0,130 & 0,230 & \\
\hline GP & $8,57 \pm 5,99$ & $6,25 \pm 5,47$ & $5,45 \pm 5,73$ & $5,45 \pm 5,78$ & $\begin{array}{c}\text { F0 vs F1 }<\text {.0,001 } \\
\text { Fo vs F3 }<\mathbf{0 , 0 0 1}\end{array}$ \\
\hline \hline
\end{tabular}

p: Valor de significación estadística para la comparación intergrupos e intragrupos

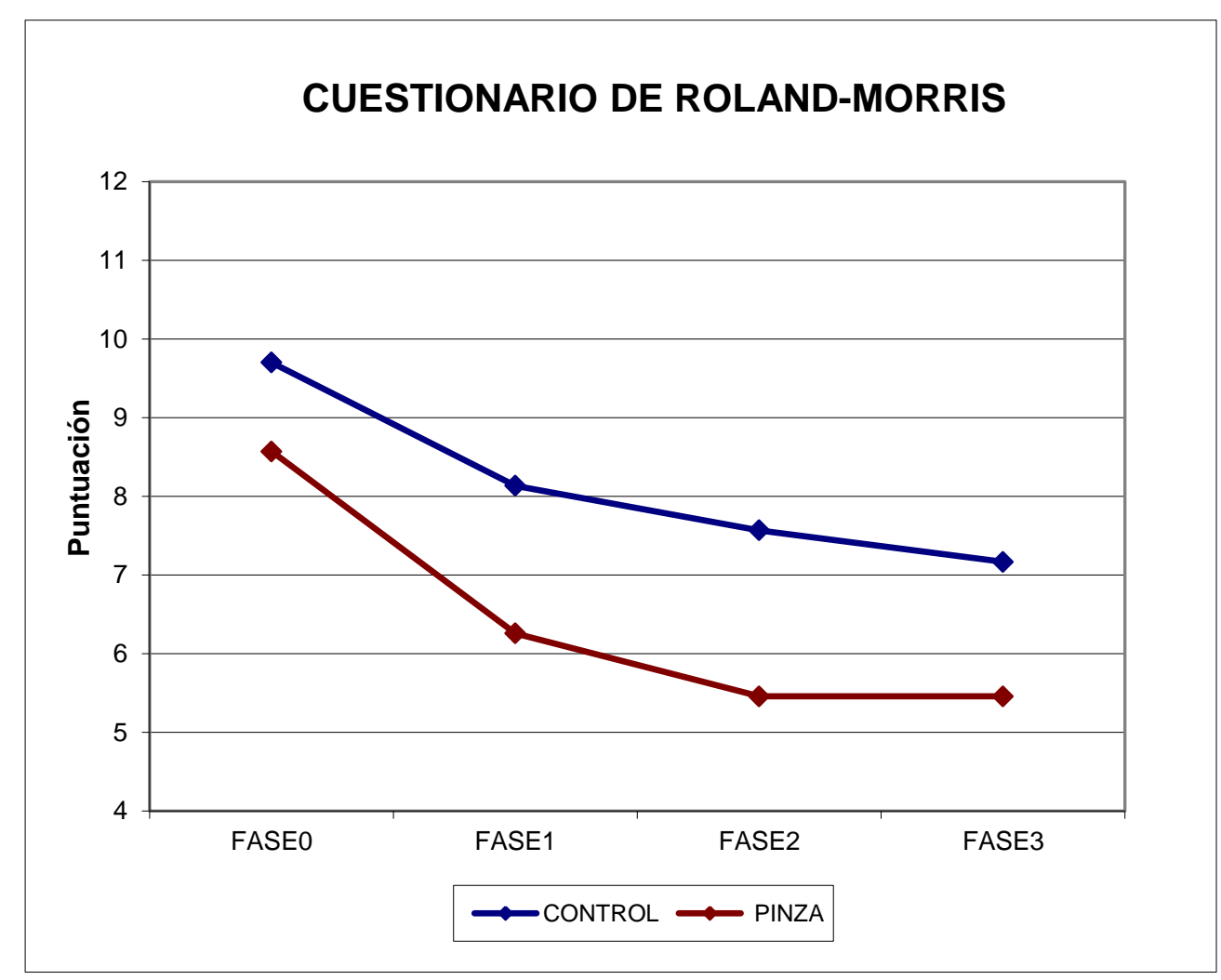

Figura 46. Evolución de los valores obtenidos en el cuestionario de RolandMorris en los GC y GP. 
Tabla 11. Valores del cuestionario de de ZUNG en los GC y GP.

\begin{tabular}{|c|c|c|c|c|c|}
\hline $\begin{array}{c}\text { ZUNG } \\
\text { (puntuación) }\end{array}$ & FASE 0 & FASE 1 & FASE 2 & FASE 3 & p intragrupo \\
\hline GC & $36,70 \pm 10,14$ & $34,20 \pm 8,91$ & $36,40 \pm 10,10$ & $32,93 \pm 9,48$ & $\begin{array}{c}F 0 \text { vs F3 }=\mathbf{0 , 0 2 3} \\
F 2 \text { vs F3 }=\mathbf{0 , 0 1 1}\end{array}$ \\
\hline $\begin{array}{c}\text { p } \\
\text { intergrupos }\end{array}$ & 0,730 & 0,830 & 0,100 & 0,460 & \\
\hline GP & $35,85 \pm 9,59$ & $33,71 \pm 9,71$ & $32,28 \pm 9,81$ & $31,11 \pm 10,25$ & $\begin{array}{c}F 0 \text { vs } F 3=\mathbf{0 , 0 0 6} \\
\text { F1 vs } F 3=\mathbf{0 , 0 3 0}\end{array}$ \\
\hline
\end{tabular}

p: Valor de significación estadística para la comparación intergrupos e intragrupos

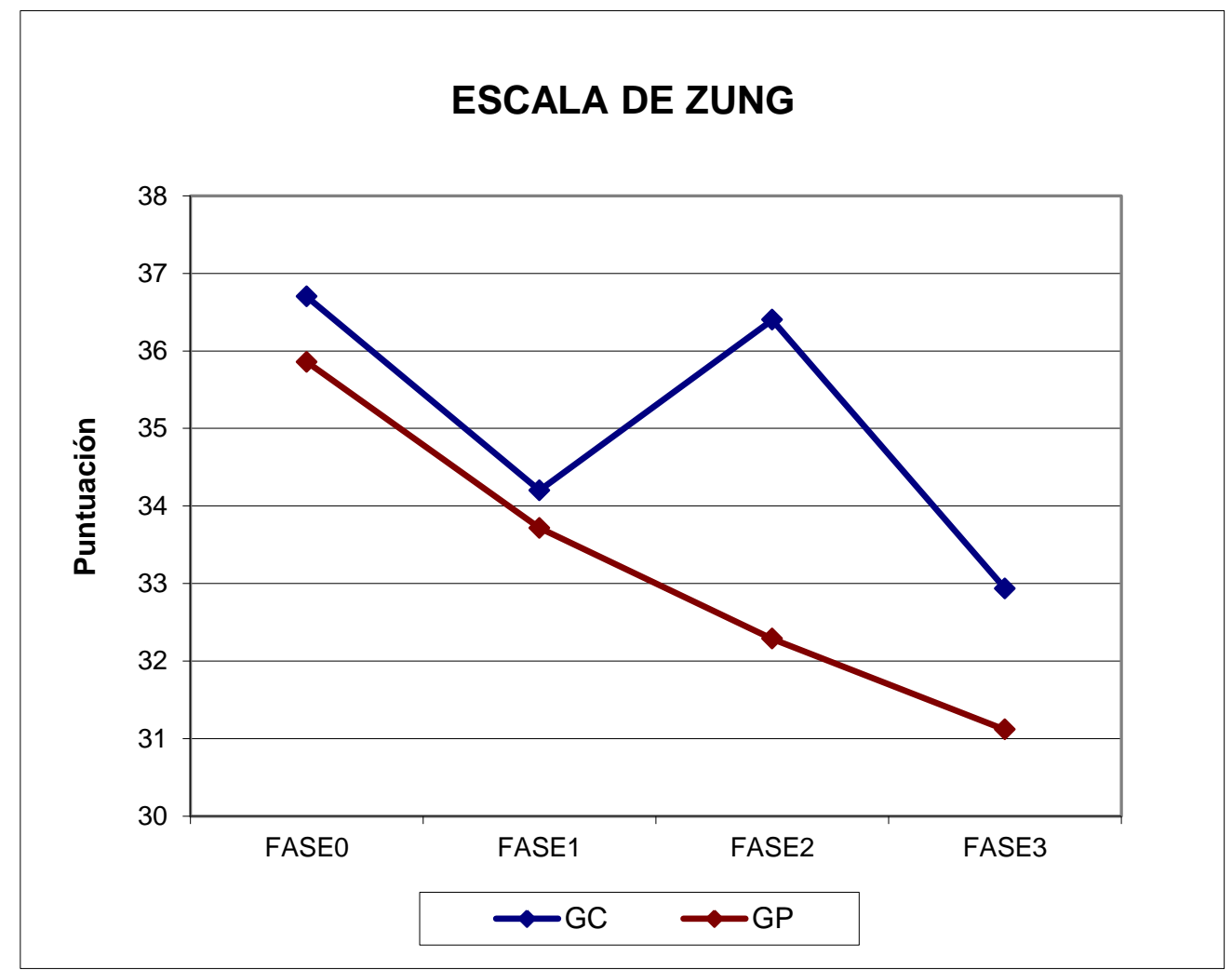

Figura 47. Evolución de los valores obtenidos en la Escala de Zung en los GC y GP. 


\section{V.2.2.3.3. Perfil de Salud de Nottingham (PSN)}

A continuación se describen los resultados obtenidos para las 6 dimensiones del Perfil de Salud del Nottingham (energía, dolor, reacciones emocionales, sueño, aislamiento social y movilidad física) y para su valor total (PSN Total)

\section{PSN ENERGÍA}

Los valores obtenidos en la dimensión PSN Energía y los cambios observados a lo largo del estudio se exponen en la Tabla 12 y en la Figura 48.

- Análisis intergrupo

En las Fases 1 y 2, esta dimensión alcanzó valores significativamente inferiores en el GP, acercándose a los del GC en la Fase 3.

- Análisis de la evolución intragrupo

La evolución que muestra el GC no ofrece diferencias significativas a lo largo de todo el proceso. En el GP, sin embargo, la Fase 2 ofrece valores significativamente inferiores al resto de las fases.

PSN DOLOR

Los valores de dolor fueron los más altos de todos los encontrados en el PSN en los dos grupos.

Los valores obtenidos en la dimensión PSN Dolor y los cambios observados a lo largo del estudio se exponen en la Tabla 13 y en la Figura 49.

- Análisis intergrupo

No existen diferencias significativas entre el GC y el GP en cada una de las fases, aunque los valores tienden hacia un distanciamiento en la Fase 2, estando por debajo los del GP.

- Análisis de la evolución intragrupo

En el GC los valores disminuyen progresivamente siendo las diferencias significativas entre las Fases 2 y 3 comparadas con la Fase 0 , y entre las Fases 1 y 3 . En el GP la evolución es similar pero el descenso es más pronunciado. En todas las fases los valores resultan significativamente inferiores con respecto a la Fase 0. 
Tabla 12. Valores medios de PSN ENERGÍA en los GC y GP.

\begin{tabular}{||c|c|c|c|c|c||}
\hline $\begin{array}{c}\text { PSN ENERGÍA } \\
\text { (\%) }\end{array}$ & FASE 0 & FASE 1 & FASE 2 & FASE 3 & p intragrupo \\
\hline GC & $32,22 \pm 39,61$ & $33,33 \pm 38,15$ & $30 \pm 36,46$ & $22,22 \pm 34,27$ & $P>0,050$ \\
\hline $\mathbf{p}$ & 0,150 & $\mathbf{0 , 0 2 2}$ & $\mathbf{0 , 0 0 2}$ & 0,250 & \\
intergrupos & $19,04 \pm 32,62$ & $13,33 \pm 28,23$ & $5,71 \pm 20,58$ & $13,33 \pm 27,05$ & $\begin{array}{c}F 1 \text { vs } F 2=\mathbf{0 , 0 1 9} \\
\text { GP }\end{array}$ \\
\hline
\end{tabular}

p: Valor de significación estadística para la comparación intergrupos e intragrupos

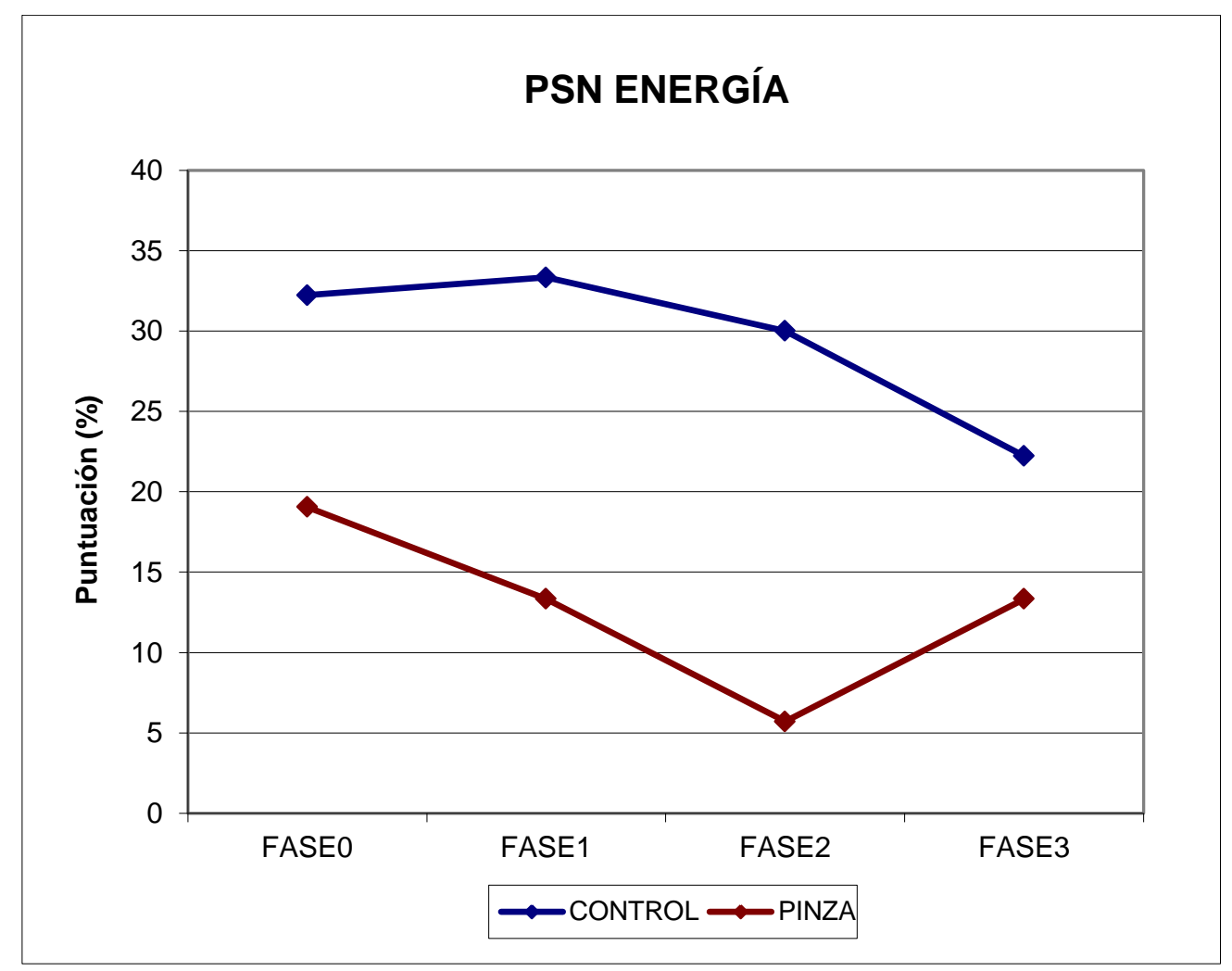

Figura 48. Evolución del PSN ENERGíA en los GC y GP. 
Tabla 13. Valores medios de PSN DOLOR en los GC y GP.

\begin{tabular}{|c|c|c|c|c|c|}
\hline $\begin{array}{c}\text { PSN DOLOR } \\
\text { (\%) }\end{array}$ & FASE 0 & FASE 1 & FASE 2 & FASE 3 & p intragrupo \\
\hline GC & $60,41 \pm 29,74$ & $51,25 \pm 29,78$ & $45,00 \pm 30,01$ & $40,00 \pm 34,80$ & $\begin{array}{c}F 0 \text { vs F3 }=\mathbf{0 , 0 0 4} \\
\text { F1 vs F3 }=\mathbf{0 , 0 4 6}\end{array}$ \\
\hline p intergrupos & 0,480 & 0,100 & 0,060 & 0,204 & \\
\hline GP & $55,35 \pm 27,50$ & $38,57 \pm 30,97$ & $30,71 \pm 29,91$ & $30,00 \pm 27,98$ & F0 vs F2 $<\mathbf{0 , 0 0 1}$ \\
\hline
\end{tabular}

p: Valor de significación estadística para la comparación intergrupos e intragrupos

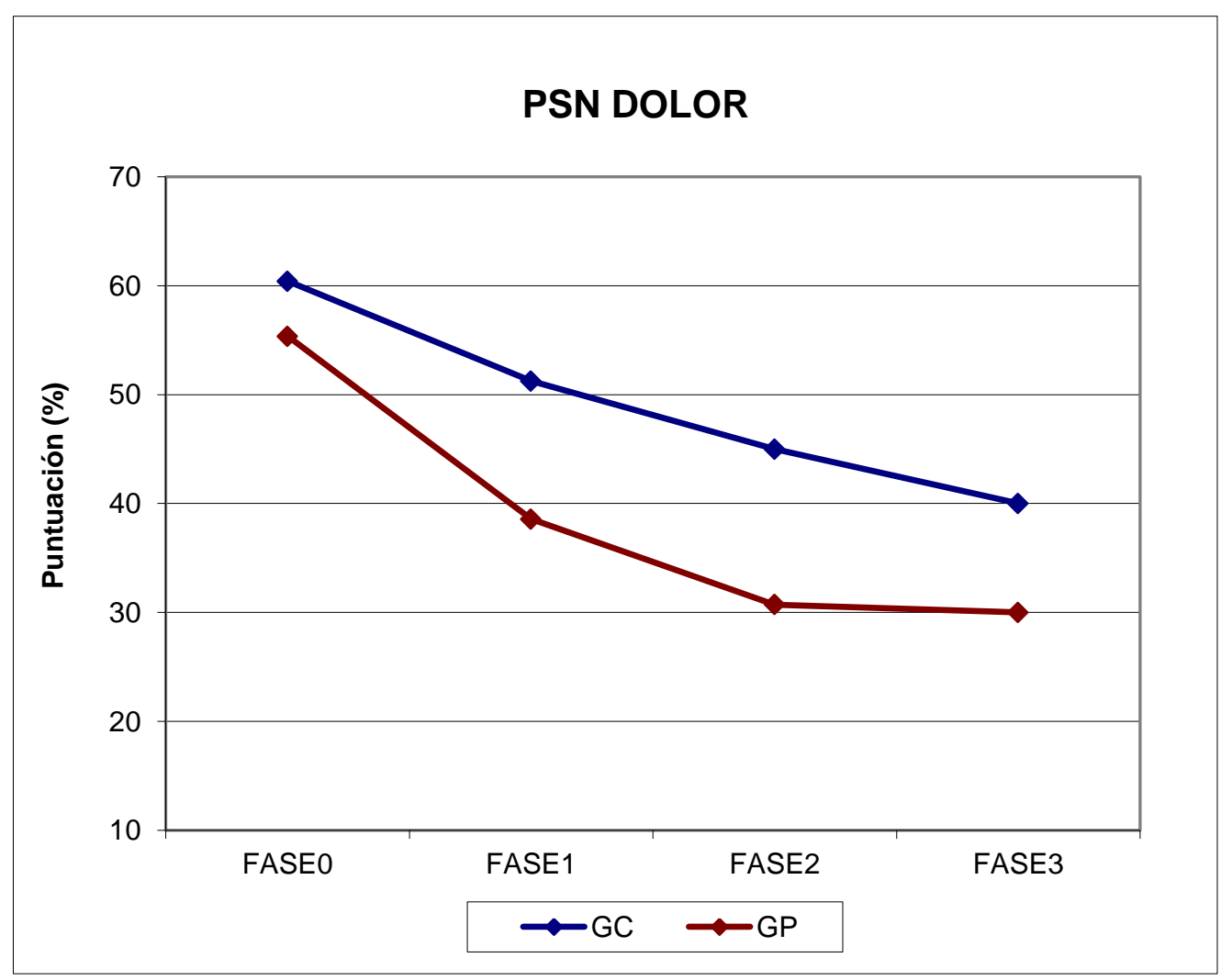

Figura 49. Evolución del PSN Dolor en los GC y GP. 


\section{PSN REACCIONES EMOCIONALES}

Los valores obtenidos en la dimensión PSN Reacciones Emocionales y los cambios observados a lo largo del estudio se exponen en la Tabla 14 y en la Figura 50.

- Análisis intergrupo

La comparación entre las medias de ambos grupos sólo son significativas en la Fase 2, con valores superiores en el GC.

- Análisis de la evolución intragrupo

En ambos grupos aparecen diferencias significativas al final del tratamiento ( $F 1$ vs F0), pero en el caso del GP, estas diferencias se mantienen a lo largo de todo el proceso.

\section{PSN SUEÑO}

Los valores obtenidos en la dimensión PSN Sueño y los cambios observados a lo largo del estudio se muestran en la Tabla 15 y en la Figura 51.

- Análisis intergrupo

Ambos grupos parten ya de medias significativamente diferentes, que desaparecen sólo en la Fase 2. Los valores son siempre inferiores en el GP.

- Análisis de la evolución intragrupo

La evolución del GC no ofrece diferencias importantes a lo largo del estudio. En el GP, sí se aprecia un descenso significativo del valor medio de la dimensión al comparar la Fase 3 con la Fase 0. 
Tabla 14. Valores medios de PSN REACCIONES EMOCIONALES en los GC y GP.

\begin{tabular}{|c|c|c|c|c|c|}
\hline $\begin{array}{c}\text { EMOCIONES } \\
\text { (\%) }\end{array}$ & FASE 0 & FASE 1 & FASE 2 & FASE 3 & p intragrupo \\
\hline GC & $22,96 \pm 24,91$ & $17,03 \pm 23,65$ & $22,96 \pm 27,97$ & $15,18 \pm 23,06$ & $\begin{array}{l}F 0 \text { vs } F 1=\mathbf{0 , 0 4 0} \\
F 0 \text { vs } F 3=\mathbf{0 , 0 3 6}\end{array}$ \\
\hline $\begin{array}{c}\mathbf{p} \\
\text { intergrupos }\end{array}$ & 0,520 & 0,500 & 0,037 & 0,380 & \\
\hline GP & $19,36 \pm 20,04$ & $13,33 \pm 21,01$ & $10,15 \pm 18,85$ & $10,47 \pm 19,79$ & $\begin{array}{l}F 0 \text { vs } F 1=\mathbf{0 , 0 4 5} \\
F 0 \text { vs } F 2=\mathbf{0 , 0 0 3} \\
F 0 \text { vs } F 3=\mathbf{0 , 0 0 1}\end{array}$ \\
\hline
\end{tabular}

p: Valor de significación estadística para la comparación intergrupos e intragrupos

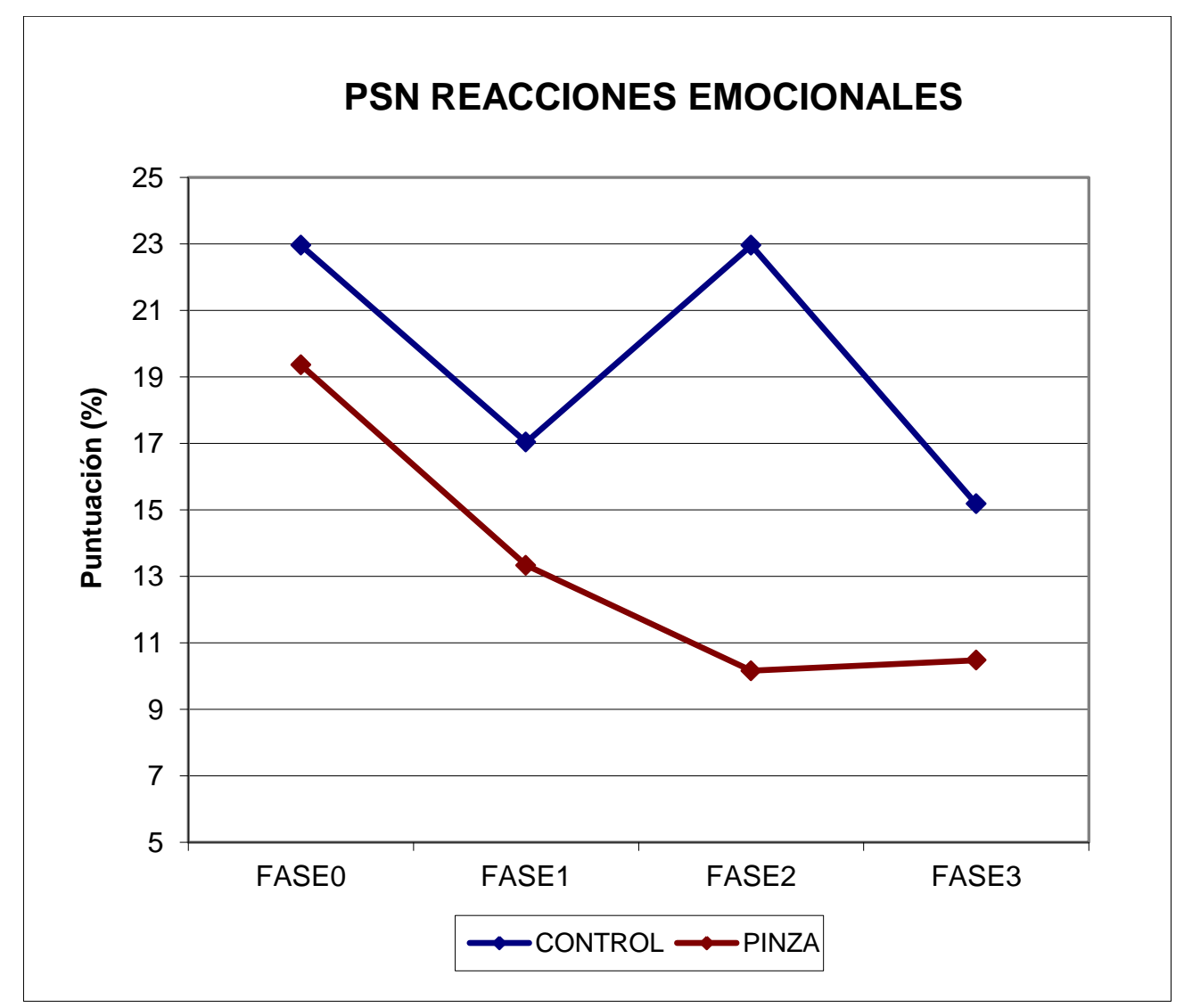

Figura 50. Evolución del PSN REACCIONES EMOCIONALES en los GC y GP. 
Tabla 15. Valores medios de PSN SUEÑO en los GC y GP.

\begin{tabular}{|c|c|c|c|c|c||}
\hline $\begin{array}{c}\text { SUEÑO } \\
\text { (\%) }\end{array}$ & FASE 0 & FASE 1 & FASE 2 & FASE 3 & p intragrupo \\
\hline GC & $48,66 \pm 30,48$ & $43,33 \pm 36,79$ & $39,33 \pm 36,19$ & $37,33 \pm 35,90$ & $p>0,05$ \\
\hline $\mathbf{p}$ & $\mathbf{0 , 0 4 0}$ & $\mathbf{0 , 0 4 5}$ & 0,062 & $\mathbf{0 , 0 3 6}$ & \\
\hline intergrupos & $32,57 \pm 30,71$ & $25,71 \pm 32,74$ & $23,42 \pm 31,24$ & $20 \pm 27,86$ & F0 vs F3 = $\mathbf{0 , 0 2 1}$ \\
\hline GP &
\end{tabular}

p: Valor de significación estadística para la comparación intergrupos e intragrupos

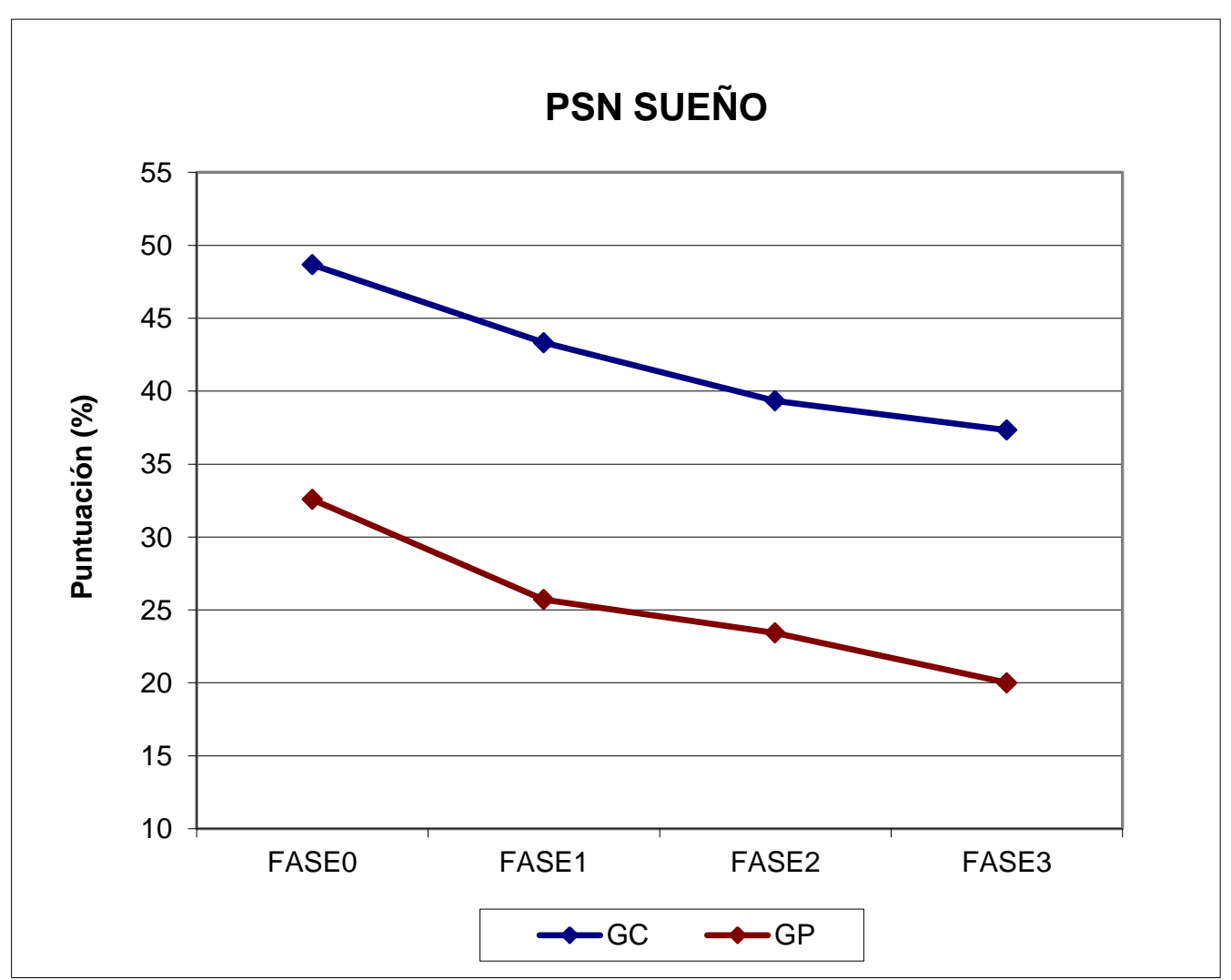

Figura 51. Evolución del PSN SUEÑO en los GC y GP. 
PSN AISLAMIENTO SOCIAL

La Tabla 16 y la Figura 52 muestran los valores obtenidos en la dimensión PSN Aislamiento Social y los cambios observados a lo largo del estudio.

- Análisis intergrupo

A pesar de que los valores medios parecen inferiores en el GP, por la amplia dispersión de los resultados no existen diferencias entre el GC y el GP en ninguna de las fases.

- Análisis de la evolución intragrupo

Así mismo, la evolución de ambos grupos no muestra valores diferentes entre las cuatro fases a lo largo del estudio.

PSN MOVILIDAD FÍSICA

Los valores obtenidos en la dimensión PSN Movilidad Física y los cambios observados a lo largo del estudio se exponen en la Tabla 17 y en la Figura 53.

- Análisis intergrupo

Sólo se aprecian diferencias significativas en la Fase 2, con valores inferiores en el GP.

- Análisis de la evolución intragrupo

En el GC no existen diferencias reseñables a lo largo de todo el proceso.

En el GP, sin embargo, la evolución muestra valores significativamente inferiores al comparar todas las fases, con la Fase 0. 
Tabla 16. Valores medios de PSN AISLAMIENTO SOCIAL en los GC y GP.

\begin{tabular}{|c|c|c|c|c|c||}
\hline $\begin{array}{c}\text { AISLAMIENTO } \\
\text { (\%) }\end{array}$ & FASE 0 & FASE 1 & FASE 2 & FASE 3 & p intragrupo \\
\hline GC & $12 \pm 19,36$ & $8,66 \pm 13,57$ & $12 \pm 19,36$ & $14,66 \pm 22,85$ & $p>0,05$ \\
\hline $\mathbf{p}$ & 0,180 & 0,650 & 0,150 & 0,112 & \\
intergrupos & $6,28 \pm 14,36$ & $6,85 \pm 16,11$ & $5,71 \pm 15$ & $4,85 \pm 16,04$ & $p>0,05$ \\
\hline GP &
\end{tabular}

p: Valor de significación estadística para la comparación intergrupos e intragrupos

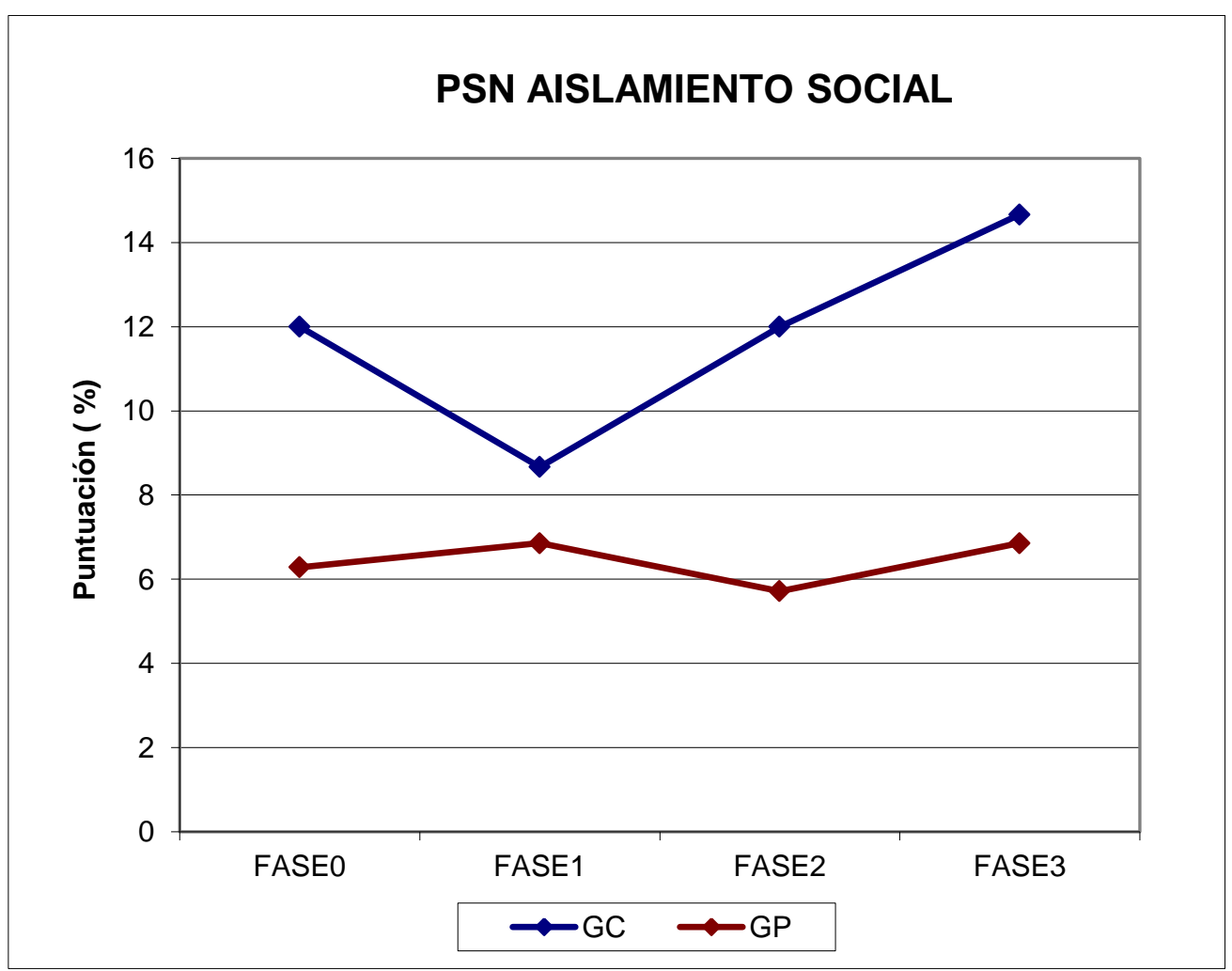

Figura 52. Evolución del PSN AISLAMIENTO SOCIAL en los GC y GP. 
Tabla 17. Valores medios de PSN MOVILIDAD FísICA en los GC y GP.

\begin{tabular}{|c|c|c|c|c|c|}
\hline $\begin{array}{c}\text { MOVILIDAD } \\
\text { (\%) }\end{array}$ & FASE 0 & FASE 1 & FASE 2 & FASE 3 & p intragrupo \\
\hline GC & $37,91 \pm 19,55$ & $34,16 \pm 19,67$ & $33,33 \pm 18,95$ & $28,75 \pm 24,81$ & $p>0,05$ \\
\hline P & 0,230 & 0,280 & $\mathbf{0 , 0 0 7}$ & 0,220 & \\
\hline intergrupos & $31,78 \pm 21,07$ & $23,21 \pm 19,44$ & $20,00 \pm 19,45$ & $21,78 \pm 20,18$ & F0 vs F2 = 0,007 \\
\hline GP & & & & F0 vs F3 = $\mathbf{0 , 0 3 0}$ \\
\hline
\end{tabular}

p: Valor de significación estadística para la comparación intergrupos e intragrupos

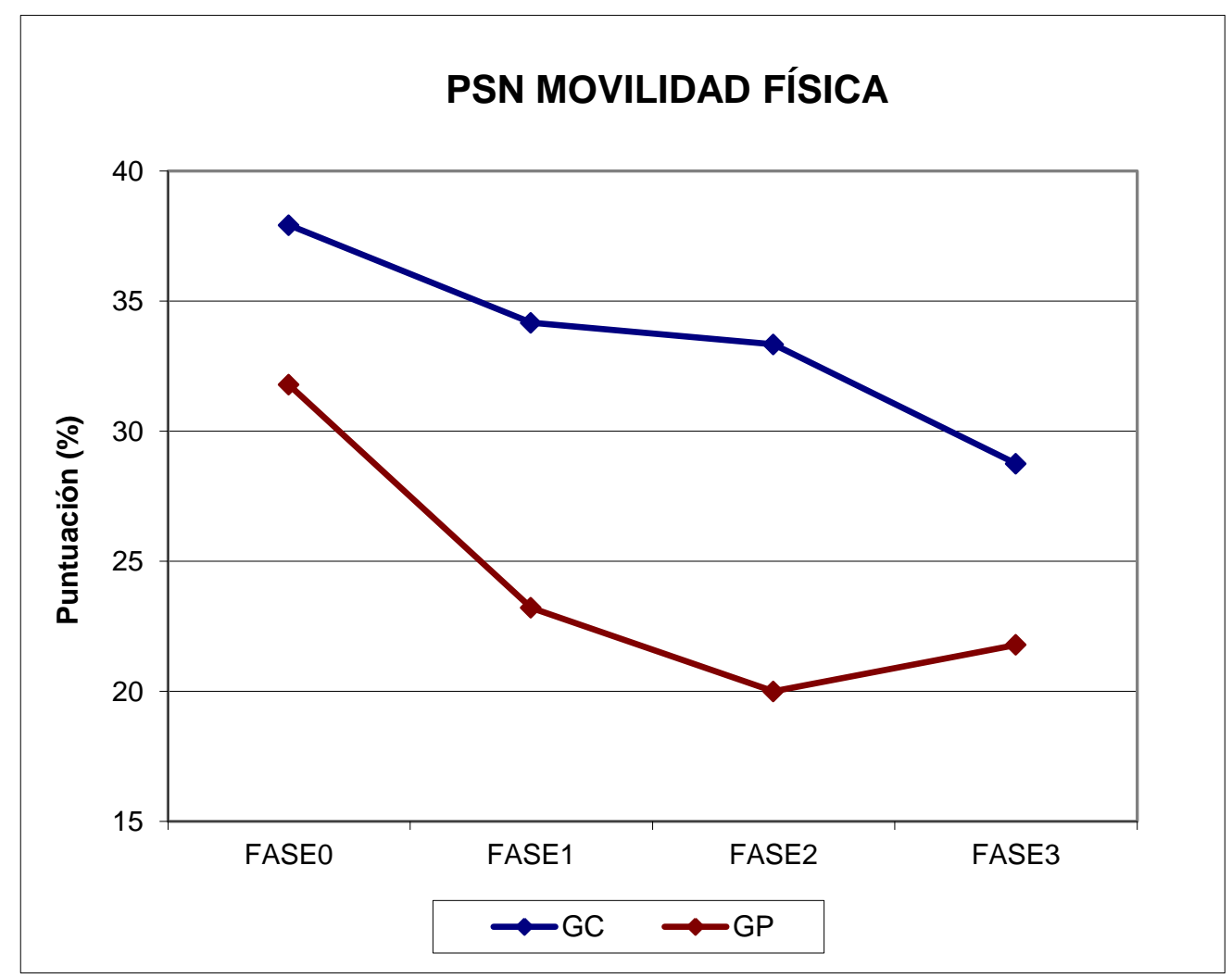

Figura 53. . Evolución del PSN MOVILIDAD FíSICA en los GC y GP. 
PSN TOTAL

Los valores obtenidos en el PSN Total y los cambios observados a lo largo del estudio se exponen en la Tabla 18 y en la Figura 54.

- Análisis intergrupo

Tras el tratamiento (Fase 1), los valores son significativamente menores en el GP, diferencias que se acentúan en la Fase 2. En la Fase 3 las diferencias existentes no son significativas.

- Análisis de la evolución intragrupo

La evolución es similar en ambos grupos. Se observa un descenso progresivo de los valores a lo largo del estudio, que es muy significativo en el GP ya en la Fase 1. El descenso en el GC no es tan pronunciado.

Todas las preguntas que integraban la parte II del PSN no arrojaron diferencias significativas ni en la parte global (con hombres y mujeres juntos) ni en la separación posterior por sexos, por lo que se decidió no incluirlas para no ser repetitivos en todos los resultados. 
Tabla 18. Valores medios de PSN TOTAL en los GC y GP.

\begin{tabular}{||c|c|c|c|c|c||}
\hline $\begin{array}{c}\text { PSN TOTAL } \\
\text { (\%) }\end{array}$ & FASE 0 & FASE 1 & FASE 2 & FASE 3 & p intragrupo \\
\hline GC & $35,69 \pm 18,83$ & $31,29 \pm 20,18$ & $30,43 \pm 21,31$ & $26,35 \pm 21,69$ & $\begin{array}{c}F 0 \text { vs F2 }=\mathbf{0 , 0 4 4} \\
F 0 \text { vs F3 }=\mathbf{0 , 0 1 1}\end{array}$ \\
\hline p intergrupos & 0,070 & $\mathbf{0 , 0 2 6}$ & $\mathbf{0 , 0 0 3}$ & 0,062 & \\
\hline GP & $27,40 \pm 18,06$ & $20,17 \pm 19,18$ & $15,95 \pm 16,79$ & $17,07 \pm 17,70$ & $\begin{array}{c}\text { F0 vs F2 }<\mathbf{0 , 0 0 1} \\
\text { F0 vs F3 }<\mathbf{0 , 0 0 1}\end{array}$ \\
\hline
\end{tabular}

p: Valor de significación estadística para la comparación intergrupos e intragrupos

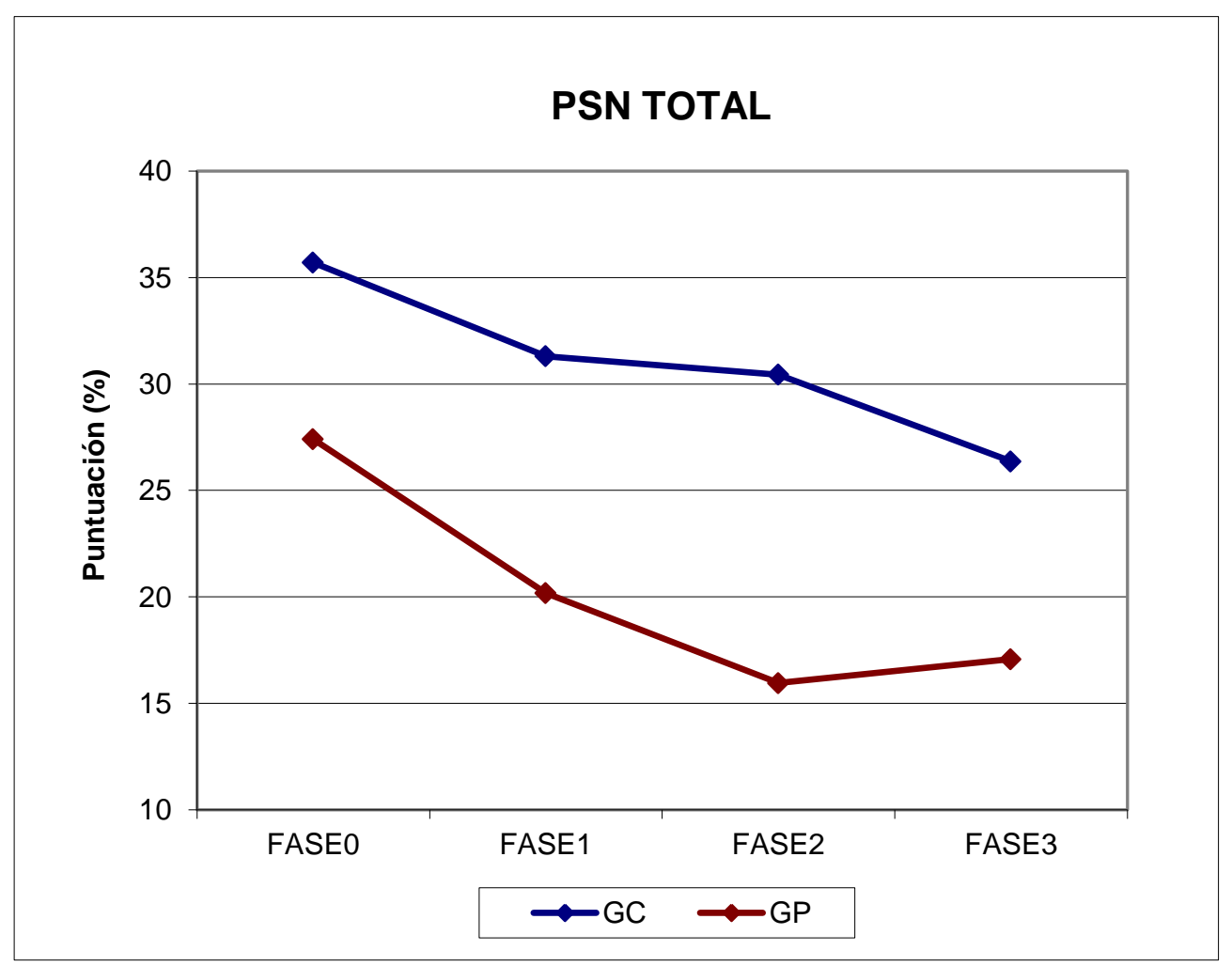

Figura 54. Evolución del PSN TOTAL en los GC y GP. 


\section{V.2.3. Análisis de las variables en los diferentes grupos (GC y GP) y en} cada una de las fases, en función del sexo

\section{V.2.3.1. Variables antropométricas.}

En la fase inicial de recogida de datos, aparecen diferencias entre los hombres del GC y GP en la talla. Igualmente, el peso y la talla son diferentes comparando los grupos de Hombres con los de Mujeres tanto del GC como del GP.

Tabla 19. Comparación de las variables de edad y antropométricas por grupos y por sexos antes del tratamiento (Fase 0).

\begin{tabular}{|c|c|c|c|c|}
\hline FASE 0 & EDAD & PESO & TALLA & IMC \\
\hline GC HOMBRE & $54,50 \pm 12,70$ & $74,10 \pm 8,97$ & $1,69 \pm 0,05$ & $25,88 \pm 2,49$ \\
\hline p GC vs GP (Hombre) & 0,158 & 0,115 & $\mathbf{0 , 0 3 3}$ & 0,927 \\
\hline GP HOMBRE & $44,15 \pm 19,34$ & $80,38 \pm 11,72$ & $1,76 \pm, 093$ & $25,71 \pm 3,03$ \\
\hline GC MUJER & $46,25 \pm 12,96$ & $67,55 \pm 16,69$ & $1,61 \pm 0,048$ & $25,79 \pm 5,54$ \\
\hline p GC vs GP (Mujer) & 0,737 & 0,743 & 0,982 & 0,339 \\
\hline GP MUJER & $44,77 \pm 15,11$ & $65,04 \pm 11,68$ & $1,61 \pm 0,068$ & $24,89 \pm 4,06$ \\
\hline p Hombre vs Mujer & 0,109 & $\mathbf{0 , 0 1 1}$ & $\mathbf{0 , 0 0 1}$ & 0,397 \\
\hline $\begin{array}{c}\text { (GC) } \\
\text { p Hombre vs Mujer }\end{array}$ & 0,917 & $<0,001$ & $<0,001$ & 0,319 \\
\hline (GP) & & & & \\
\hline
\end{tabular}


V.2.3.2. Análisis del dolor mediante la EVA.

Los resultados se pueden observar en la Tabla 20 y en la Figura 55. Se observa un dolor moderado en ambos sexos y en todas las fases, a excepción de la Fase 1 en hombres GP, que es ligero.

Comparación entre Hombres GC y Hombres GP

Los hombres del GP mostraron niveles de dolor inferiores a los del grupo control en todas las fases posteriores al tratamiento.

Comparación entre Mujeres GC y Mujeres GP

En las mujeres el resultado fue similar, los niveles de dolor fueron inferiores en el GP en las fases 1, 2 y 3, con niveles de significación incluso superiores a los del hombre

Comparación entre Hombres y Mujeres, GC

Las mujeres expresan mayor dolor que los hombres, en la Fase 2.

Comparación entre Hombres y Mujeres, GP

El dolor fue superior en las mujeres tanto antes como inmediatamente después del tratamiento. Las diferencias desaparecieron en las fases 2 y 3.

Evolución de Hombres GC en las diferentes fases

No existen diferencias significativas a lo largo de las fases.

Evolución de los Hombres GP en las diferentes fases

El dolor disminuye después del tratamiento, y se mantiene en valores significativamente inferiores hasta el final del estudio.

Evolución de Mujeres GC en las diferentes fases

El dolor experimentado disminuye de forma significativa en la Fase 1, para volver a incrementarse en la Fase 2.

Evolución de Mujeres GP en las diferentes fases

El dolor disminuye de forma muy significativa ya en la Fase 1, manteniéndose hasta la Fase 3. 
Tabla 20. Grado de dolor (EVA) en los grupos por sexos.

\begin{tabular}{|c|c|c|c|c|c|}
\hline EVA & FASE 0 & FASE 1 & FASE 2 & FASE 3 & p \\
\hline GC HOMBRE & $6,29 \pm 2,08$ & $3,65 \pm 1,85$ & $4,12 \pm 1,86$ & $4,11 \pm 2,10$ & $p>0,050$ \\
\hline p GC vs GP Hombre) & 0,066 & 0,042 & 0,047 & 0,026 & \\
\hline GP HOMBRE & $4,83 \pm 1,51$ & $1,91 \pm 1,50$ & $2,45 \pm 1,88$ & $2,64 \pm 1,37$ & $p=0,002$ \\
\hline GC MUJER & $6,04 \pm 1,41$ & $4,51 \pm 2,11$ & $6,06 \pm 1,98$ & $4,94 \pm 2,69$ & $\begin{array}{l}F 0 \text { vs } F 1=\mathbf{0 , 0 0 5} \\
F 1 \text { vs } F 2=\mathbf{0 , 0 1 6}\end{array}$ \\
\hline p GC vs GP (Mujer) & 0,286 & 0,023 & $<0,001$ & 0,018 & \\
\hline GP MUJER & $6,60 \pm 1,91$ & $3,18 \pm 1,55$ & $3,20 \pm 2,11$ & $3,10 \pm 2,14$ & $\begin{array}{l}F 0 \text { vs } F 1<\mathbf{0 , 0 0 1} \\
\text { F0 vs } F 2<\mathbf{0 , 0 0 1} \\
\text { F0 vs F3 }<\mathbf{0 , 0 0 1}\end{array}$ \\
\hline $\begin{array}{l}\text { p Hombre vs Mujer } \\
\text { (GC) }\end{array}$ & 0,700 & 0,267 & 0,015 & 0,422 & \\
\hline $\begin{array}{c}\text { p Hombre vs Mujer } \\
\text { (GP) }\end{array}$ & 0,008 & 0,024 & 0,301 & 0,578 & \\
\hline
\end{tabular}

p: Valor de significación estadística para la comparación intergrupos e intragrupos

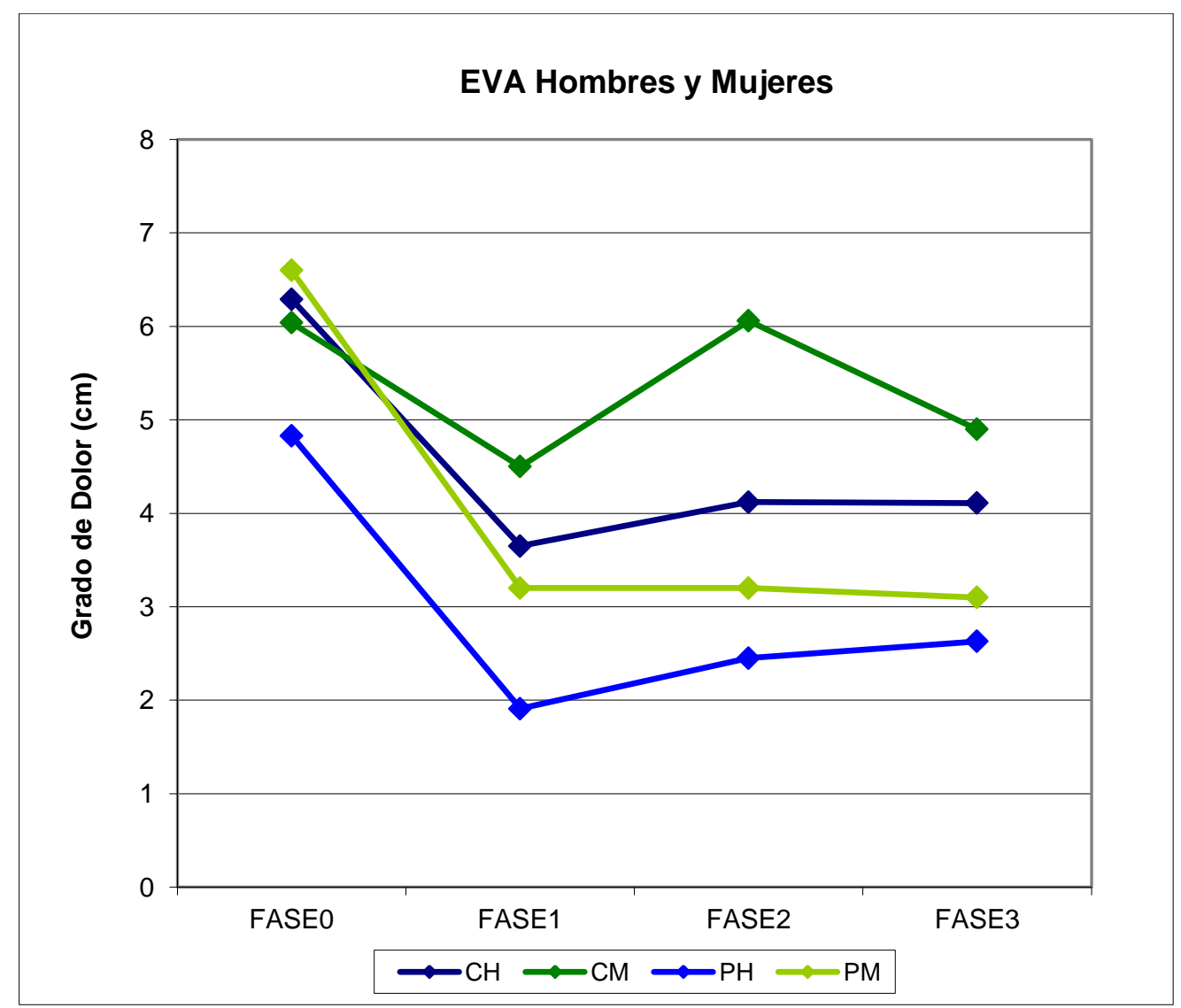

Figura 55. Evolución del grado de dolor en los grupos por sexos. 
V.2.3.3. Análisis de las variables de Balance Articular.

V.2.3.3.1. Flexión.

En la Tabla 21 y en la Figura 56 se muestran los resultados relativos al BA en flexión en las diferentes fases distribuidas por grupos y por sexos.

Comparación entre Hombres GC y Hombres GP

En un principio la flexión es mayor en el GP, disminuyendo las diferencias al finalizar el tratamiento y volviendo a surgir en la Fase 3.

Comparación entre Mujeres GC y Mujeres GP

Se muestran diferencias en la última fase donde el GP experimenta mayor capacidad de flexión.

Comparación entre Hombres y Mujeres, GC

En la Fase 2 las mujeres muestran un grado de flexión mayor que el de los hombres.

Comparación entre Hombres y Mujeres, GP

No se observan diferencias significativas en ninguna de las fases.

Evolución de Hombres GC en las diferentes fases

No aparecen diferencias significativas a lo largo de las fases.

Evolución de los Hombres GP en las diferentes fases

No se observan diferencias significativas a lo largo de las fases.

Evolución de Mujeres GC en las diferentes fases

No existen diferencias significativas a lo largo de las fases.

Evolución de Mujeres GP en las diferentes fases

Se observa una mayor flexibilidad en la Fase 3 del estudio. 
Tabla 21. Balance articular de la Flexión en los grupos por sexos.

\begin{tabular}{|c|c|c|c|c|c|}
\hline FLEXIÓN & FASE 0 & FASE 1 & FASE 2 & FASE 3 & p \\
\hline GC HOMBRE & $4,50 \pm 1,61$ & $5,00 \pm 1,58$ & $4,60 \pm 1,45$ & $4,50 \pm 1,56$ & $p>0,050$ \\
\hline p GC vs GP (Hombre) & 0,040 & 0,077 & 0,088 & 0,012 & \\
\hline GP HOMBRE & $5,76 \pm 1,16$ & $6,15 \pm 1,36$ & $5,85 \pm 1,53$ & $6,00 \pm 0,89$ & $p>0,050$ \\
\hline GC MUJER & $5,22 \pm 1,82$ & $5,70 \pm 1,65$ & $5,67 \pm 1,22$ & $5,22 \pm 1,74$ & $p>0,050$ \\
\hline p GC vs GP (Mujer) & 0,149 & 0,075 & 0,173 & 0,004 & \\
\hline GP MUJER & $6,11 \pm 1,31$ & $6,54 \pm 1,34$ & $6,18 \pm 1,15$ & $6,70 \pm 1,09$ & $\begin{array}{l}F 0 \text { vs } F 3=\mathbf{0 , 0 2 1} \\
F 2 \text { vs } F 3=\mathbf{0 , 0 2 4}\end{array}$ \\
\hline $\begin{array}{l}\text { p Hombre vs Mujer } \\
\text { (GC) }\end{array}$ & 0,214 & 0,276 & 0,041 & 0,169 & \\
\hline $\begin{array}{c}\text { p Hombre vs Mujer } \\
\text { (GP) }\end{array}$ & 0,440 & 0,533 & 0,724 & 0,091 & \\
\hline
\end{tabular}

p: Valor de significación estadística para la comparación intergrupos e intragrupos

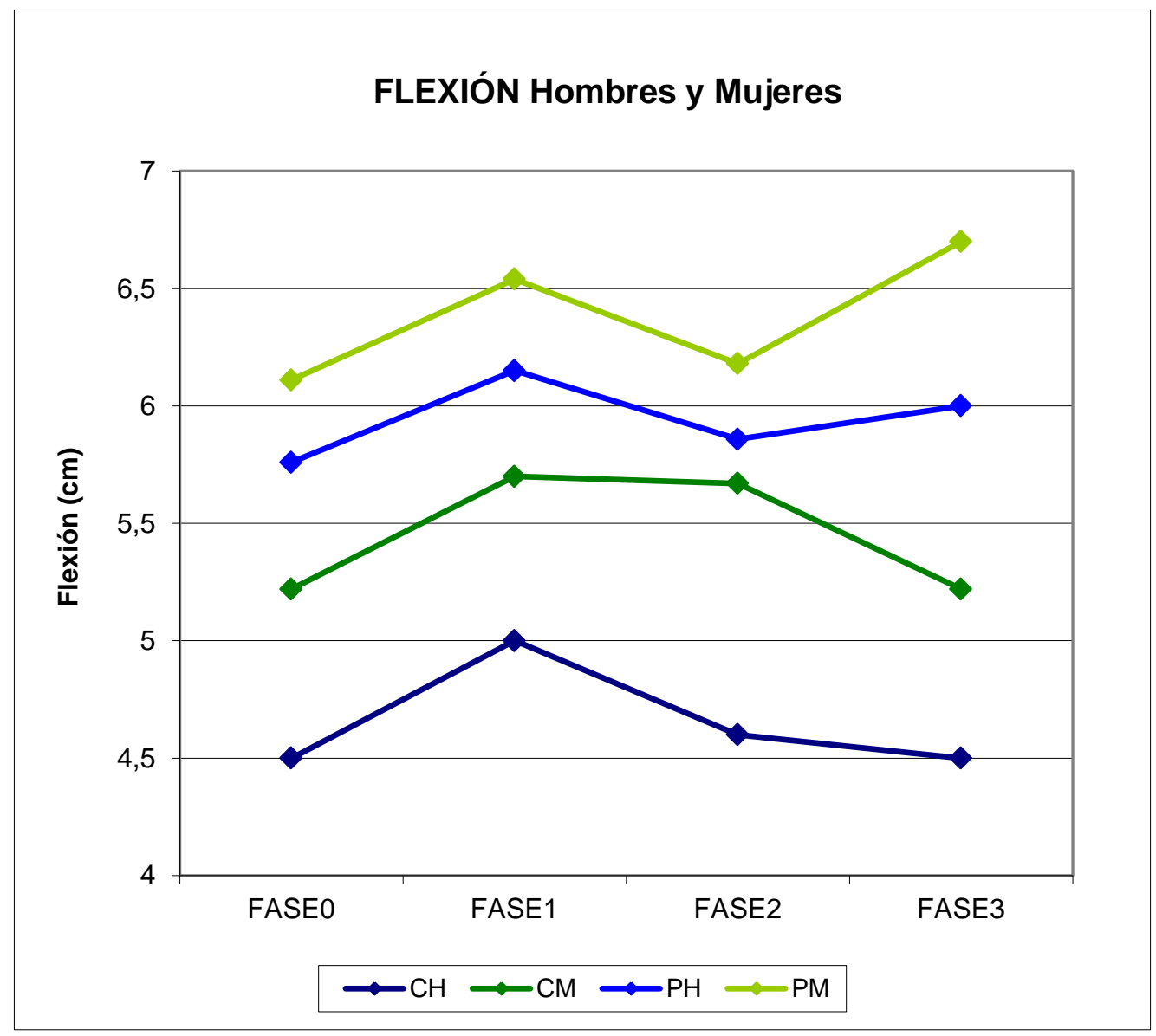

Figura 56. Evolución del balance articular en Flexión en los grupos por sexos. 


\section{V.2.3.3.2. Extensión.}

En la Tabla 22 en la Figura 57 se muestran los resultados relativos al BA en extensión en las diferentes fases distribuidas por grupos y por sexos.

Comparación entre Hombres GC y Hombres GP

Tras el tratamiento (Fase 1), el grupo de hombres GP alcanza valores más elevados de balance articular en extensión.

Comparación entre Mujeres GC y Mujeres GP

No se observan diferencias significativas en ninguna de las fases.

Comparación entre Hombres y Mujeres, GC

Las mujeres experimentan mayor grado de movilidad tras el tratamiento.

Comparación entre Hombres y Mujeres, GP

No aparecen diferencias significativas en ninguna de las fases.

Evolución de Hombres GC en las diferentes fases

No existen diferencias significativas a lo largo de las fases.

Evolución de los Hombres GP en las diferentes fases

Se encuentran valores más elevados de extensión tras el tratamiento, que se mantienen a lo largo del seguimiento.

Evolución de Mujeres GC en las diferentes fases

No se muestran diferencias significativas a lo largo de las fases.

Evolución de Mujeres GP en las diferentes fases

Después del tratamiento, las mujeres incrementan su movilidad en extensión, manteniéndola prácticamente hasta el final del estudio. 
Tabla 22. Balance articular de la Extensión en los grupos por sexos.

\begin{tabular}{|c|c|c|c|c|c|}
\hline EXTENSIÓN & FASE 0 & FASE 1 & FASE 2 & FASE 3 & p \\
\hline GC HOMBRE & $1,65 \pm 0,50$ & $1,85 \pm 0,91$ & $2,30 \pm 0,63$ & $2,45 \pm 1,06$ & $p>0,050$ \\
\hline p GC vs GP Hombre) & 0,446 & $\mathbf{0 , 0 2 0}$ & 0,446 & 0,841 & \\
\hline GP HOMBRE & $1,96 \pm 0,86$ & $3,07 \pm 0,73$ & $2,65 \pm 1,26$ & $2,54 \pm 1,01$ & $\mathbf{p}=\mathbf{0 , 0 1 1}$ \\
\hline GC MUJER & $2,30 \pm 1,14$ & $2,70 \pm 1,08$ & $2,42 \pm 0,75$ & $2,52 \pm 0,85$ & $p>0,050$ \\
\hline p GC vs GP (Mujer) & 0,586 & 0,095 & 0,072 & 0,100 & \\
\hline $\begin{array}{c}\text { GP MUJER } \\
\text { G Hombre vs Mujer } \\
\text { (GC) }\end{array}$ & 0,103 & $\mathbf{0 , 0 4 2}$ & 0,502 & 0,836 & $\mathbf{p}=\mathbf{0 , 0 4 2}$ \\
\hline $\begin{array}{c}\text { p Hombre vs Mujer } \\
\text { (GP) }\end{array}$ & 0,169 & 0,569 & 0,439 & 0,216 & \\
\hline \begin{tabular}{c} 
(GP \\
\hline
\end{tabular}
\end{tabular}

p: Valor de significación estadística para la comparación intergrupos e intragrupos

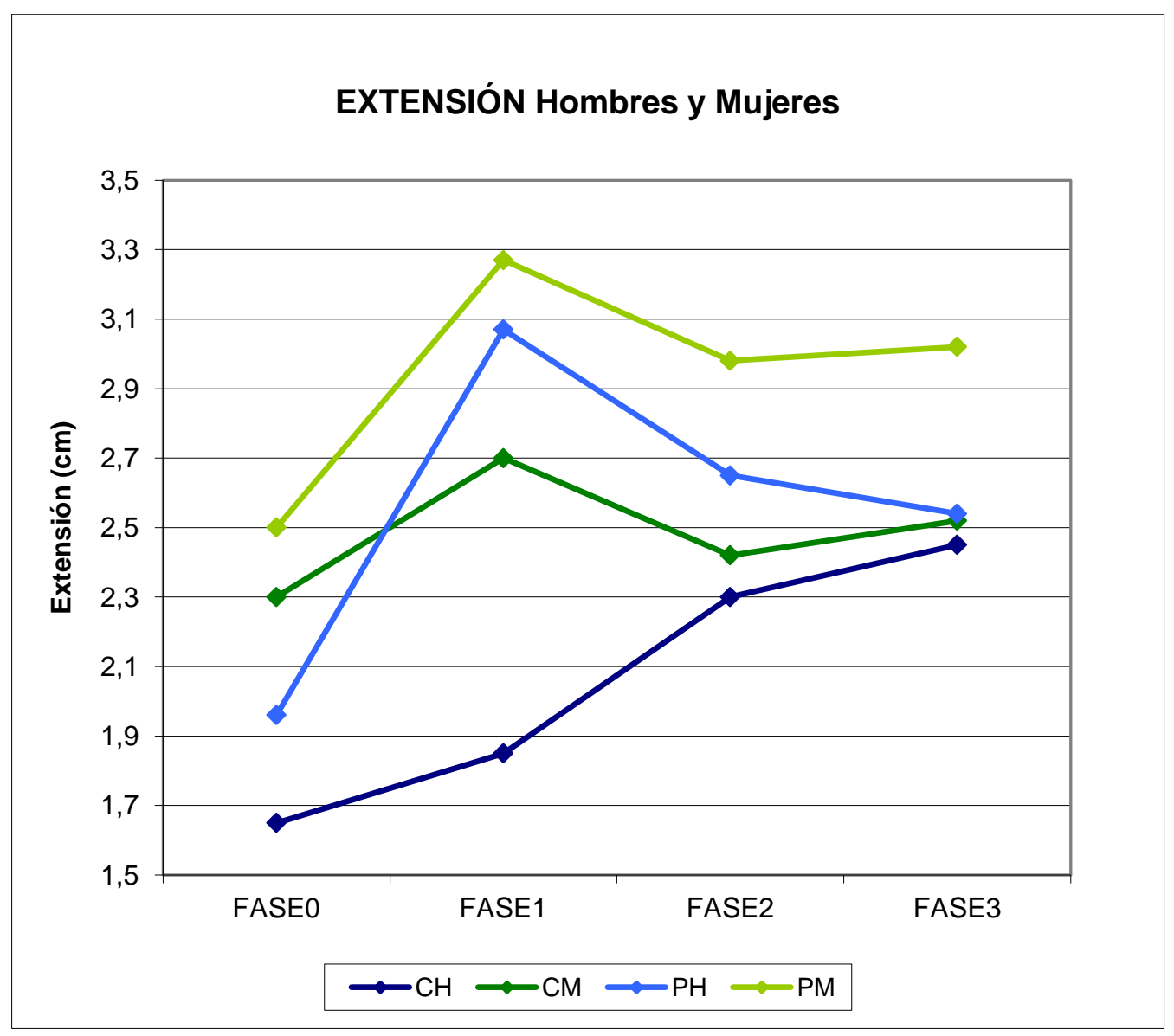

Figura 57. Evolución del balance articular de Extensión en los grupos por sexos. 
V.2.3.3.3. Inclinación Lateral Derecha.

En la Tabla 23 y en la Figura 58 se muestran los resultados relativos al BA en extensión en las diferentes fases distribuidas por grupos y por sexos.

Comparación entre Hombres GC y Hombres GP

No existen diferencias significativas en ninguna de las fases.

Comparación entre Mujeres GC y Mujeres GP

Aparece cierta tendencia a incrementar la capacidad de ILD al acabar el tratamiento, que se mantienen hasta el final, siendo las Mujeres GP quienes aumentan más su grado de movilidad.

Comparación entre Hombres y Mujeres, GC

No se observan diferencias significativas en ninguna de las fases.

Comparación entre Hombres y mujeres, GP

No aparecen diferencias significativas en ninguna de las fases.

Evolución de Hombres GC en las diferentes fases

No se muestran diferencias significativas a lo largo de las fases.

Evolución de los Hombres GP en las diferentes fases

Se produce un incremento de movilidad al acabar el tratamiento, aunque no resulta significativo.

Evolución de Mujeres GC en las diferentes fases

No se observan diferencias significativas a lo largo de las fases.

Evolución de Mujeres GP en las diferentes fases

No aparecen diferencias significativas a lo largo de las fases. 
Tabla 23. Balance articular de Inclinación Lateral Derecha en grupos por sexos.

\begin{tabular}{|c|c|c|c|c|c|}
\hline LATDCHA & FASE 0 & FASE 1 & FASE 2 & FASE 3 & p \\
\hline GC HOMBRE & $15,05 \pm 4,95$ & $16,35 \pm 5,10$ & $15,15 \pm 5,00$ & $15,20 \pm 4,93$ & $p>0,050$ \\
\hline p GC vs P (Hombre) & 0,384 & 0,116 & 0,257 & 0,410 & \\
\hline GP HOMBRE & $17,07 \pm 5,75$ & $19,77 \pm 4,85$ & $17,61 \pm 5,06$ & $17,27 \pm 5,50$ & $p>0,050$ \\
\hline GC MUJER & $15,23 \pm 4,09$ & $16,03 \pm 3,72$ & $15,52 \pm 3,25$ & $14,95 \pm 4,28$ & $p>0,050$ \\
\hline p GC vs GP (Mujer) & 0,211 & 0,057 & 0,033 & 0,064 & \\
\hline GP MUJER & $17,07 \pm 3,87$ & $18,09 \pm 3,10$ & $17,66 \pm 3,01$ & $17,16 \pm 3,21$ & $p>0,050$ \\
\hline $\begin{array}{l}\text { p Hombre vs Mujer } \\
\text { (GC) }\end{array}$ & 0,919 & 0,844 & 0,806 & 0,887 & \\
\hline $\begin{array}{l}\text { p Hombre vs Mujer } \\
\text { (GP) }\end{array}$ & 0,996 & 0,219 & 0,578 & 0,699 & \\
\hline
\end{tabular}

p: Valor de significación estadística para la comparación intergrupos e intragrupos

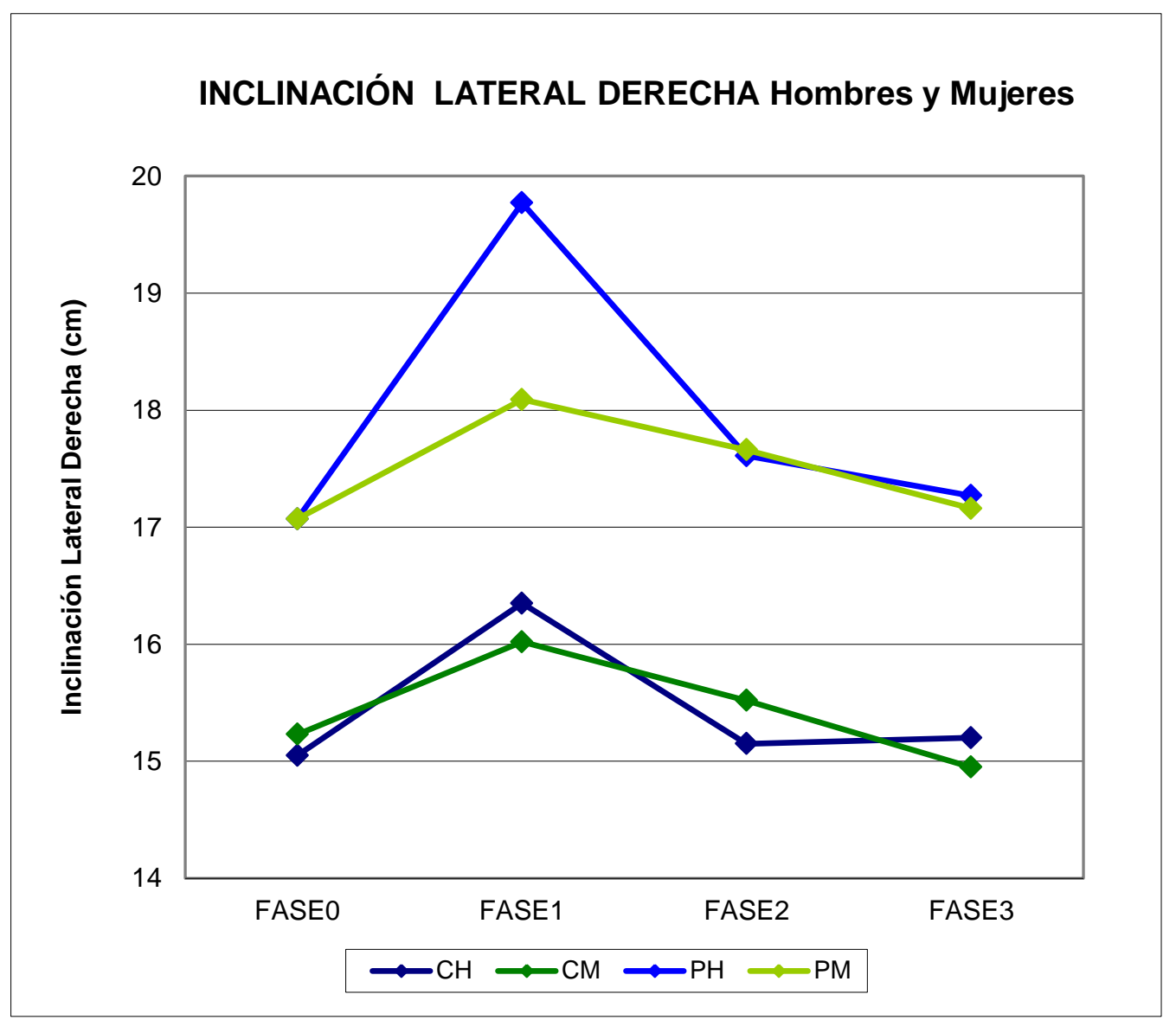

Figura 58. Evolución del balance articular de Inclinación lateral derecha en los grupos por sexos. 
V.2.3.3.4. Inclinación Lateral Izquierda

En la Tabla 24 y en la Figura 59 se muestran los resultados relativos al BA en extensión en las diferentes fases distribuidas por grupos y por sexos.

Comparación entre Hombres GC y Hombres GP

No se observan diferencias significativas en ninguna de las fases.

Comparación entre Mujeres GC y Mujeres GP

Aunque parten de valores diferentes, ambos grupos tienden a acercarse tras la aplicación del tratamiento.

Comparación entre Hombres y Mujeres, GC

No se muestran diferencias significativas en ninguna de las fases.

Comparación entre Hombres y Mujeres, GP

No existen diferencias significativas en ninguna de las fases.

Evolución de Hombres GC en las diferentes fases

No aparecen diferencias significativas a lo largo de las fases.

Evolución de los Hombres GP en las diferentes fases

No se observan diferencias significativas a lo largo de las fases.

Evolución de Mujeres GC en las diferentes fases

No se muestran diferencias significativas a lo largo de las fases.

Evolución de Mujeres GP en las diferentes fases

Una vez aplicado el tratamiento, los valores de balance articular en ILI son significativamente superiores a las fases posteriores. 
Tabla 24. Balance articular de Inclinación Lateral Izquierda en grupos por sexos.

\begin{tabular}{|c|c|c|c|c|c|}
\hline LATIZDA & FASE 0 & FASE 1 & FASE 2 & FASE 3 & p \\
\hline GC HOMBRE & $15,45 \pm 4,66$ & $17,25 \pm 4,64$ & $15,00 \pm 5,65$ & $15,55 \pm 5,67$ & $p>0,050$ \\
\hline p GC vs GP (Hombre) & 0,208 & 0,274 & 0,309 & 0,425 & \\
\hline GP HOMBRE & $17,15 \pm 6,24$ & $19,46 \pm 4,72$ & $17,54 \pm 5,89$ & $17,46 \pm 5,52$ & $p>0,050$ \\
\hline GC MUJER & $15,00 \pm 3,40$ & $16,70 \pm 4,34$ & $15,22 \pm 4,08$ & $15,57 \pm 4,59$ & $p>0,050$ \\
\hline p GC vs GP (Mujer) & $\mathbf{0 , 0 0 8}$ & 0,056 & $\mathbf{0 , 0 2 8}$ & 0,121 & \\
\hline $\begin{array}{c}\text { GP MUJER } \\
\text { p Hombre vs Mujer } \\
\text { (GC) }\end{array}$ & 0,765 & 0,751 & 0,901 & 0,990 & F1 vs F2 = 0,028 \\
\hline $\begin{array}{c}\text { p Hombre vs Mujer } \\
\text { (GP) }\end{array}$ & 0,669 & 0,793 & 0,886 & 0,997 & $\mathbf{1 7 , 4 5 \pm 3 , 0 0}$ \\
\hline
\end{tabular}

p: Valor de significación estadística para la comparación intergrupos e intragrupos

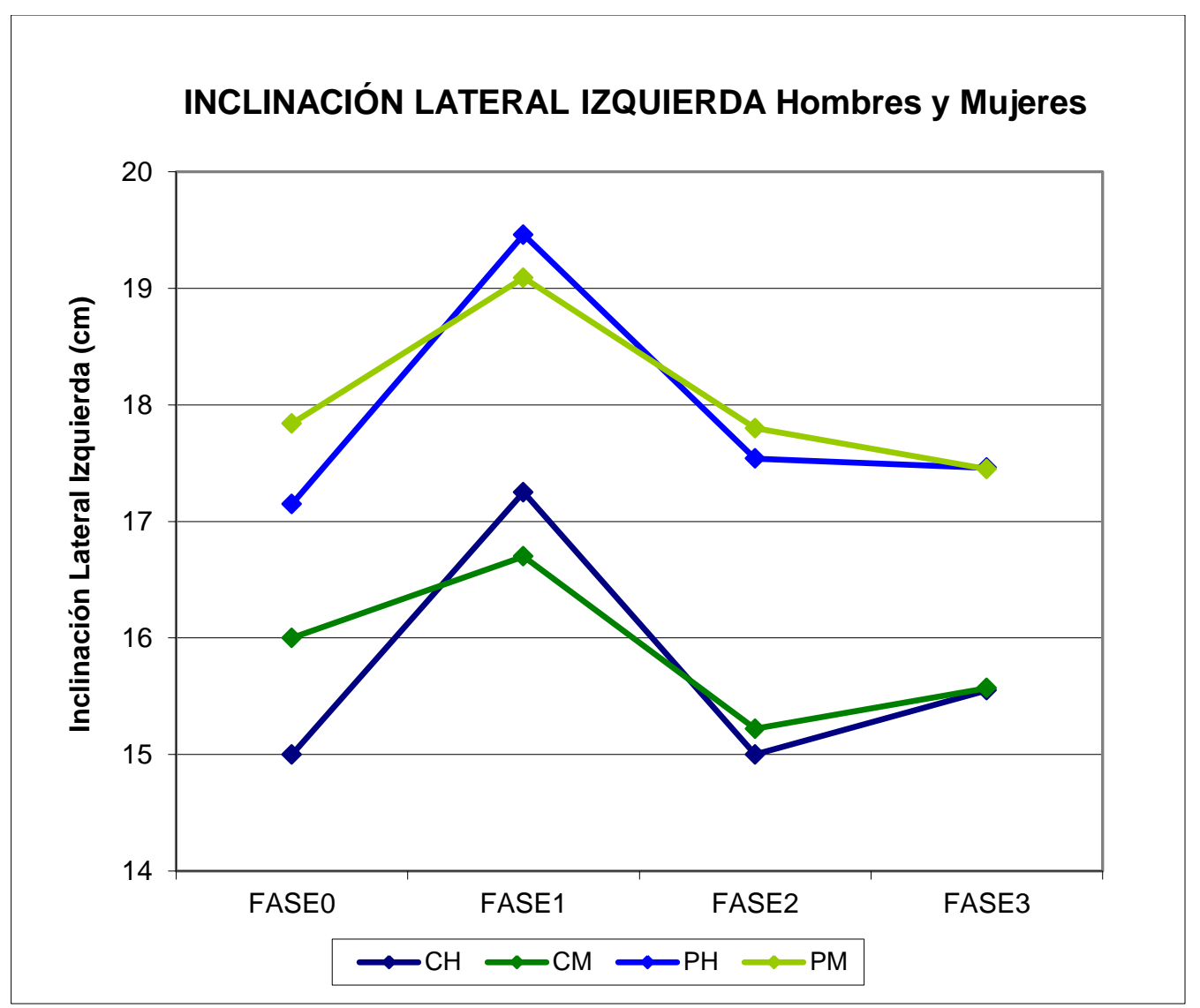

Figura 59. Evolución del balance articular de inclinación lateral izquierda en los grupos por sexos. 
V.2.3.4. Análisis de las variables medidas mediante cuestionarios.

\section{V.2.3.4.1. Escala de Roland Morris}

Los resultados se pueden observar en la Tabla 25 y en la Figura 60.

Comparación entre Hombres GC y Hombres GP

Los valores son similares en ambos grupos, aunque es en la Fase 2 donde aparece mayor grado de incapacidad en el GC.

Comparación entre Mujeres GC y Mujeres GP

No se observan diferencias significativas en ninguna de las fases.

Comparación entre Hombres y Mujeres, GC

No existen diferencias significativas en ninguna de las fases.

Comparación entre Hombres y Mujeres, GP

Las mujeres presentan mayor grado de incapacidad que los hombres justo después del tratamiento y se mantiene a los tres meses.

Evolución de Hombres GC en las diferentes fases

No se muestran diferencias significativas a lo largo de las fases.

Evolución de los Hombres GP en las diferentes fases

No aparecen diferencias significativas a lo largo de las fases.

Evolución de Mujeres GC en las diferentes fases

No existen diferencias significativas a lo largo de las fases.

Evolución de Mujeres GP en las diferentes fases

Se observa un descenso progresivo de la incapacidad en cada Fase a partir del final de tratamiento, con respecto a la situación de partida. 
Tabla 25. Valores del cuestionario de Roland-Morris en los grupos por sexos.

\begin{tabular}{|c|c|c|c|c|c|}
\hline MORRIS & FASE 0 & FASE 1 & FASE 2 & FASE 3 & $\mathbf{p}$ \\
\hline GC HOMBRE & $7,80 \pm 4,36$ & $6,50 \pm 5,25$ & $6,10 \pm 5,26$ & $5,70 \pm 5,93$ & $p>0,050$ \\
\hline p GC vs GP (Hombre) & 0,644 & 0,136 & 0,030 & 0,410 & \\
\hline GP HOMBRE & $6,92 \pm 4,50$ & $3,77 \pm 3,16$ & $3,00 \pm 4,30$ & $3,31 \pm 4,07$ & $p>0,050$ \\
\hline GC MUJER & $10,65 \pm 3,84$ & $8,95 \pm 5,21$ & $8,30 \pm 5,13$ & $7,90 \pm 5,44$ & $p>0,050$ \\
\hline p GC vs GP (Mujer) & 0,509 & 0,390 & 0,429 & 0,525 & \\
\hline GP MUJER & $9,54 \pm 6,62$ & $7,73 \pm 6,06$ & $6,90 \pm 6,06$ & $6,72 \pm 6,33$ & $\begin{array}{l}F 0 \text { vs } F 1=0,014 \\
F 0 \text { vs } F 2=0,013 \\
F 0 \text { vs } F 3=0,025\end{array}$ \\
\hline $\begin{array}{l}\text { p Hombre vs Mujer } \\
\text { (GC) }\end{array}$ & 0,078 & 0,231 & 0,328 & 0,319 & \\
\hline $\begin{array}{c}\text { p Hombre vs Mujer } \\
\text { (GP) }\end{array}$ & 0,216 & 0,016 & 0,024 & 0,159 & \\
\hline
\end{tabular}

p: Valor de significación estadística para la comparación intergrupos e intragrupos

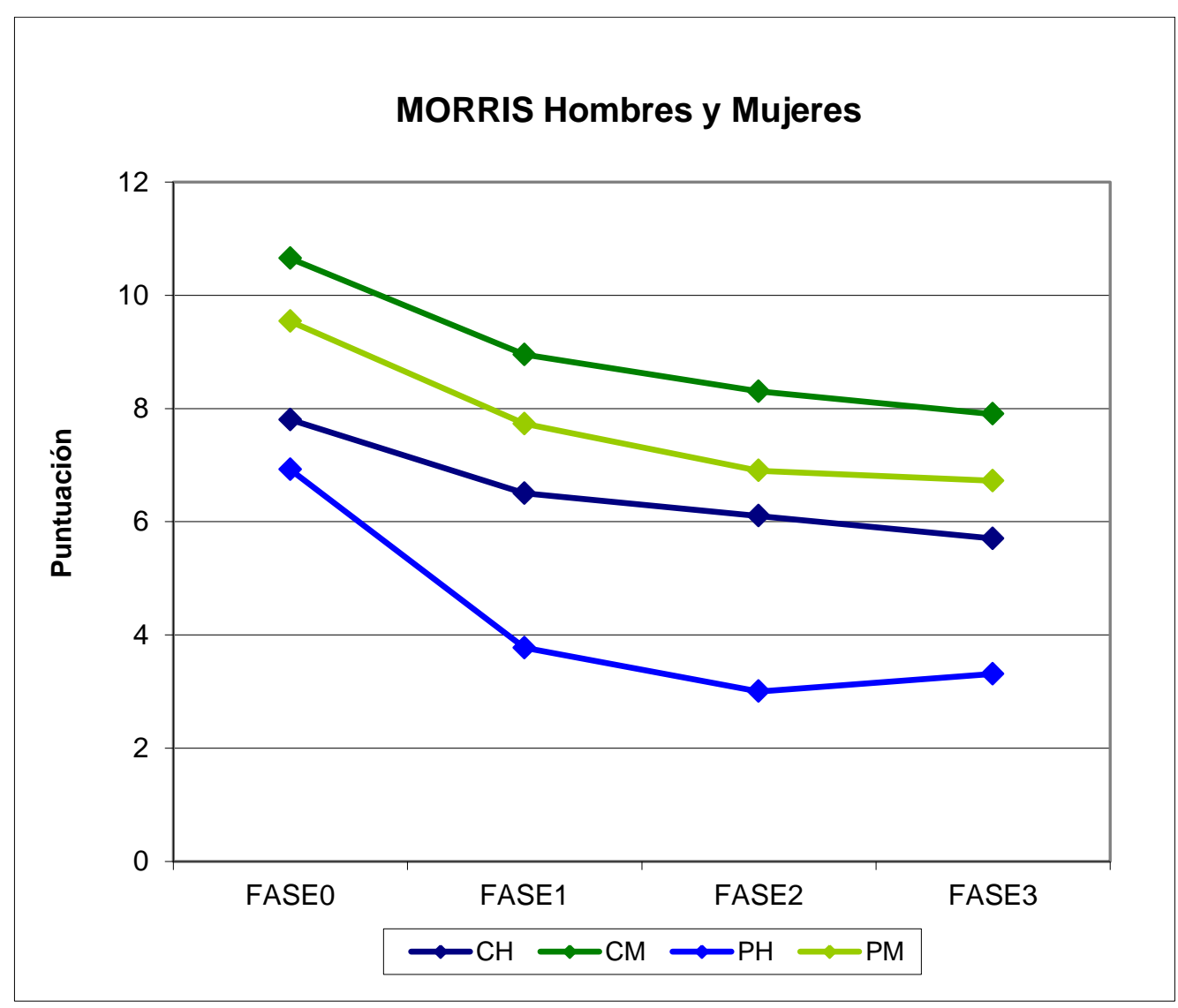

Figura 60. Evolución de los valores obtenidos en el cuestionario de RolandMorris en los grupos por sexos. 
V.2.3.4.2. Cuestionario de Zung

Los resultados se pueden observar en la Tabla 26 y en la Figura 61.

Comparación entre Hombres GC y Hombres GP

No aparecen diferencias significativas en ninguna de las fases.

Comparación entre Mujeres GC y Mujeres GP

No se observan diferencias significativas en ninguna de las fases.

Comparación entre Hombres y Mujeres, GC

No existen diferencias significativas en ninguna de las fases.

Comparación entre Hombres y Mujeres, GP

No se muestran diferencias significativas en ninguna de las fases.

Evolución de Hombres GC en las diferentes fases

No aparecen diferencias significativas a lo largo de las fases.

Evolución de los Hombres GP en las diferentes fases

En las fases 2 y 3 , el grado de depresión autopercibida fue inferior a la fase 0 .

Evolución de Mujeres GC en las diferentes fases

La valoración de la depresión disminuye en Fase 1 sufriendo pequeñas variaciones hasta final del estudio.

Evolución de Mujeres GP en las diferentes fases

Se alcanzan valores más bajos tras el tratamiento que siguen disminuyendo a lo largo del estudio. 
Tabla 26. Valores del cuestionario de ZUNG en los grupos por sexos.

\begin{tabular}{|c|c|c|c|c|c|}
\hline ZUNG & FASE 0 & FASE 1 & FASE 2 & FASE 3 & p \\
\hline GC HOMBRE & $32,30 \pm 8,56$ & $31,70 \pm 10,06$ & $34,20 \pm 9,41$ & $30,00 \pm 7,90$ & $p>0,050$ \\
\hline p GC vs GP (Hombre) & 0,650 & 0,869 & 0,172 & 0,754 & F0 vs F2 = 0,045 \\
\hline GP HOMBRE & $34,00 \pm 8,93$ & $32,38 \pm 9,50$ & $29,23 \pm 7,46$ & $28,92 \pm 8,19$ & F0 vs F3 = 0,042 \\
\hline GC MUJER & $38,90 \pm 10,34$ & $35,45 \pm 8,27$ & $37,50 \pm 10,49$ & $34,40 \pm 10,05$ & $\mathbf{p}=\mathbf{0 , 0 2 0}$ \\
\hline p GC vs GP (Mujer) & 0,539 & 0,562 & 0,212 & 0,398 & $\mathbf{p = 0 , 0 3 1}$ \\
\hline $\begin{array}{c}\text { GP MUJER } \\
\text { G Hombre vs Mujer } \\
\text { (GC) }\end{array}$ & 0,093 & 0,285 & 0,409 & 0,231 & \\
\hline $\begin{array}{c}\text { p Hombre vs Mujer } \\
\text { (GP) }\end{array}$ & 0,387 & 0,649 & 0,216 & 0,335 & \\
\hline
\end{tabular}

p: Valor de significación estadística para la comparación intergrupos e intragrupos

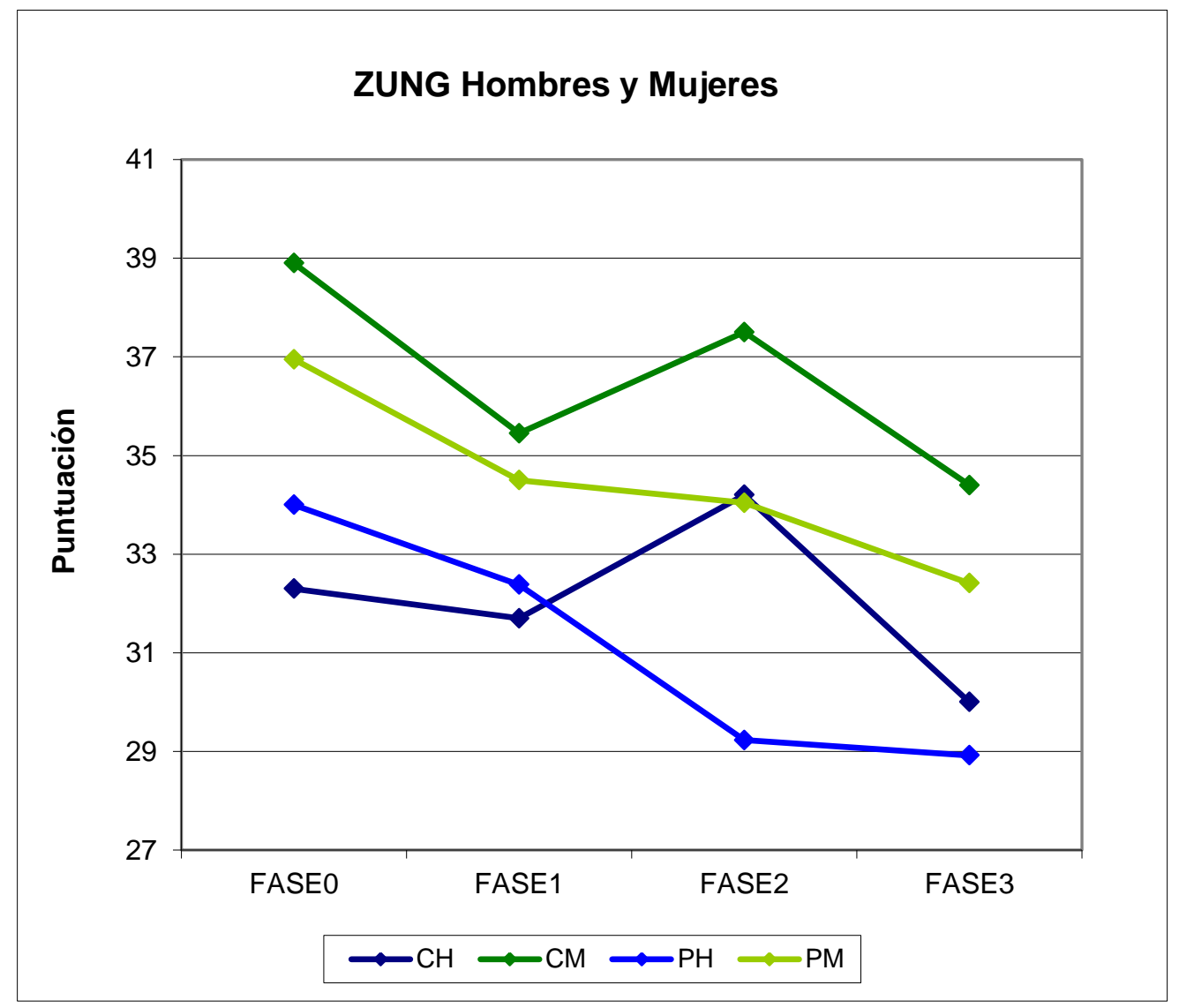

Figura 61. Evolución de los valores obtenidos en la Escala de Zung en los grupos por sexos. 
V.2.3.4.3. Perfil de Salud de Nottingham (PSN)

- PSN ENERGía

Los resultados se pueden observar en la Tabla 27 y en la Figura 62.

Comparación entre Hombres GC y Hombres GP

No se observan diferencias significativas en ninguna de las fases.

Comparación entre Mujeres GC y Mujeres GP

Sólo aparecen diferencias en la Fase 2 donde son inferiores los valores en el GP.

Comparación entre Hombres y Mujeres, GC

No existen diferencias significativas en ninguna de las fases.

Comparación entre Hombres y Mujeres, GP

No se muestran diferencias significativas en ninguna de las fases.

Evolución de Hombres GC en las diferentes fases

No aparecen diferencias significativas a lo largo de las fases.

Evolución de los Hombres GP en las diferentes fases

Los valores descienden de forma notable en Fase 1, alcanzando el "0" en las últimas fases.

Evolución de Mujeres GC en las diferentes fases

No existen diferencias significativas a lo largo de las fases.

Evolución de Mujeres GP en las diferentes fases

La sensación de Energía mejora tras el tratamiento, y sobre todo a los tres meses; esa mejoría desaparece a largo plazo (6 meses). 
Tabla 27. Valores medios de PSN ENERGíA en los grupos por sexos.

\begin{tabular}{|c|c|c|c|c|c||}
\hline NOTEN & FASE 0 & FASE 1 & FASE 2 & FASE 3 & p \\
\hline GC HOMBRE & $20,00 \pm 42,16$ & $30,00 \pm 42,89$ & $20,00 \pm 35,83$ & $16,66 \pm 28,33$ & $p>0,050$ \\
\hline p GC vs G (Hombre) & 0,976 & 0,257 & 0,232 & 0,232 & \\
\hline GP HOMBRE & $15,38 \pm 29,23$ & $5,12 \pm 12,52$ & $0,00 \pm 0,00$ & $0,00 \pm 0,00$ & $\mathbf{p}=\mathbf{0 , 0 4 1}$ \\
\hline GC MUJER & $38,33 \pm 37,90$ & $35,00 \pm 36,63$ & $35,00 \pm 36,63$ & $25,00 \pm 37,27$ & $p>0,050$ \\
\hline p GC vs GP (Mujer) & 0,125 & 0,093 & $\mathbf{0 , 0 0 7}$ & 0,871 & \\
\hline $\begin{array}{c}\text { GP MUJER } \\
\text { p Hombre vs Mujer } \\
\text { (GC) }\end{array}$ & 0,183 & 0,681 & 0,307 & 0,681 & $\mathbf{p}=\mathbf{0 , 0 5 0}$ \\
\hline $\begin{array}{c}\text { p Hombre vs Mujer } \\
\text { (GP) }\end{array}$ & 0,601 & 0,489 & 0,511 & 0,079 & \\
\hline
\end{tabular}

p: Valor de significación estadística para la comparación intergrupos e intragrupos

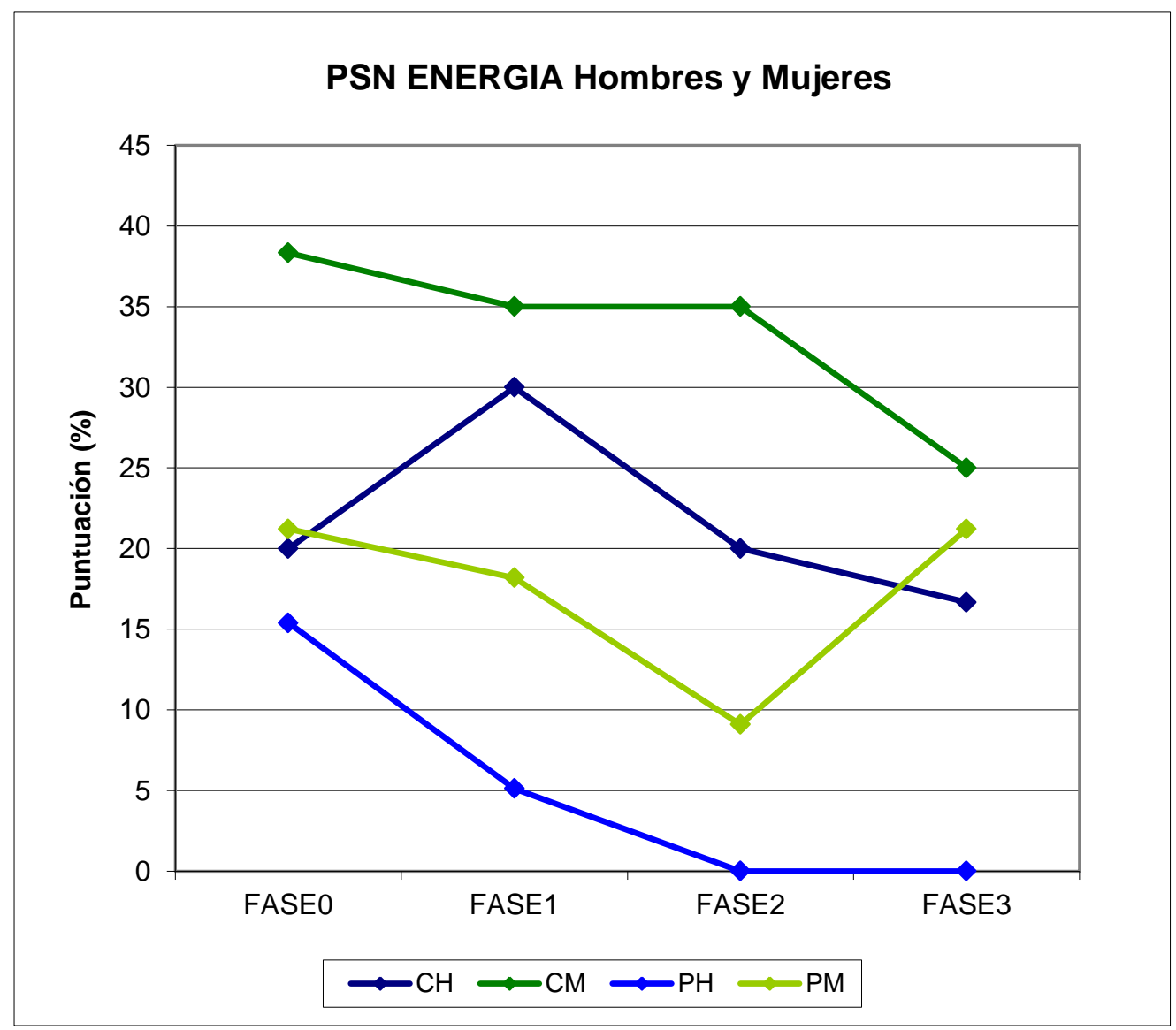

Figura 62. Evolución del PSN ENERGÍA en los grupos por sexos. 
- PSN DOLOR

Los resultados se pueden observar en la Tabla 28 y en la Figura 63.

Comparación entre Hombres GC y Hombres GP

No existen diferencias significativas en ninguna de las fases.

Comparación entre Mujeres GC y Mujeres GP

Los valores sólo difieren en la Fase 2, siendo inferiores en el GP que en el GC.

Comparación entre Hombres y Mujeres, GC

Sólo a los tres meses se encuentran diferencias, siendo mayor la sensación de dolor en las mujeres.

Comparación entre Hombres y Mujeres, GP

Se encuentran diferencias a los tres meses, siendo mayor la sensación de dolor en las mujeres.

Evolución de Hombres GC en las diferentes fases

No se aprecian diferencias significativas a lo largo de las fases.

Evolución de los Hombres GP en las diferentes fases

La sensación de dolor disminuye desde la aplicación de la PR y se mantiene durante el estudio.

Evolución de Mujeres GC en las diferentes fases

No se muestran diferencias significativas a lo largo de las fases.

Evolución de Mujeres GP en las diferentes fases

El descenso del dolor se observa de forma progresiva a lo largo de todo el estudio. 
Tabla 28. Valores medios de PSN DOLOR en los grupos por sexos.

\begin{tabular}{|c|c|c|c|c|c|}
\hline NOTDOL & FASE 0 & FASE 1 & FASE 2 & FASE 3 & $\mathbf{p}$ \\
\hline GC HOMBRE & $43,75 \pm 32,41$ & $42,50 \pm 27,13$ & $27,50 \pm 29,34$ & $30,00 \pm 34,46$ & $p>0,050$ \\
\hline p GC vs GP (Hombre) & 0,458 & 0,205 & 0,522 & 1,000 & \\
\hline GP HOMBRE & $52,88 \pm 25,60$ & $27,88 \pm 26,10$ & $19,23 \pm 29,14$ & $28,85 \pm 29,48$ & $p=0,020$ \\
\hline GC MUJER & $68,75 \pm 25,16$ & $55,62 \pm 30,74$ & $53,75 \pm 26,93$ & $45,00 \pm 34,74$ & $p>0,050$ \\
\hline p GC vs G (Mujer) & 0,161 & 0,279 & 0,040 & 0,146 & \\
\hline GP MUJER & $56,82 \pm 29,05$ & $44,88 \pm 32,43$ & $37,50 \pm 2887$ & $30,68 \pm 27,74$ & $\begin{array}{l}\text { F0 vs } F 1=0,012 \\
F 0 \text { vs } F 2=0,022 \\
F 0 \text { vs } F 3=0,001 \\
F 1 \text { vs } F 3=0,028\end{array}$ \\
\hline $\begin{array}{l}\text { p Hombre vs Mujer } \\
\text { (GC) }\end{array}$ & 0,061 & 0,262 & 0,028 & 0,231 & \\
\hline $\begin{array}{l}\text { p Hombre vs Mujer } \\
\text { (GP) }\end{array}$ & 0,689 & 0,118 & 0,038 & 0,854 & \\
\hline
\end{tabular}

p: Valor de significación estadística para la comparación intergrupos e intragrupos

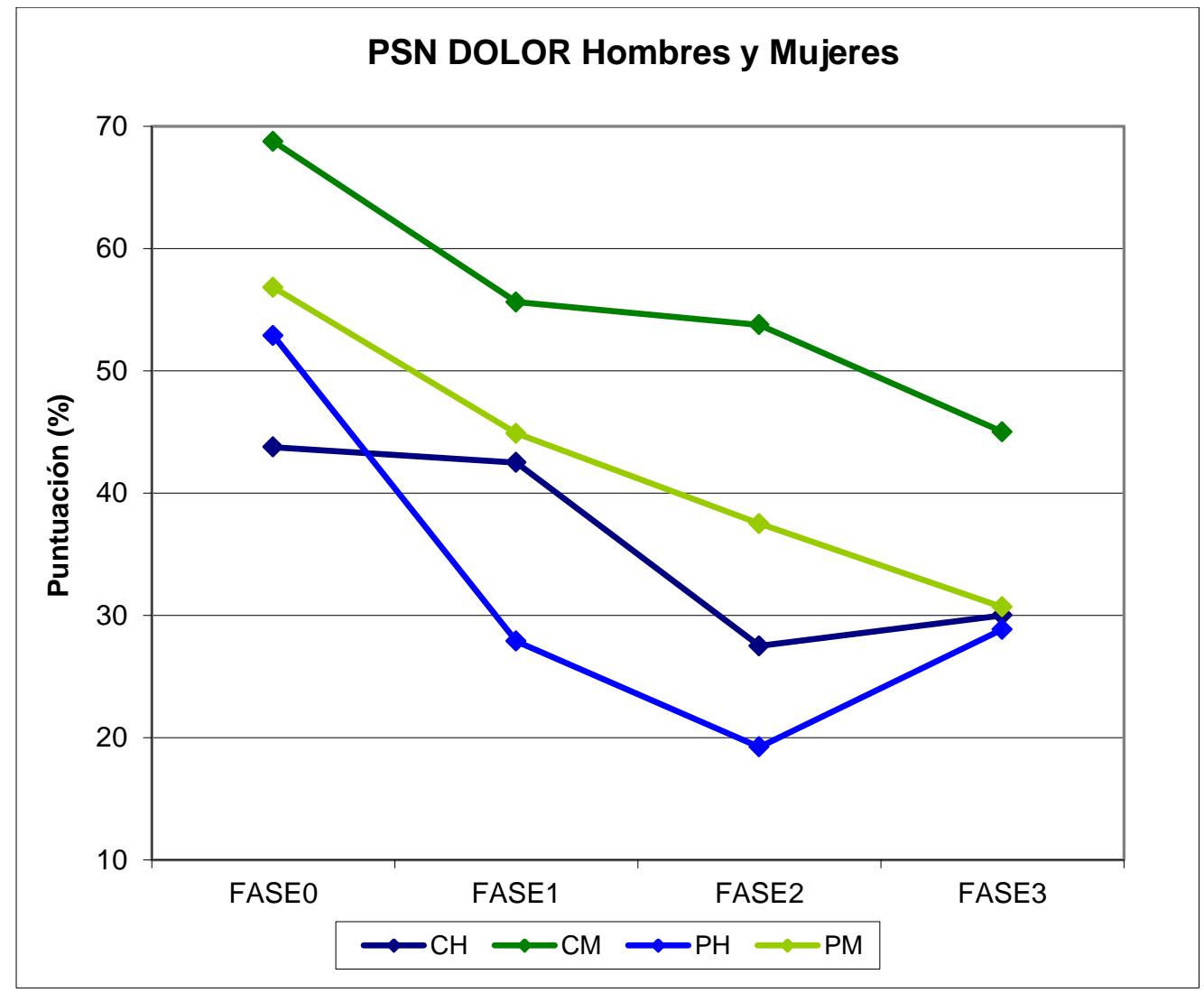

Figura 63. Evolución del PSN Dolor en los grupos Control y Pinza en los grupos por sexos. 
- PSN REACCIONES EMOCIONALES

Los resultados se pueden observar en la Tabla 29 y en la Figura 64.

Comparación entre Hombres GC y Hombres GP

No se aprecian diferencias significativas en ninguna de las fases.

Comparación entre Mujeres GC y Mujeres GP

La valoración de las reacciones emocionales fue muy superior en la mujeres control comparadas con las del GP en la fase 2.

Comparación entre Hombres y Mujeres, GC

No se observan diferencias significativas en ninguna de las fases.

Comparación entre Hombres y Mujeres, GP

No se muestran diferencias significativas en ninguna de las fases.

Evolución de Hombres GC en las diferentes fases

No existen diferencias significativas a lo largo de las fases.

Evolución de los Hombres GP en las diferentes fases

No se encuentran diferencias significativas a lo largo de las fases.

Evolución de Mujeres GC en las diferentes fases

Hay una disminución en la valoración de las reacciones emocionales tras el tratamiento y a los 6 meses.

Evolución de Mujeres GP en las diferentes fases

En el GP la mejoría se produce justo al finalizar el tratamiento y esa mejoría se mantiene en el resto de las fases. 
Tabla 29. Valores medios de PSN REACCIONES EMOCIONALES en los grupos por sexos.

\begin{tabular}{|c|c|c|c|c|c|}
\hline NOTEMO & FASE 0 & FASE 1 & FASE 2 & FASE 3 & p \\
\hline GC HOMBRE & $14,44 \pm 25,15$ & $15,55 \pm 26,30$ & $14,44 \pm 22,86$ & $14,44 \pm 18,18$ & $p>0,050$ \\
\hline p GC vs GP (Hombre) & 0,879 & 0,784 & 0,410 & 0,101 & \\
\hline GP HOMBRE & $12,82 \pm 16,28$ & $5,98 \pm 7,33$ & $4,27 \pm 9,66$ & $2,56 \pm 4,87$ & $p>0,050$ \\
\hline GC MUJER & $27,22 \pm 24,31$ & $17,77 \pm 22,91$ & $27,22 \pm 29,83$ & $15,55 \pm 25,60$ & $\mathbf{p}=\mathbf{0 , 0 2 2}$ \\
\hline p GC vs GP (Mujer) & 0,609 & 0,722 & $\mathbf{0 , 0 4 6}$ & 0,827 & \\
\hline $\begin{array}{c}\text { GP MUJER } \\
\text { p Hombre vs Mujer } \\
\text { (GC) }\end{array}$ & 0,074 & 0,350 & 0,131 & 0,713 & $\mathbf{p}=\mathbf{0 , 0 4 7}$ \\
\hline $\begin{array}{c}\text { p Hombre vs Mujer } \\
\text { (GP) }\end{array}$ & 0,113 & 0,203 & 0,216 & 0,106 & \\
\hline
\end{tabular}

p: Valor de significación estadística para la comparación intergrupos e intragrupos

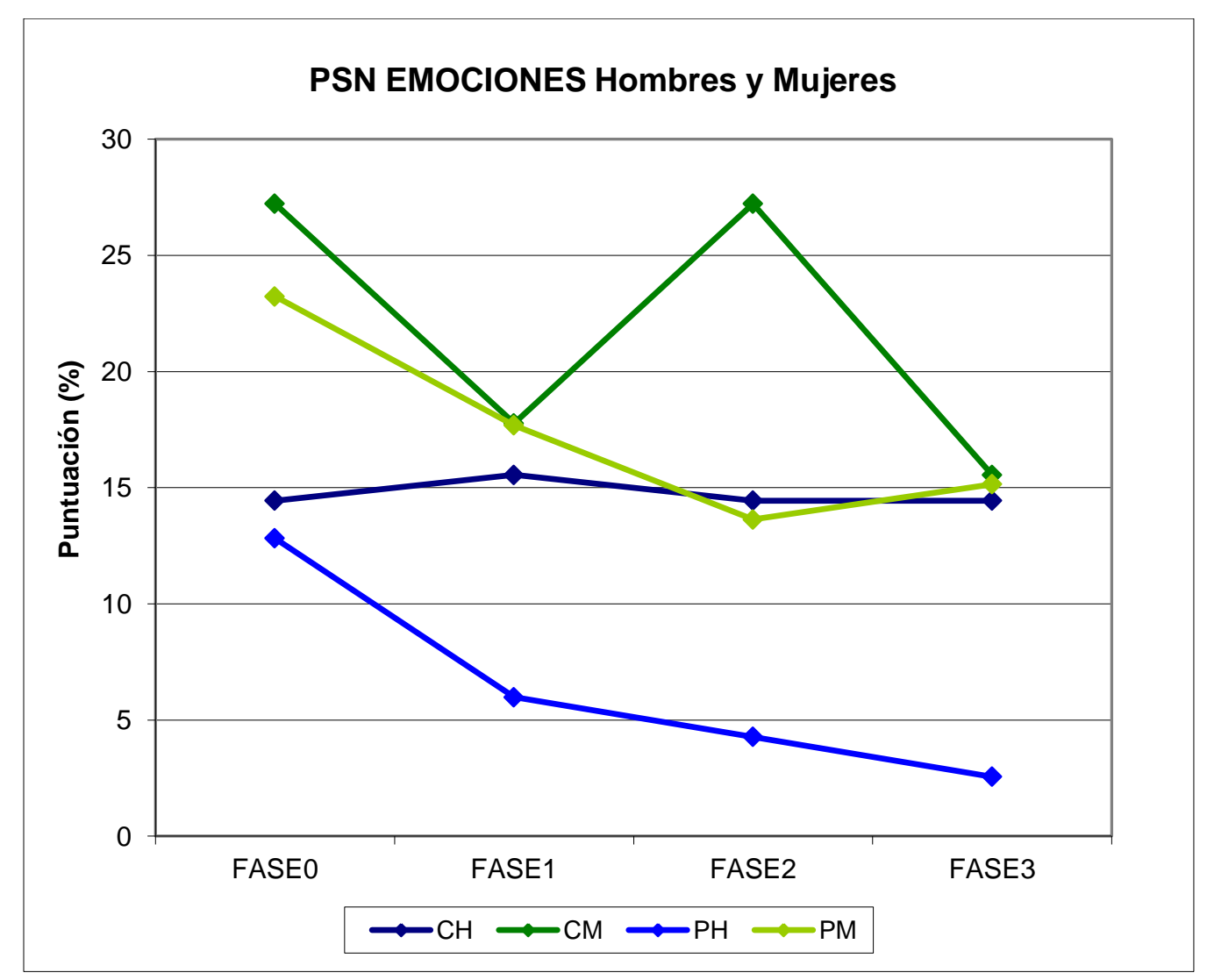

Figura 64. Evolución del PSN REACCIONES EMOCIONALES en los grupos por sexos. 
- PSN SUEÑO

Los resultados se pueden observar en la Tabla 30 y en la Figura 65.

Comparación entre Hombres GC y Hombres GP

No se observan diferencias significativas en ninguna de las fases.

Comparación entre Mujeres GC y Mujeres GP

No existen diferencias significativas en ninguna de las fases.

Comparación entre Hombres y Mujeres, GC

El sueño es más difícil y complicado en las Fases 0 y 2, para las mujeres.

Comparación entre Hombres y Mujeres, GP

Después del tratamiento el grupo de hombres muestra menos problemas con el sueño que el de las mujeres

Evolución de Hombres GC en las diferentes fases

No se encuentran diferencias significativas a lo largo de las fases.

Evolución de los Hombres GP en las diferentes fases

Tras el tratamiento el sueño mejora de forma significativa en todas las fases.

Evolución de Mujeres GC en las diferentes fases

No se aprecian diferencias significativas a lo largo de las fases.

Evolución de Mujeres GP en las diferentes fases

Las mujeres experimentan una mejoría progresiva en las características del sueño a lo largo del estudio. 
Tabla 30. Valores medios de PSN SUEÑO en los grupos por sexos.

\begin{tabular}{|c|c|c|c|c|c|}
\hline NOTSUE & FASE 0 & FASE 1 & FASE 2 & FASE 3 & p \\
\hline GC HOMBRE & $30,00 \pm 21,60$ & $34,00 \pm 41,15$ & $18,00 \pm 28,98$ & $22,00 \pm 30,48$ & $p>0,050$ \\
\hline p GC vs GP Hombre) & 0,257 & 0,166 & 0,784 & 0,605 & \\
\hline GP HOMBRE & $20,00 \pm 21,60$ & $6,15 \pm 12,61$ & $9,23 \pm 13,20$ & $10,77 \pm 17,54$ & $\mathbf{p}=\mathbf{0 , 0 4 6}$ \\
\hline GC MUJER & $58,00 \pm 30,36$ & $48,00 \pm 3458$ & $50,00 \pm 35,24$ & $45,00 \pm 36,63$ & $p>0,050$ \\
\hline p GC vs GP (Mujer) & 0,068 & 0,324 & 0,077 & 0,073 & \\
\hline $\begin{array}{c}\text { GP MUJER } \\
\text { p Hombre vs Mujer } \\
\text { (GC) }\end{array}$ & $\mathbf{0 , 0 0} \pm 33,24$ & $37,27 \pm 35,61$ & $31,82 \pm 35,81$ & $25,45 \pm 31,58$ & $\mathbf{p}=\mathbf{0 , 0 4 6}$ \\
\hline $\begin{array}{c}\text { p Hombre vs Mujer } \\
\text { (GP) }\end{array}$ & 0,091 & 0,328 & $\mathbf{0 , 0 1 7}$ & 0,100 & \\
\hline
\end{tabular}

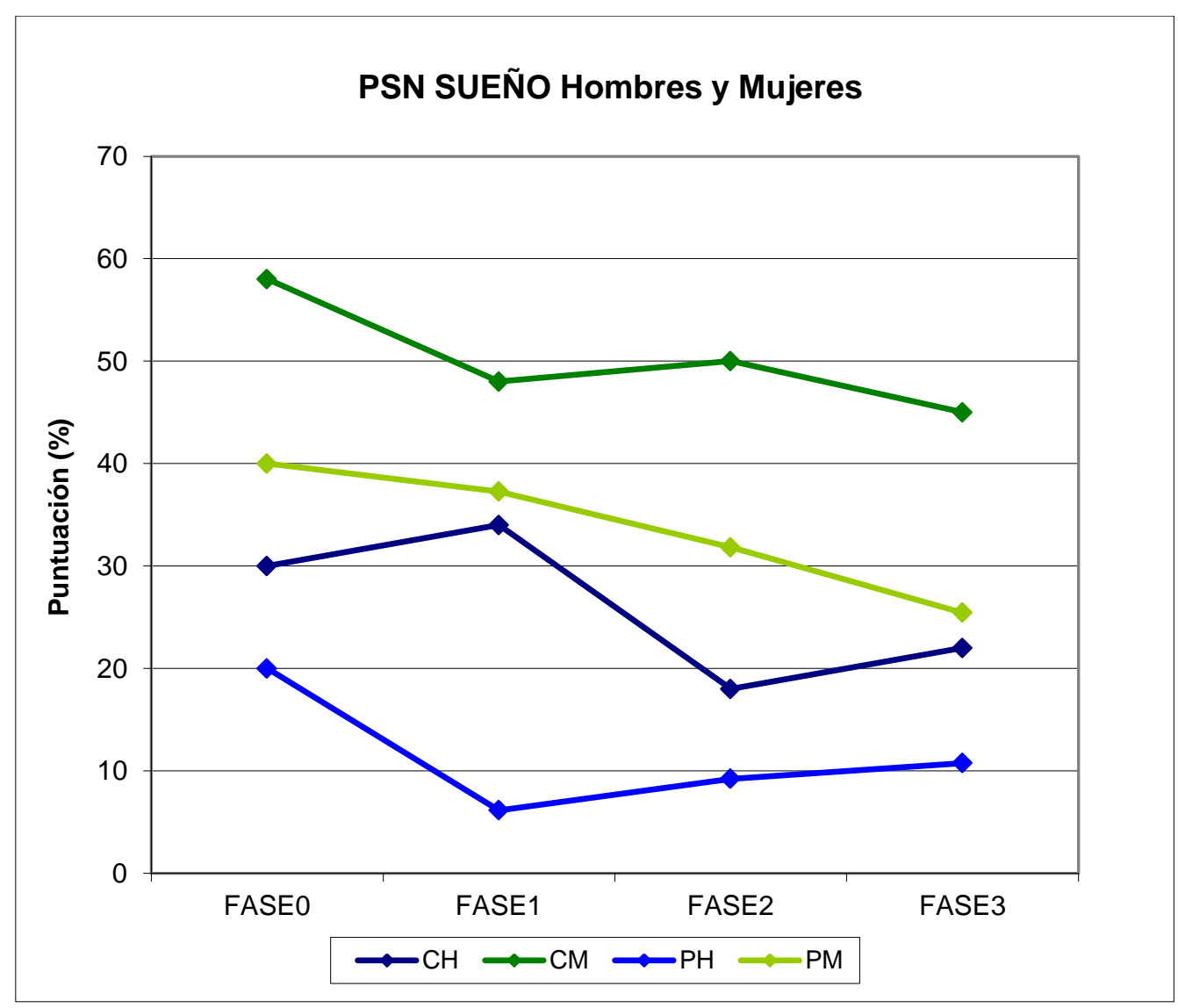

Figura 65. Evolución del PSN SUEÑO en los grupos por sexos. 
- PSN AISLAMIENTO SOCIAL

Los resultados se pueden observar en la Tabla 31 y en la Figura 66.

Comparación entre Hombres GC y Hombres GP

No se muestran diferencias significativas en ninguna de las fases.

Comparación entre Mujeres GC y Mujeres GP

No se observan diferencias significativas en ninguna de las fases.

Comparación entre Hombres y Mujeres, GC

No existen diferencias significativas en ninguna de las fases.

Comparación entre Hombres y Mujeres, GP

No se encuentran diferencias significativas en ninguna de las fases.

Evolución de Hombres GC en las diferentes fases

No se aprecian diferencias significativas a lo largo de las fases.

Evolución de los Hombres GP en las diferentes fases

No aparecen diferencias significativas a lo largo de las fases.

Evolución de Mujeres GC en las diferentes fases

No se muestran diferencias significativas a lo largo de las fases.

Evolución de Mujeres GP en las diferentes fases

No se observan diferencias significativas a lo largo de las fases. 
Tabla 31. Valores medios de PSN AISLAMIENTO SOCIAL en los grupos por sexos.

\begin{tabular}{|c|c|c|c|c|c|}
\hline NOTAISL & FASE 0 & FASE 1 & FASE 2 & FASE 3 & p \\
\hline GC HOMBRE & $8,00 \pm 10,33$ & $2,00 \pm 6,32$ & $8,00 \pm 13,98$ & $6,00 \pm 9,66$ & $p>0,050$ \\
\hline p GC vs GP (Hombre) & 0,343 & 0,832 & 0,376 & 0,376 & \\
\hline GP HOMBRE & $3,07 \pm 7,51$ & $3,07 \pm 7,51$ & $1,54 \pm 5,55$ & $1,54 \pm 5,55$ & $p>0,050$ \\
\hline GC MUJER & $14,00 \pm 22,57$ & $12,00 \pm 15,08$ & $14,00 \pm 21,62$ & $19,00 \pm 26,38$ & $p>0,050$ \\
\hline p GC vs GP (Mujer) & 0,273 & 0,134 & 0,232 & 0,151 & $p>0,050$ \\
\hline GP MUJER & $8,18 \pm 17,08$ & $9,09 \pm 22,02$ & $8,18 \pm 18,16$ & $10,00 \pm 19,27$ & $p$ \\
\hline p Hombre vs Mujer \\
(GC)
\end{tabular}

p: Valor de significación estadística para la comparación intergrupos e intragrupos

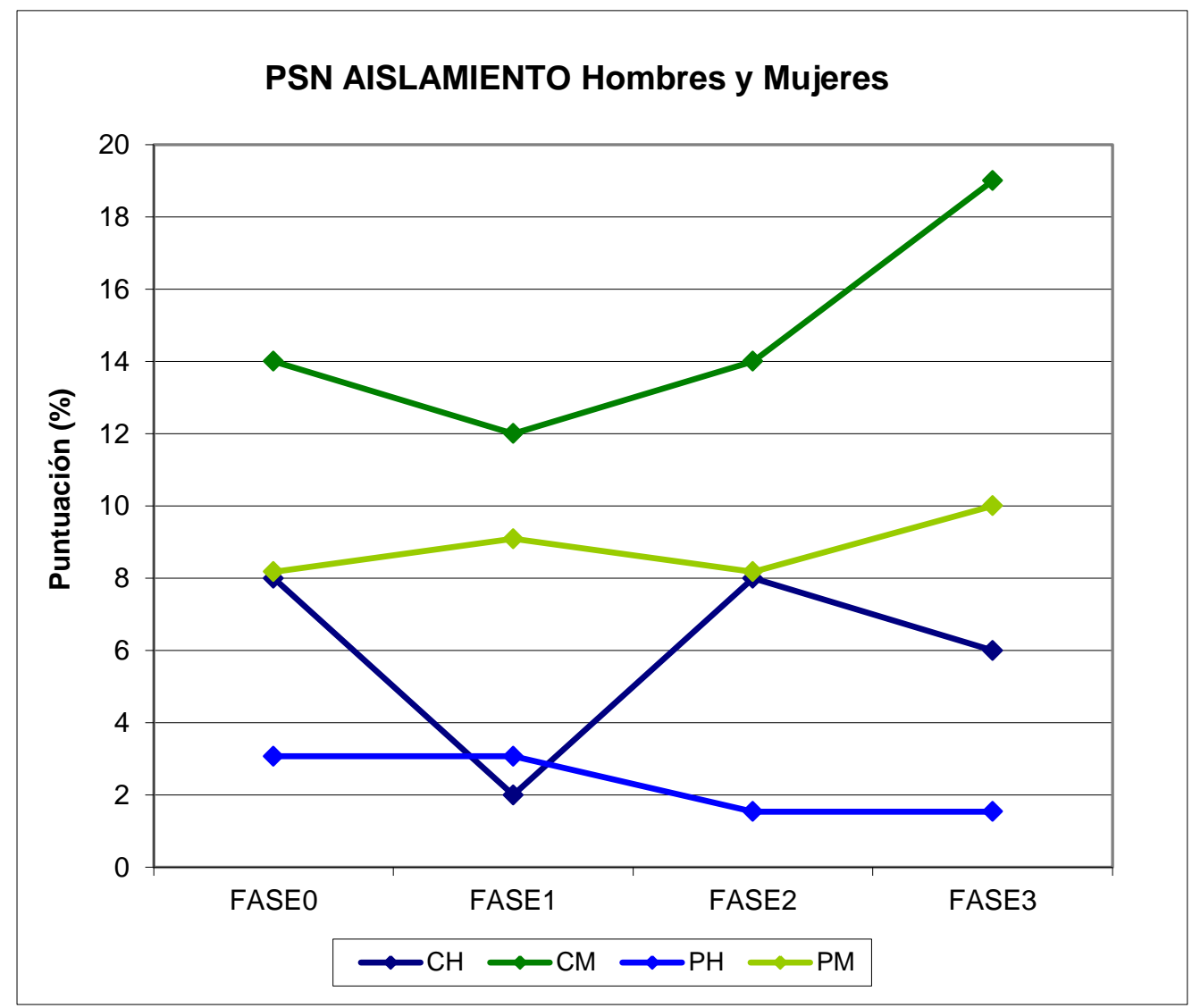

Figura 66. Evolución del PSN AISLAMIENTO SOCIAL en los grupos por sexos. 
- PSN MOVILIDAD FÍSICA

Los resultados se pueden observar en la Tabla 32 y en la Figura 67.

Comparación entre Hombres GC y Hombres GP

En la Fase 2 la movilidad física fue significativamente mejor en el grupo pinza.

Comparación entre Mujeres GC y Mujeres GP

No existen diferencias significativas en ninguna de las fases, salvo cierta tendencia a una mejor movilidad en la Fase 2.

Comparación entre Hombres y Mujeres, GC

No se aprecian diferencias significativas en ninguna de las fases.

Comparación entre Hombres y Mujeres, GP

Se observan diferencias en la Fase 2, con peor movilidad en las mujeres.

Evolución de Hombres GC en las diferentes fases

No se observan diferencias significativas a lo largo de las fases.

Evolución de los Hombres GP en las diferentes fases

Se encuentra una mejoría importante a partir de aplicación del tratamiento.

Evolución de Mujeres GC en las diferentes fases

No se muestran diferencias significativas a lo largo de las fases.

Evolución de Mujeres GP en las diferentes fases

No aparecen diferencias significativas a lo largo de las fases. 
Tabla 32. Valores medios de PSN MOVILIDAD FísICA en los grupos por sexos.

\begin{tabular}{|c|c|c|c|c|c|}
\hline NOTFIS & FASE 0 & FASE 1 & FASE 2 & FASE 3 & p \\
\hline GC HOMBRE & $33,75 \pm 18,69$ & $36,25 \pm 19,94$ & $25,00 \pm 19,54$ & $23,75 \pm 26,65$ & $p>0,050$ \\
\hline p G C vs GP (Hombre) & 0,660 & 0,060 & $\mathbf{0 , 0 4 9}$ & 0,563 & \\
\hline GP HOMBRE & $29,80 \pm 22,55$ & $14,42 \pm 14,29$ & $9,61 \pm 11,58$ & $16,35 \pm 20,02$ & $\mathbf{p}=\mathbf{0 , 0 1 0}$ \\
\hline GC MUJER & $40,00 \pm 20,11$ & $33,12 \pm 19,98$ & $37,50 \pm 17,68$ & $31,25 \pm 24,16$ & $p>0,050$ \\
\hline p GC vs GP (Mujer) & 0,397 & 0,405 & 0,064 & 0,465 & \\
\hline $\begin{array}{c}\text { GP MUJER } \\
\text { p Hombre vs Mujer } \\
\text { (GC) }\end{array}$ & 0,419 & 0,689 & 0,131 & 0,373 & $p>0,050$ \\
\hline $\begin{array}{c}\text { p Hombre vs Mujer } \\
\text { (GP) }\end{array}$ & 0,649 & 0,053 & $\mathbf{0 , 0 1 5}$ & 0,216 & \\
\hline
\end{tabular}

p: Valor de significación estadística para la comparación intergrupos e intragrupos

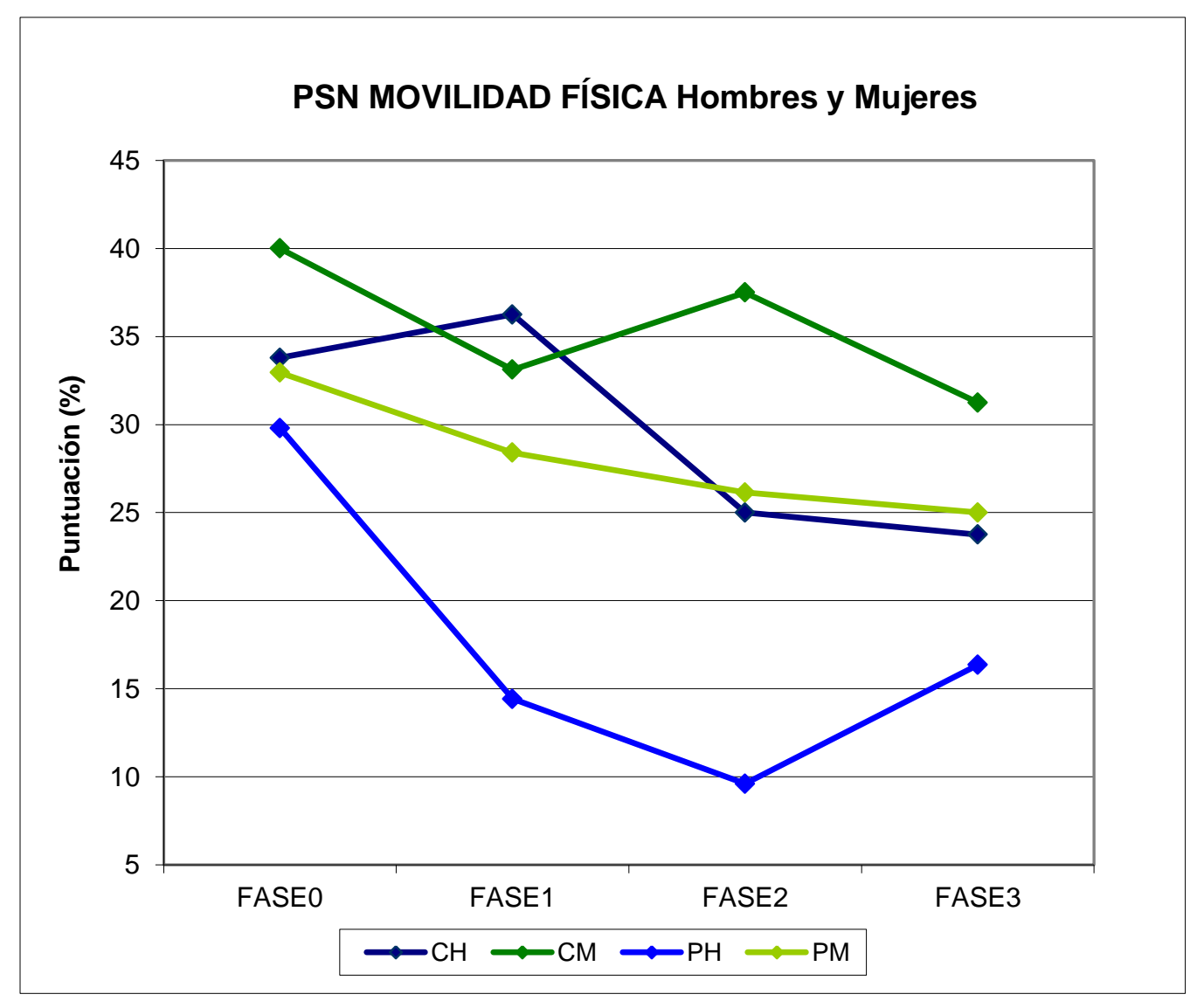

Figura 67. Evolución del PSN MOVILIDAD FíSICA en los grupos por sexos. 
- PSN TOTAL

Los resultados se pueden observar en la Tabla 33 y en la Figura 68.

Comparación entre Hombres GC y Hombres GP

No se observan diferencias significativas en ninguna de las fases.

Comparación entre Mujeres GC y Mujeres GP

Los valores son similares excepto en la Fase 2, donde las mujeres GP obtienen un perfil de salud global mejor.

Comparación entre Hombres y Mujeres, GC

Aparecen diferencias al comienzo del estudio que desaparecen tras el tratamiento. La calidad de vida percibida es mayor en hombres que en mujeres en las fases 0 y 2.

Comparación entre Hombres y Mujeres, GP

Después del tratamiento la calidad de vida percibida en los hombres es mejor que la de las mujeres, diferencias que persisten a los tres y a los seis meses.

Evolución de Hombres GC en las diferentes fases

No existen diferencias significativas a lo largo de las fases.

Evolución de los Hombres GP en las diferentes fases

El descenso del PSN es importante ya desde la aplicación de la PR y a lo largo de todo el estudio.

Evolución de Mujeres GC en las diferentes fases

No se muestran diferencias significativas a lo largo de las fases.

Evolución de Mujeres GP en las diferentes fases

EI PSN mejora en las mujeres Pinza al finalizar el tratamiento, manteniéndose la mejoría hasta los 6 meses. 
Tabla 33. Valores medios de PSN TOTAL en los grupos por sexos.

\begin{tabular}{|c|c|c|c|c|c|}
\hline NOTTOT & FASE 0 & FASE 1 & FASE 2 & FASE 3 & p \\
\hline GC HOMBRE & $25,00 \pm 16,94$ & $26,71 \pm 22,30$ & $18,82 \pm 21,65$ & $18,81 \pm 19,36$ & $p>0,050$ \\
\hline p GC vs GP (Hombre) & 0,700 & 0,051 & 0,208 & 0,410 & \\
\hline GP HOMBRE & $22,33 \pm 15,60$ & $10,44 \pm 8,53$ & $7,31 \pm 8,20$ & $10,01 \pm 8,69$ & $\begin{array}{l}F 0 \text { vs } F 1=0,001 \\
F 0 \text { vs } F 2=0,004 \\
F 0 \text { vs } F 3=0,009\end{array}$ \\
\hline GC MUJER & $41,05 \pm 17,75$ & $33,59 \pm 19,22$ & $36,24 \pm 19,11$ & $30,13 \pm 22,00$ & $p>0,050$ \\
\hline p GC vs GP (Mujer) & 0,069 & 0,141 & 0,013 & 0,185 & \\
\hline GP MUJER & $31,40 \pm 19,08$ & $25,92 \pm 21,48$ & $21,06 \pm 18,57$ & $21,25 \pm 20,38$ & $p=0,001$ \\
\hline $\begin{array}{l}\text { p Hombre vs Mujer } \\
\text { (GC) }\end{array}$ & 0,025 & 0,389 & 0,049 & 0,155 & \\
\hline $\begin{array}{c}\text { p Hombre vs Mujer } \\
\text { (GP) }\end{array}$ & 0,206 & 0,013 & 0,005 & 0,031 & \\
\hline
\end{tabular}

p: Valor de significación estadística para la comparación intergrupos e intragrupos

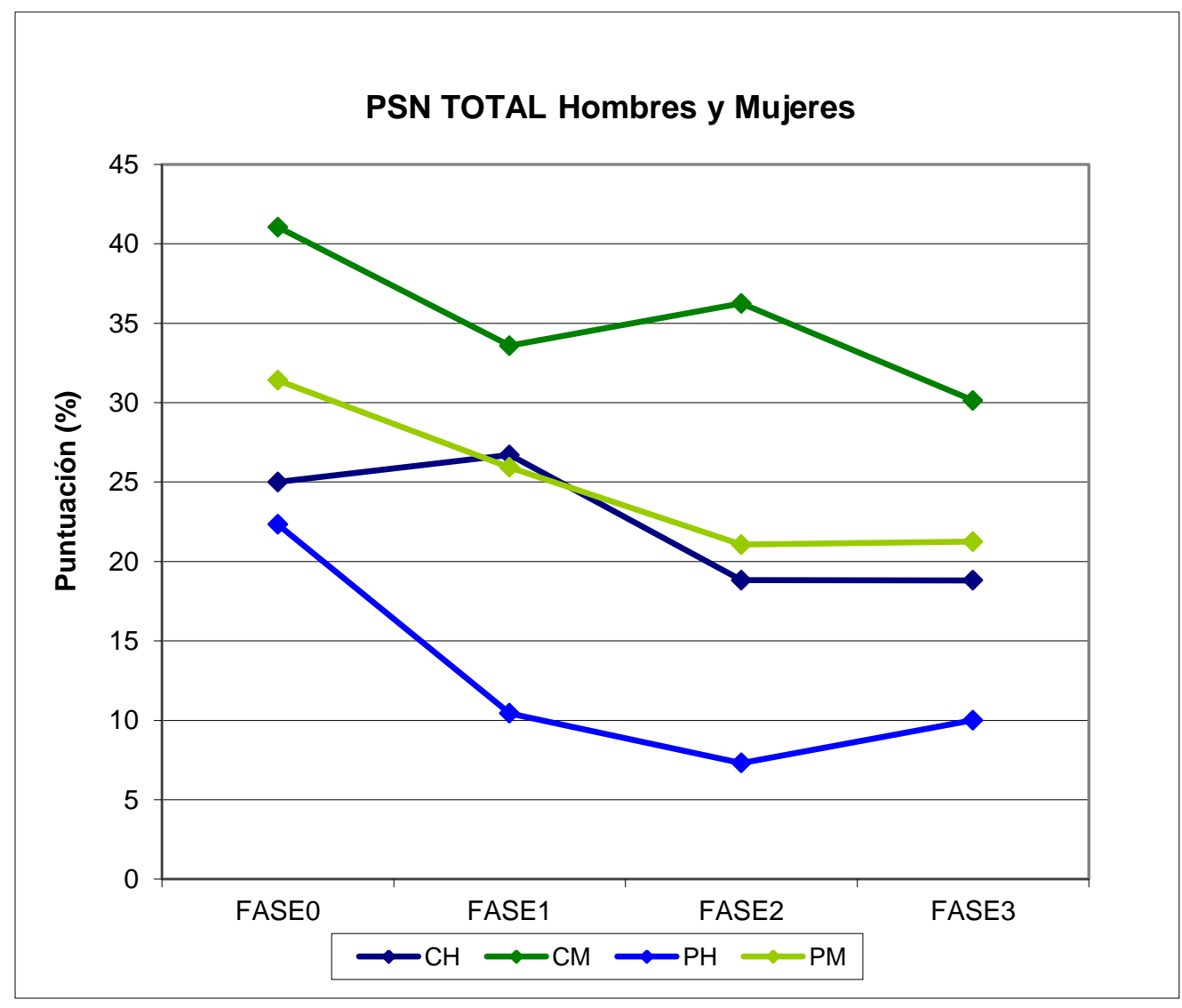

Figura 68. Evolución del PSN TOTAL en los grupos por sexos. 
Como dijimos anteriormente en el apartado del PSN total con toda la población, las preguntas que integraban la parte II del PSN no arrojaron diferencias significativas ni en la parte global ni en la separación posterior por sexos.

\section{V.2.4. PORCENTAJE DE RECIDIVAS}

El porcentaje de recidivas al final del estudio fue del 10,77\%, es decir, 7 de los 65 pacientes volvió a sufrir un cuadro de dolor lumbar en esos 6 meses de duración del seguimiento. De ellos, 3 pertenecían al GC (10\%) y 4 al GP $(11,42 \%)$.

\section{V.2.5. MEDICACIÓN}

La mayoría de los pacientes tomaban algún analgésico cuando acudieron en la Fase 0, y muchos de ellos lo eliminaron en la Fase 1. Los medicamentes más consumidos fueron Paracetamol e Ibuprofeno. En el resto de las fases, algunos reconocieron la toma de fármacos a demanda.

No fue posible realizar un análisis fiable de la reducción de la medicación en la población de estudio, ya que muchos de los pacientes se automedican ante la presencia del dolor, sea lumbar o de cualquier otra localización. 


\section{DISCUSIÓN}




\section{DISCUSIÓN}

Se ha realizado un estudio observacional analítico de cohorte de incepción en una población adulta con dolor lumbar de tipo inespecífico (LIC), y con un seguimiento de 6 meses a contar desde el inicio del estudio. El objetivo ha sido analizar la influencia de la aplicación de la técnica de PR sobre el dolor, el balance articular de la columna lumbar, la incapacidad física, la depresión y la calidad de vida en los pacientes con LIC, comparándola con el tratamiento habitual protocolizado en AP del SACYL.

Es de interés conocer las características clínicas de los pacientes con LIC asistidas en nuestras Unidades de Fisioterapia, así como, constatar el tratamiento recibido, los resultados del mismo y las recidivas. Resulta de particular utilidad saber si existen factores asociados o relacionados con los efectos del tratamiento fisioterápico. Todo ello, implicaría una posible modificación en el planteamiento de este tratamiento.

Además, las recomendaciones para definir la LIC, la consistencia en la información y establecer claramente las características de los pacientes facilitará las comparaciones entre los diferentes estudios ${ }^{202}$.

Conviene expresar en este momento un hándicap importante que ha condicionado el desarrollo del trabajo. Mientras que en los años precedentes el tratamiento fisioterápico de la LIC a lo largo de un año suponía un total de 150 casos, en el año que se plantea el periodo de captación de pacientes los casos se redujeron a 100 , lo que influyó sensiblemente, por una parte, en su reclutamiento $y$, por otra, en el periodo de seguimiento. Es posible que esto tenga relación con la situación social vivida en el país en esos momentos, ya que ha coincidido con los años más duros de la crisis económica, cuando más afectado se ha visto el panorama laboral. Los pacientes comenzaban el tratamiento y lo interrumpían o abandonaban, por incompatibilidad con el mantenimiento de su puesto de trabajo. Era algo que muchos de ellos verbalizaba, por lo que las pérdidas experimentadas en el seguimiento del estudio han sido mayores de las esperadas. 
Sin embargo, se han realizado estudios de gran validez con muestras reducidas como los de Chatztheodorou et al. ${ }^{203}$ y los de Descarreaux et al. ${ }^{204}$, realizados ambos con 20 sujetos, hasta estudios multicéntricos con $200^{205} \mathrm{o}$ 1334 sujetos $^{206}$ pasando por estudios medios de alrededor de 50 casos $^{207}$.

La mayoría de esas pérdidas pertenecen al GC, grupo donde el contacto terapeuta-paciente era menos estrecho. Los resultados coinciden con otros autores, que sugieren que la supervisión del paciente juega un papel fundamental en la adherencia al tratamiento ${ }^{208}$. Se señala como una clave del éxito clínico de los programas, la adherencia inducida por la supervisión directa y especializada del tratamiento ${ }^{209}$. Para obtener el compromiso de adherencia al programa los pacientes necesitan entender no sólo cómo se hace o tienen que hacer el tratamiento, sino el porqué del mismo, jugando así un papel activo en su terapia y obteniendo mayores beneficios ${ }^{210}$.

Así, la muestra terminó siendo inferior a lo proyectado, aunque la calidad y el rigor en el desarrollo del estudio han sido exhaustivos.

\section{VI.1. PERFIL DE LA MUESTRA}

\section{VI.1.1. Género}

La mayoría de los sujetos del estudio (65\%) fueron mujeres (Figura 31). Este predominio femenino coincide con el reseñado en la literatura científica ${ }^{41}$. Estudios recientes revelan que el género femenino es, no sólo un factor de riesgo para el desarrollo de la LIC sino que también influye en el manejo de la misma $^{211}$.

Las mujeres consultan más frecuentemente por sus problemas de salud $^{212}$, lo que puede afectar a los resultados encontrados. De cualquier forma, no existe unanimidad en cuanto al predominio de uno $u$ otro sexo en esta patología. Mientras que para algunos autores ${ }^{41,213}$ durante los años de trabajo hombres y mujeres tienen dolor lumbar con la misma frecuencia, hay estudios que encuentran un predominio masculino y que defienden que la LIC afecta más frecuentemente a hombres a partir de los 50 años ${ }^{214}$. 


\section{VI.1.2. Edad}

En cuanto a la edad media de la muestra, se encontró entre los 35-45 años, franja de madurez laboral. Estos resultados coinciden con los de Koes et al. ${ }^{13}$. Según Kim et al. ${ }^{214}$, es a partir de los 50 cuando la LIC tiene su máxima incidencia. En nuestro trabajo no se apreciaron diferencias significativas entre el porcentaje de casos con más de 50 años (60\%) y de menos de esta edad (40\%) (Ji-cuadrado, $\mathrm{p}=0,107$ ). (Tablas 4 y 19 y Figuras 32 y 37 ).

Boocock et al. ${ }^{215}$ afirman que la edad es un factor predisponente en el dolor lumbar, ya que, en edades cercanas a los 50 se observa un detrimento de la movilidad articular lumbar asociado a fatiga y a levantamientos repetitivos. Además, con la edad el balance articular en flexión-extensión se reduce ${ }^{216}$.

Para Caillard ${ }^{217}$, el dolor lumbar aparece como causa principal de limitación de actividad en personas menores de 45 años y como tercera causa en mayores de 45 años. Fundamentalmente, los primeros episodios de dolor lumbar se presentan en edades comprendidas entre los 20 y 40 años ${ }^{14,41}$, existiendo un riesgo de lumbalgia creciente con la edad, con un máximo para el grupo de 45 a 50 años y una disminución del riesgo después de esa edad. En relación a la asociación sexo-edad, Caillard ${ }^{217}$ encontró que en cada grupo de edad, los índices de prevalencia masculina eran superiores a los femeninos.

Según Humbría ${ }^{43}$ el grupo de edad más afectado es el comprendido entre los 30-60 años, siendo los grupos de edad menos afectados los de más de 60 años y los de menos de 21 años. Coincidiendo con éste, se encuentran los estudios de Rustoen et al. ${ }^{218}$. Sin embargo, estos resultados son contrarios a los de Bigos et al. ${ }^{219}$, pues comprobaron que en personas de 14 a 64 años, los más jóvenes y los mayores fueron los que presentaron mayor riesgo de padecer una lumbalgia.

\section{VI.1.3. Estatura y peso}

Respecto a la talla y al peso, ambos fueron mayores en hombres que en mujeres, tanto en el GC como en el GP (Figuras 38 y 39, Tabla 4). Un resultado lógico y observable en cualquier ámbito ya que, además de los factores ambientales, las características antropométricas ligadas al cromosoma "Y" y a 
la concentración de andrógenos condicionan un crecimiento en altura superior en los hombres ${ }^{220}$.

Si se tienen en cuenta los estudios que hay al respecto, se puede decir, que ambos factores no tienen una clara relación con la lumbalgia ${ }^{221}$. Así, en relación a la talla hay estudios que sugieren una mayor prevalencia de dolor ciático en individuos altos, mientras que otros afirman que los trabajadores más altos son los que presentan dolores lumbares con menor frecuencia ${ }^{40}$. En cuanto al peso, hay autores ${ }^{222}$ que demuestran la asociación entre obesidad y lumbalgia, tanto en su establecimiento como en el aumento del número de episodios y su cronificación.

\section{VI.1.4. Índice de masa corporal}

El límite del IMC saludable ${ }^{223}$ se sitúa entre $18,5-25 \mathrm{Kg} / \mathrm{m}^{2}$. Estos intervalos se aplican a personas de entre 25 y 34 años, y aumentan en un punto por cada diez años por encima de 25. Así, un IMC de 28 es normal para personas de 55 a 65 años, mientras que autores como Moore ${ }^{224}$ y Triana y Vélez $^{225}$ sugieren, para esa franja de edad, unos valores entre $27,3 \mathrm{Kg} / \mathrm{m}^{2}$ y $27,8 \mathrm{Kg} / \mathrm{m}^{2}$.

En lo referente a las cualidades antropométricas de los sujetos de nuestro estudio el 57\% se encontraba en situación de normopeso (Figura 40). En cuanto al porcentaje de sobrepeso, fue mayor en hombres, lo que facilitaría la aparición de $\mathrm{LIC}^{208}$. Los pacientes con sobrepeso presentan síntomas de dolor más acentuado ${ }^{226}$, y ello se refleja en menor movilidad para evitar ese dolor.

En este trabajo se apreciaron diferencias significativas $(p=0,036)$ entre los porcentajes de pacientes con LIC de los grupos sobrepeso $(36,20 \%)$ y normopeso $(63,80 \%)$, lo que podría indicar que no solo el IMC interviene en el desarrollo de esta patología.

\section{VI.1.5. Estado civil}

El estado civil predominante fue el de casado (Figura 33). Esto contrasta con los resultados de Schoenborn ${ }^{227}$, quien otorga a los casados mejor nivel de 
salud comparado con el resto los adultos pertenecientes a otro estado civil. Este autor informó que el único indicador negativo de salud para el cual los casados presentaban mayor prevalencia era el IMC en sus grados de sobrepeso u obesidad, aspecto similar a lo que dicen Vilagut et al. ${ }^{228}$, según los cuales la buena calidad de vida se relaciona con la situación civil de estar casado.

\section{VI.1.6. Nivel de estudios}

En cuanto al nivel de estudios realizados, la mayoría de los pacientes sólo había cursado estudios de primaria (Figura 34). Coincidimos así con Unde Ayvat et al., ${ }^{229}$ quienes afirmaron que junto a otros factores (nivel económico precario, trabajo intenso y tabaquismo) un nivel de formación bajo constituye un factor de riesgo para padecer lumbalgia y que evitando estos factores, se podría reducir la incidencia de la LIC.

La explicación podría basarse en que las personas con un nivel de estudios superior poseen mayores conocimientos sobre los peligros que conllevan los malos hábitos posturales y sobre el mejor manejo del estrés, a diferencia de la mano de obra no profesional, con menor formación, que carece de esos conocimientos y está expuesta a trabajos más exigentes ${ }^{50}$. Otra razón podría ser el acceso de los sujetos con menor formación a puestos de trabajo de mayor exigencia física laboral que pudiera desencadenar el desarrollo de LIC.

\section{VI.1.7. Actividad laboral}

En este estudio, el mayor porcentaje de pacientes con LIC se encontró en los trabajos de exigencia física media (Figura 35), y personas en activo (Figura 36). Hay que fijarse, sin embargo, en que los pacientes con exigencias laborales altas o medias representaban casi el 50\% de la población estudiada y el otro $50 \%$ eran personas con cargas de trabajo suaves o nulas. Eso indica que las exigencias físicas laborales no son la única justificación para desarrollar un proceso lumbálgico.

En la literatura consultada, existe una evidencia razonable de la relación

entre factores ocupacionales y dolor de espalda como son: el trabajo 
físicamente pesado, las posturas de trabajo estáticas, las flexiones y los giros frecuentes del tronco, los levantamientos y movimientos bruscos, el trabajo repetitivo y las vibraciones ${ }^{42,45,230}$. En el mismo sentido, otros estudios afirman que las lumbalgias profesionales se deben a esfuerzos de gran intensidad, a un proceso de agotamiento o cansancio asociado a vibraciones y a esfuerzos menos intensos pero de tipo repetitivo ${ }^{213,231}$.

Cuando la vibración que deriva, por ejemplo, de la conducción prolongada se combina con el levantamiento y el transporte de cargas, el riesgo de lumbalgia aumenta considerablemente. Resulta evidente que las lesiones de espalda suelen ser causadas por un sobre esfuerzo y no por un traumatismo directo. También los complejos movimientos del tronco a altas velocidades, principalmente con inclinación y torsión, aumentan el riesgo de lumbalgias ocupacionales. $Y$ no sólo eso, sino que las posiciones mantenidas con inclinación del tronco hacia delante también suponen riesgo de lumbalgia, que se multiplica por seis cuando los movimientos de flexión anterior se acompañan de torsión del tronco ${ }^{232-235,255-258}$. La explicación puede ser un fallo tisular, una acumulación de microdaños tisulares o fatiga. Por ello, la prevención de la lumbalgia debe focalizarse en la reducción de factores laborales como el manejo de cargas pesadas y trabajar en malas posturas ${ }^{256}$.

Coenen et al. ${ }^{237}$ estiman que levantar pesos por encima de $25 \mathrm{Kg}$ con una frecuencia de 25 veces al día incrementará la incidencia anual de LIC, comparado con la situación de no levantar peso. La intensidad y la frecuencia de levantar pesos predicen significativamente la aparición de LIC al afectar la salud musculoesquelética de la población trabajadora. En estos sujetos, el estiramiento de la musculatura lumbar paraespinal, podría ser beneficioso para la prevención de la cronicidad de la $\operatorname{LIC}^{238}$. Además, el control postural resulta eficaz en la corrección de la misma ${ }^{239}$.

Varios estudios ${ }^{240,241}$ sobre la relación lumbalgia-trabajo sugieren que el impacto de los factores psicosociales y del entorno es más importante en el desarrollo de la LIC que los factores físicos y mecánicos. Según Gómez y Méndez ${ }^{221}$, los aspectos psicosociales causan mayor número de problemas de 
espalda en el trabajo que los aspectos físicos, por lo que se les considera indicadores de riesgo de lumbalgia.

Esto podría justificar también la alta incidencia de lumbalgia en la mitad de nuestra población, aunque tuvieran cargas físicas bajas.

Por otra parte, la completa inactividad, es decir el sedentarismo y el abandonar el puesto de trabajo de forma prolongada, no constituyen una buena alternativa terapéutica como se ha podido observar en la introducción, en el apartado I.1.4. sobre el tratamiento de la lumbalgia. De hecho, el trabajo como actividad física puede afectar de forma positiva en la prevención de la incapacidad $^{242}$.

\section{VI.2. DOLOR}

\section{VI.2.1. Análisis del dolor del Grupo Pinza frente al Grupo Control}

Los resultados de nuestro estudio demostraron que, partiendo de un grado de dolor similar, los pacientes con LIC que recibieron tratamiento convencional y además, terapia manual con la técnica de PR experimentaban una mayor reducción del dolor, valorado mediante la Escala Visual Analógica (EVA), que el grupo de pacientes que solamente recibió el tratamiento de fisioterapia según protocolo (Tabla 5 y Figura 41).

Es importante destacar que las diferencias fueron, no sólo significativas desde el punto de vista estadístico, sino que también presentaron una significación clínica ya que sobrepasan la Diferencia Mínima Clínicamente Importante (DMCl; del inglés "Minimal Clinically Important Difference”, MCID) que se ha identificado en dos puntos $(20 \mathrm{~mm})^{182}$. La incorporación de este concepto surge debido a que, en campos de estudio como la lumbalgia, aparecen cientos de publicaciones anuales que muestran resultados estadísticamente significativos de muchas intervenciones terapéuticas ${ }^{243}$, y sin embargo, en muchas ocasiones no se puede deducir si los pacientes han percibido clínicamente esta mejoría.

El DMCl se define como el menor cambio clínico que puede ser considerado por encima del error de medida del cuestionario utilizado, con un 
intervalo de confianza del $95 \%$. La diferencia es clínicamente relevante cuando el cambio en los resultados de los cuestionarios autocumplimentados por el paciente, antes y después del tratamiento, es mayor que un valor establecido. Este valor de referencia ha sido hallado con anterioridad en pacientes de similares características y dentro de la misma patología ${ }^{244}$. Dentro de las publicaciones, se sugiere que el cambio mínimo clínicamente relevante en el cuestionario EVA debería ser de al menos $20 \mathrm{~mm}^{245}$.

El presente estudio muestra un periodo de seguimiento que se prolonga mucho más allá de la finalización del tratamiento, observándose que los beneficios clínicos de la técnica de PR superan los $20 \mathrm{~mm}$ del $\mathrm{DMCl}$ y se mantienen a los 90 y a los 180 días después de su inicio.

En un estudio ${ }^{246}$ realizado con 30 pacientes, se midió con ultrasonidos de alta frecuencia $(22 \mathrm{MHz})$ el cambio en la estructura de la matriz de colágeno de la dermis inmediatamente antes y después de su primer tratamiento con PR, en una zona de dolor y/o restricción de movilidad. Los cambios observados reflejan las diferencias a la palpación en la tensión, la firmeza y la uniformidad, posiblemente debidos a cambios en las fuerzas mecánicas de los fibroblastos (los miofibroblastos son células asociadas a la reparación del tejido ${ }^{247}$ y al aumento de la microcirculación. La medida de la distribución del colágeno mostró una reducción de los mayores aumentos de la densidad en la dermis, principalmente en la zona de transición con el tejido subdérmico y un aumento del grosor de la dermis ${ }^{248}$. Es decir, la PR modifica estructuralmente el tejido sobre el que se realiza la técnica y ello puede modificar la sensibilidad de la zona tratada explicando la reducción del dolor observada.

Por otra parte, cuando movilizamos o realizamos terapia manual sobre una articulación, no todos los efectos se ejercen directamente sobre la estructura tratada. Existe un importante efecto neurofisiológico, tanto a nivel periférico como sobre el sistema nervioso central, que influye en la actividad motora y el dolor ${ }^{81,135,136}$. A nivel periférico se observan cambios en los niveles de $\beta$-endorfinas, serotonina y sustancia $P$ después de la aplicación de terapia manual. Estos estudios sugieren la existencia de cambios en el dolor a nivel musculoesquelético por efecto o mediados por el sistema nervioso periférico ${ }^{249}$. 
La terapia manual produce efectos sobre la médula espinal. Se considera que puede modular el dolor a través de un bombardeo de estímulos propioceptivos sobre el sistema nervioso central ${ }^{250}$. Los estudios de Malisza et al. ${ }^{251}$ demuestran que después de la aplicación de terapia manual disminuye la activación del asta posterior de la médula. Estos cambios fueron observados en resonancias magnéticas funcionales y en estudios realizados sobre ratas.

Glover et al. ${ }^{252}$, observaron una disminución del campo doloroso cutáneo tras recibir los pacientes una única manipulación, asociando la terapia manual con la disminución del dolor por efecto neurofisiológico. Además, la expectativa de mejoría a través de la terapia manual produce un efecto placebo que repercute positivamente en los resultados del tratamiento ${ }^{253}$.

Estos efectos también pueden explicarse como una inhibición supraespinal descendente asociada a los cambios en el sistema opioide endógeno ${ }^{254}$. La actividad supraespinal inhibitoria, después de la aplicación de la terapia manual, sugiere su influencia sobre estas estructuras nerviosas, demostrando que sus acciones no se limitan sólo al tejido tratado sino que se extienden a niveles superiores del sistema nervioso que, en circuitos de vuelta, repercuten nuevamente sobre dicho tejido.

El dolor afecta al bienestar psicológico y social de los pacientes con $\operatorname{LIC}^{255} \mathrm{y}$, aunque la meta de cualquier paciente es lograr la eliminación del dolor, raramente es un resultado real, por eso, el papel de los terapeutas en el manejo del dolor crónico incluye su alivio tan pronto como sea posible.

Una cuidadosa explicación y educación podría ser necesaria para conseguir un mejor manejo del dolor y una mejoría de la función y de la calidad de vida ${ }^{80}$.

\section{VI.2.2. Análisis del dolor por sexos}

El mismo perfil comentado para la población total se observó al separar a la población en función del sexo, menos dolor en el GP que en el GC tras el tratamiento (Tabla 20 y Figura 55). Es decir los efectos de la PR no parecen estar condicionados por la variable sexo. Si parece existir diferencia en la percepción del grado de dolor más alto en mujeres que en hombres, entre hombres y mujeres del GP antes de comenzar el tratamiento y justo después 
de finalizarlo. Por otra parte, se confirma que los descensos del dolor tras el tratamiento en los GP de hombres y mujeres son significativos y mantenidos en el tiempo, lo que hace pensar que esta técnica de manipulación provoca cambios estructurales $\mathrm{y} / \mathrm{o}$ funcionales duraderos.

Llorca $^{256}$ postula que las hormonas femeninas pueden modificar los procesos nociceptivos y determinar que las mujeres no solamente tengan un umbral para el dolor más bajo, sino también que lo perciban con mayor intensidad. Kovacs et al. ${ }^{257}$, han observado que después de dos meses del tratamiento más de un tercio de los pacientes continúan con dolor y alrededor de un $10 \%$ ha empeorado. En nuestro estudio, después de casi 6 meses de finalizado el tratamiento los niveles de dolor se mantienen muy por debajo de los iniciales.

\section{VI.3. BALANCE ARTICULAR}

Como ya dijimos en el apartado de material y métodos, usamos el test de Schober Modificado para realizar la medición del balance articular en flexión y extensión del tronco. Este test tiene una alta fiabilidad intertestador ${ }^{258}$ aunque, en este caso, todas las medidas fueron tomadas por el mismo fisioterapeuta. El cambio producido puede medirse con facilidad con el empleo de una cinta métrica, que es un instrumento fácilmente accesible. La modificación de la distancia manifiesta el grado de movimiento ${ }^{195}$ y en algunos estudios se correlaciona con el grado de discapacidad haciendo de este simple utensilio una herramienta útil para medir los resultados del tratamiento ${ }^{259}$.

En la lumbalgia, la movilidad no parece estar afectada a largo plazo. Sin embargo, hay autores que han visto cambios en el rango de movimiento según la edad y el sexo $0^{259,260}$. Los hombres en la juventud, presentan mayores valores de flexión que las mujeres, pero ambos pierden movilidad con la edad, aunque las mujeres lo hacen de forma más lenta ${ }^{259}$.

Moll y Wright ${ }^{261}$ usando el método de distracción de la piel, observaron que los hombres tenían un mayor rango de movimiento en flexión y extensión, y las mujeres lo tenían mayor en inclinación lateral. Las diferencias entre hombres y mujeres podrían deberse a la diferencia de altura entre ambos 
sexos. Según el Gray's Anatomy, citado por Russell et al. ${ }^{259}$, la columna vertebral de las mujeres es un promedio de $10 \mathrm{~cm}$ menor que la de los hombres. Además, las mujeres presentan una mayor lordosis lumbar que los hombres, lo que podría explicar en parte las diferencias de rango de movimiento entre ambos $\operatorname{sexos}^{259}$. Aún así, no existen en la literatura datos normativos para el BA de la columna lumbar ${ }^{260}$ medido en centímetros.

Para Dvorák et al. ${ }^{260}$ el BA aumenta a lo largo del día. Este aumento es mayor durante la primera mitad del día. Por ello, cualquier medición del BA lumbar debe ser realizado después de mediodía para obtener valores más fiables. En nuestro caso, todos los pacientes fueron medidos entre las 15:30 y las 19:00 horas, manteniendo así la fiabilidad de los resultados.

Langevin et al. ${ }^{140}$ examinaron con ultrasonidos la movilidad de la fascia en la flexión lumbar pasiva y encontraron una reducción significativa del estiramiento de la fascia en el grupo con lumbalgia. Además, los pacientes de este grupo presentaron una mayor densificación en la fascia. La reducción de dicho estiramiento puede ser debida a adherencias en el tejido.

Saber que la flexión/extensión es máxima en los segmentos lumbares inferiores, mientras que la inclinación lateral está más limitada a la unión lumbosacra ${ }^{193}$, puede ayudar en el diagnóstico de las zonas afectas

\section{VI.3.1. Flexión}

VI.3.1.1. Análisis de la Flexión del Grupo Pinza frente al Grupo Control.

El BA en Flexión es el movimiento más estudiado en cualquier valoración que incluya a la columna lumbar, sin embargo, en la literatura no existe acuerdo sobre el rango fisiológico de este parámetro ${ }^{262}$. Mientras que Pfleger et al. ${ }^{263}$ consideran normal un valor del test Schober modificado a partir de $5 \mathrm{~cm}$, López et al. ${ }^{262}$ no dan ningún valor de referencia ya que estiman que puede verse influido por múltiples factores.

Los valores obtenidos en nuestra investigación se encuentran, en todos los grupos y fases, alrededor del valor considerado por Pfleger et al. ${ }^{263}$ (Tabla 6 y Figura 42). Dichos valores eran diferentes antes de comenzar el tratamiento 
en ambos grupos, sin que exista una explicación lógica puesto que los pacientes eran asignados por orden de llegada a cada uno de los grupos. Bien es cierto, que se observó un mejor balance en el GP que en el GC al finalizar el estudio (Fase 3), tanto en la comparación intergrupo como intragrupo.

Como se puede apreciar, el nivel de significación estadística al comparar el GC y el GP en la fase 3 es superior al de la fase 0 . Eso podría ser debido a que la movilización del tejido conectivo evita la formación de adherencias y, por tanto, facilita el movimiento (264). Cuando uno o varios niveles vertebrales lumbares se afectan en su amplitud articular, el rango de movilidad del tronco experimenta una reducción paralela. Esto es lo que ocurre, por ejemplo, al realizar una fusión de niveles de forma quirúrgica en la columna, donde se observa una disminución en la máxima flexión hacia adelante y un aumento en la distancia dedos-suelo ${ }^{265}$. En el caso que nos ocupa, si el tratamiento mediante PR consigue liberar la fascia ${ }^{81}$, estaría justificado el incremento de la flexión observado al final del estudio ${ }^{136}$.

Los sucesivos estiramientos de la fascia producen un incremento en su rigidez, y por tanto, en la deshidratación del tejido, que podría recuperarse tras una hora de descanso ${ }^{92}$. La flexión completa de la columna vertebral conlleva un aumento de la longitud de la fascia de un $30 \%$, disminuyendo sus dimensiones laterales. Esta deformación aporta eficiencia a los músculos extensores y a la estabilidad de la columna ${ }^{92}$. Conocer dichos hallazgos es importante para los terapeutas a la hora de planificar cualquier tipo de ejercicio y tratamiento.

\section{VI.3.1.2. Análisis de la Flexión por sexos}

Las diferencias entre grupos observadas antes de iniciar el tratamiento (Tabla 21 y Figura 56) quedan justificadas por las que se aprecian al comparar los hombres del GC con los del GP, aunque sigue sin existir explicación para esta diferencia, por la forma en la que los pacientes se asignaron a cada grupo. Hay una coincidencia entre los hombres y las mujeres al final del estudio, es decir, a largo plazo (Fase 3), ya que la diferencia en el grado de flexión había aumentado en ambos sexos del GP con respecto al GC (con una significación 
mayor que en la fase 0). Es decir, la técnica de PR, a largo plazo, mejora el grado de flexión frente a un tratamiento convencional.

En cuanto a la evolución de los distintos grupos, sólo las mujeres del GP experimentaron una mejoría significativa al final del estudio con respecto a los valores pretratamiento. Los hombres, tanto del GP como del GC, y las mujeres del GC, apenas experimentaron variaciones en la medición de la Flexión articular lumbar. Esta ganancia de flexibilidad observada en las mujeres del GP podría estar justificada por la gran reducción del dolor lumbar que se observa en este grupo al finalizar el estudio. Como dicen Laird et al. ${ }^{266}$ los pacientes con LIC ven reducido su rango de movimiento y propiocepción en comparación con los pacientes sin LIC, apoyando el posible efecto del dolor sobre el grado de flexión. Sin embargo, autores como Williams et al. ${ }^{267}$, afirman que el dolor no afecta a la movilidad en la cinemática lumbar.

También se ha comprobado que el trabajo del músculo TrA (y por tanto de la FTL) en la LIC, reduce el dolor y mejora el rango de movimiento, aunque de forma significativa sólo en las mujeres ${ }^{268}$. Siguiendo con esta línea de pensamiento, Waxman y Flamenbaum ${ }^{269}$, convierten la lumbalgia en la principal causa de restricción de movilidad, discapacidad a largo plazo y disminución de la calidad de vida.

Al comparar el comportamiento de la flexión entre hombres y mujeres en los respectivos grupos GC y GP, no se apreciaron diferencias salvo, en la Fase 2 de los GC. A este respecto, se sabe que la flexibilidad disminuye con la edad y se acepta que esta disminución es más lenta en las mujeres que en los hombres. El sexo femenino tiene menos tono muscular, lo que contribuye aún más a su flexibilidad, aunque no existen estudios concluyentes ${ }^{270}$. De hecho, para Fitzgerald et al. ${ }^{271}$, Mellin ${ }^{272}$, Battie et al. ${ }^{273}$, Wolf et al. ${ }^{274}$, y McRae et al. ${ }^{275}$ el grado de flexión disminuye significativamente con la edad y es diferente en ambos sexos. Sin embargo, Ensink et al. ${ }^{276}$ no han encontrado diferencias significativas en función de la edad y del sexo, hecho que coincide con nuestros resultados.

Para Dvorák et al., ${ }^{260}$ el BA decrece con la edad (a mayor edad, menor movilidad), pero no se ve afectado por el género del sujeto. Sin embargo, para 
Russell et al. ${ }^{259}$ y Moll y Wright ${ }^{261}$ el BA se ve afectado por la edad y el sexo de los sujetos. Para Dreischarf et al. ${ }^{216}$ la lordosis y el BA en la parte media de la columna lumbar se reducen con la edad, afectando menos a las charnelas lumbo-sacra y toraco-lumbar.

Por su parte, Sullivan et al. ${ }^{277}$ opinan que obtener una ganancia en flexión no puede considerarse un indicador de éxito terapéutico ya que entran en juego muchos elementos.

A la luz de todas estas investigaciones se puede concluir que la asociación entre dolor lumbar y limitación del movimiento en flexión es cuestionable.

\section{VI.3.2. Extensión}

VI.3.2.1 Análisis de la Extensión del Grupo Pinza frente al Grupo Control.

Por las características de este movimiento, las variaciones de su medida son menores tanto después del tratamiento como durante su evolución ${ }^{262}$. A pesar de ello, la movilidad en extensión fue mayor en el GP, inmediatamente después del tratamiento, y esta mejoría se mantuvo en la evolución de dicho grupo a medio y largo plazo en las fases siguientes (Tabla 7 y Figura 43). La extensión es el parámetro de balance articular que más se modifica con el tratamiento PR. Si tenemos en cuenta que los pacientes con lumbalgia adoptan una posición antiálgica en flexión de tronco, esto resulta totalmente positivo en el tratamiento para su recuperación.

La edad es un factor crucial en la reducción del BA, sobre todo en extensión, reduciéndose casi un $31 \%$ entre jóvenes y adultos ${ }^{278,279}$. En este movimiento, la zona intermedia de la columna lumbar se aplana y se hace menos móvil.

\section{VI.3.2.2. Análisis de la Extensión por sexos.}

El análisis por sexos vuelve a señalar que la extensión mejora tras el tratamiento con PR especialmente en el hombre (en la mujer a pesar de la misma tendencia la diferencia no es significativa), observándose también que 
las mejoras obtenidas en el GP tienden a mantenerse en el tiempo (Tabla 22 y Figura 57).

La extensión fue mayor en las mujeres del GC que en los hombres del GC justo después del tratamiento, dato que coincide con los resultados de López et al. ${ }^{262}$ donde las mujeres mostraron más movilidad en extensión.

Esta mejoría observada en el grado de extensión tras el tratamiento y que se mantiene en el tiempo, de nuevo podría ser achacable al efecto de la PR sobre el comportamiento mecánico del tejido conjuntivo, liberado de adherencias gracias a la técnica empleada ${ }^{136,280}$.

Para Hukins et al. ${ }^{281}$ las capas media y posterior de la FTL forman una envoltura que rodea los músculos espinales desde las apófisis transversas hasta las espinosas, y limita la expansión radial que acompaña a la contracción. Así, la FTL puede incrementar la eficacia de estos músculos durante la extensión lumbar, ya que los músculos por sí solos no serían lo suficientemente fuertes para proporcionar el momento extensor, por ejemplo, cuando se levanta una carga ${ }^{281}$. Al actuar sobre la FTL influimos en el movimiento de extensión.

\section{VI.3.3. Inclinación lateral derecha e izquierda}

VI.3.3.1. Análisis de la Inclinación lateral derecha e izquierda del Grupo Pinza frente al Grupo Control.

La mejoría de este parámetro en ambos lados se manifiesta inmediatamente después del tratamiento en el GP. Los valores alcanzados tras el tratamiento son superiores en el GP comparados con el GC, diferencia que se mantiene en las fases 2 y 3 (Tablas 8 y 9 , y Figuras 44 y 45).

Hay autores ${ }^{272,282}$ que consideran la inclinación lateral del tronco como un elemento importante a valorar, ya que su disminución se ha asociado con un riesgo creciente de LIC. Así mismo, este movimiento se ha encontrado útil a la hora de diferenciar entre sujetos con o sin LIC. En nuestro estudio, como ocurre en el trabajo de Gombatto et al. ${ }^{282}$, los valores de inclinación fueron similares en lateralización izquierda y derecha. Estos resultados discrepan de 
lo que han comunicado otros autores ${ }^{260}$ que observan mayor inclinación hacia el lado derecho.

Los segmentos toracolumbares contribuyen de forma importante en la inclinación lateral del tronco ${ }^{283}$, por lo que al tratar la FTL se produce un aumento del BA. Los estudios de Barker et al. ${ }^{284}$ defienden que la tensión de la FTL se ve influida por la contracción del músculo TrA, afectando a la rigidez segmentaria de la misma, sobre todo en la zona intermedia, donde tiene lugar la inclinación lateral. Los factores biomecánicos de estructuras pasivas juegan un papel importante en el LIC ${ }^{158}$.

Hay que tener en cuenta que la inclinación lateral se acompaña, además, de una rotación axial opuesta, por lo que entraría en juego otro parámetro de movilidad ${ }^{259}$. Como ya hemos dicho anteriormente, este aspecto no se ha tenido en cuenta por no disponer de valores de referencia en relación con la lumbalgia y por la dificultad de su medición.

VI.3.3.2. Análisis de la Inclinación lateral derecha e izquierda por sexos.

En los hombres no se apreciaron diferencias ni intergrupo ni intragrupo para la inclinación lateral hacia ambos lados. Las diferencias entre las mujeres de ambos grupos mostraron un comportamiento desigual hacia el lado derecho y hacia el izquierdo (Tabla 23 y Figuras 58; Tabla 24 y Figura 59, respectivamente).

Para Russell et al. ${ }^{259}$ la inclinación lateral decrece con la edad para ambos sexos, y es mayor generalmente en mujeres. También Wolf et al. ${ }^{274}$ encuentran mayores rangos de movilidad lateral en mujeres. Esto contrasta con los resultados de Dvorák et al. ${ }^{260}$ quienes observan una ligera mayor movilidad en el sexo masculino (en todos los planos de movimiento y prácticamente en todas las décadas), siendo además, ligeramente mayor en ILD que ILI.

Las diferencias entre hombres y mujeres, aunque en nuestro estudio no se han observado, podrían ser debidas a la distinta altura entre los dos sexos como ya se ha comentado con anterioridad. 
Hay estudios que demuestran que la curvatura de la columna y su BA están relacionados entre $s^{285,286}$. En las mujeres se produce una pérdida significativa de esta lordosis de forma progresiva con la edad. Sin embargo, en los hombres esa pérdida es discontinua y ocurre sobre todo entre los grupos de edad 30-39 y 40-49 años ${ }^{287}$. Este perfil evolutivo diferente podría explicar porqué en algunos estudios no aparecen diferencias de movilidad entre hombres y mujeres ${ }^{288}$.

El cambio de lordosis difiere entre sujetos con LIC y sin ella, ya que los primeros suelen presentar una rectificación lumbar debido al dolor y la contractura muscular que acabaría provocando una disminución de la movilidad, y por tanto, del $\mathrm{BA}^{260}$.

Burton y Tilotson ${ }^{289}$ llegaron a la conclusión de que la reducción de movilidad articular podría ser debida, en parte, a la infiltración del tejido fibroso en las estructuras elásticas periarticulares. Por medio de la PR, se favorece la liberación del tejido conectivo de la zona, disminuyendo el dolor y la contractura muscular, y por tanto, se justificaría el aumento de BA en la zona lumbar.

Cuando hay una lesión fascial, el cuerpo deja de recibir los estímulos apropiados, estableciéndose un proceso patológico con deficiente circulación y limitación en el aporte de nutrientes en la sustancia fundamental del TC. Esto provoca la densificación del tejido. Como el tejido denso es hipomóvil, esta situación provoca la limitación de movimiento ${ }^{290}$.

En resumen, considerando el conjunto de la población estudiada, todos los valores de movilidad lumbar se han visto incrementados después del tratamiento, tanto los del GC como los del GP, aunque en estos últimos la tendencia a la mejoría presentaba una mayor significación estadística. Teniendo en cuenta que los datos considerados como normales para el BA en la columna lumbar no están satisfactoriamente documentados ${ }^{260}$, y que la muestra no es tan amplia como se pretendía, el presente estudio podría no tener el poder suficiente para establecer conclusiones definitivas. Quizás una muestra más amplia lograría este objetivo. Además, se deberían de tener en cuenta episodios previos de LIC $^{259}$. 


\section{VI.4. INCAPACIDAD FÍSICA}

\section{VI.4.1. Análisis de la Escala de Roland Morris en el Grupo Pinza frente al Grupo Control.}

Como ya dijimos en el apartado VI.2. sobre el dolor, la $\mathrm{DMCl}$ ha sido definida como la mejoría mínima clínica y significativa experimentada por los pacientes. Para la incapacidad, medida con la escala Roland-Morris ${ }^{291}$, la DMCI es de 2,5 puntos, o al menos entre 2 y $3^{244,292,293}$. Esto significa que, por ejemplo, si un paciente antes de la intervención tenía en la escala 12,5 puntos, la diferencia es clínicamente relevante cuando dicho paciente marca en la siguiente evaluación 10 puntos o menos en la escala, pudiendo decir entonces que el paciente ha tenido una mejoría clínica relevante.

En nuestro trabajo (Tabla 10 y Figura 46), aunque no se detectó un grado alto de incapacidad, esta mejoró en todos los grupos después del tratamiento, y alcanzó un mínimo de dos puntos por debajo de los iniciales. Pero, es en el GP donde los resultados son más llamativos. Como se ha apuntado anteriormente al hablar del dolor y del BA, ambos parámetros mejoran al aplicar la PR, por lo que el paciente, al sentir menos dolor y moverse con más libertad, experimenta una mejoría en la incapacidad física que presentaba. Bongi et al. ${ }^{293}$ defienden el tratamiento del TC para reducir la incapacidad creada por la fibrosis periarticular y de la piel que ocurre en los pacientes.

La lumbalgia cursa con dolor, discapacidad y disminución de la movilidad espinal. La intensidad del dolor tiene una asociación moderada con la disminución de la movilidad y no se correlaciona bien con el grado de discapacidad pues están asociados a factores de riesgo diferentes ${ }^{294}$. En el dolor influyen factores biomecánicos, mientras que el comportamiento de evitación, el sufrimiento psicológico y otros factores psicosociales influyen de forma determinante en el desarrollo y la duración de la discapacidad ${ }^{78,295}$. El impacto de la lumbalgia sobre la incapacidad y la merma de la calidad de vida, depende más de su duración que de su intensidad, por lo que los casos crónicos son los que generan mayor sufrimiento a los pacientes ${ }^{53}$. 
Las diferentes variaciones de dolor e incapacidad a lo largo del tiempo indican la necesidad de aplicar una visión bio-psico-social del dolor, tanto en su evaluación como en su pronóstico ${ }^{296}$. Los comportamientos de evitación y los factores psicosociales influyen en el desarrollo y la duración de la discapacidad $^{297,298}$. Otro aspecto a tener en cuenta es la ansiedad y la depresión que se puede presentar en estos pacientes ${ }^{299}$, así como niveles de estrés psicológico y miedo, que orientan el tratamiento ${ }^{300}$.

La incapacidad presente en la LIC está, por tanto, determinada por una combinación de factores como dolor, factores psicológicos y adaptaciones neuromusculares ${ }^{301}$. El miedo al movimiento y a que reaparezca el dolor está relacionado con la incapacidad funcional y con el desarrollo y el mantenimiento del dolor lumbar crónico. Por el contrario, cuando el paciente se enfrenta al miedo y se expone, tanto la intensidad del dolor como el grado de discapacidad se reducen ${ }^{302}$.

\section{VI.4.2. Análisis de la Escala de Roland Morris por sexos.}

Las mujeres del GP experimentan una mejoría significativa de su incapacidad a lo largo de todo el estudio. Además, los hombres del GP reducen su grado de incapacidad de forma más marcada que los hombres del GC en la Fase 2. Así mismo, el nivel de incapacidad de los hombres del GP fue inferior al de las mujeres del GP (Tabla 25 y Figura 60).

Nuestros resultados coinciden con los de da Silva et al., ${ }^{303}$ que demuestran que las mujeres presentan mayor incidencia de incapacidad funcional que los hombres y que esta incapacidad se mantiene incluso después de controlar los factores de vulnerabilidad social. Por contra, los resultados hallados por Sauné et al. ${ }^{31}$ muestran una mayor incapacidad en hombres que en mujeres, quizás al encontrar los mismos una mayor prevalencia de lumbalgia en hombres y basar sus resultados en datos de incapacidad laboral.

Hay que tener en cuenta que las mujeres presentan mayor prevalencia de dolor que los hombres ${ }^{304}$, lo que afecta a su capacidad funcional. Sin embargo, cuando las variables sociodemográficas y diagnósticas son las mismas, las diferencias entre hombres y mujeres ya no son observables ${ }^{305}$. 
Parece existir una asociación sinérgica y positiva entre los recursos sociales disponibles (factor social) y el estilo de afrontamiento (factor psicológico), que permite que estos dos constructos se potencien mutuamente y ofrezcan un modelo psicosocial de la discapacidad en el adulto mayor. De modo que el estudio de ambos componentes se hace indispensable si se busca mejorar la salud y prevenir la discapacidad ${ }^{306}$.

Reducir la incapacidad física es importante no sólo a nivel médico sino también socio-económico, a fin de evitar el incremento de costes médicos y los servicios de cuidados a largo plazo ${ }^{307}$.

\section{VI.5. DEPRESIÓN}

\section{VI.5.1. Análisis de la Escala de Zung en el Grupo Pinza frente al Grupo}

\section{Control.}

Los pacientes aquejados de lumbalgia muestran una mayor prevalencia de depresión, ansiedad, abuso de sustancias y somatizaciones si se compara con la población general. Así la depresión está presente en el 40-65 \% de los afectados de lumbalgia, mientras que este porcentaje se reduce al 5-17\% en la población general ${ }^{78}$. De la misma forma, se ha comprobado que la presencia de depresión y somatizaciones son predictores de mala evolución de la lumbalgia, y que una mala relación social en el trabajo y la poca satisfacción en el mismo actúan como factores de riesgo de lumbalgia ${ }^{295}$. La depresión es un factor modificable en beneficio de la incapacidad ${ }^{308}$.

En nuestro estudio, a pesar de que los pacientes se encontraban dentro del rango normal de depresión, se observa una mejoría generalizada de la puntuación en ambos grupos, GC y GP, comparando la situación inicial con el final del estudio (Tabla 11 y Figura 47). Esto podría ser explicado por la relación que existe entre el paciente y el fisioterapeuta en la Unidad de Fisioterapia. El hecho de pasar cada día de tratamiento, en este caso 3 semanas (de lunes a viernes), más de media hora al día hablando, hace que el paciente se libere de sus tensiones emocionales y las comparta con el fisioterapeuta o con el resto de pacientes. El tiempo en el que se interactúa con 
los pacientes podría suponer un efecto psicoterápico para los mismos ${ }^{309}$. En este sentido, Coderch ${ }^{310}$ destaca la idea de que la relación paciente-terapeuta debe ser igualitaria y asimétrica. Igualitaria porque ambos pueden buscar y reconocer la verdad, y asimétrica porque desempeñan papeles diferentes dentro de la relación. Esta es en sí misma terapéutica, siempre que esté desarrollada en un clima de libertad de expresión, franca aceptación, sinceridad, ausencia de crítica y enjuiciamiento; unido todo ello, a la constancia y regularidad de tiempo y lugar ${ }^{311}$.

En un tratamiento individual, como el realizado con la PR, se profundiza en el conocimiento de la persona y el diálogo tiene un desarrollo similar al de la narración de una historia, pues los temas se van hilando y se avanza o profundiza en ellos. Así mismo, la comunicación corporal es diferente, puesto que con la aplicación de la PR, o cualquier otro tipo de terapia manual, se observa un contacto más cercano y permanente ${ }^{311}$. Por el contrario, la sesión realizada con el GC, en el conjunto de la sala de fisioterapia, exige una comunicación paralela para atender las demandas de varios sujetos al mismo tiempo. Aquí se sostienen diálogos comunitarios en los que cada persona, desde su camilla o sitio de tratamiento, participa con apreciaciones personales sobre el tema en cuestión y, evidentemente la comunicación corporal es completamente diferente.

Para Verechei et al. ${ }^{312}$ hay correlación entre la depresión de los pacientes y la LIC. Además, los trastornos psicológicos se han identificado no solo como consecuencia sino como causa de cronificación de la lumbalgia, ya que actúan como factores de riesgo de la misma.

Como ya se ha comentado, las constantes conductas de evitación del dolor que presentan los pacientes con lumbalgia aumentan la percepción del mismo, al focalizar la atención sobre él; además, aumentan el miedo al dolor y crean estados emocionales negativos (ansiedad, síntomas depresivos, etc.). Estos estados exacerban la sensación dolorosa ${ }^{313}$ y aumentan el deterioro psicológico inhibiendo los procesos de recuperación. 


\section{VI.5.2. Análisis de la Escala de Zung por sexos.}

Al hacer la disociación por sexos, se hace evidente el efecto positivo del tratamiento en ambos grupos de mujeres y en el GP de los hombres (Tabla 26 y Figura 61).

Hay evidencia en la literatura de que la depresión se presenta con más frecuencia en mujeres que en varones, casi duplicando los $\operatorname{casos}^{314}$, en nuestro estudio no hemos apreciado esa circunstancia. Quizás sea por la posibilidad de hablar y comentar sus problemas o por sentirse cuidadas y no cuidadoras, las mujeres experimentan mejoría en sus problemas de salud. Es curioso que, tanto hombres como mujeres del GC, muestren cierta tendencia al repunte de su estado depresivo a los tres meses del tratamiento mientras que en los GP la tendencia es descendente y significativamente mejor al finalizar el estudio.

\section{VI.6. CALIDAD DE VIDA}

La calidad de vida (CV) se basa en mediciones que conllevan una importante carga de subjetividad, ya que se evalúa la sensación de bienestar que puede ser expresada por los pacientes y configura un grupo de sensaciones como percepciones personales del "sentirse bien". La sensación de dolor, discapacidad y funcionalidad de una persona está influida por sus características individuales así como por sus expectativas ${ }^{315}$.

El estudio de la CV relacionada con la salud en pacientes que sufren LIC es objeto de un creciente interés, pero la información generada hasta ahora no es muy clara ${ }^{316}$. Documentar en qué medida la $\mathrm{CV}$ de los enfermos de lumbalgia se encuentra afectada, puede ser un paso importante para establecer un manejo integral de los enfermos, limitar las posibles secuelas asociadas, y lograr la pronta incorporación de los pacientes a sus actividades familiares, sociales y laborales ${ }^{316}$.

El alto grado de subjetividad a la hora de medir la CV hace que no exista una base conceptual para cuantificar este término ${ }^{317,318}$. La Figura 69 explica cómo se va modificando la $\mathrm{CV}$ en un sujeto con el paso del tiempo. En el tiempo 1 hay un paciente que sufre un episodio agudo y se recupera 
completamente. Su CV es la misma que al inicio. En el tiempo 2, el sujeto sufre un episodio crónico, la diferencia entre las expectativas y la realidad se agranda y, por lo tanto, sufre un deterioro de su CV. En el tiempo 3, el sujeto ha «reajustado» sus expectativas y la diferencia entre éstas y la realidad es la misma que al inicio, su percepción de CV no se modifica.

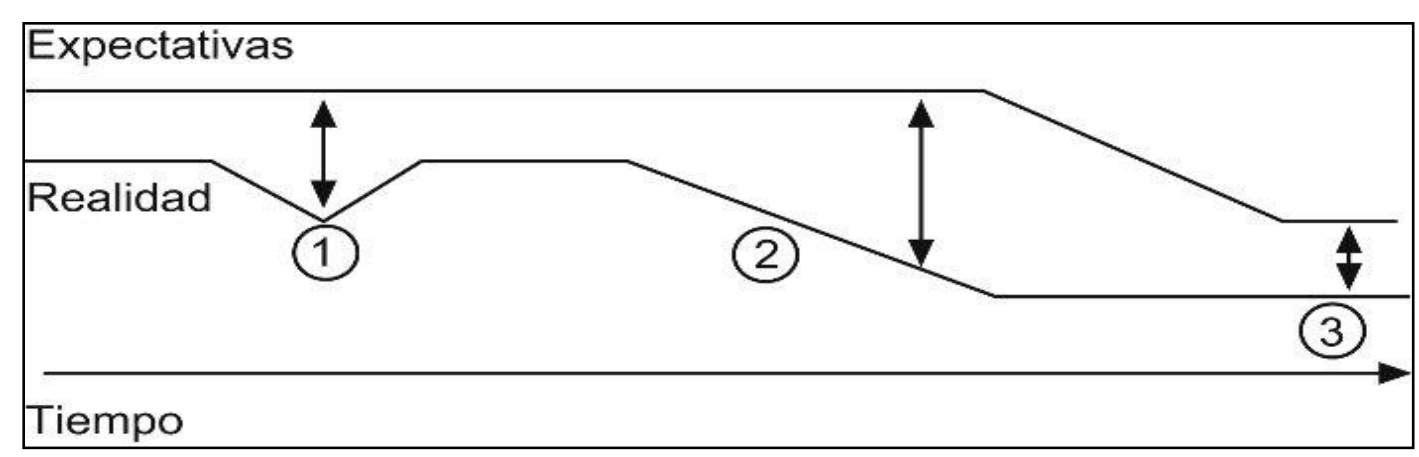

Figura 69. La calidad de vida es el resultado de la diferencia entre las expectativas y la realidad de la experiencia. (Adaptado de Carr et al. ${ }^{319}$ )

Como comentamos en el apartado Material y Métodos, el PSN no es un instrumento eficaz para medir los cambios a lo largo del tiempo entre las poblaciones sanas, pero sí para establecer comparaciones de CV entre grupos $^{320}$.

Se han valorado los resultados en el PSN en la Fase 0 en comparación con los valores normativos Tablas 34 y 35, coincidiendo con García et al. ${ }^{321}$ en la observación de valores más elevados en prácticamente todas las dimensiones (excepto para las dimensiones "Reacciones Emocionales" y "Aislamiento Social"), lo que indica una percepción peor de la CV en pacientes con LIC que en la población general sobre la que se desarrolló el estudio.

Estos resultados pueden ser explicados estudiando las diferencias que existen entre las poblaciones comparadas, ya que nuestros pacientes presentan una patología crónica, lo que podría explicar su peor CV. Una vez acabado el tratamiento, los valores disminuyen en todas las dimensiones, sobre todo en el GP.

En este apartado, Contreras ${ }^{322}$ defiende que se encuentran asociados con las discapacidades por lumbalgia los siguientes factores: sexo femenino, mayor edad, tener otros familiares con antecedentes de lumbalgia, más dolor, 
consumo de alcohol, el consumo de tabaco, mantener la postura de bipedestación por más de 5 horas, mantener la postura sedente por más de 5 horas, tener diagnóstico de depresión, y realizar trabajos donde predominan los movimientos repetitivos. Serían factores protectores ${ }^{262,322}$ : la condición de soltero, tener menos de tres hijos, vivir en viviendas adecuadas, usar apoyabrazos, asistir inmediatamente a los servicios médicos y/o a los Servicios de Rehabilitación.

Tabla 34. Distribución de las puntuaciones para cada dimensión de la versión española del NHP en la Población General de 41 años o más de Barcelona ${ }^{190}$

\begin{tabular}{|c|c|c|c|c|c|c|}
\hline Energía & Dolor & $\begin{array}{c}\text { Reacciones } \\
\text { Emocionales }\end{array}$ & Sueño & $\begin{array}{c}\text { Aislamiento } \\
\text { Social }\end{array}$ & $\begin{array}{c}\text { Movilidad } \\
\text { física }\end{array}$ & $\begin{array}{c}\text { PSN } \\
\text { TOTAL }\end{array}$ \\
\hline $14.1 \pm 28.0$ & $15.6 \pm 25.9$ & $20.8 \pm 22.8$ & $23.2 \pm 29.2$ & $7.2 \pm 15.0$ & $14.9 \pm 20.3$ & $15.5 \pm 17.5$ \\
\hline
\end{tabular}

Modificado de BiblioPRO, www.rediryss.net según el estudio realizado por Antó et al. en España.

Tabla 35. Puntuaciones medias y desviaciones estándar para cada dimensión de la versión española del NHP por sexo en la población general de 41 años o más de Barcelona ${ }^{190}$

\begin{tabular}{|c|c|c|c|c|c|c|c|}
\hline & Energía & Dolor & $\begin{array}{c}\text { Reacciones } \\
\text { Emocionales }\end{array}$ & Sueño & $\begin{array}{c}\text { Aislamiento } \\
\text { Social }\end{array}$ & Movilidad & TOTAL \\
\hline Hombres & $8.5 \pm 21.6$ & $9.1 \pm 20.8$ & $16.1 \pm 19.5$ & $17.6 \pm 25.4$ & $5.7 \pm 13.0$ & $10.6 \pm 17.4$ & $11.0 \pm 13.7$ \\
\hline Mujeres & $19.0 \pm 31.9$ & $21.5 \pm 28.4$ & $25.0 \pm 24.6$ & $28.2 \pm 31.4$ & $8.6 \pm 16.5$ & $18.8 \pm 21.9$ & $19.7 \pm 19.4$ \\
\hline
\end{tabular}

Modificado de BiblioPRO, www.rediryss.net

A pesar de que la literatura consultada muestra los datos de CV en conjunto y no por dimensiones, a continuación se analizan de forma independiente cada una de las dimensiones estudiadas en el PSN (energía, dolor, reacciones emocionales, sueño, aislamiento social y movilidad física) mostrando los resultados obtenidos en este estudio.

\section{VI.6.1. Análisis de la dimensión Energía del Perfil de salud de Nottingham en el Grupo Pinza frente al Grupo Control y por sexos.}

Se observó una tendencia al aumento de la sensación de Energía en el GP tras el tratamiento, que aumenta haciéndose significativo a los tres meses del mismo (Tabla 12 y Figura 48). La liberación de la fascia hace que se 
rompan adherencias de la misma, dando movilidad al tejido ${ }^{290} \mathrm{y}$, por tanto, mejorando la sensación de energía del individuo.

Al hacer la separación por sexos, los resultados son significativamente más bajos que los valores normativos en el GP, tanto en hombres como en mujeres (Tabla 27 y Figura 62).

\section{VI.6.2. Análisis de la dimensión Dolor del Perfil de salud de Nottingham en el Grupo Pinza frente al Grupo Control y por sexos.}

Hay un descenso del dolor en ambos grupos justo al finalizar el tratamiento, aunque más acentuado en el grupo Pinza (Tabla 13 y Figura 49). Esto se corresponde con lo encontrado en el apartado VI.2. sobre el dolor valorado mediante la escala EVA.

En la separación por sexos, la sensación de dolor se reduce sobre todo en Fase 2, y se hace evidente en hombres y mujeres del GP (Tabla 28 y Figura 63). En la fase 2 las mujeres siempre manifiestan más grado de dolor que los hombres resultados que coinciden con diferentes estudios ${ }^{323,324}$. Esta mayor frecuencia de dolor intenso en el sexo femenino se justifica por la presencia de factores psicosociales aludiendo a que la mujer soporta una carga mayor de tareas y responsabilidades en el entorno familiar a pesar de su inserción social como trabajadora. Por otra parte, como ya se comentó en el apartado VI.2.2., las hormonas femeninas pueden modificar los procesos nociceptivos y el umbral para el dolor de manera que las mujeres pueden percibirlo con mayor intensidad ${ }^{256}$.

A pesar de todo ello, López et al. ${ }^{324}$ sugieren que la edad y el sexo carecen de influencia en el deterioro de la CV de las personas que sufren dolor. 


\section{VI.6.3. Análisis de la dimensión Reacciones Emocionales del Perfil de salud de Nottingham en el Grupo Pinza frente al Grupo Control y por sexos.}

Al acabar el tratamiento la mejoría se muestra en ambos grupos, GC y GP, pero en este último los resultados se mantienen en el tiempo (Tabla 14 y Figura 50). Resulta muy llamativo observar cómo la Figura 43 (Escala de Zung de depresión) y la figura 46 (PSN de reacciones emocionales) muestran el mismo perfil. El repunte en la fase 2 que se produce en ambas variables en el GC, y no en el GP, indica que este último tratamiento tiene mucho que ver con las respuestas psicológicas del paciente frente a su enfermedad. Es muy probable que se deba a la mayor relación fisioterapeuta-paciente que se establece en esta técnica fisioterápica como en el resto de terapias manuales ${ }^{309-311}$.

Cuando observamos lo que ocurre en la separación por sexos, sólo las mujeres obtienen mejoría significativa. Generalmente, son estas las que presentan mayor labilidad emocional y por ello los cambios pudieran ser más manifiestos (Tabla 29 y Figura 64).

\section{VI.6.4. Análisis de la dimensión Sueño del Perfil de salud de Nottingham en el Grupo Pinza frente al Grupo Control y por sexos.}

Los pacientes con lumbalgia presentan alteraciones del sueño y su conocimiento podría tener importantes implicaciones clínicas ${ }^{325}$. Cuando mejoran las reacciones emocionales, sentimos menos dolor y nos movemos mejor, el descanso durante el sueño es más reconfortante. Los resultados de sueño mejoraron solo al final del estudio en el GP (Tabla 15 y Figura 51).

Al tener en cuenta el sexo se aprecia que tanto hombres como mujeres del GP mejoraron este parámetro (Tabla 30 y Figura 65).

\section{VI.6.5. Análisis de la dimensión Aislamiento Social del Perfil de salud de Nottingham en el Grupo Pinza frente al Grupo Control y por sexos.}

El comportamiento de esta variable tanto teniendo en cuenta a toda la población como en la división por sexos, no ofrece diferencias significativas y 
además muestra perfiles muy diferentes y discordantes (Tabla 16 y Figura 52; Tabla 31 y Figura 65, respectivamente).

Según Hiyama et al. ${ }^{255}$ el dolor afecta al bienestar social y psicológico de los pacientes con LIC, por lo que, su alivio mantendría al margen el aislamiento social, con un comportamiento estable de la variable a lo largo del estudio.

\section{VI.6.6. Análisis de la dimensión Movilidad Física del Perfil de salud de Nottingham en el Grupo Pinza frente al Grupo Control y por sexos.}

La LIC tiene un importante impacto en el aspecto físico de la $\mathrm{CV}^{326}$. En este estudio la percepción del paciente sobre su movilidad mejoró significativamente en el GP coincidiendo con lo que objetivamente se midió en el BA (Tabla 17 y Figura 53).

Al hacer la separación por sexos, son los hombres del GP los que experimentan mayores cambios, coincidiendo también con lo encontrado en el BA (Tabla 32 y Figura 67).

Estudios recientes ${ }^{294}$ muestran que las limitaciones físicas que acompañan a la lumbalgia son las causantes directas de que se desarrolle una mala CV. Kovacs et al. ${ }^{294}$ muestran que la probabilidad de desarrollar una mala CV y discapacidad física se incrementa en relación directa al tiempo de evolución de la lumbagia.

\section{VI.6.7. Análisis de del Perfil de salud de Nottingham "Total" en el Grupo Pinza frente al Grupo Control y por sexos.}

EI PSN Total al acabar el tratamiento es menor en el GP, mejoría que se mantiene a los tres meses y casi lo hace al final del estudio (Tabla 18 y Figura 54). Al mejorar cada dimensión por separado, sobre todo en mujeres, es lógico que mejore el cómputo total del baremo. Las puntuaciones obtenidas en nuestro estudio son similares a las aportadas por otros investigadores como Kampfe et al. ${ }^{327}$ quienes observaron que los valores alcanzados por las mujeres son superiores en la mayoría de las dimensiones indicando una peor CV que los hombres. Aún así, tanto hombres como mujeres del GP mejoraron su CV de forma significativa (Tabla 33 y Figura 68). 


\section{VI.7. RECIDIVAS}

De los 65 pacientes que acabaron el estudio, sólo un 10,77\% presentó un nuevo episodio de dolor lumbar a lo largo de los 6 meses de duración del seguimiento. Es decir, 7 de los 65 pacientes volvieron a sufrir un cuadro de lumbalgia en ese tiempo. De ellos, 3 pertenecían al GC (10\%) y 4 al GP $(11,42 \%)$. Estos datos son inferiores a los encontrados en la literatura consultada, donde más del $20 \%$ de las lumbalgias recurren en 6 meses $^{15}$. Los resultados de Hestbaek et $\mathrm{al}^{30}$ muestran un porcentaje de recaídas incluso más elevado, del $60 \%$ después de 6 meses. De esta forma, se hace patente una disminución importante del porcentaje de recidivas esperado, apoyando positivamente el empleo de la fisioterapia como tratamiento para la lumbalgia, aunque no se puede relacionar directamente con la PR, ya que ambos grupos obtuvieron buenos resultados.

\section{VI.8. MEDICACIÓN}

A los pacientes se les prescribía sobre todo Paracetamol e lbuprofeno. El Paracetamol es el medicamento inicial usado para la lumbalgia aguda, sin embargo, no hay una evidencia científica firme que apoye esta recomendación. Una dosis regular o a demanda de paracetamol no afecta al tiempo de recuperación comparado con placebo, lo que cuestiona el uso universal del mismo para los pacientes de esta patología ${ }^{4,55,328}$.

De la misma manera, el uso de antiinflamatorios no esteroideos en el tratamiento de la LIC beneficia sólo a corto plazo. Además, muchos pacientes muestran efectos secundarios a su ingesta ${ }^{329-333}$. Siguiendo con esta línea de investigación, Brzezinsky ${ }^{334}$ opina que la administración de dexketoprofeno en el manejo de la LIC facilita un rápido retorno a la actividad física y por tanto, un pronto retorno al trabajo. Sin embargo, no es el antiinflamatorio más recetado en nuestro Centro de Salud.

No fue posible realizar un análisis fiable de la reducción de la medicación en la población de estudio, ya que muchos de los pacientes se automedican ante la presencia del dolor, sea lumbar o de cualquier otra localización. 


\section{VI.9. LIMITACIONES DEL ESTUDIO}

Es evidente que el presente estudio presenta ciertas limitaciones:

- El hecho de que un único fisioterapeuta haya realizado todas las mediciones da homogeneidad a los resultados, pero puede limitar en cierta manera la generalización de los mismos.

- La hipótesis planteada requiere una investigación mucho más profunda. Nosotros hemos decidido utilizar un programa ya establecido por protocolo de electroterapia y termoterapia y añadir la técnica de Pinza Rodada para valorar las posibles mejoras, y quizás la combinación de esta técnica con otras diferentes a las protocolizadas alcance los mismos o mejores resultados.

- La época profunda de crisis económica que se vivió durante la recopilación de datos para el estudio es un aspecto a tener en cuenta, pues dificultó el cumplimiento del tratamiento por parte de los pacientes y afectó su estado de ánimo.

- La posibilidad de reclutamiento del servicio donde se ha realizado el estudio es relativamente pequeña, debiendo de continuar tanto el reclutamiento como el seguimiento a largo plazo de las cohortes experimentales. Con ello sería posible realizar futuros estudios donde los resultados inter-grupos obtengan mayor potencia clínica y estadística. 


\section{CONCLUSIONES}




\section{CONCLUSIONES}

1. El perfil del paciente con lumbalgia inespecífica crónica de nuestro estudio es: mujer, entre 35 y 45 años de edad, casada, con estudios primarios y trabajos de exigencia física media.

2. La aplicación de la Pinza Rodada añadida al tratamiento estándar de la lumbalgia inespecífica crónica proporciona una mejoría estadísticamente significativa en la disminución del dolor, en una cuantía que supera la diferencia mínima clínicamente relevante.

3. La incorporación de la técnica de Pinza Rodada al tratamiento estándar de la lumbalgia inespecífica crónica mejora del balance articular, sobre todo en extensión lumbar e inclinación lateral.

4. La incorporación de la técnica de Pinza Rodada reduce significativamente el grado de discapacidad, medido con el cuestionario de Roland Morris, inmediatamente después de finalizar el periodo de tratamiento.

5. Las modifiaciones que la técnica de Pinza Rodada provoca en la estructura y fisiología del tejido conectivo justifica las mejorías clínicas de dolor, balance articular y discapacidad observadas.

6. La técnica de Pinza Rodada incorporada al tratamiento habitual de la lumbalgia mecánica crónica disminuye el sentimiento de depresión, evaluado mediante la escala de Zung, de forma progresiva y mantenida en el tiempo.

7. La incorporación de la técnica de Pinza Rodada favorece la calidad de vida de los pacientes con lumbalgia inespecífica crónica, especialmente en las dimensiones de energía, dolor, reacciones emocionales y movilidad física, manteniéndose las ganancias incluso a medio plazo.

8. La relación terapéutica que se establece con esta técnica de terapia manual, en la que el contacto con el paciente, tanto físico como 
psicológico es mucho más cercano, está relacionado con las mejoras observadas en el plano psicológico y de calidad de vida.

9. El sexo establece diferencias en el comportamiento de algunas de las variables evaluadas como el dolor, la discapacidad y algunos aspectos de la calidad de vida (dolor, sueño y valoración global), siempre con peores valoraciones en las mujeres.

10. La mejoría observada con la técnica de Pinza Rodada en la incidencia de recidivas no supera al obtenido con el tratamiento estándar, por lo que sería conveniente realizar estudios más detallados sobre este parámetro.

11. No se han podido extraer conclusiones evidentes sobre la influencia de la técnica de Pinza rodada en el uso de medicación, haciéndose necesarios estudios que profundicen en este aspecto.

Creemos que este estudio tiene interés socio-sanitario en el sistema sanitario de Castilla y León, ya que se podrían reducir costes y listas de espera en el tratamiento de la lumbalgia inespecífica crónica. La técnica de Pinza Rodada requiere un tiempo adicional al del tratamiento estándar y, para su aplicación, el fisioterapeuta de Atención Primaria debería disponer del mismo para atender a cada persona de manera individual y así obtener los beneficios observados con esta técnica específica. 


\section{BIBLIOGRAFÍA}




\section{BIBLIOGRAFIA}

1. Vrbanic T. Low back pain: from definition to diagnosis. Reumatizam. 2011; 58: 105-7.

2. Pérez I, Alcorta I, Aguirre G, Arístegui G, Caso J, Esquisabel R, et al. Guía de Práctica Clínica en la Lumbalgia. Osakidetza; 2007.

3. Kovacs F. Manejo clínico de la lumbalgia inespecífica. Semergen. 2002; 28: 1-3.

4. Grupo Español de trabajo del Programa Europeo CB. Guía de Práctica Clínica para la Lumbalgia Inespecífica [monografía en Internet].Consultado el 15 octubre del 2012. Disponible en: www.REIDE.org.

5. González M, Condón M. Incapacidad por dolor lumbar en España. Med Clin. 2000; 114: 491-2.

6. Chou R, Qaseem A, Snow V, Casey D, Cross J, Shekelle P, et al. Diagnosis and treatment of low back pain: a joint clinical practise guideline from the American College of Physicians and the American Pain Society. Ann Inter Med. 2007; 147: 478-91.

7. Caracuel M. Protocolo diagnóstico de la lumbalgia mecánica. Medicine. 2005; 9: 1928-30.

8. Ehrlich G. Low back pain. Bull World Health Organ. 2003; 91: 671-76.

9. Woolf A, Pfleger B. Burden of major musculoskeletal conditions. Bull World Health Organ. 2003; 81: 646-56.

10. Manek N, McGregor A. Epidemiology of back disorders: prevalence, risk factors and prognosis. Curr Opin Rheumatol. 2005; 17: 134-40.

11. Peña J, Brieva P, Peña C, Humbría A. Unidades de espalda: un modelo multidisciplinario. Rev Esp Reumatol. 2002; 29: 499-502.

12. Hoving $\mathrm{J}$, Koes $\mathrm{B}$, de Vet $\mathrm{H}$, van der Windt $\mathrm{D}$, Assendelft $\mathrm{W}$, van Mameren $\mathrm{H}$, et al. Manual therapy, physical teherapy or continued care by a general practitioner for patients with neck pain. A randomizes, controlled trial. Ann Intern Med. 2002; 136: 713-22.

13. Koes B, van Tulder M. Acute low back pain. Am Fam Physician. 2006; 74: 
803-5.

14. Cassidy J, Cote P, Carrol L, Kristman V. Incidence and course of low back pain episodes in the general population. Spine. 2005; 30: 2817-23.

15. Burton A, Balagué $F$, Cardon G, Eriksen $H$, Henrotin $Y$, Lahad A, et al. European guidelines for prevention in low back pain. Eur Spine J. 2006; 15: $136-68$.

16. Foster N, Hill J, Hay E. Subgrouping patientes with low back pain in primary care: are we getting any better at it? Man Ther. 2011; 16: 3-8.

17. Marras W, Davis K, Ferguson S, Lucas B, Gupta P. Spine loading characteristics of patients with low back pain compared with asymptomatic individuals. Spine. 2001; 26: 2566-74.

18. Richmond J. Multi-factorial causative model for back pain management; relating causative factors and mechanisms to injury presentations and designing time and cost effective treatment thereof. Med Hypotheses. 2012; 79: 232-40.

19. Whittaker J, Warner M, Stokes M. Comparison of the sonographic features of the abdominal wall muscles and connective tissues in individuals with and without lumbopelvic pain. J Orthop Sports Phys Ther. 2013; 43: 11-9.

20. Izzo R, Popolizio T, D’Aprile P, Muto M. Spinal pain. Eur J Radiol. 2015; 84: 746-56.

21. Rull M, Miralles M, Añez C. Fisiopatología del dolor radicular. Rev. Soc. Esp. Dolor. 2001; 8: 22-34.

22. Fairbank J, Gwilym S, France J, Daffner S, Dettori J, Hermsmeyer J, et al. The role of classification of chronic low back pain. Spine. 2011; 36: 19-42.

23. Sanz B, González A, Galán A. Lumbalgia: guía de actuación basada en la evidencia científica. SMMFYC. 2001; 3: 35-40.

24. Abenhaim L, Rossignol M, Valat J, Nordin M, Avouac B, Blotman F, et al. The role of activity in the therapeutic management of back pain. Report of the International Paris Task Force on Back Pain. Spine. 2000; 25: 1-33.

25. van Tulder M, Becker A, Bekkering T, Breen A, del Real M, Hutchinson A, 
et al. European guidelines for the management of acute nonspecific low back pain in primary care. Eur Spine J. 2006; 15: 169-91.

26. Mcintosh G, Hall H. Low back pain (acute). BMJ Clin Evid. 2011; 2011: 1102.

27. Insausti J. Lumbalgia inespecífica: en busca del origen del dolor. Reumatol Clin. 2009; 5: 19-26.

28. Savigny P, Kuntze S, Watson P, Underwood M, Ritchie G, Cotterell M, et al. Low back pain: early management of persistent non-specific low back pain. Full guideline. National Collaborating Centre for Primary Care and Royal College of General Practitioners. 2009.

29. Field J. Back pain: what is happening when it becomes chronic? Clin Chiropractic. 2009; 12: 45-51.

30. Hestbaek L, Leboeuf $Y$, Manniche $C$. Low back pain: what is the long-term course? A review of studies of general patient populations. Eur Spine J. 2003; 12: 149-65.

31. Sauné $M$, Arias $R$, Lleget I, Ruiz A, Escribá J, Gil M. Estudio epidemiológico de la lumbalgia. Análisis de factores predictivos de incapacidad. Rehabilitación. 2003; 37: 3-10.

32. Humbría A, Carmona L, Ortiz A, Peña J. Tratamiento de la lumbalgia inespecífica: ¿qué nos dice la literatura médica? Rev Esp Reumatol. 2002; 29: 494-8.

33. Balagué F, Mannion A, Pellisé F, Cedraschi C. Non specific low back pain. Lancet. 2012; 379: 482-91.

34. Deyo R, Weinstein J. Low back pain. N Engl J Med. 2001; 344: p. 63-370.

35. Ariza R. Criterios de baja laboral en lumbalgias. Medicine. 2005; 9: 193436.

36. Bueno J, Rodríguez J, Humbría A. Abordaje diagnóstico y terapéutico de la lumbalgia en atención primaria. FMC- Formación Médica Continuada en Atención Primaria. 2001; 8: 152-69.

37. Ehrlich GE. Back pain. J Rheumatol Suppl. 2003; 67: 26-31.

38. Humbría A. ¿Pedimos demasiadas exploraciones complementarias a los 
pacientes con lumbalgia crónica inespecífica? Revista española de reumatología. 2003; 30: 185.

39. Lloyd D, Findley G, Roberts N, Nurmikko T. Illness behavior in patients with chronic low back pain and activation of the affective circuitry of the brain. Psychosom Med. 2014; 76: 413-21.

40. Pérez J. Contribución al estudio de la lumbalgia inespecífica. Rev Cubana Ortop Traumatol. 2006; 20.

41. Valat J, Goupille P, Védere V. Low back pain: risk factors for chronicity. Rev Rhum Engl Ed. 1997; 64: 189-94.

42. Stevenson J, Weber C, Smith T, Dumas G, WJ A. A longitudinal study of the development of low back pain in industrial population. Spine. 2001; 26 : 1370-7.

43. Humbría A. Consulta monográfica de columna lumbar. Protocolo de investigación clínica, ¿cómo son los pacientes con lumbalgia crónica inespecífica? Rev Esp Reumatol. 2004; 31: 453-61.

44. Work Safe BC. Prevención del estrés térmico en el trabajo. Work Safe. 2005.

45. Grupo de trabajo de salud laboral de la Comisión de Salud Pública del Consejo Interterritorial del Sistema Nacional de Salud. Protocolo de vigilancia sanitaria específica para los/as trabajadores/as expuestos/as a riesgos derivados de la manipulación manual de cargas. Consejo Interterritorial de Salud. 1999.

46. Costa-Black K, Loisel P, Anema J, Pransky G. Back pain and work. Best Pract Res Clin Rheumatol. 2010; 24: 227-40.

47. Haldorsen $E$, Indahl $A$, Ursin $H$. Patients with low back pain not returning to work. A 12- month follow-up study. Spine. 1998; 23: 1202-8.

48. Ocaña U. Lumbalgia ocupacional y discapacidad laboral. Rev Fisioter. 2007; 6: 17-26.

49. Ellegaard $\mathrm{H}$, Pedersen $B$. Stress is dominant in patients with depression and chronic low back pain. A qualitative study of psychotherapeutic interventions for patients with non-specific low back pain of 3-12 months duration. BMC Musculoskelet Disord. 2012; 13: 166. 
50. Tan B, Smith A, O'Sullivan P, Chen G, Burnett A, Briggs A. Low back pain beliefs are ssociated to age, location of work, education and pain-related disability in Chinese healthcare professionals working in China: a cross sectional survey. BMC Musculoskelet Disord. 2014; 15: 255.

51. Hagen K, Hilde G, Jantvedt G, Winnem M. The Cochrane review of advice to stay active as a single treatment for low back pain and sciatica. Spine. 2002; 27: 1736-41.

52. Hagen K, Jantvedt G, Hilde G, Winnem M. The updated cochrane review of bed rest for low back pain and sciatica. Spine. 2005; 30: 542-6.

53. Kamper S, Stanton T, Williams C, Maher C, Hush J. How is recovery from low back pain measured? A systematic review of the literature. Eur Spine J. 2011; 20: 9-18.

54. Jovella A, Navarro-Rubio M. Evaluación de la evidencia científica. Med Clin. 1995; 105: 740-3.

55. Cuesta A, Montes A. Evidencia clínica en la lumbalgia crónica. Rev Fisioter. 2007; 6: 5-8.

56. Chou R, Huffman L. Medications for Acute and Chronic low back pain: a review of the evidence for an American Pain Society/American College of Physicians Clinical Practice Guideline. Ann Inten Med. 2007; 147: 505-14.

57. Kovacs F, Llobera J, Abraira V, Lázaro P, Pozo F, Kleinbaum D. Effectiveness and cost-effectiveness analysis of Neuroreflexotherapy for subacute and chronic low back pain in Routine General Practice: a cluster randomized, controlled trial. Spine. 2002; 27: 1149-59.

58. Chou R, LH H. Nonpharmacologic therapies for acute and chronic low back pain: A review of the evidence for an American Pain Society/American College of Physicians Clinical Practice Guideline. Ann Intern Med. 2007; 147: 492-504.

59. Shakoor M, Rahman M, Moyeenuzzaman M. Effects of deep heat therapy on the patients with chronic low back pain. Mymensingh Med J. 2008; 17: 32-8.

60. Lloyd A, Scott D, Akehurst R, Lurie-Luke E, Jessen G. Cost-effectiveness of low-level heat wrap therapy for low back pain. Value Health. 2004; 7 : 
413-22.

61. Cherkin D, Sherman K, Kahn J, Wellman R, AJ C, Johnson E, et al. A comparison of the effects of 2 types of massage and usual care on chronic low back pain: a randomized, controlled trial. Ann Intern Med. 2011; 155: 1-9.

62. Furlan A, Imamura M, Dryden T, Irvin E. Massage for low back pain: an updated systematic review within the framework of the Cochrane Back Review Group. Spine. 2009; 34: 1669-84.

63. Melzack R. Gate control theory: on the evolution of pain concepts. Pain Forum. 1996; 5: 128-38.

64. Van Tulder M, Cherkin D, Berman B, Lao L, Koes B. The effectiveness of acupuncture in the management of acute and chronic low back pain. A systematic review within the framework of the cochrane collaboration back review group. Spine. 1999; 24: 1113-23.

65. Brosseau L, Milne S, Robinson V, Marchand S, Shea B, Wells G. Efficacy of the transcutaneous electrical nerve stimulation for the treatment of chronic low back pain: A meta-analysis. Spine. 2002; 27: 596-603.

66. Zimmermann $F$. Les massages réflexes au service des douleurs. Kinésithér Ann. 2002; 1: 27-8.

67. Bossy J. Le massage réflexe et autres methodes de therapie manuelle réflexe. Enclo. Méd. Chir. Kinésithérapie. 1987; 26-130-A-10.

68. Khadilkar A, Milne S, Brosseau L, Robinson V, Saginur M, Shea B, et al. Neuroestimulación eléctica transcutánea (TENS) para el dolor lumbar crónico. La Biblioteca Cochrane Plus. 2008; 4.

69. Facci L, Nowotny J, Tormem F, Trevisani V. Effects of transcutaneous electrical nerve stimulation (TENS) and interferential currents (IFC) in patients with nonspecific chronic low back pain: randomized clinical trial. Sao Paulo Med. 2011; 129: 206-16.

70. Barker K, Elliott C, Sackley C, Fairbank J. Treatment of chronic back pain by sensory discrimination training. A phase I RCT of a novel device (FairMed) vs. TENS. BMC Musculoskelet Disord. 2008; 9: 97.

71. Daffada P, Walsh N, McCabe C, Palmer S. The impact of cortical 
remapping interventions on pain and disability in chronic low back pain: a systematic review. Physiotherapy. 2015; 101: 25-33.

72. Ganesh G, Chhabra D, Pattnaik M, Mohanty P, Patel R, Mrityunjay K. Effect of trunk muscles training using a star excursion balance test grid on strength, endurance and disability in persons wity chronic low back pain. $J$ Back Musculoskelet Rehabil. 2015; 28: 521-30.

73. Lederman E. The myth of core stability. J Bodyw Mov Ther. 2010; 14: 8498.

74. Akuthota V, Nadler S. Core strengthening. Arch Phys Med Rehabil. 2004; 85: 86-92.

75. Massé-Alaire H, Schneider C. Corticomotor control of deep abdominal muscles in chronic low back pain and anticipatory postural adjustments. Exp Brain Res. 2012; 218: 99-109.

76. Massé-Alarie $\mathrm{H}$, Schneider $\mathrm{C}$. Cerebral reorganization in chronic low back pain and neurostimulation to improve motor control. Neurophysiol Clin. 2011; 41: 51-60.

77. Hodges $P$. Changes in motor planning of feedforward postural responses of the trunk muscles in low back pain. Exp Brain Res. 2001; 141: 261-6.

78. Pincus T, Burton A, Vagel S, AP F. A systematic review of psychological factors as predictors of chronicity/disability in prospective cohorts of low back pain. Spine. 2002; 27: 109-20.

79. Brennan G, Fritz J, Hunter S, Thackeray J, Delitto A, Erhard R. Identifying subgroups of patients with acute/subacute "nonspecific" low back pain: results of a randomized clinical trial. Spine. 2006; 31: 623-31.

80. Govenden D, Serpell M. Improving outcomes for chronic pain in primary care. Practitioner. 2014; 258: 13-7.

81. Goats G, Keir K. Connective tissue massage. Br J Sp Med. 1991; 25: 131 33.

82. Pilat A. Terapias miofasciales: Inducción miofascial. $1^{\underline{a}}$ ed. Madrid: McGraw-Hill; 2003.

83. Calle $P$, Muñoz-Cruzado $M$, Catalán $D$, Fuentes $M$. Tratamiento 
fisioterapéutico sistemático del tejido conjuntivo en el aparato musculoesquelético. Fisioterapia. 2007; 29: 145-52.

84. Schleip R, Muller D. Training principles for fascial connective tissues. Scientific foundation and suggested practical applications. J Bodyw Mov Ther. 2012; 20: 1-13.

85. Gartner L, Hiatt J. Histología Básica. 1ํㅡㄹ ed. Barcelona: Elsevier-Mosby; 2011.

86. Gartner L, Hiatt J. Color textbook of Histology. $3^{\underline{a}}$ ed. Edinburgh: Elsevier Saunders; 2007.

87. Ross M, Pawlina P. Histology: a text and atlas: with correlated cell and

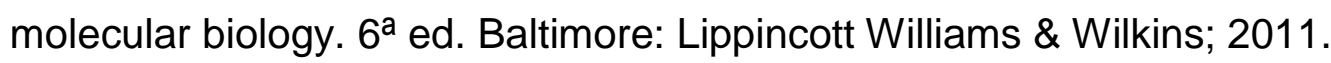

88. Schleip R, Duerselen L, Vleeming A, Naylor I, Lehmann-Horn F, Zorn A, et al. Strain hardening of fascia: Static stretching of dense fibrous connective tissues can induce a temporary stiffness increase accompanied by enhanced matrix hydration. J Bodyw Mov Ther. 2012; 16: 94-100.

89. Rodriguez I. Efectividad de la terapia de liberación miofascial en el tratamiento de la cervicalgia mecánica en el ámbito laboral. Facultad de Ciencias de la salud. A Coruña. La Coruña: tesis doctoral; 2011.

90. Stecco C, Porzionato A, Lancerotto L, SteccoA, Macchi V, Day D, et al. Histological study of the deep fasciae of the limbs. J Bodyw Mov Ther. 2008; 12: 225-30.

91. Stecco C, Gagey O, Belloni A. Anatomy of the deep fascia of the upper limb. Second part: study of innervation. Morphologie. 2007; 91: 38-43.

92. Willard F, Vleeming A, Schuenke M, Danneels L, Schleip R. The thoracolumbar fascia: anatomy, function and clinical considerations. J Anat. 2012; 221: 507-36.

93. Stecco C, Macchi V, Porzionato A, Fabrice D, De Caro R. The fascia: the forgotten structure. IJAE. 2011; 3: 127-38.

94. Findley $\mathrm{T}$. Second International Fascia Research Congress. Int $\mathrm{J}$ Ther Massage Bodywork. 2009; 29: 1-6. 
95. Schleip R, Findley T, Chaitow L, Huijing P. Fascia: the tensional network of the human body. 1a ed. Londres: Elsevier; 2012.

96. Findley T, Shalwala M. Fascia Research Congress evidence from the 100 year perspective of Andrew Taylor Still. Int J Ther Massage Bodyw. 2013; 3: 356-64.

97. Bordoni B, Zanier E. Clinical and symptomatological reflections: the fascial system. J Multidiscip Healthc. 2014; 7: 401-11.

98. Schleip $R$, Jäger $H$, Klingler W. What is 'fascia'? A review of different nomenclatures. J Bodyw Mov Ther. 2012; 16: 496-502.

99. Kumka M, Bonar J. Fascia: a morphological description and classification system based on a literature review. J Can Chiropr Assoc. 2012; 56: 17991.

100. Langevin $H$, Huijing $P$. Communicating about fascia: history, pitfalls and recommendations. Int J Ther Massage Bodywork. 2009; 2: 3-8.

101. Mirkin S. What is fascia? Unveiling an obscure anatomical construct. J Bodyw Mov Ther. 2008; 12: 391-2.

102. Wendell-Smith C. Fascia: An illustrative problem in international terminology. Surg Radiol Anat. 1997; 19: 273-7.

103. LeMoon K. Fascia 2007: the First International Fascia Research Congress. J Bodyw Mov Ther. 2008; 12: 3-6.

104. Han D. The other mechanism of muscular referred pain: the "connective tissue" theory. Med Hypotheses. 2009; 73: 292-5.

105. Marquart C, Varnaiso E. Le tisú cellulaire sous-cutané. Ann. Dermatol. 2001; 128: 1207-13.

106. Stecco L, Stecco C. Manipulación fascial. Parte práctica. 1a ed. Padova: Amolca; 2011.

107. Benetazzo L, Bizzego A, De Caro R, Frigo G, Guidolin D, Stecco C. 3D Reconstruction of the crural and thoracolumbar fasciae. Surg Radiol Anat. 2011; 33: 855-62.

108. Abu-Hijleh M, Roshier A, Al-Shboul Q, et a. The membranous layer of superficial fascia: evidence for its widespread distribution in the body. 
Surg Radiol Anat. 2006; 28: 606-19.

109. Stecco C, Pavan P, Porzionato A, Macchi V, Lancerotto L, Carniel E, et al. Mechanics of crural fascia: from antomy to constitutive modelling. Surg Radiol Anat. 2009; 31: 523-9.

110. Guimberteau J, Delage J, McGrouther D, Wong J. The microvacuolar system: how connective tissue sliding works. J Hand Surg Eur. 2010; 35: 641-22.

111. Guimberteau G, Sentucq-Rigall J, Panconi B. Introduction to the knowledge of subcutaneous sliding system in humans. Ann Chir Plast Esth. 2005; 50: 19-34.

112. Myer T. Anatomy Trains: Myofascial meridians for manual and movement therapists. 3ํㅡㄹ ed. Philadelphia: Elsevier Health Sciences; 2014.

113. Huijing P, Baan G. Myofascial force transmission causes interaction between adjacent muscles and connective tissue: effects of blunt dissection and compartmental fasciotomy on length force characteristics of rat extensor digitorum longus muscle. Arch Physiol Biochem. 2011; 109: 97-109.

114. Langevin $\mathrm{H}$. Connective tissue: a body-wide signaling network? Med Hypotheses. 2006; 66: 1074-7.

115. Jauregui V. Tensegridad. Estructuras tensegríticas en ciencia y arte. Santander: Universidad de Cantabria; 2007.

116. Stecco A, Macchi V, Stecco C, Porzionato A, Ann Day J, Delmas V, et al. Anatomical study of myofascial continuity in the anterior region of the upper limb. J Bodyw Mov Ther. 2009; 13: 53-62.

117. Paoletti S. Las fascias. El papel de los tejidos en la mecánica humana. $1^{a}$ ed. Barcelona: Paidotribo; 2004.

118. Ingber D. Tensegrity and mechanotransduction. J Bodyw MovTher. 2008; 12: $198-200$.

119. Ingber D. Cellular tensegrity: defining new rules of biological design that govern the cytoskeleton. J Cell Sci. 1993; 104: 613-27.

120. Gaona L, Moreno M, Espinosa A, Katime I. Síntesis de hidrogeles de 
base acrílica mediante polimerización en emulsión inversa. Rev Iberoam Polímeros. 2002; 3: 33-47.

121. Pilat A. Rol de la fascia en el proceso de mecanotransducción. Fisioterapia en Aragón. 2012; 3: 12-7.

122. Ingber D. Mechanosensation through integrins cells at locally but think globally. Proc Natl Acad Sci USA. 2003; 100: 1472-4.

123. Schleip R. Fascial plasticity, a new neurobiological explanation. J Bodyw Mov Ther. 2003; 7: 11-9.

124. Yahia L, Rhalmi S, Newman N, Isler M. Sensory innervation of human thoracolumbar fascia. An immunohistochemical study. Acta Orthop Scand. 1992; 63: 195-7.

125. Vleeming A, Pool-Goudzwaard A, Stoeckart R, van Wingerden J, Snijders C. The posterior layer of the thoracolumbar fascia. Its function in load transfer from spine to legs. Spine. 1995; 20: 753-8.

126. Tesarz J, Hoheisel U, Wiedenhofer B, Mense S. Sensory innervation of the thoracolumbar fascia in rats and humans. Neuroscience. 2011; 194: 302-8.

127. Langevin $\mathrm{H}$, Sherman K. Pathophysiological model for chronic low back pain integrating connective tissue and nervous system mechanisms. Med Hypotheses. 2007; 68: 74-80.

128. Benjamin M. The fascia of the limbs and back- a review. J Anat. 2009; 214: 1-18.

129. Bhattacharya V, Barooah P, Nag T, Chaudhuri G, Bhattacharya S. Detail microscopic analysis of deep fascia of lower limb and its surgical implication. Indian J Plast Surg. 2010; 43: 135-40.

130. Schleip R, Klinger W. Chronic low back pain may originate from sub failure injuries in lumbar fasciae. J Bodyw Mov Ther. 2008; 12: 263.

131. Saz P, Gálvez J, Ortiz M, Saz S. Masaje del tejido conjuntivo. Fundamentos. Offarm. 2011; 30: 65-9.

132. Patton K, Thibodeau G. Anatomía y fisiología. $8^{\mathrm{a}}$ ed. Barcelona: Elsevier; 2013. 
133. Association AO. Fundamentos de medicina osteopática. $2^{\mathrm{a}}$ ed. Buenos Aires: Panamericana; 2006.

134. Pradal-Prat D. Bases neurophysiologiques des réflexothérapies. Kinesither Rev. 2009; 91: 36-41.

135. Bossy J. Anatomie clinique. Neuroanatomie. Berlin: Springer-Verlag; 1990.

136. Korr I. Bases fisiológicas de la osteopatía. 1aㅡ ed. Madrid: Mandala Ediciones; 2004.

137. Pedrajas J, Molino A. Bases neuromédicas del dolor. Clínica y salud. 2008; 19: 277-93.

138. Premkumar $\mathrm{K}$. The massage connection: Anatomy and physiology. $2^{\mathrm{a}}$ ed. Philadelphia: Williams \& Wilkins; 2004.

139. Gallou J, Grinspan F. Masaje reflejo y otros métodos de terapia manual refleja. In Médico-Quirúrgica E. París: Elsevier; 1987. 26-130-A-10.

140. Langevin H, Fox J, Koptiuch C, Badger G, Greenan-Naumann A, Bouffard $\mathrm{N}$, et al. Reduced thoracolumbar fascia shear strain in human chronic low back pain. BMC Musculoskelet Disord. 2011; 12: 203.

141. Schuenke M, Vleeming A, van Hoof $T$, Willard F. A description of the lumbar interfascial triangle and its relation with the lateral raphe: anatomical constituents of load transfer through the lateral margin of the thoracolumbar fascia. J Anat. 2012; 221: 568-76.

142. Langevin H, Bouffard N, Fox J, Palmer B, Wu J, latridis J, et al. Fibroblast cytoskeletal remodeling contributes to connective tissue tension. J Cell Physiol. 2011; 226: 1166-75.

143. Barker P, Urquhart D, Story I, Briggs C. The middle layer of lumbar fascia and attachments to lumbar transverse processes: implications for segmental control and fracture. Eur Spine J. 2007; 16: 2232-7.

144. McCombe D, Brown T, Slavin J, Morrison W. The histochemical structure of the deep fascia and its structural response to surgery. J Hand Surg Br. 2001; 26: 89-97.

145. Tesh K, Shaw D, Evans J. The abdominal muscles and vertebral stability. 
Spine. 1987; 12: 501-8.

146. Grimm D. Cell biology meets Rolfing. Science. 2007; 318: 1234-5.

147. Chaudhry H, Schleip R, Ji Z, Bukiet B, Maney M, Findley T. Threedimensional mathematical model for deformation of human fasciae in manual therapy. J Am Osteopath Assoc. 2008; 108: 379-90.

148. Chaudhry H, Huang C, Schleip R, Ji Z, Bukiet B, Findley T. Viscoelastic behavior of human fasciae under extension in manual therapy. J Bodyw Mov Ther. 2007; 11: 159-67.

149. Yahia L, Pigeon P, DesRosiers E. Viscoelastic properties of the human lumbodorsal fascia. J Biomed Eng. 1993; 15: 425-9.

150. Rubio J, Paredes J. Fibromialgia: Propuesta de modelo fisiopatológico fascial. Ensayo clínico. 1를. Madrid: Digital; 2004.

151. Hertling D. Management of common musculoskeletal disorders: Physical therapy principles and methods. $4^{\mathrm{a}}$ ed. Philadelphia: Lippincott Williams \& Wilkins; 2005.

152. Chaitow L. Fascia's function: Classical osteopathic perspectives and current research compared. J Bodyw Mov Ther. 2013; 17: 355.

153. Swann E, Graner S. Uses of manual therapy techniques in pain management. ATT. 2002; 7: 14-7.

154. Corey S, Vizzard M, Bouffard N, Badger G, Langevin H. Stretching of the back improves gait, mechanical sensitivity and connective tissue inflammation in a rodent model. On line. 2012; 7(PLoS One: e29831).

155. Ribinik P, Quesnot A, Barrois B. Prise en charge en médecine physique et de réadaptation des patients présentant des douleurs neuropathiques. Lett Méd Phys Réadapt. 2010; 26: 42-50.

156. Heuleu J, Augé R. La masso-kinésithérapie dans les lombalgies et lombosciatiques. In Médico-Quirúrgica E. París: Elsevier; 1987. 26-294-A-10 et A-20.

157. Loukas M, Shoja M, Thurston T, Jones V, Linganna S, Tubbs R. Anatomy and biomechanics of the vertebral aponeurosis part of the posterior layer of the thoracolumbar fascia. Surg Radiol Anat. 2008; 30: 125-9. 
158. Mellor F, Thomas $\mathrm{P}$, Thompson $\mathrm{P}$, Breen A. Proporcional lumbar spine inter-vertebral motion patterns: a comparison of patients with chronic nonspecific low back pain and healthy controls. Eur Spine J. 2014; 23: 205967.

159. Kawamata S, Ozawa J, Hashimoto M, Kurose T, Shinohara H. Structure of the rat subcutaneous connective tissue in relation to its sliding mechanism. Arch Histol Cytol. 2003; 66: 273-9.

160. Lelean P. The migratory fascia hypothesis. J Bodyw Mov Ther. 2009; 13: 304-10.

161. Vora A, Doerr K, Wolfer L. Functional anatomy and pathophysiology of axial low back pain: disc, posterior elements, sacroliliac joint, and associated pain generators. Phys Med Rehabil Clin N Am. 2010; 21: 679709.

162. Tozzi P, Bongiorno D, Vitturini C. Fascial release effects on patients with non-specific cervical or lumbar pain. J Bodyw Mov Ther. 2011; 15: 405-16.

163. Borges $T$, Kurebayashi L, Silva M. Occupational low back pain in nursing workers: massage versus pain. Rev Esc Enferm USP. 2014; 48: 669-75.

164. Chen S, Alexander R, Lo S, Cook J. Effects of functional fascial taping on pain and function inpatients with non specific low back pain: a pilot randomized controlled trial. Clin Rehab. 2012; 265: 924-33.

165. Ercole B, Antonio S, Julie Ann D, Stecco C. How much time is required to modify a fascial fibrosis? J Bodyw Mov Ther. 2010; 14: 318-25.

166. Alcántara S, Hernández M, Ortega E, San Martín M. Técnicas especiales de masoterapia y vendajes funcionales. En Alcántara S, Hernández M, Ortega E, San Martín M. Fundamentos de fisioterapia. Madrid: Síntesis; 1995. 95.

167. Vergereau R. Utilisation du palper rouler mécanique en médecine esthétique. J Méd Esth Chir Derm. 1995; 22: 49-53.

168. Torres M, Yuste M, Zapico A, Prieto D, Mayoral O, Cerezo E, et al. Effectiveness of early physiotherapy to prevent lymphoedema after surgery for breast cancer randomised, single blindend, clinical trial. BMJ. 2010; 340 . 
169. Augé R. Le massage: technologie de base. Techniques particulaires. In Enciclopedia Médico-Quierúrgica. París: Elsevier; 1987. 26-110-A-10.

170. Bonneau D. La peau du diagnostic á la thérapeitique. Revue de medécine manuelle-ostheopatie. 2010; 30: 16-23.

171. Herbert F. Método de exploración del aparato locomotor y de la postura. $1^{\text {a }}$ ed. Barcelona: Paidotribo; 2005.

172. Backup K. Pruebas clínicas para patología ósea, articular y muscular. 1aㅡ ed. Barcelona: Masson; 2000.

173. Katz J. Lumbar disc disorder and low back pain: socioeconomic factors and consequences. J Bone Join Surg. 2006; 88: 21-4.

174. Kenta P, Keating J. Can we predict poor recovery from recent-onset nonspecific low back pain? A systematic review. Man Ther. 2008; 13: 1228.

175. O'Sullivan P. Diagnosis and classification of chronic low back pain disorders: Maladaptive movement and motor control impairments a sunderlying mechanism. Man Ther. 2005; 10: 242-55.

176. Liddlea S, Graceya J, Baxterb G. Advice for the management of low back pain: A systematic review of randomised controlled trials. Man Ther. 2007; 12: 310-27.

177. Guzmán J, Esmail R, Karjalainen K, Malmivaara A, Irvin E, Bombardier E. Multidisciplinary rehabilitation for chronic low back pain: systematic review. BMJ. 2001; 322: 1511-6.

178. Koes B. Management of low back pain in primary care: a new approach. Lancet. 2011; 378: 1530-2.

179. Borg-Stein J, Wilkins A. Soft tissue determinants of low back pain. Curr Pain Headache Rep. 2006; 10: 339-44.

180. Simmonds N, Miller P, Gemmell H. A theoretical framework for the role of fascia in manual therapy. J Bodyw Mov Ther. 2010; 16: 83-93.

181. Lee $H$, Ko Y. Back massage intervention for relieving lower back pain in puerperal women: Arandomized control trial study. Int J Nurs Pract. 2015; 21: 32-7. 
182. Childs J, Piva S, Fritz J. Responsiveness of the numeric pain rating scale in patients with low back pain. Spine. 2005; 30: 1331-4.

183. Williams J. The Declaration of Helsinki and public health. Bull World Health Org. 2008; 86: 650-2.

184. Cuesta A, Rodríguez A. Frecuencia de uso de escalas de dolor, incapacidad física y calidad de vida en el esudio de lumbalgia con interveniones fisioterápicas. Fisioterapia. 2008; 30: 204-8.

185. Serrano-Atero M, Caballero J, Cañas A, García-Saura $P$, Serrano-Álvarez C, Prieto J. Valoración del dolor (I). Rev Soc Esp Dolor. 2002; 9: 94-108.

186. Huskinson E. Measurement of pain. Lancet. 1974; 2: 1127-31.

187. Price D, McGrath $P$, Rafii A, Buckingham B. The validation of visual analogue scales as ratio scale measures for chronic and experimetnal pain. Pain. 1983; 17: 45-56.

188. Kovacs F, Llobera J, Gil del Real M, Abraira V, Gestoso M, Fernández C. Validation of the spanish version of the Roland-Morris questionnaire. Spine. 2002; 27: 538-42.

189. Kovacs F. El uso del cuestionario de Roland-Morris en los pacientes con lumbalgia asistidos en Atención Primaria. SEMERGEN. 2005; 31: 331-5.

190. Zung W. A self rating depresion scale. Arch Gen Psychiatry. 1965; 12: 6370.

191. Alonso J, Anto J, Moreno C. Spanish version of the Nottingham Health Profile: translation and preliminary validity. Am J Public Health. 1990; 80: 704-8.

192. Iveson B, Mc Laughlin S, Todd R, Gerber J. Reliability and exploration of the side-lying thoraco-lumbar rotation measurement (strm). N Am J Sports Phys Ther. 2010; 5: 201-7.

193. Clarkson H. Proceso evaluativo Musculoesquelético. $2^{\text {a }}$ ed. Barcelona: Paidotribo; 2003.

194. Williams R, Binkley J, Block R, Goldsmith C, Minuk T. Reliability of the modified Schober and double inclinometer methods for measuring lumbar flexion and extension. Phys Ther. 1993; 73: 26-33. 
195. Fransoo P. Examen clínico del paciente con lumbalgia. Compendio práctico de reeducación. $1^{\text {a }}$ ed. Barcelona: Paidotribo; 2003.

196. Parks K, Crichton K, Goldford R, McGill S. A comparison of lumbar range of motion and functional ability scores in patients with low back pain: assessment for range of motion validity. Spine. 2003; 28: 380-4.

197. Mette F, Demiautte S. Étude de la mobilité du raquis lombaire dans le plan sagittal: comparation et correlation entre les mesures clilniques et radiologiques. Ann Kinésitheérapie. 1996; 6: 270-3.

198. Mellin G. Accuracy of measuring lateral flexion of the spine with a tape. Clin Biomech. 1986; 1: 85-9.

199. Escorpizo R. Defining the principles of musculoskeletal disability and rehabilitation. Best Pract Res Clin Rheumatol. 2014; 28: 367-75.

200. Aragonés E, Masdéu R, Cando G, Coll G. Validez diagnóstica de la SelfRating Depression Scale de Zung en pacientes de Atención Primaria. Actas Esp Psiquiatr. 2001; 29: 310-6.

201. Díaz L, Campo A, Rueda G, Barros J. Propuesta de una versión abreviada de la escala de Zung para depresión. Colomb Med. 2005; 36: 168-72.

202. Deyo R, Dworkin S, Amtmann D, Andersson G, Borenstein D, Carragee $\mathrm{E}$, et al. Focus article: report of the NIH Task Force on Research Standards for Chronic Low Back Pain. Eur Spine J. 2014; 23: 2028-45.

203. Chatztheodorou D, Kabitsis C, Malliou P, Mougios V. A pilot study of the effects of high-intensity aerobic exercise versus passive interventions on pain, disability strain, and serum cortisol concentrations in people with chronic low back pain. Phys Ther. 2007; 87: 304-12.

204. Descarreaux M, Normand M, Laurencelle L, Dugas C. Evaluation of a specific home exercise program for low back pain. J Manipulative Physiol Ther. 2002; 25: 497-503.

205. Cairns M, Foster N, Wright C. Randomized controlled trial of specific spinal stabilization exercises and conventional physiotherapy for recurrent low back pain. Spine. 2006; 31: 670- 81.

206. Brealey S, Coulton S, Farrin A, Morton V, torgerson D, Burton A. Short 
term trial of chiropractic adjustments for the relief of chronic low back pain. Manual Med. 1986; 2: 63-7.

207. Moseley L. Combined physiotherapy and education is efficacious for chronic low back pain. Aust J Physiother. 2002; 48: 297-302.

208. Martin S, Morrw JJ, Jackson A, Dunn A. Variables related to meeting the CDC/ACSM physical activity guidelines. Med Sci Sports Exerc. 2000; 32: 2087-92.

209. Ljunggren A, Weber H, Kogstad O, Thom E, Kirkesola G. Effect of exercise on sick leave due to low back pain. A randomized, comparative, long-term study. Spine. 1997; 22: 1610-6.

210. Staal J, Hlobil H, van Tulder M, Köke A, Smid T, van Mechelen W. Return to work interventions for low back pain: a descriptive review of contents and concepts of working mechanisms. Sports Med. 2002; 32: 251-67.

211. Sagy I, Friger M, Sagy T, Rudich Z. Gender-based diferences in the mangement of low back pain. Harefuah. 2014; 153: 380-4.

212. Barra M. Unidad de fisioterapia de Atención Primaria, estudio descriptivo de la actividad asistencial. Fisioterapia. 1999; 21: 27-38.

213. Biering-Sörensen F, Thomsen C. Medical, social and occupational hystory as risk indicators for low back trouble in a general population. Spine. 1986; 11: 720-5.

214. Kim W, Jin Y, Lee C, Bin S, Lee S, Choi K. Influence of knee pain and low back pain on the quality of life in adults older than 50 years of age. PM R. 2015; 15: 955-61.

215. Boocock M, Mawston G, Taylor S. Age-related differences do affect postural kinematics and joint kinetics during repetitive lifting. Clin Biomech. 2015; 30: 136-43.

216. Dreischarf M, Albiol L, Rohlmann A, Pries E, Bashkuev M, Zander T, et al. Age-related loss of lumbar spinal lordosis and mobility- A study of 323 asymptomatic volunteers. PLoS ONE. 2014 ; http://journals.plos.org/plosone/article?id=10.1371/journal.pone.0116186.

217. Caillard J. Le risque lombalgique professionnel à I'hopital. Etude au centre hospitalier de Rouen. Arch Mal Prof. 1987; 48: 623-7. 
218. Rustoen T, Wahl A, Hanestad B, Lerdal A, Paul S, Miaskowski C. Age and the experience of chronic pain: differences in health and quality of life among younger, middle-aged, and older adults. Clin J Pain. 2005; 21: 513-23.

219. Bigos S, Battié M, Spengler D, Fisher L, Fordyce W, Hansson T, et al. A prospective study of work perceptions and psychosocial factors affecting the report of back injury. Spine. 1991; 16: 1-6.

220. Ellis J, Stebbing M, Harrap S. Significant population variation in adult male height associated with the $\mathrm{Y}$ chromosome and the Aromatase gene. J Clin Endocrinol Metab. 2001; 86: 4147-50.

221. Gómez Conesa A, Méndez Carrillo F. Lumbalgia ocupacional. Fisioterapia. 2002; 24: 43-50.

222. Shiri R, Solovieva S, Husgafvel-Pursiainen K, Telama R, Yang X, Viikari J, et al. The role of obesity and physical activity in non-specific and radiating low back pain: the Young Finns study. Semin Arthritis Rheum. 2013; 42: 640-50.

223. Rubio M, Salas-Salvadó J, Barbany M, Moreno B, Aranceta J, Bellido D, et al. Consenso SEEDO 2007 para la evaluación del sobrepeso y la obesidad y el establecimiento de criterios de intervención terapéutica. Rev Esp Obes. 2007; 7-48.

224. Moore M. Nutrición y dietética: guía clínica de enfermería Madrid: Mosby; 1994.

225. Triana $H$, Ramírez $R$. Efecto en la calidad de vida relacionada a la salud (CVRS) de un programa de actividad física terapéutica en medio acuático, en un grupo de adultos mayores de 55 años no institucionalizado. Revista Iberoamericana de Fisioterapia y Kinesiología. 2007; 10: 24-37.

226. Fanuele J, Abdu W, Hanscom B, Wienstein J. Association between obesity and functional status in patients with spine disease. Spine. 2002; 27: 306-12.

227. Schoenborn C. Marital status and health: United States, 1999-2001. Adv Data. 2004; 351: 1-32.

228. Vilagut G, Ferrer M, Rajmil L, Rebollo P, Permanyer-Miralda G, Quintana 
$J$, et al. El cuestionario de salud SF-36 español: una década de experiencia y nuevos desarrollos. Gac Sanit. 2005; 19: 135-50.

229. Unde Ayvat $P$, Aydin O, Ogurlu M. Risk factors associated with lower back pain in the Polyclinic of Algology. Agri. 2012; 24: 165-70.

230. Stubbs D, Buckle P. Back and upper limb disorders. The Practitioner. 1992; 236: 34-8.

231. Kelsey J, Golden A, Mundt D. Low back pain/ Prolapsed lumbar intervertebral disc. Rheum Dis Clin North Am. 1990; 16: 699-716.

232. Magnusson M, Pope M, Wilder D, Areskouk B. Are occupational drivers at an increased risk for developing musculoskeletal disorders? Spine. 1996; 21: 710-7.

233. Fathallah F, Marras W, Parnianpour M. The role of complex, simultaneous trunk motions in the risk of occupation-related low back disorders. Spine. 1998; 23: 1035-42.

234. Damkot D, Pope M, Lord J, Frymoyer J. Relationship between work history, work-enviroment and low-back pain in men. Spine. 1984; 9: 395-9.

235. Kelsey J, Githens P, White A, Walter S. An epidemiological study of lifting and twisting at the job and risk for acute prolapsed lumbar intervertebral disc. J Orthop Res. 1984; 2: 61-6.

236. Coenen P, Kingma I, Boot C, Bongers $P$, van Dieen J. Cumulative mechanical low back load at work is a deteminant of low back pain. Occup Environ Med. 2014; 71: 332-7.

237. Coenen $P$, Gouttebarge V, van der Burght A, van Dieen J, Frings-Dresen $M$, van $\operatorname{der}$ Beek $A$, et al. The effect of lifting during work on low back pain: a health impact assessment based on a meta-analysis. Occup Environ Med. 2014; 71: 871-7.

238. Lee H, Lee S, Kim M, Ryu J. Sex differences in predicting chronicity of low back pain after acute trauma using lumbar muscle area. Am J Phys Med Rehabil. 2015; 94: 123-30.

239. Li R, Wang N, Yan X, Wei K. Comparison of postural control between healthy subjects and individuals with nonspecific low back pain during exposure to visual stimulus. Chin Med J. 2014; 127: 1229-34. 
240. Viikari-Juntura E, Vuori J, Silverstein B. A life long prospective study on the role of psychosocial factors in neck-shoulder and low back pain. J Clin Epidemiol. 1992; 45: 543-5.

241. Thorbjornsson C, Alfredsson L, Frediksson K, Koster M, Michélsen H, Vingard E, et al. Psychosocial and physical risk factors associated with low back pain: a 24 year follow up among women and men in a broad range occupations. Occup Environ Med. 1998; 55: 84-90.

242. Enthoven P, Skargren E, Carstensen J, Oberg B. Predictive factors for 1year and 5-year outcome for disability in a working population of patients with low back pain treated in primary care. Pain. 2006; 122: 137-44.

243. Schenkan M, Jordan S, Akuthota V, Roman M, Kohrt W, Hearty T, et al. Functional movement training for recurrent low back pain: lessons from a pilot randomized controlled trial. PM\&R. 2009; 1: 137-46.

244. Kovacs F, Abraira V, Royuela A, Corcoll J, Alegre L, Cano A, et al. Minimal clinically important change for pain intensity and disability in patients with nonspecific low back pain. Spine. 2007; 32: 2915-20.

245. Ostelo R, de Vet $\mathrm{H}$. Clinically importan outcomes in low back pain. Best Pract Res Clin Rheumatol. 2005; 19: 593-607.

246. Pohl $\mathrm{H}$. Changes in the structure of collagen distribution in the skin caused by a manual technique. J Bodyw Mov Ther. 2010; 14: 27-34.

247. Micallef L, Vedrenne N, Billet F, Coulomb B, Darby I, Desmouliere A. The myofibroblast, multiple origins for major roles in normal and pathological tissue repair. Fibrogenesis Tissue Repair. 2012. eCollection; 5: 5.

248. Langevin $\mathrm{H}$, Stevens-Tuttle D, Fox J, et a. Ultrasound evidence of altered lumbar connective tissue structure in human subjects with chronic low back pain. BMC Musculoskelet Disord. 2009; 10: 151.

249. Field T, Diego M, Cullen C, Hernandez-Reif M, Sunshine W, Douglas S. Fibromyalgia pain and substance $P$ decrease and sleep improves after massage therapy. J Clin Rheumatol. 2002; 8: 72-6.

250. Pickar J, Wheeler J. Response of muscle propioceptors to spinal manipulative-like loads in the anesthetized cat. J Manipulative Physiol Ther. 2001; 24: 2-11. 
251. Malisza K, Stroman P, Turner A, Gregorash L, Foriok T, Wright A, et al. Functional MRI involving painful stimulation of the ankle and the effect of physiotherapy joint mobilization. Magn Reson Imaging. 2003; 18: 152-9.

252. Glover J, Morris J, Khosla T. Back pain: a randomized clinical trial of rotational manipulation of the trunk. Br J Ind Med. 1974; 31: 59-64.

253. Kalauokalani D, Cherkin D, Sherman K, Koepsell T, Deyo R. Lessons from a trial of acupuncture and massage for low back pain: patients expectations and treatment effects. Spine. 2001; 26: 1418-24.

254. Sauro M, Greenberg R. Endogenous opiates and the placebo effect: a meta-analytic review. J Psychosom Res. 2005; 58: 115-20.

255. Hiyama A, Watanabe M, Katoh H, Sato M, Sakai D, Mochida J. Evaluation of quallity of life and neuropathic pain in patients with low back pain using the Japanese Orthopedic Association Back Pain Evaluation Questionnaire. Eur Spine J. 2015; 24: 503-12.

256. Llorca G. Intervención psicológica para la mejora de la calidad de vida en las Unidades de Dolor. In V Congreso de la Sociedad Española del Dolor. ; 2007. 19-23.

257. Kovacs F, Fernández C, Cordero A, Muriel A, Gonzálex-Luján L, Gil del Real M. Non-specific low back pain in primary care in the Spanish National Health Service: a prospective study on clinical outcomes and determinants of management. BMC Health Serv Res. 2006; 6: 57-64.

258. Robinson $\mathrm{H}$, Mengshoel A. Assessments of lumbar flexion range of motion: intertester reliability and concurrent validity of 2 commonly used clinical tests. Spine. 2014; 39: 270-5.

259. Russell P, Pearcy M, Unsworth A. Measurement of the range and coupled movements observed in the lumbar spine. $\mathrm{Br} J$ Rheumatol. 1993; 32: 4907.

260. Dvorák J, Vajda E, Grob D, Panjabi M. Normal motion of the lumbar spine as related to age and gender. Eur Spine J. 1995; 4: 18-23.

261. Moll J, Wright V. Normal range of spinal mobility. Ann Rheum Dis. 1971; 30: 381.

262. López C, Barra M, Villar E. Correlación entre dolor, discapacidad y rango 
de movilidad en pacientes con lumbalgia crónica. Fisioterapia. 2009; 31: 177-82.

263. Pfleger B, Hoiriis K, Brown S. Implementation of outcome measures in a multi-site study of low back pain. WHO Department of noncomunicable disease management. Low back pain initiative. 1999;13-22.

264. Miralles I, Beceiro J, Montull S, Monterde S. Fisiopatología de la rigidez articular: bases para su prevención. Fisioterapia. 2007; 29: 90-8.

265. Stief F, Meurer A, Wienand J, Rauschmann M, Rickert M. Has a mono- or bisegmental lumbar spinal fusion surgery an influence on self-assessed quality of life, trunk range of motion and gait perfomance? Spine. 2015; 40: 618-26

266. Laird R, Gilbert J, Kent P, Keating J. Comparing lumbo-pelvic kinematics in people with and without back pain: a systematic review and metaanalysis. BMC Musculoskelet Disord. 2014; 15: 229.

267. Williams J, Haq I, Lee R. An experimental study investigating the effect of pain relief from oral analgesia on lumbar range of motion, velocity, acceleration and movement irregularity. BMC Musculoskelet Disord. 2014; 15: 304.

268. Kim T, Kim E, Cho H. The effects of the CORE programme on pain at rest, movement induced and secondary pain, active range of motion, and proprioception in female office workers with chronic low back pain: a randomized controlled trial. Clin Rehabil. 2015; 29: 653-62.

269. Waxman S, Tripp D. The mediating role of depression and negative partner responses in chronic low back pain and relationship satisfaction. $J$ Pain. 2008; 9: 434-42.

270. Alter M. Los estiramientos. Desarrollo de ejercicios. $6^{\mathbf{a}}$ ed. Barcelona: Paidotribo; 2004.

271. Fitzgerald G, Wynveen K, Rheault W, Rothschild B. Objective assessment with establishment of normal values for lumbar spinal range of motion. Phys Ther. 1983; 63: 1776-81.

272. Mellin G. Correlations of spinal mobility with degree of chronic low back pain after correction for age and anthropometric factors. Spine. 1987; 12: 
464-8.

273. Battie M, Bigos S, Sheehy A, Wortley M. Spinal flexibility and individual factor that influence it. Phys Ther. 1987; 67: 653-8.

274. Wolf S, Basmajian J, Russe C, Kutner M. Normative data on low back mobility and activity levels. Implications for neuromuscular reeducation. Am J Phys Med. 1979; 58: 217-29.

275. Macrae I, Wright V. Measurement of back movement. Ann Rheum Dis. 1969; 28: 584-9.

276. Ensink F, Saur P, Frese K, Seeger D, Hildebrandt J. Lumbar range of motion: Influence of time of day and individual factors on measurements. Spine. 1996; 21: 1339-43.

277. Sullivan M, Shoaf L, Riddle D. The relationship of lumbar flexion to disability in patients with low back pain. Phys Ther. 2000; 80: 240-50.

278. McGregor A, McCarthy I, Huhes S. Motion characteristics of the lumbar spine in the normal population. Spine. 1995; 20: 2421-8.

279. Consmüller T, Rohlmann A, Weinland D, Druschel C, Duda G, et a. Comparative evaluation of a novel measurement tool to assess lumbar spine posture and range of motion. Eur Spine J. 2012; $21: 2170-80$.

280. Findley T. Fascia research from a Clinician/Scientist's perspective. Int $J$ Ther Massage Bodywork. 2011; 4: 1-6.

281. Hukins D, Aspden R, Hickey D. Thoracolumbar fascia can increase the efficiency of the erector spinae muscles. Clin Biomech. 1990; 5: 30-4.

282. Gombatto S, Collins D, Sahrmann S, Engsbert J, Van Dillen L. Patterns of lumbar region movement during trunk lateral bending in 2 subgroups of people with low back pain. Phys Ther. 2007; 87: 441-54.

283. Fujimori T, Iwasaki M, Nagamoto $Y$, Matsuo $Y$, Ishii $T$, Sugiura $T$, et al. Kinematics of the thoracic spine in trunk lateral bending: in vivo threedimensional analysis. Spine J. 2014; 14: 1991-9.

284. Barker P, Guggeheimer K, Grkovic I, et a. Effects of tensioning the lumbar fasciae on segmental stiffeness during flexion and extension. Spine. 2006; 31: 397-405. 
285. Stokes I, Bevins T, Lunn R. Back surface curvature and measurement of lumbar spinal motion. Spine. 1987; 12: 355-61.

286. Adams M, Dolan P, Marx C, Hutton W. An electronic inclinometer technique for measuring lumbar curvature. Clin Biomech. 1986; 1: 130-4.

287. Tsuji T, Matsuyama Y, Sato K, Hasegawa Y, Yimin Y, et a. Epidemiology of low back pain in the elderly: correlation with lumbar lordosis. J Orthop Scien. 2001; 6: 307-11.

288. Hammerberg E, Wood K. Sagittal profile of the elderly. J Spinal disord tech. 2003; 16: 44-50.

289. Burton A, Tilotson K. Does leisure sports activity influence lumbar mobility or the risk of low back trouble? J Spinal Disord. 1991; 4: 329-36.

290. Castro A, Matarán G, Granero J, Aguilera G, Quesada J, Moreno C. Benefits of massage-myofascial release therapy on pain, anxiety, quality of sleep, depressión and quality of life in patients with fibromyalgia. Evid Based complemet Alternat med. 2011; 2011: 561753.

291. Parker S, McGirt M. Determination of the minimum improvement in pain, disability nad health state associated with cost-effectiveness: introduction of the concept of minimum cost-effective difference. Neurosurgery. 2015; 76: 64-70.

292. Bombardier C, Hayden J, Beaton D. Minimal clinically important difference. Low back pain: outcome measures. J Rheumatol; 28: 431-43.

293. Bongi S, Del Rosso A, Galluccio F, Sigismondi F, Miniati I, Conforti L, et al. Efficacy of connective tissue massage and Mc Mennell joint manipulation in the rehabilitative treatment of the hands in systemic sclerosis. Clin Rheumatol. 2009; 28:1167-73.

294. Kovacs F, Abraira V, Zamora J, Gil del Real M, Llobera J, Fernández C, et al. Correlation between pain, disability and quality of life in patients with common low back pain. Spine. 2004; 29: 206-10.

295 Hoogendoom W, Van Pollel M, PM B, BW K, Bouter L. Systematic review of psychosocial factors at work and private life as risk factors for back pain. Spine. 2000; 25: 2114-25.

296. Lundberg G, Gerdle B. The relationships between pain, disability and 
health-related quality of life: an 8-year follow-up study of female home care personnel. Disabil Rehabil. 2015; 1-10.

297. Stratford P, Binkley J, Solomon P, Gill C, Finch E. Assessing change over time in patients with low back pain. Phys Ther. 1994; 74: 528-33.

298. Waddell G, Newton M, Henderson I, Somerville D, Main C. A FearAvoidance Beliefs Questionnaire ( $F A B Q)$ and the role of fear-avoidance beliefs in chronic low back pain and disability. Pain. 1993; 52: 157-68.

299. Moya F, Grau M, Riesco N, Núñez M, Brancos M, Valdés M, et al. Dolor lumbar crónico. Valoración multidisciplinaria de 100 pacientes. Aten Primaria. 2000; 26: 97-106.

300. Lee H, Hübscher M, Moseley G, Kamper S, Traeger A, Mansell G, et al. How does pain lead to disability? A systematic review and meta-analysis of mediation studies in people withback and neck pain. Pain. 2015; 156: 988-97.

301. Dubois J, Abboud J, St-Pierre C, Piché $M$, Descarreaux $M$. Neuromuscular adaptations predict functional disability independently of clinical pain and psychological factors in patients with chronic no-specific low back pain. J Electromyogr Kinesiol. 2014; 24: 550-7.

302. Casado M, Moix J, Vidal J. Etiología, cronificación y tratamiento del dolor lumbar. Clínica y Salud. 2008; 19: 379-92.

303. Alexandre T, Corona L, Nunes D, Santos J, Duarte Y, Lebrao M. Disability in instrumental activities of daily living among older adults: gender differences. Rev Saude Publica. 2014; 48: 379-89.

304. Fillingim R, King C, Rahim B, Ribeiro M, Riley J. Sex, gender and pain: a review of recent cllinical and experimental findings. J Pain. 2008; 10: 44785.

305. Gjesdal S, Bratberg E, Maeland J. Gender differences in disability after sickness absence with musculoskeletal disorders: five-year prospective study of 37,942 women and 26,307 men. BMC Musculoskelet Disord. 2011; $12: 37$.

306. Serrani D. Modelo psicosocial y de género de la discapacidad funcional en adultos mayores. El rol del afrontamiento proactivo y los recursos 
sociales. Rev Arg Clin Neuropsiqu. 2008; 14: 42-55.

307. Kuzuya M. Process of physical disability among older adults. Contribution of frailty in the super-aged society. Nagoya J Med Sci. 2012; 74: 31-7.

308. Gebauer S, Scherrer J, Salas J, Burge S, Scheneider F. Disability and disability benefit seeking in chronic low back pain. Occup Med. 2015; 65: 309-16.

309. Licciardone J, Stoll S, Fulda K, Russo D, Siu J, Winn W, et al. Osteopathic manipulative treatment for chronic low back pain: a randomized controlled trial. Spine. 2003; 28: 1355-62.

310. Coderch J. La relación paciente-terapeuta. $1^{\underline{a}}$ ed. Barcelona: Paidós; 2001.

311. García L. La relación terapeuta-paciente en la práctica fisioterapéutica. Rev. Cienc. Salud. 2006; 4: 39-51.

312. Vereckei E, Susansky E, Kopp M, Ratko I, Czimbalmos A, Nagy Z, et al. Psychosocial, educational, and somatic factors in chronic nonspecific low back pain. Rheumatol Int. 2013; 33: 587-92.

313. Casado M, Urbano M. Emociones negativas y dolor crónico. Ansiedad y estrés. 2001; 7: 273-82.

314. Matud M, Guerrero K, Matías R. Relevancia de las variables sociodemográficas en las diferencias de género en depresión. Int $\mathrm{J}$ Clin Health Psychol. 2006; 6: 7-21.

315. Verde E, Ávila C. Evaluación de la calidad de vida. Salud Pública de México. 2002; 44: 349-55.

316. Saldívar A, Joffre V, Barrientos M, Lin D, Vázquez F, Llanes A. Factores de riesgo y calidad de vida de los enfermos que sufren lumbalgia. Revista electrónica Medicina, Salud y Sociedad. 2010; 1.

317. Lizán L. La calidad de vida relacionada con la salud. Aten Primaria. 2009; 41: 411-6.

318. Leplege A, Hunt S. El problema e la calidad de vida en medicina. JAMA. 1998; 7: 19-23.

319. Carr A, Gibson B, Robinson P. Is quality of life determined by 
expectations or experience? BMJ. 2001; 322: 1240-3.

320. Lamarca R, Alonso J, Santed R, Prieto L. Performance of perceived health measure in diferents groups of the population: a comprehensive study in Spain. J Clin Epidemiol. 2001; 54: 127-35.

321. García P, Leiva F, Martos C, García R, Prados T, Sánchez C, et al. Calidad de vida en pacientes con hipertensión arterial y diabetes mellitus tipo 2. Medicina de Familia. 2001; 2: 29-34.

322. Contreras N. Factores de riesgo en discapacidades por lumbalgia. Rehabilitación Médica de Venezuela. 2000; 2(http://www.angelfire.com/id2/rehabilitacionmedica/paginas/boletinuno/pri mera2.htm).

323. Casals M, Samper D. Epidemiología, prevalencia y calidad de vida del dolor crónico no oncológico. Rev Soc Esp Dolor. 2004; 11: 260-9.

324. López M, Sánchez M, Rodríguez M, Vázquez E. Cavidol: Calidad de vida y dolor en atención primaria. Rev Soc Esp del Dolor. 2007; 14: 9-19.

325. O’Donoghue G, Fox N, Heneghan C, Hurley D. Objective and subjecive assessment of sleep in chronic low back pain patients compared with healthy age and gender matched controls: a pilot study. BMC Musculoskelet Disord. 2009; 10: 122.

326. Nolet $\mathrm{P}$, Kristman V, Coté $\mathrm{P}$, Carroll L, Cassidy J. Is low back pain associated with worse health-related quality of life 6 months later? Eur Spine J. 2015; 24: 458-66.

327. Kampfe C, Wadsworth J, Mamboleo G, Schonbrun S. Aging, disability, and employment. Work. 2008; 31: 337-44.

328. Williams C, Maher C, Latimer J, McLachlan A, Hancock M, Day R, et al. Efficacy of paracetamol for acute low back pain: a double -blind randomised controlled trial. Lancet. 2014; 384: 1586-96.

329. Majchrzycki M, Kocur P, Kotwicki T. Deep tissue massage and nonsteroidal anti-inflammatory drugs for low back pain: a prospective randomized trial. Scientific World Journal. eCollection. 2014.

330. van Tulder M, Ostelo R, Vlaeyen J, Linton S, Morley S, Assemdelft W. Behavioral treatment for chronic low back pain: a systematic review within 
the framework of the Cochrane Back Review Group. Spine. 2000; 25: 2688-99.

331. van Tulder M, Scholten R, Koes B, Deyo R. Nonsteroidal antiinflammatory drugs for low back pain: a systematic review within the framework of the Cochrane Collaboration Back Review Group. Spine. 2000; 25: 2501-13.

332. Al-Turki D, Abou-Zeid L, Shehata I, Al-Omar M. Therapeutic and toxic effects of new nsaids and related compounds: a review and prospective study. Int J Pharm. 2010; 6: 813-25.

333. Antman E, Bennett J, Daugherty A, Furberg C, Roberts H, Taubert K. Use of nonsteroidal antiinfalmmatory drugs: an update for clinicicans: a scientific statement from the American Heart Association. Circulation. 2007; 115: 1634-42.

334. Brzezinski K, Wordliczek J. Comparison of the efficacy of kexketoprofen and diclofenac in treatment of non-specific low back pain. Ann Agric Environ Med. 2013; 1: 52-6. 
IX. ANEXOS 
VIII. ANEXOS.

Anexo I. Flujograma de derivación de la lumbalgia en la Gerencia de Atención Primaria de Soria.

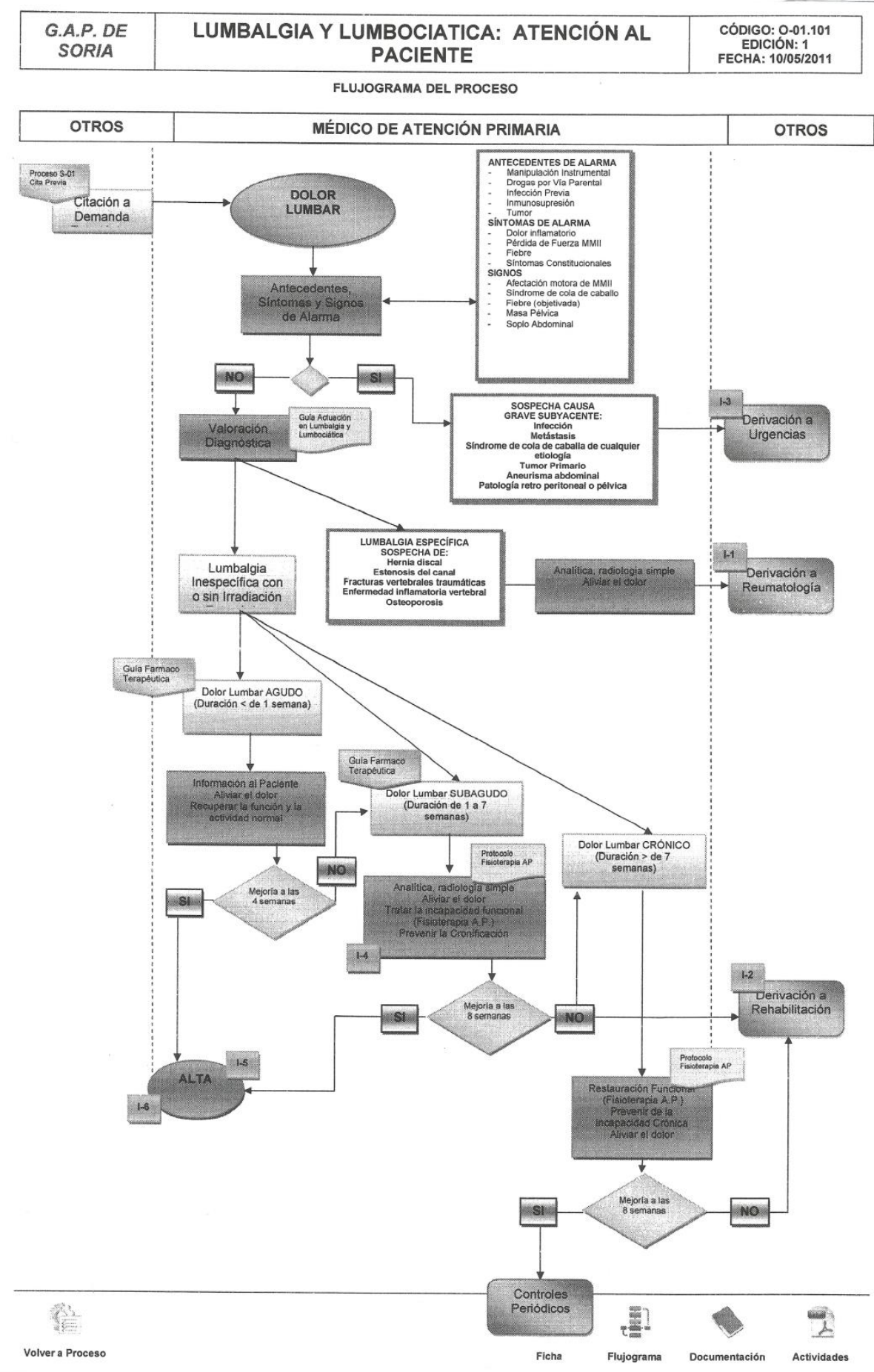


Anexo II. Consentimiento Informado.

\section{Consentimiento informado}

Título del estudio: “ La técnica de la Pinza Rodada en el tratamiento de la Lumbalgia Inespecífica Crónica".

Yo,

He entendido la explicación que el fisioterapeuta que va a llevar a cabo el estudio me ha dado,

He podido hacer preguntas sobre el estudio,

He recibido suficiente información sobre el estudio,

Comprendo que mi participación es voluntaria,

Comprendo que puedo retirarme del estudio:

1. Cuando quiera.

2. Sin tener que dar explicaciones.

3. Sin que esto repercuta en mis cuidados o atención sanitaria.

Presto libremente mi conformidad para participar en el estudio.

En Soria a .... ... de de 20 


\section{Anexo III. Permiso de la Gerencia de Salud de Soria.}
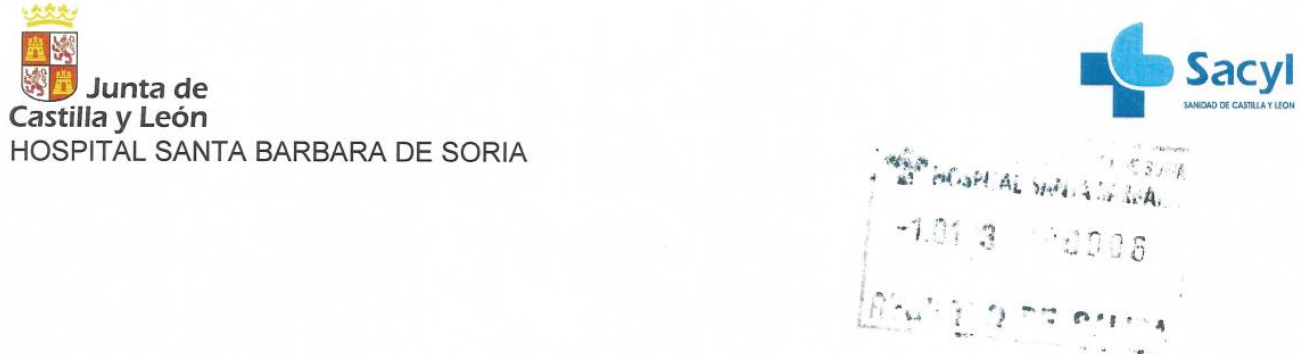

ENRIQUE DELGADO RUIZ, Director Gerente de Atención Primaria y Especializada del área de Salud de Soria, hace constar su conformidad para que se inicie el proyecto de investigación titulado "La técnica de la Pinza Rodada en el tratamiento de la Lumbalgia Mecánica Crónica". Se trata de un estudio observacional analítico de una cohorte de incepción a realizar en la población adulta de la Unidad de Fisioterapia del Centro de Salud La Milagrosa, turno de tarde, mediante muestreo no probabilístico consecutivo.

Participan como investigador principal Dña. Susana Domingo Esteban, NIF: 16810118Q, fisioterapeuta del Complejo Asistencial de Soria, que lo realiza como trabajo de Tesis Doctoral.

Atentamente

Soria, a 2 de Enero de 2013

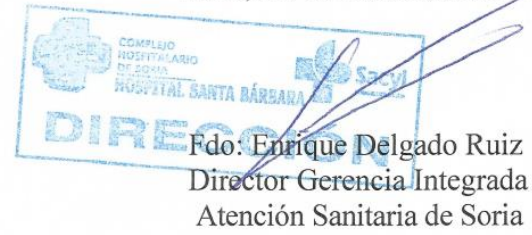

Paseo de Santa Barbara, s/n - 42005 SORIA - g Tel. 975234300 - Fax. 975234305 
Anexo IV. Cuestionario Sociodemográfico.

\begin{tabular}{|l|l|}
\hline Día 0 & Inicio de tratamiento \\
\hline
\end{tabular}

\begin{tabular}{|c|c|c|c|c|}
\hline \multicolumn{5}{|l|}{ Apellidos } \\
\hline \multicolumn{5}{|l|}{ Nombre } \\
\hline \multicolumn{5}{|l|}{ Teléfono } \\
\hline Edad & & \multicolumn{3}{|l|}{ Años } \\
\hline Sexo & \multicolumn{4}{|c|}{$\square \Delta$ Hombre $\quad \square \Delta$ Mujer } \\
\hline Estado Civil & $\square \Delta$ Soltero & \multicolumn{2}{|c|}{$\square \Delta$ Casado } & $\Delta$ Viudo \\
\hline Estatura & & \multicolumn{3}{|l|}{ Metros } \\
\hline Peso & & \multicolumn{3}{|l|}{ Kilogramos } \\
\hline \multicolumn{5}{|l|}{ Nivel de Estudios } \\
\hline Situación laboral & $\square \Delta$ Activo & $\square \Delta$ Pasivo & $\square \Delta$ Paro & $\square \Delta$ Baja \\
\hline \multicolumn{5}{|l|}{ Puesto de Trabajo } \\
\hline \multicolumn{5}{|l|}{$\begin{array}{l}\text { Tratamiento } \\
\text { Farmacológico }\end{array}$} \\
\hline Recidivas & & & & \\
\hline
\end{tabular}


Anexo V. Escala Visual Analógica. EVA.

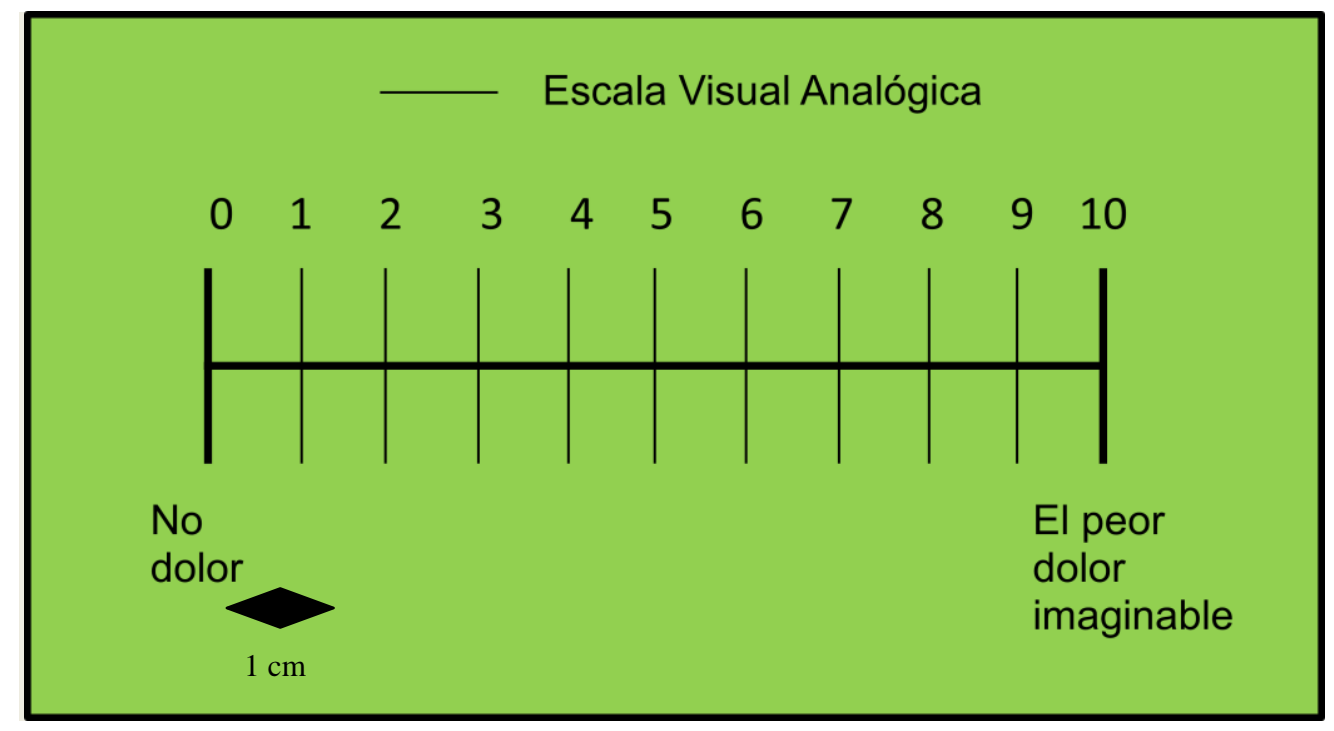


Anexo VI. Cuestionario de Roland Morris.

\section{ROLAND MORRIS QUESTIONNAIRE}

1.- Me quedo en casa la mayor parte del tiempo por mi dolor de espalda.

2.- Cambio de postura con frecuencia para intentar aliviar la espalda.

3.- Debido a mi espalda camino más lentamente de lo normal.

4.- Debido a mi espalda, no puedo hacer ninguna de las faenas que habitualmente hago en casa.

5.- Por mi espalda uso los pasamanos para subir escaleras.

6.- A causa de mi espalda, debo acostarme más a menudo para descansar.

7.- Debido a mi espalda debo agarrarme a algo para levantarme de los sillones (sofás)

$\square$ 8.- Por culpa de mi espalda, pido a los demás que me hagan las cosas.

9.- Me visto más lentamente de lo normal a causa de mi espalda.

10.- A causa de mi espalda, solo me quedo de pié durante cortos períodos de tiempo.

11.- A causa de mi espalda, procuro evitar inclinarme o arrodillarme.

$\square$ 12.- Me cuesta levantarme de una silla por culpa de mi espalda.

$\square$ 13.- Me duele la espalda casi siempre.

$\square$ 14.- Me cuesta darme la vuelta en la cama por culpa de mi espalda.

$\square$ 15.- Debido a mi dolor de espalda, no tengo mucho apetito.

$\square$ 16.- Me cuesta ponerme los calcetines -o medias- por mi dolor de espalda.

$\square$ 17.- Debido a mi dolor de espalda, tan sólo ando distancias cortas.

$\square$ 18.- Duermo peor debido a mi espalda.

$\square$ 19.- Por mi dolor de espalda, deben ayudarme a vestirme.

$\square$ 20.- Estoy casi todo el día sentado/a a causa de mi espalda.

$\square$ 21.- Evito hacer trabajos pesados en casa, por culpa de mi espalda.

$\square$ 22.- Por mi dolor de espalda, estoy más irritable y de peor humor de lo normal.

23.- A causa de mi espalda, subo las escaleras más lentamente de lo normal.

24.- Me quedo casi constantemente en la cama por mi espalda. 
Anexo VII. Escala de Zung.

\section{Escala de Autoevaluación para la Depresión de Zung (SDS)}

Por favor lea cada enunciado y decida con qué frecuencia describe la forma en que usted se ha sentido en los últimos días.

\begin{tabular}{|c|c|c|c|c|}
\hline Por favor marque la columna adecuada & $\begin{array}{c}\text { Poco } \\
\text { tiempo }\end{array}$ & $\begin{array}{l}\text { Algo del } \\
\text { tiempo }\end{array}$ & $\begin{array}{c}\text { Una } \\
\text { buena } \\
\text { parte del } \\
\text { tiempo }\end{array}$ & $\begin{array}{c}\text { La mayor } \\
\text { parte del } \\
\text { tiempo }\end{array}$ \\
\hline 1. Me siento decaído y triste & & & & \\
\hline 2. Por la mañana es cuando me siento mejor & & & & \\
\hline 3. Siento ganas de llorar o irrumpo en llanto & & & & \\
\hline 4. Tengo problemas para dormir por la noche. & & & & \\
\hline 5. Como la misma cantidad de siempre. & & & & \\
\hline 6. Todavía disfruto el sexo. & & & & \\
\hline 7. He notado que estoy perdiendo peso. & & & & \\
\hline 8. Tengo problemas de estreñimiento. & & & & \\
\hline 9. Mi corazón late más rápido de lo normal. & & & & \\
\hline 10. Me canso sin razón alguna. & & & & \\
\hline 11. Mi mente está tan clara como siempre. & & & & \\
\hline 12. Me es fácil hacer lo que siempre hacía. & & & & \\
\hline 13. Me siento agitado y no puedo estar quieto. & & & & \\
\hline 14. Siento esperanza en el futuro. & & & & \\
\hline 15. Estoy más irritable de lo normal. & & & & \\
\hline 16. Me es fácil tomar decisiones. & & & & \\
\hline 17. Siento que soy útil y me necesitan. & & & & \\
\hline 18. Mi vida es bastante plena. & & & & \\
\hline $\begin{array}{l}\text { 19. Siento que los demás estarían mejor si yo } \\
\text { muriera. }\end{array}$ & & & & \\
\hline $\begin{array}{l}\text { 20. Todavía disfruto de las cosas que disfrutaba } \\
\text { antes. }\end{array}$ & & & & \\
\hline
\end{tabular}


Anexo VIII. Perfil de Salud de Nottingham.

$\square$

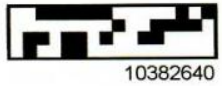

Datos para el estudio
Día:
$\square 1 \square 2 \square 3 \square 4 \square 5$
$\square 6 \square 7 \square 8 \square 9 \square 10$
$\square 11 \square 12 \square 13 \square 14 \square 15$
$\square 16 \square 17 \square 18 \square 19 \square 20$
$\square 21 \square 22 \square 23 \square 24 \square 25$
$\square 26 \square 27 \square 28 \square 29 \square 30$
31

$\square 31$

Mes:

$\square$ Enero $\square$ Julio

$\square$ Febrero $\square$ Agosto

$\square$ Marzo $\square$ Septiembre

$\square$ Abril $\square$ Octubre

$\square$ Mayo $\square$ Noviembre

$\square$ Junio $\square$ Diciembre
Año: (20...)

Número identificador:

$0 \quad \square$

$1 \quad \square \square$

$2 \square \square$

$3 \square \square$

$5 \square \square$

6 ㅁ

$7 \square \square$

$\begin{array}{ll}8 & \square \square \\ 9 & \square \square\end{array}$

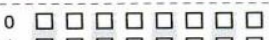

1 맘ㅁㅁㅁㅁ문

2 맘ㅁㅁㅁ맘

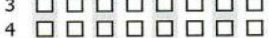

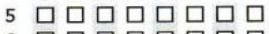

6 ㅁㅁㅁㅁ

7 .

ร

8
9

\section{PERFIL DE SALUD DE NOTTINGHAM \\ (PSN)}

Versión española del Nottingham Health Profile (NHP) (C) 1989, adaptada por JM Antó, J. Alonso, SM Hunt (C) 1990.

Institut Municipal d'Investigació Mèdica (IMIM-IMAS)

Unidad de Investigación en Servicios Sanitarios

c/Doctor Aiguader, 80 E-08003 Barcelona

Tel. (+34) 9322575 53, Fax (+34) 932214002

www.imim.es

Institut Municipal

Institut Municipal

Este instrumento ha superado los estándares de calidad de la Red Cooperativa para la Investigación en Resultados de Salud y Servicios Sanitarios (Red IRYSS).

El cuestion (RistioPRO, la biblioteca virtual de la Red IRYSS (umw.rediryss.net). 


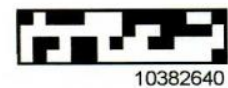

A CONTINUACIÓN VERÁ ALGUNOS DE LOS PROBLEMAS QUE LA GENTE PUEDE TENER EN SU VIDA DIARIA.

LEA ATENTAMENTE LA LISTA DE PROBLEMAS.

EN CADA PROBLEMA, SI USTED LO TIENE, MARQUE UNA CRUZ EN LA CASILLA DEL "SÍ". SI USTED NO TIENE ESE PROBLEMA, MARQUE UNA CRUZ EN LA CASILLA DEL "NO".

POR FAVOR, CONTESTE TODAS LAS PREGUNTAS. SI NO ESTÁ MUY SEGURO/A DE CONTESTAR "SÍ" O "NO", SEÑALE LA RESPUESTA QUE USTED CREA QUE ES LA MÁS CIERTA EN LA ACTUALIDAD.

\section{Sí No}

1. Siempre estoy fatigado/a

2. Tengo dolor por las noches

3. Las cosas me deprimen

4. Tengo un dolor insoportable

5. Tomo pastillas para dormir

6. He olvidado qué es pasarlo bien

7. Tengo los nervios de punta

8. Tengo dolor al cambiar de postura

\section{Sí No}

9. Me encuentro solo

10. Sólo puedo andar por dentro de casa

11. Me cuesta agacharme

12. Todo me cuesta un esfuerzo

13. Me despierto antes de hora

14. Soy totalmente incapaz de andar

15. Últimamente me resulta difícil contactar con la gente

16. Los días se me hacen interminables 
17. Me cuesta subir y bajar escaleras

18. Me cuesta coger las cosas

19. Tengo dolor al andar

20. Últimamente me enfado con facilidad

21. Creo que soy una carga para los demás

22. Me paso la mayor parte de la noche despierto/a

23. Siento que estoy perdiendo el control de mí mismo/a

24. Tengo dolor cuando estoy de pie

25. Me cuesta vestirme

26. Enseguida me quedo sin fuerzas

27. Me cuesta estar de pie mucho rato (por ejemplo, haciendo cola)

\section{Sí No}

28. Tengo dolor constantemente

29. Me cuesta mucho dormirme

30. Creo que no tengo a nadie en quien confiar

31. Las preocupaciones me desvelan por la noche

32. Creo que no vale la pena vivir

33. Duermo mal por las noches

34. Me cuesta llevarme bien con la gente

35. Necesito ayuda para caminar fuera de casa (como por ejemplo, bastón, muletas o alguien que me ayude)

36. Tengo dolor al subir y bajar escaleras

37. Me despierto desanimado/a

38. Tengo dolor cuando estoy sentado/a 
EN LA LISTA SIGUIENTE SEÑALE "SÍ" PARA CADA UNO DE LOS ASPECTOS DE SU VIDA QUE SE HAYA VISTO AFECTADO POR SU SALUD. CONTESTE "NO" PARA AQUELLOS ASPECTOS QUE NO ESTÉN AFECTADOS

\section{Sí NO}

39. Actualmente, su estado de salud, ċle causa problemas con su puesto de trabajo?.

40. Actualmente, su estado de salud, ¿̇le causa problemas con los trabajos domésticos?.

(como por ejemplo, limpiar, cocinar, pintar, hacer reparaciones)

41. Actualmente, su estado de salud, ċle causa problemas con su vida social?.

(como por ejemplo, salir, ver a los amigos, ir al bar)

42. Actualmente, su estado de salud, ¿̇le causa problemas con su vida familiar?

(es decir, las relaciones con los de casa)

43. Actualmente, su estado de salud, ċle causa problemas con su vida sexual?

44. Actualmente, su estado de salud, ċle causa problemas con sus pasatiempos y aficiones?.

(como por ejemplo, hacer deportes, ver la TV, hacer media, etc...)

45. Actualmente, su estado de salud, ¿̇le causa problemas con los días de fiesta? (vacaciones, navidades, fines de semana)

\section{GRACIAS POR SU COLABORACIÓN}

